\title{
The stepparent role: how it is defined and negotiated in stepfamilies in New Zealand
}

By

\section{Rebecca Kate Graham}

\author{
A thesis \\ submitted to Victoria University of Wellington \\ in fulfilment of the requirements for the degree of \\ Doctor of Philosophy \\ in Public Policy
}

Victoria University of Wellington 2010 
Many children in New Zealand spend at least part of their lives growing up in stepfamilies. Yet despite the prevalence of stepfamilies and indications that they are increasing, there is little certainty regarding the parenting role stepparents should adopt to benefit their stepchildren the most. This ambiguity is further reflected in the law; with stepparents having few legal responsibilities to their stepchildren.

This research sought to identify how individuals define and negotiate the stepparent's role in newly formed stepfamilies in New Zealand. Previous research and clinical practice indicates that how this role is defined is closely tied to stepfamily well-being. However there is still a great deal we do not understand about how stepfamily members construct this role, the nature of change over time, and how it is negotiated among stepfamily members.

One hundred and five stepfamilies that had been cohabiting full-time for less than four years completed questionnaires assessing individual perceptions of stepparent roles and stepfamily functioning. Three stepfamily members completed questionnaires at two points in time, twelve months apart- a target stepchild between the ages of seven and eleven, the resident biological parent, and stepparent.

Results suggest that stepparents, parents and children perceive stepparents to play active roles in both the warmth and control aspects of the stepparent role and these perceptions change minimally over a twelve-month period. When discrepancies between actual and ideal role scores were examined (intra-role discrepancies), all stepfamily members reported wanting the stepparent to be more involved in warmth behaviours than they actually were. However, although parents and stepparents reported ideally wanting stepparents to be more involved in control behaviours as well, children wanted them to be less involved in control behaviours than they were currently. Role discrepancies at time 1 were associated with aspects of stepfamily functioning at time 2, particularly for children. 
There was some evidence that role discrepancies reduced over time. In particular, stepparents and children reported lower inter-role discrepancies (higher role agreement) and stepparents and children both reported lower intra-role discrepancies over time.

When role discrepancies between stepfamily members were examined (inter-role discrepancies), stepchildren reported wanting stepparents to be less involved in warmth and control dimensions than either parents or stepparents. Regression analyses revealed that children's inter and intra role discrepancies were significantly associated with their reports of stepfamily functioning twelve months later, after taking into account the stepparent's actual involvement.

Adults in stepfamilies used various strategies to negotiate the stepparent role; including partner discussions, talks with children, checking in for feedback with children and biological parents, and gate keeping behaviours by the biological parent. Role negotiation was more likely to occur in the following twelve months when stepfamily functioning was more problematic at time 1 , and there was some evidence that this led to improvements in functioning over time. This was not the case for gate keeping behaviours-while these were reported to be more frequently used when stepfamily functioning was problematic; they had a detrimental effect on the quality of the stepparent-stepchild relationships. These findings have important implications for organisations that work with, and make decisions affecting stepfamilies. 


\section{ACKNOWLEDGEMENTS}

I would like to say a huge thank you to all the people who helped me in reaching the end of this milestone.

Firstly I would like to say a big thank you to all the families who opened up their homes to me. Talking to a stranger about personal aspects of their family lives can be confronting, and so I appreciate their courage and honesty. Some participants found this very difficult, yet were determined to participate due to the help they could offer other families. I want to thank them for their generosity, and I hope that this research will do just that. On a personal note, I thank you for providing me with such a great insight into New Zealand family life; an insight I doubt few would ever receive. Thank you to the few families who were kind enough to make me a roast meal when I came for the second time - despite their dismay at learning of my vegetarianism!

I would like to thank my two supervisors, Jan and Jeremy for helping me, every step along the way. They were always available to me with help and advice, despite the busy lives they both lead. It was such a privilege to have you both as my supervisors. Thank you for all the help and friendship you have given me over the last five years, and I know that this friendship will continue in the future. This thesis is just the beginning - there is a lot more to be written about this important subject!

Thank you to the Social Policy Evaluation and Research Committee (SPEaR) for identifying the need for this research and for assisting me financially by granting me the Social Science Research Award (2008) at just the right time. To Victoria University of Wellington for all your help and assistance: with special thanks to Dawn Yeabsley, Amanda Wolf and Lynn Todd for always being available for help and assistance.

And finally to those who I call my family: Robin and Alan (my parents), Tori (sister), Prabhat (partner) and last but not least, Mia (Cat) and Felicity (my beloved Rottweiler who passed away at the time of submitting this thesis). The last four years have been 
difficult and you have all been there for me, in one small way or another. Not only did this $\mathrm{PhD}$ take a lot of my time, it also took a lot from me financially, geographically...not to mention emotionally! Mum and Dad - you have both been such a source of support to me, over all these years. As emphasised by so many of the families I interviewed: we are not perfect (is there any family that is?), but so much that I have achieved would be unattainable without you there beside me. 


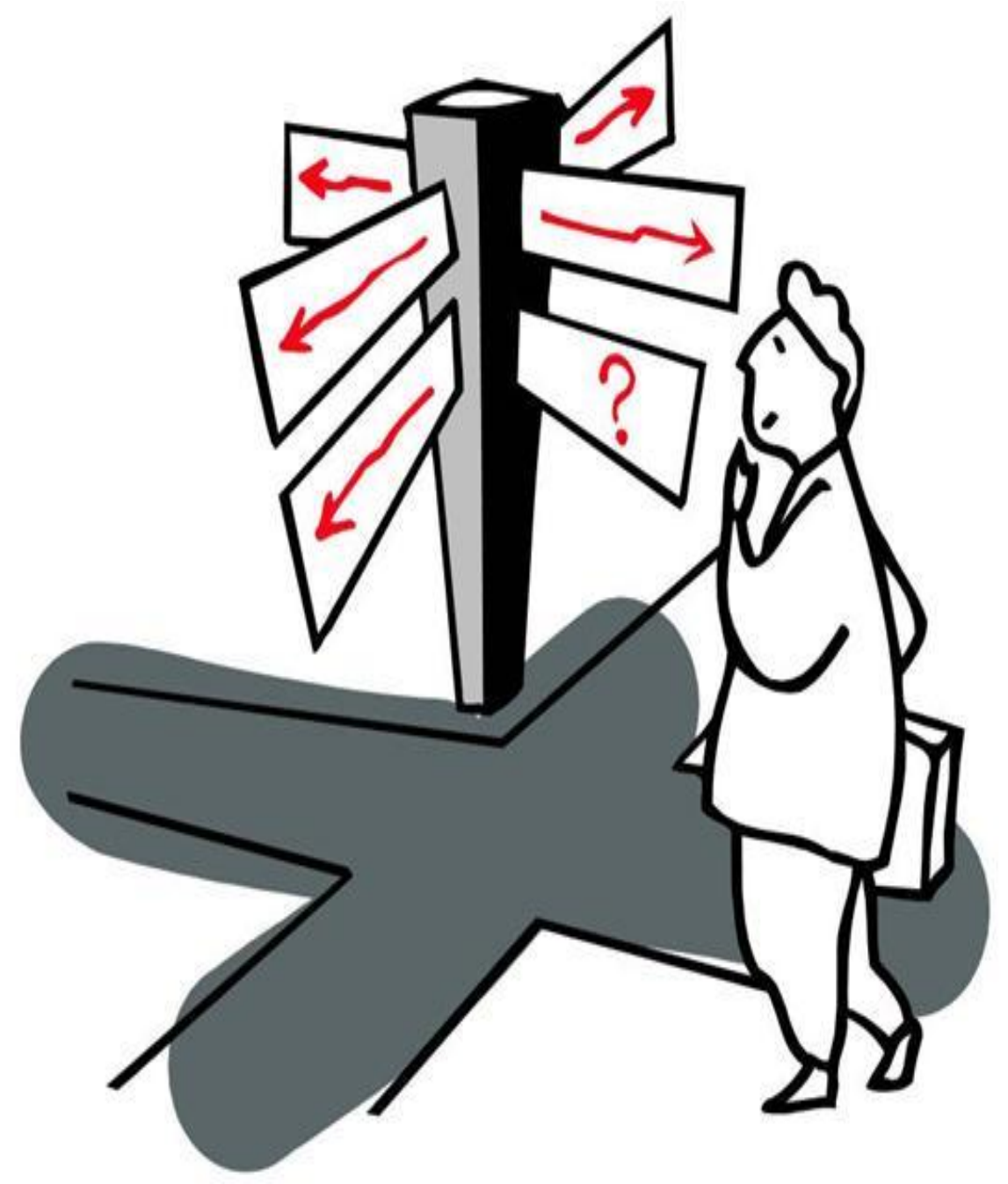

[Being a stepparent] is a different sort of parenting to what I've got with my biological child. It's been something I've been puzzling over for some time, because the roles are just so different...it's more a negotiated parentage between both parties... that is [stepchild] and I can vary widely in how we interpret that parenting role. So that means that things are quite dynamic. I'm a parent but then I'm not ......

(Stepparent interviewed in this study) 


\section{TABLE OF CONTENTS}

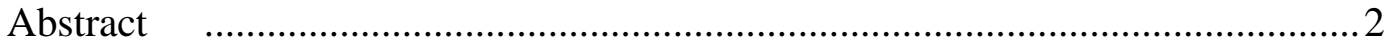

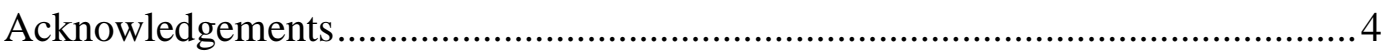

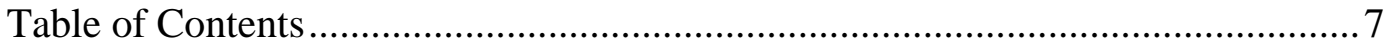

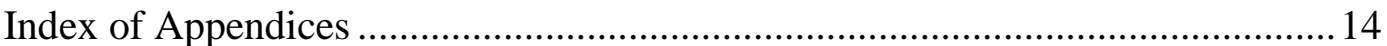

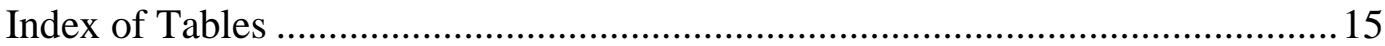

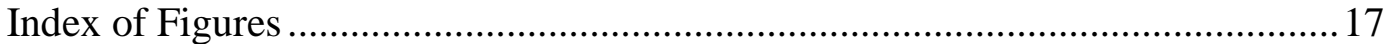

\section{LITERATURE REVIEW}

\section{CHAPTER ONE - Review of Research on Stepfamilies................18}

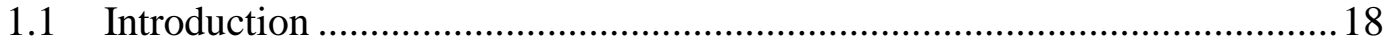

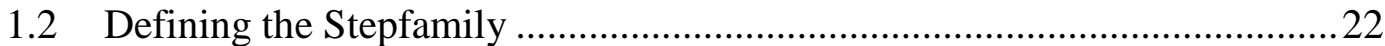

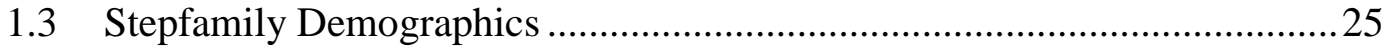

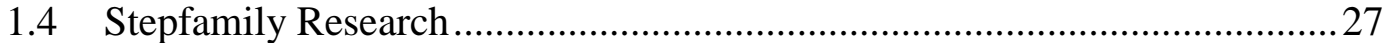

1.4.1 Children's Adjustment in Stepfamilies ..........................................28

1.4.2 Dissolution Rates in Stepfamilies ................................................ 32

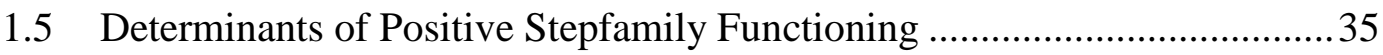

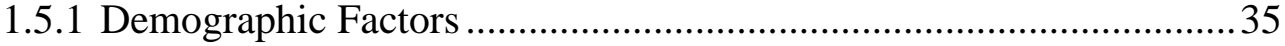

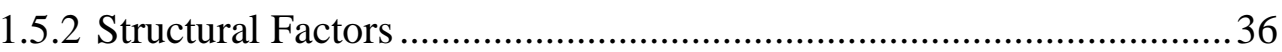

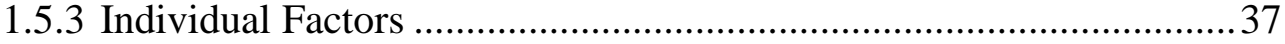

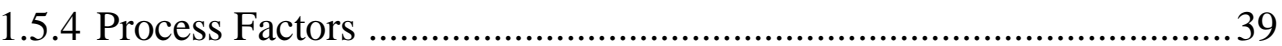

\section{CHAPTER TWO - The Stepparent Role .......................................42}

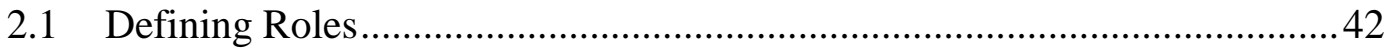

2.1.1 Defining the Stepparent Role ...................................................... 44

2.2 Research on the Stepparent Role .........................................................4

2.2.1 Issues Affecting the Establishment of the Stepparent Role ................47

2.2.2 Roles Stepparents' play in their Stepchildren's Lives ...................... 49 
2.3 The Stepparent Role and Stepfamily Functioning ...................................56

2.4 Factors Affecting the Stepparent Role and Stepfamily Functioning............58

2.4.1 Individual Factors ............................................................................5

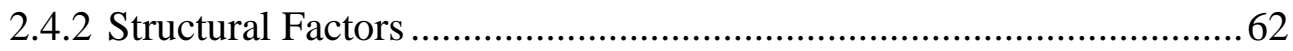

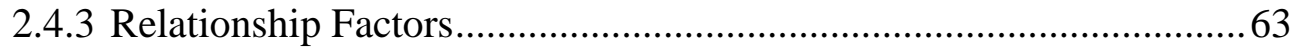

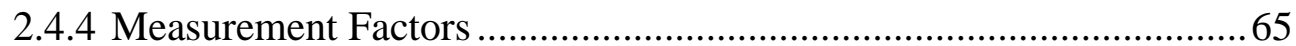

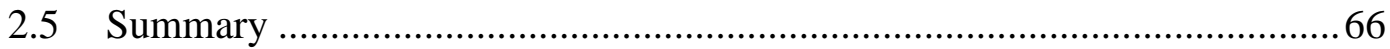

CHAPTER THREE - Discrepancies in the Stepparent Role......67

3.1 Discrepancies among Stepfamily Members .........................................67

3.1.2 Inter-Role Discrepancies and Stepfamily Functioning ......................69

3.2 Discrepancies within Individuals- Intra-Role Discrepancies ..................... 70

3.2.1 Intra-Role Discrepancies and Stepfamily Functioning ..................... 70

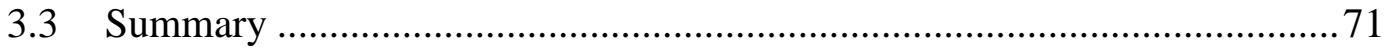

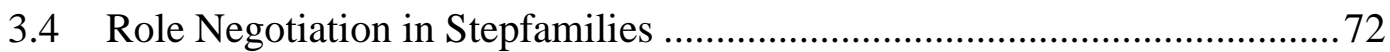

3.4.1 Evidence for the Importance of Role Negotiation ............................ 73

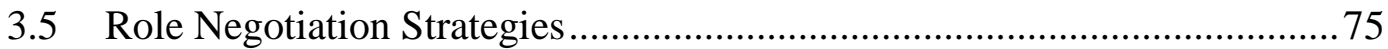

3.5.1 Role Negotiation Strategies Involving Adults .................................76

3.5.2 Role Negotiation Strategies Involving Children............................. 79

3.5.3 Gate Keeping Behaviours by the Biological Parent ......................... 82

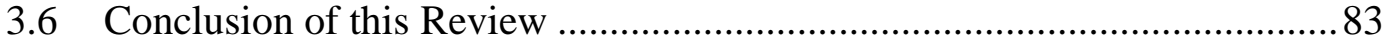

\section{RESEARCH QUESTIONS AND METHODOLOGY}

\section{CHAPTER FOUR Research Questions and Design ...................85}

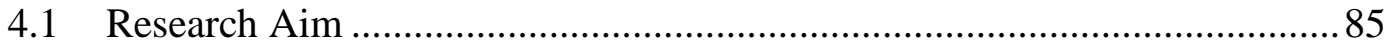

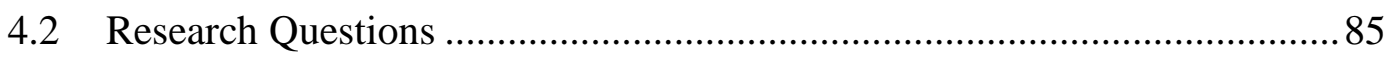

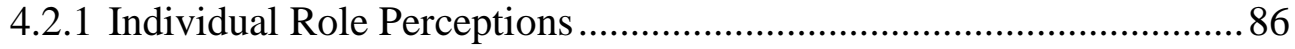

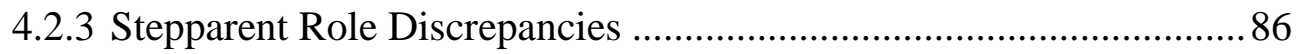

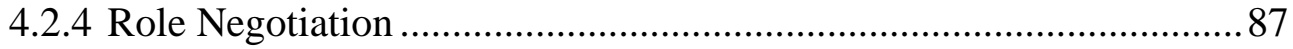


4.2.5 Children's Views of Stepfamily Functioning and

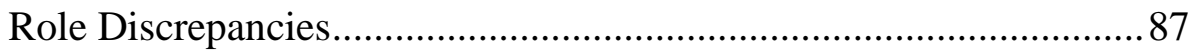

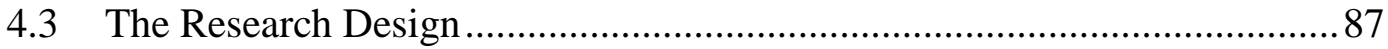

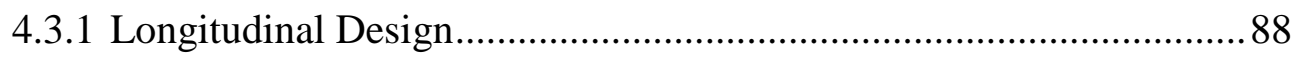

4.3.2 Multi-Informant Approach........................................................90

4.4 Research Sample Criteria .......................................................... 90

4.4.1 Residential Stepfamily …............................................................. 91

4.4.2 The Age of the Target Stepchild ................................................... 91

4.4.3 Number of Children ............................................................... 91

4.4.4 Length of Cohabitation ................................................................ 91

4.4.5 Community Sample ................................................................ 92

CHAPTER FIVE - Research Methodology ...................................93

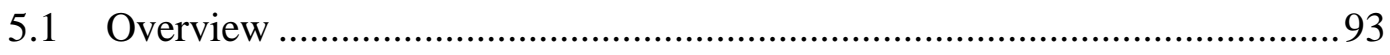

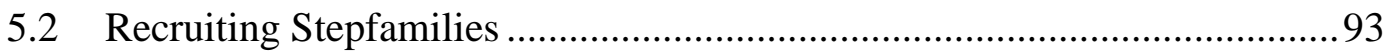

5.3 Data Collection Procedure..................................................................... 94

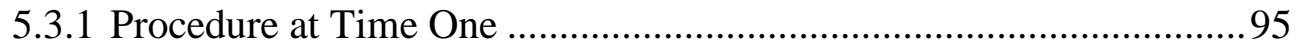

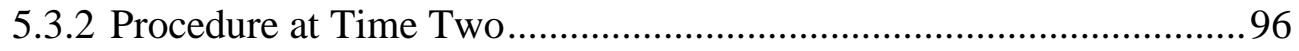

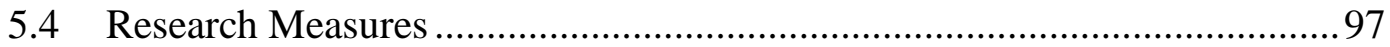

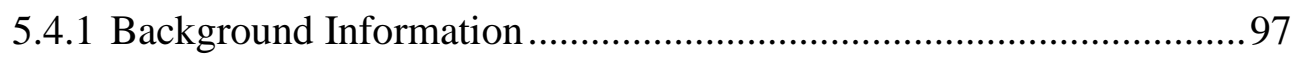

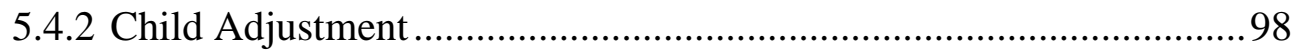

5.4.3 Quality of the Couple Relationship............................................... 101

5.4.4 Quality of the Parent-Child Relationship....................................... 102

5.4.5 The Stepparent Role............................................................... 102

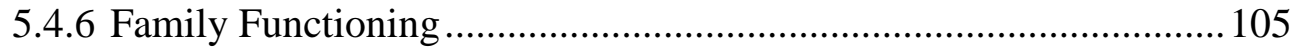

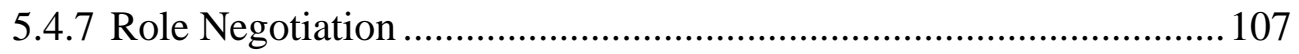

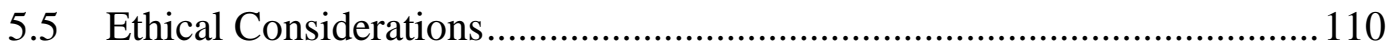

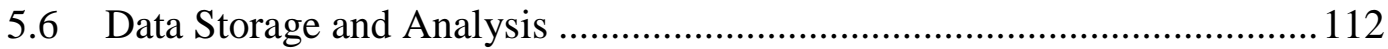

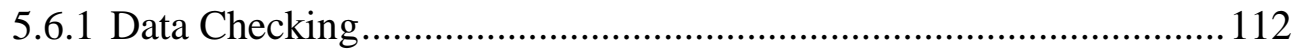

5.6.2 Creating Composite Scores ...................................................... 112

5.6.3 Creating Role Discrepancy Scores............................................ 113 


\section{RESULTS}

CHAPTER SIX - Results -Time One ............................................115

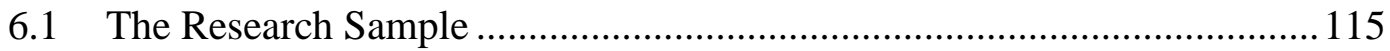

6.1.1 Household Demographic Characteristics ........................................... 115

6.1.2 Relationship Histories of Parents ..................................................... 117

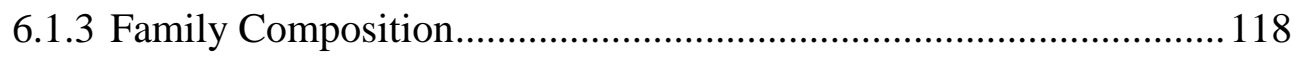

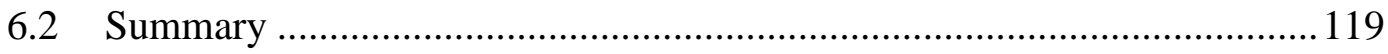

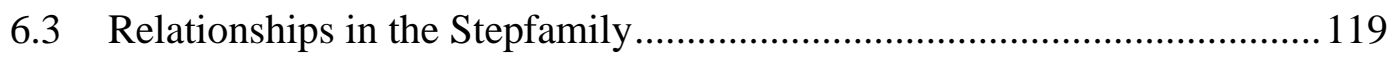

6.3.1 The Couple Relationship.................................................................119

6.3.2 Children's Relationship with their Biological Parents....................... 120

6.3.3 The Stepparent-Stepchild Relationship.............................................. 121

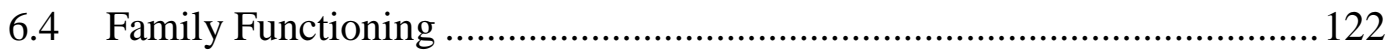

6.4.1 Family Cohesion .............................................................................. 122

6.4.2 Family Conflict .............................................................................. 123

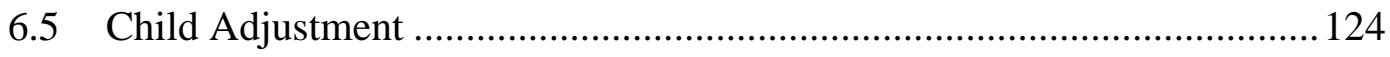

6.5.1 Children's Strengths and Difficulties.................................................. 124

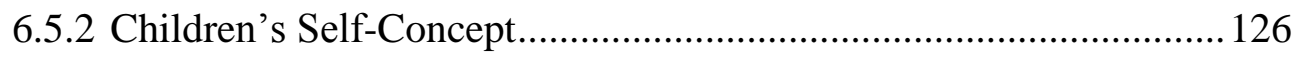

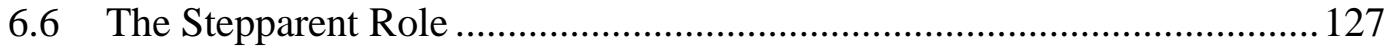

6.6.1 Labels to Describe the Stepparent Role .............................................127

6.6.2 Stepparent Parenting Behaviours ...................................................... 129

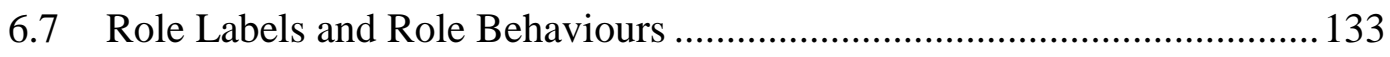

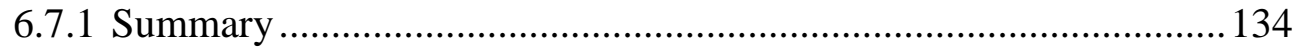

6.8 Discrepancies in Stepparent Role Perceptions ……….................................135

6.8.1 Intra-Role Discrepancies................................................................. 135

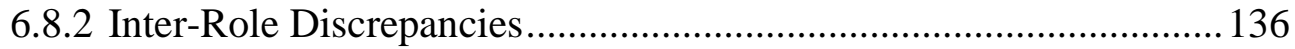

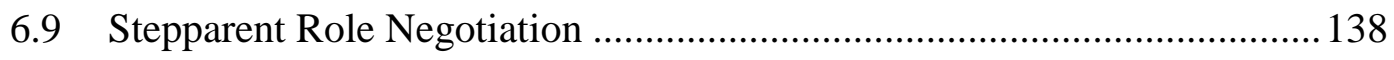

6.9.1 Adults' Perceptions of Role Negotiation .............................................138

6.9.2 Children's Perceptions of Role Negotiation ...................................... 141

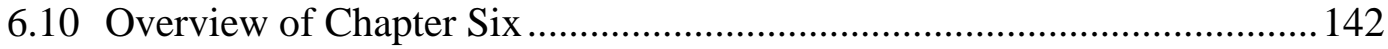




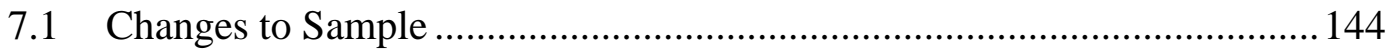

7.2 The Stepparent Role: Changes over Time …………………………......... 146

7.2.1 The Actual Stepparent Role ..............................................................146

7.2.2 The Ideal Stepparent Role............................................................ 147

7.3 Stepparent Role Discrepancies: Changes Over Time.....................................148

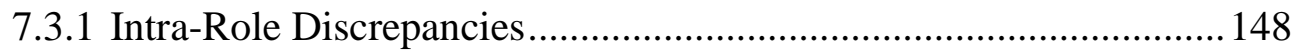

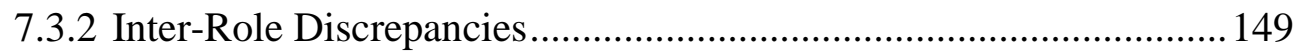

7.4 Frequency of Stepparent Role Negotiation ..............................................151

7.4.1 Parents' Role Negotiation and Stepfamily Functioning .................... 152

7.4.2 Stepparents' Role Negotiation and Stepfamily Functioning ............ 153

7.5 Role Negotiation and Changes in Stepfamily Functioning .........................154

7.5.1 Parents' Role Negotiation and Changes in

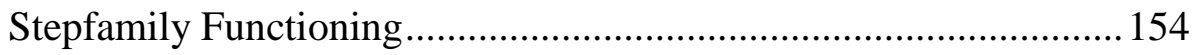

7.5.2 Stepparents' Role Negotiation and Changes in

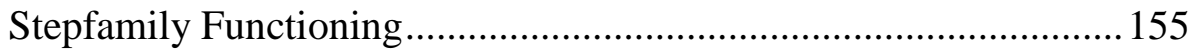

7.6 Role Negotiation and Changes in Inter-Role Discrepancies ........................156

7.6.1 Parents' Role Negotiation and Changes in

Inter-Role Discrepancies.................................................................157

7.6.2 Stepparents' Role Negotiation and Changes in

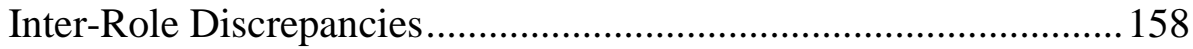

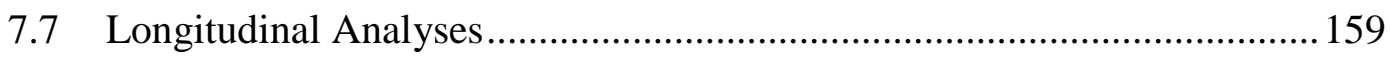

7.7.1 The Actual Stepparent Role and Stepfamily Functioning .................159

7.7.2 Intra-Role Discrepancies and Stepfamily Functioning ...................... 161

7.7.3 Inter-Role Discrepancies and Stepfamily Functioning ...................... 162

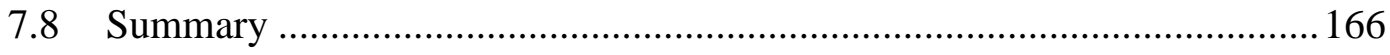

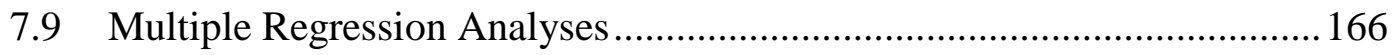

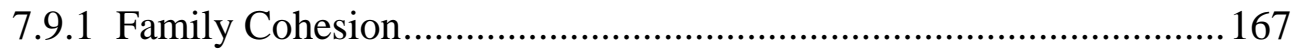

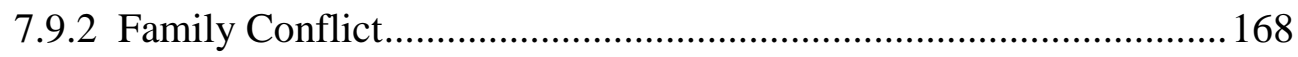

7.9.3 Quality of Stepparent - Stepchild Relationship ..................................169

7.9.4 Quality of Biological Parent - Child Relationship ............................ 170 


\section{DISCUSSION}

CHAPTER EIGHT - Discussion of Findings....................................173

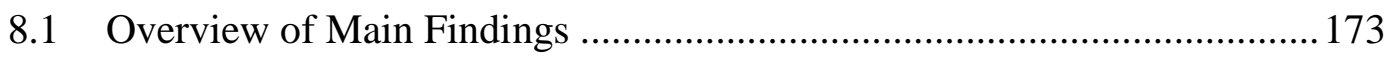

8.2 Overview of Stepfamily Outcomes .................................................. 174

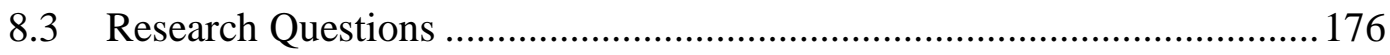

8.3.1 Perceptions of the Actual and Ideal Stepparent Role....................... 176

8.3.2 Role Labels and Role Behaviours ................................................ 178

8.3.3 Perceptions of Stepparent Role Behaviours.................................. 179

8.4 Discrepancies in Perceptions of the Stepparent Role ............................... 181

8.4.1 Intra-Role Discrepancies...................................................... 181

8.4.2 Inter-Role Discrepancies...................................................... 183

8.5 The Stepparent Role and Stepfamily Functioning ….............................. 186

8.5.1 The Actual Stepparent Role ...................................................... 186

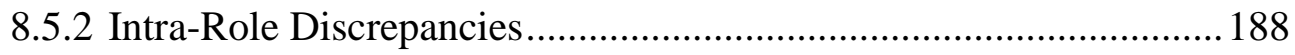

8.5.3 Inter-Role Discrepancies....................................................... 189

8.6 Results of Regression Analyses .................................................... 193

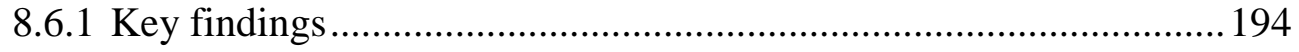

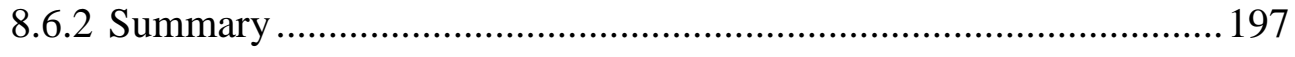

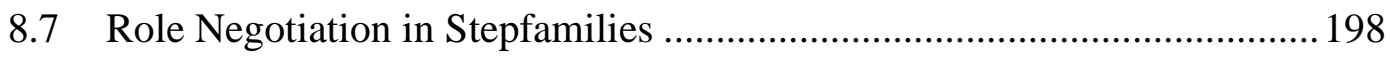

8.7.1 Role Negotiation and Stepfamily Functioning .............................200

8.7.2 Role Negotiation and Inter-Role Discrepancies ............................203

8.8 Changes over Time in the Stepparent Role …..........................................205

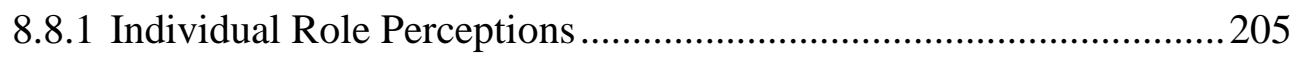

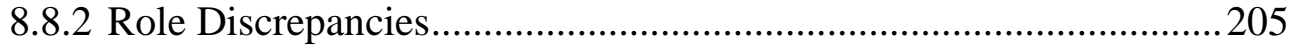

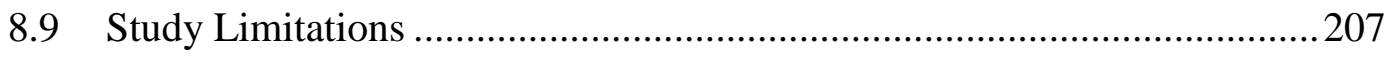

8.9.1 Representativeness of the Sample...............................................2207

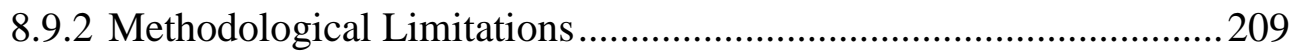

8.10 Study Strengths and Significant New Findings ....................................211 


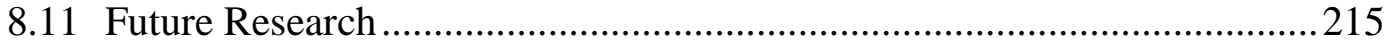

8.12 Implications for Policy and Practice ...................................................2 218

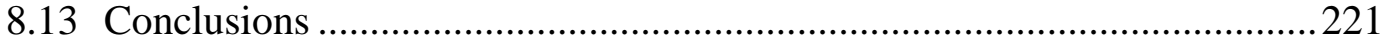

REFERENCES ..............................................................................225 


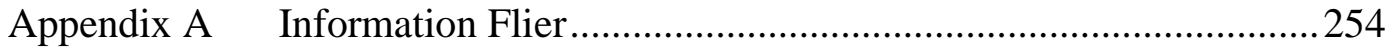

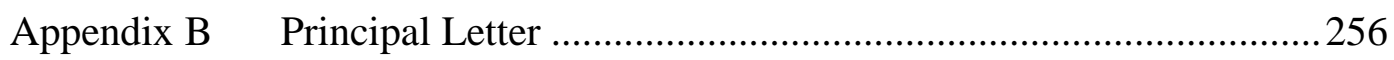

Appendix C Recruitment Notice ..............................................................2258

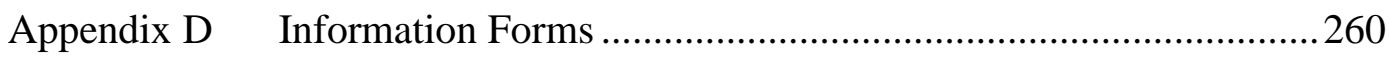

Appendix E Adult Consent Forms …......................................................265

Appendix F Child Assent Form ...........................................................269

Appendix G Background Information Forms..........................................2271

Appendix H Biological Parent Questionnaire ..........................................2276

Appendix I Child Questionnaire …...........................................................290

Appendix J Adults' Role Negotiation Interview Time One.........................306

Appendix K Adults' Role Negotiation Questionnaire Time Two ...................312

Appendix L Internal Consistency Scores at Time Two ................................318

Appendix M Wording Changes for About Myself .....................................320

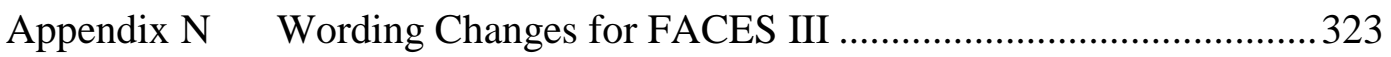

Appendix O Dimensions of the Stepparent Role Questionnaire ...................325

Appendix P Conceptualisation of Intra-Role and Inter-Role

Discrepancies

Appendix Q Changes to Outliers and Extreme Scores.................................330

Appendix R Comparison of Outcome Variables with Norm Scores ..............334

Appendix S Cross-Tabulation for Stepparent Role Labels Time One...........337

Appendix T Results from Factor Analysis: Stepparent Role

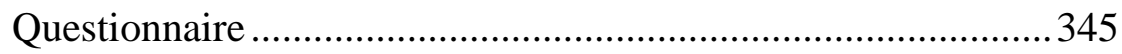

Appendix U Distribution of Role Negotiation Variables: Time One .............347

Appendix V Correlations between Demographic Variables and

Stepfamily Functioning and Role Discrepancies......................349 


\section{Chapter Five.}

Table 5.1 Procedure for Data Collection at Time One and Time Two........94

Table 5.2 Facets Measured in the About Myself Scale ............................. 100

Table 5.3 Internal Consistency Scores for the Stepparent Role

Questionnaire

Chapter Six.

Table 6.1 Characteristics of the Stepfamily Sample at Time One

Table 6.2 Mean Scores for Stepfamily Relationships

Table 6.3 Mean Scores for Stepfamily Members for

Family Functioning....

Table 6.4 Mean Scores for the SDQ for Stepfamily Members.....

Table 6.5 Commonly Selected Labels for the Stepparent Role.

Table 6.6 Factor Analysis of the Stepparent Role Questionnaire

Table 6.7 Comparison of the Actual and Ideal Stepparent Role

for Stepfamily Members

Table 6.8 Percentages for Role Negotiation Strategies for Adults

at Time One

Chapter Seven.

Table 7.1 Changes over Time for the Actual Stepparent Role

Table 7.2 Changes over Time for the Ideal Stepparent Role.

Table 7.3 Changes over Time for Intra-Role Discrepancies....

Table 7.4 Changes over Time for Inter-Role Discrepancies.

Table 7.5 Correlations between Role Negotiation Strategies for

Parents at Time Two and Stepfamily Functioning at

Time One .....

Table 7.6 Correlations between Role Negotiation Strategies for

Stepparents at Time Two and Stepfamily Functioning

at Time One 
Table 7.7 Correlations between Role Negotiation at Time Two and Changes in Stepfamily Functioning

Over Time - for Parents

Table 7.8 Correlations between Role Negotiation for Stepparents at

Time Two and Changes in Stepfamily Functioning

Over Time - for Stepparents.....

Table 7.9 Correlations between Role Negotiation Strategies for

Parents at Time Two and Changes in Inter-Role

Discrepancies Over Time.

Table 7.10 Correlations between Role Negotiation Strategies for

Stepparents at Time Two and Changes in Inter-Role

Discrepancies Over Time

Table 7.11 Correlations between the Actual Stepparent Role at

Time One and Stepfamily Functioning at Time Two

Table 7.12 Correlations between Intra-Role Discrepancies

at Time One and Stepfamily Functioning at Time Two

Table 7.13 Correlations between Stepparent-Stepchild Inter-Role

Discrepancies at Time One and Stepfamily Functioning

at Time Two

Table 7.14 Correlations between Stepparent-Parent Inter-Role

Discrepancies at Time One and Stepfamily Functioning

at Time Two.... 164

Table 7.15 Correlations between Parent-Child Inter-Role Discrepancies

at Time One and Stepfamily Functioning at Time Two 165

Table 7.16 Multiple Regression Summary Table for Family Cohesion ...... 168

Table 7.17 Multiple Regression Summary Table for Family Conflict ........ 169

Table 7.18 Multiple Regression Summary Table for

Stepparent-Stepchild Relationship Quality

Table 7.19 Multiple Regression Summary Table for

Parent-Child Relationship Quality. 


\section{INDEX OF FIGURES}

\section{Chapter Two.}

Figure 2.1 The Components of the Stepparent Role .46

Chapter Three.

Figure 3.1 Research Model of the Association between the

Stepparent Role and Stepfamily Functioning

Chapter Five.

Figure 5.1 Excerpt from the Stepparent Role Questionnaire -

Parent Version

\section{Chapter Six}

Figure 6.1 Ages of Stepchildren Interviewed

Figure 6.2 Comparison of Family Cohesion Scores for

Stepfamily Members

Figure 6.3 Comparison of Family Conflict Scores for

Stepfamily Members

Figure 6.4 SDQ Subscale Scores for Stepfamily Members.

Figure 6.5 Mean Self-concept Scores for Children

Figure 6.6 Comparison of Mean Warmth and Control Scores for

Stepparent Labels

Figure 6.7 Comparison of Actual and Ideal Scores for Warmth and

Control Dimensions of the Stepparent Role.

Figure 6.8 Comparison of the Ideal Stepparent Role among

Stepfamily Members 


\section{Chapter One}

\section{Review of Research on Stepfamilies}

\subsection{Introduction}

The past few decades have witnessed an increased interest in stepfamilies and their role in bringing up children successfully in modern society. This interest has been stimulated by two factors; the first being a series of social changes leading to increased numbers of children in stepfamilies, and the second being the emergence of research which has highlighted the increased risks for children in stepfamilies.

Firstly, the numbers of children growing up in stepfamilies has increased dramatically over the last few decades, so that in New Zealand, approximately $20 \%$ of children have lived in a stepfamily before they reach seventeen years of age (Dharmalingam, Pool, Sceats \& Mackay, 2004; 1995, New Zealand Women: Family, Education and Employment Survey; Nicholson, Fergusson \& Horwood, 1999). There are many reasons for this, but the main one is that modern society has witnessed a change in the way relationships are formed and children are raised. The number of couples cohabiting prior to marriage has increased dramatically, as has the number of single mothers having children (Dharmalingam et al; 2004; Pryor, 2005). There has also been a significant increase in marital disruptions and subsequent re-partnering by adults (Statistics New Zealand, 2006) - an increase observable in many Western countries, including New Zealand, Australia, the United Kingdom, and the United States (Rodgers \& Pryor, 1998).

These changes have led to a social climate in which many children are growing up in families where one of their biological parents is living elsewhere (Dunn, 2005). The Family Characteristics Survey (1997), carried out by the Australian Bureau of 
Statistics (1998) reported that approximately $27 \%$ of all children under eighteen had one biological parent living elsewhere. In New Zealand, the proportion of children in sole parent families has increased from $16 \%$ in 1986 to $26 \%$ in 2006 (The Kiwi Nest; June, 2008). Many of these children will then go on to experience stepfamily life when their biological parent re-partners.

Secondly, although many children experience stepfamily life as positive, there are indications that stepchildren are at greater risk for adjustment difficulties during childhood, and difficulties in close relationships in adulthood (Amato, 2000; Nicholson et al., 1999; Pryor \& Rodgers, 2001; Wallenstein, Lewis \& Blakeslee, 2000). Stepfamilies are, too, more likely to separate than families with two biological (or adoptive) parents living together. The majority of research and demographic information indicates that divorce is higher in subsequent marriages than in first marriages (Amato, 2010; Coleman, Ganong \& Fine, 2000; Greene, Anderson, Hetherington, Forgatch \& De Garmo, 2003). This is a concern since multiple family transitions (e.g. the dissolution of the stepfamily) are associated with increased risks for children (Coleman et al, 2000; Osborne \& McLanahan, 2004; Pryor and Rodgers, 2001). These concerns have highlighted the need to better understand the factors that are associated with children's well-being, and those promoting positive functioning so that stepfamilies stay together.

Earliest research on stepfamilies typically compared them with biological families, interpreting differences between the two as evidence of deficiencies of the stepfamily as an institution- an era that has been labelled the 'Deficit Comparison Approach' (Coleman \& Ganong, 1990). In contrast, more recent research has explored processes within stepfamilies. That is, rather than simply comparing outcomes in different family structures, stepfamilies are assessed on specific factors and the degree to which these affect aspects of family functioning are explored. This approach is based on a theoretical underpinning that views stepfamilies as neither inherently problematic nor successful; rather, a heterogeneous group for which there is great variability in children and family outcomes. Research findings examining family processes carry practical implications for both clinical and policy spheres. For example, research has found the relationship between stepparents and stepchildren to be fundamental to the 
success of the stepfamily (Crosbie-Burnett, 1984; Pasley, Ihinger-Tallman \& Lofquist, 1994); therefore, research is increasingly exploring how this relationship is best developed to assist stepfamilies in developing and maintaining this pivotal relationship.

Since the relationship between stepparents and stepchildren appears to be important, research has increasingly focused on the role stepparents' play in their stepchildren's lives. The difficulties stepchildren experience in dealing with their stepparent's disciplinary behaviours is frequently discussed by researchers and clinicians (Barber \& Lyons, 1994; Funder, 1996; Pryor, 2004) and is a popular topic in books, movies and children's stories. Images of stepparents portrayed in movies and books have tended to be negative; for example, the wicked stepparent portrayed in fairy tales, such as 'Cinderella', 'Hansel and Gretel' and 'Snow White.' These negative portrayals of stepparents may have had a detrimental effect on perceptions of stepparents (ClaxtonOldfield, 1992; Claxton-Oldfield \& Voyer, 2001). Research, therefore, plays an important role in providing a more accurate portrayal of stepfamily relationships, in particular that between stepparents and stepchildren, and identifying factors that contribute to positive relationships.

There is some indication of a shift in attitudes regarding stepparent responsibilities over time. In the 1990's, both the law and current ideology emphasised the importance to a child of their biological parents, which was based on the accepted wisdom that a child can have only one mother and father (Fleming, 1997). This emphasis on biological ties remains evident in many of the social policies currently in existence (Fine, 1997; Malia, 2005; Marsiglio, 1992). However, previous studies have suggested that there was an expectation, in less recent times, that a new partner would undertake a parental role. Non-resident parents were advised not to interfere in their children's lives, so that children could form strong relationships with their stepparents (Burgoyne \& Clark, 1982; Duberman, 1973). This lies in sharp comparison to that of more recent times where stepparents are often encouraged to gradually become involved in a parental role (Bray \& Kelly, 1999; Visher \& Visher, 1996) and non-resident parents to remain involved in their children's lives. Research of this nature suggests that 
stepparents may be currently expected to function in a different way to those in previous generations although this has received scant empirical attention.

While there has been some focus on the stepparent role, research has generally not explored the parenting behaviours that stepparents' perform. When attitudes regarding the stepparent role are examined, very rarely are perceptions relating to specific parenting behaviours examined (Mason, Harrison-Jay, Svare \& Wolfinger, 2002). The main objective of the current study was to assess perceptions of the stepparent role in more detail than previously, by exploring stepfamily members' expectations of the stepparent's involvement in specific parenting behaviours. Furthermore, a longitudinal design was selected in order to examine changes in the stepparent role over time and to better explore causal dynamics in the association between components of the stepparent role and stepfamily functioning. While this has not been explored in previous research, there are indications that roles and behaviours are not static and may change over time (Erera-Weatherley, 1996; Furstenberg, Morgan \& Allison, 1987; Ganong \& Coleman, 1992, Stern, 1978).

This study explores other components of the stepparent role that have been outlined as important in previous research and clinical literature. The extent to which stepfamily members agree on the most appropriate stepparent role (inter-role discrepancies) is considered to be an important component of positive stepfamily functioning (Fine, Coleman \& Ganong, 1998). Similarly, there is some research that points to the importance of individual discrepancies between the ideal stepparent role and the actual role performed by the stepparent (intra-role discrepancies). Inter and intra role discrepancies are explored in terms of the effect they have on stepfamily functioning at three levels - individual, relationship and whole family functioning. Family functioning refers to how the stepfamily is functioning as a group, and has been less commonly examined than individual and relationship functioning, despite indications that aspects of family functioning (e.g. family cohesion) are important determinants of stepfamily and child well-being, and that they are generally lower in stepfamilies (Barber \& Lyons, 1994; Bray, 1988; Peek \& Wampler, 1985; Pryor \& Rodgers, 1998). The effect role negotiation has on important stepfamily variables is also considered. Negotiating the stepparent role is typically encouraged both by clinicians and 
researchers, and this study was the first known quantitative study to explore the value of this.

This literature review addresses theories and research related to stepfamilies and the stepparent role. It begins by examining stepfamily demographics and definitional issues. It then addresses research exploring outcomes for children, and the unstable nature of stepfamilies. The second half of the review then considers research focused on stepfamily members' perceptions of the stepparent role. Structural and relational differences inherent in the stepfamily structure are discussed as a possible explanation for the salience of the stepparent role.

The chapter also considers the way in which the stepparent role has been measured in research studies. Particular attention is given to the studies on the stepparent role performed by Fine, Coleman and Ganong $(1997,1998)$ since these researchers were the first to examine how stepparent role perceptions, and role discrepancies, are associated with stepfamily functioning. The chapter then introduces the research model that was examined in this study and outlines the multitude of factors that are considered to be important in the association between the stepparent role and stepfamily functioning.

\subsection{Defining the Stepfamily}

While the definition of a stepfamily may appear relatively clear-cut, examination of the terminology and the history of stepfamilies suggests otherwise. The Old English translation of the word 'step' referred to something created after death (Oxford English Dictionary, 1989), hence the original conception of a stepfamily as a family created when a biological parent of a child dies and the remaining parent remarries. In fact, the term stepfamily originated from the Anglo-Saxon word 'steop' meaning 'to bereave' or 'to make orphan' (Bray \& Berger, 1993). However, in contrast to stepfamilies formed due to the death of a parent, it has become increasingly likely that a child will experience the separation of their parents and subsequently acquire a stepparent when one of their biological parents re-partners (Coleman et al., 2000; Qu \& Weston, 2005; Stewart, 2008). In addition, children born into sole parent families are increasing, so 
that many children will acquire a stepparent when their parent, usually their mother, enters a new partnership.

These changes have introduced a more complex familial situation - where a child may have two sets of parents acting in 'mother' and 'father' roles, and many functioning as grandparents, siblings, uncles and aunts (Rodgers \& Pryor, 1998). There may be key differences between stepfamilies formed by divorce and those formed by death, particularly regarding the stepparent role, the organisation of finances, and children's living arrangements (Howden, 2004; Qu \& Weston, 2005). They may, too, be key differences between stepfamilies formed due to parental separation and those formed via birth into a sole parent family. Namely, the child does not have the parenting history of another mother or father figure prior to the stepparent, which may lead to different patterns of interaction between stepparents and children and different parenting roles performed by stepparents.

Modern stepfamilies are, then, different in many ways from those formed in the past. It could be argued that the term 'stepfamily' is now referring to family situations not envisaged in the original construction of the term. The fact that we still use the term has its disadvantages; in particular the negative connotations raised when we recall the lengths the evil stepmothers of fairy tales went to secure their superior position to their new husband's child (e.g. 'Snow White', 'Hansel and Gretel'). These stories may reinforce the stereotype that stepparents are sinister and harmful (Wald, 1981). Research indicates that the existence of the wicked stepmother can be traced back to the ninth century (Ceglian \& Gardner, 2000). While some researchers have suggested other terms, such as 'reconstituted', 'remarried' and 'reformed' families, these terms are not as commonly understood and are not devoid of problems. For example, defining stepfamilies as 'remarried' families suggests that a prerequisite is the marriage of the couple, despite the fact that many stepfamilies cohabit prior to eventually remarrying (Cherlin \& Furstenberg, 1994; Montgomery, Anderson, Hetherington \& Clingempeel, 1992) or remain permanently as cohabiting stepfamilies (Bumpass, Raley \& Sweet, 1995; Ganong \& Coleman, 1994; Pryor, 2008). 
Complexities are encountered when deciding what couple relationships are included in the definition. Given the numerous ways in which individuals may form relationships, researchers have not always defined stepfamilies in the same way when recruiting research samples. For example, some have not included cohabiting couples (see Coleman et al., 2000), often because their data comes from national datasets where cohabiting couples have been excluded (e.g. National Survey of Family and Households, NSFH; National Longitudinal Study of Adolescent Health, Add Health), and the majority have not included gay and lesbian stepfamilies, despite indications that these stepfamilies are increasing (Berger, 1998; Hall \& Kitson, 2000).

While definitions are important in guiding research, they can imply that stepfamilies are a homogeneous entity. However, research illustrates that stepfamilies are diverse in their organisation and come in many different forms (Coleman et al., 2000; De'Ath 1992; Dunn, 2002; Stewart, 2008). This diversity is reflected at two levels; firstly, there are a multitude of types of stepfamilies (Burgoyne \& Clark, 1984; Clingempeel, Brand \& Segal, 1987; Pryor \& Rodgers, 2001) and secondly, there is great variability within stepfamilies themselves. Stepfamilies differ both in the adjustment of family members and the functioning of relationships, depending on factors such as the characteristics of children, for example their gender and age (Amato, 1993; Hetherington \& Clingempeel, 1992), and the level of involvement and closeness between non-resident parents and children (Bray \& Berger, 1993; Hetherington, 1993; McDonald \& Demaris, 2002; Pryor, 2008).

In this study, a definition of stepfamilies was chosen that reflected this heterogeneity. Similar to the definition proposed by the New Zealand Families Commission (2008) a stepfamily is a family where one of the adults in the couple is not the child's biological (or adoptive) parent, while the other one is (The Kiwi Nest: June, 2008). A stepmother family is one in which the non-biological parent is the woman, and a stepfather family is one in which the non-biological parent is the man. 'Complex' stepfamilies are those in which both adults have children from a previous relationship living, at least some of the time, in the household. In contrast, stepfamilies are 'simple' when only one adult has children from a previous relationship living in the household. In both types of stepfamilies, adults may have a biological (or adoptive) child together. Furthermore, 
stepchildren may live part time or full-time in the stepfamily household, and these are referred to as non-residential and residential stepfamilies, respectively.

This definition includes cohabiting, legally remarried, and couples joined by a civil union $^{1}$, as well as heterosexual and homosexual couples. These couples will be referred to throughout this thesis as 'stepfamily couples' or 'stepfamily adults' unless the relevant research study that is being discussed only measured remarried stepfamilies; in which case, this term is used. While the researcher recognises the negative connotations regarding the term stepfamily and the hesitance of many stepfamilies to use this term (Fleming, 1997; Robertson, 2008), it was chosen because it is readily understood in society. However, particular care was taken at all stages of the research not to impose this term on the families, with stepparents referred to in interviews by their first name.

The term 'first families' is used to describe families in which both adults are the biological (or adoptive) parents of the children and the couple lives together in the same household. Other commonly used terms such as 'biological', 'intact' and 'nuclear' families were not used as children may not be biologically related to their parents, nor are stepfamilies necessarily less intact, or deficient, than other families.

\subsection{Stepfamily Demographics}

Although demographic information in New Zealand is limited due to the lack of stepfamily measurement in the Government Census, it appears that stepfamilies are an increasingly common family form. According to estimates, 18 to $20 \%$ of children have been in a stepfamily by age seventeen (Christchurch Health \& Development Study; Nicholson et al., 1999; Dharmalingam et al; 2004) and more than half of Americans have been or will be in a stepfamily at some time in their lives (Larson, 1992). When stepfamilies are measured at one point in time, approximately $10.9 \%$ of New Zealand children aged between ten and fourteen are living in stepfamilies (Roy Mackenzie Centre for the Study of Families: Youth Connectedness Project, 2007). Similar estimates are found in Australia where stepfamilies represent $10.6 \%$ of couple families

\footnotetext{
${ }^{1}$ Civil union $=$ A civil union is a legally recognized union similar to a marriage.
} 
with children; a 50\% increase over ten years (Australian Bureau of Statistics, 1998).

Stepfather families are more common than stepmother families, mainly because children are more likely to live with their mothers after separation. In New Zealand, as is generally found in other Western countries, $82 \%$ of sole-parent households are headed by mothers (Statistics New Zealand, 2007) therefore stepfather families have been studied more closely than stepmother families (Ganong \& Coleman, 1994). However, this does not negate the fact that there are numerous stepmother families, where the stepchildren live in the household part-time (Pryor \& Rodgers, 2001). As shared care arrangements after separation or divorce become more common (Mackay, 2005; Pryor, 2008; Smyth, 2004; Statistics New Zealand, 2007) residential stepmother families will likely increase, where children spend equal portions of time in both their parents' households. Understanding the key processes at work in stepmother families is crucial in building more resilient stepmother families.

The main reason for growing numbers of stepfamilies is the increase in marital disruptions and subsequent re-partnering by adults (Statistics New Zealand, 2005). In New Zealand forty years ago (1971), approximately one in six marriages involved the remarriage of one or both partners, and this had risen to represent one in three marriages by 1996 (Statistics New Zealand, 1997). More recent figures suggest that these levels have not significantly changed since this time, with $34 \%$ of all marriages in 2006 being remarriages for one or both of the individuals (Statistics New Zealand, 2007). These figures are, however, an approximation of stepfamilies since not all remarried couples will have children from previous relationships, and figures have not generally included cohabiting couples. Despite these limitations, these figures suggest an increase in the proportion of children who live in stepfamily households.

Stepfamily numbers are also rising due to the increased numbers of children living in sole parent families. The numbers of children living in sole parent families has increased by $10 \%$ in the last twenty years and these proportions are projected to remain stable from now until 2021 (Statistics New Zealand, 2007). This increase in soleparent families is relevant to the formation of stepfamilies as many children in these families will experience life in a stepfamily when their parent re-partners. For 
example, there is research in Australia to suggest that 52\% of children live in stepfamilies five to eight years after the separation of their parents (Funder, 1996: Australian Institute of Families Study) and American research suggests that four out of five children born into sole parent families will experience the partnering of their mother before the age of 16 (Aquilino, 1996). Comparable figures have been found in New Zealand, where the majority of separated women (74\%) re-partner within ten years of separation; and a third within two years (Dharmalingam et al; 2004).

A significant number of children will also experience the dissolution of their stepfamily. The Christchurch Longitudinal Study reported that nearly one in five children had experienced three or more family transitions by the age of nine (Fergusson, Horwood, \& Shannon, 1984) and Canadian demographic trends indicate that an increasing number of women will experience at least two separations before they reach the age of forty (Leduc, 2004). These figures suggest that multiple family transitions may feature in the lives of a significant number of New Zealand, and Australian, children.

\subsection{Stepfamily Research}

The past few decades have witnessed an increased level of attention given to stepfamilies and their value in raising children successfully. Earlier studies were largely focused on whether children in stepfamilies were at greater risk for experiencing adjustment difficulties when compared to children in first or sole parent families. These studies found that children in stepfamilies were at increased risk for adjustment difficulties, although there were no significant differences from children in stable single parent homes (Pryor \& Rodgers, 2001). These findings led to an increased empirical focus on the well-being of stepchildren; with the aim of uncovering the factors that placed them at greater risk for adverse outcomes (e.g. Bray \& Berger, 1993; Hetherington \& Clingempeel, 1992; Kiernan, 1992).

As previously mentioned, comparison studies are based on the theoretical underpinning that adjustment differences between children in different families are due to the family structure in which the child resides (Bray \& Berger, 1993; Kasen, Cohen, 
Brook \& Hartmark, 1996) - an assumption that has been termed the 'deficit-familymodel' (Marotz-Baden, Adams, Bueche, Munro \& Munro, 1979) or the 'deficitcomparison' approach (Coleman \& Ganong, 1990). More recently, however, researchers have shifted their focus to exploring the dynamics within stepfamilies that lead to positive outcomes. This approach, termed the 'normative adaptive' approach (Ganong \& Coleman, 1994; Hetherington, Stanley-Hagan \& Anderson, 1989) views stepfamily life as a normative experience for many children which, like any family, is comprised of both positive and negative experiences. The development of this model led to a shift in research focus from a simple comparison of family types to exploring the nature of factors that are important determinants of positive stepfamily functioning.

The next section examines the results of research that compares children in stepfamilies and first families on various indices of adjustment.

\subsubsection{Children's Adjustment in Stepfamilies}

The majority of research examining children's adjustment in stepfamilies suggests that they are at higher risk for various adjustment problems, when compared to those in first families. Children in stepfamilies are more likely to exhibit disruptive and delinquent behaviours (Breivik \& Ulweus, 2006; Carlson, 2006; Ganong \& Coleman, 2004; Hetherington, Bridges \& Insabella, 1998; Kirby, 2006; Nicholson et al., 1999) internalising symptoms, and psychological distress (Barber \& Lyons, 1994; Falci, 2006). On average, they are more likely to perform poorly academically and leave school at an earlier age (Ganong \& Coleman, 2004; Nicholson et al., 1999). There is additional research to suggest that stepchildren report lower self-concepts than children from never-divorced and sole parent families (Ganong \& Coleman, 1993; Johnson \& Hutchinson, 1989; Ochiltree, 1990) and that the relationship stepchildren form with their stepparents plays a critical role in self-perceptions (Ochiltree, 1990; Pryor, 2004). In general, studies have found behavioural problems to be more pronounced than internalising problems (Fine, 1997) and difficulties are more evident in the early stages of stepfamily life and when stepchildren enter adolescence (Bray, Berger \& Boethel, 1994). 
In general, risks to stepchildren are not significantly different to those growing up in sole parent families (Coleman et al., 2000; Pryor \& Rodgers, 2001) despite stepfamily advantages such as increased financial resources and increased access to parental figures, with two adults in the household rather than one. Furthermore, average effects across studies are not large (Amato \& Keith, 1991), so that the majority of stepchildren adapt well to stepfamily life (Hetherington et al., 1998). However, stepchildren are at greater risk than those in sole parent families for long-term effects, such as leaving school and home at an earlier age and experiencing divorce or separation in their own marriage (Kiernan, 1991; Smith, 2008; Wallerstein et al., 2000). Some researchers have suggested that these effects can be partly explained by various contextual factors that pre-ceded entrance into a stepfamily, such as socio-economic characteristics, early childbearing and the mental health of mothers (Nicholson et al., 1999).

Research of this nature is partly responsible for the negative view of stepfamilies as a family form that is detrimental to children within them; with some advocating that we "halt the growth of stepfamilies" (Popenoe, 1994; pg 21). However, there is some indication that these increased risks are partly moderated by individual variables; such as the gender and age of the stepchild, and by family process variables; such as the parenting behaviours of the biological parent. In contrast to divorce, girls have been found to adjust less positively to stepfamily life than boys (Amato, 1993; Brand, Clingempeel, Bowen-Woodward, 1988; Hetherington \& Clingempeel, 1992), although differences have not been consistently found across all studies (Coleman et al., 2000; Nicholson et al., 1999). The majority of research has been based on the adjustment of adolescents, a group whose adjustment to stepfamily life is described as most problematic (Bray, 1999; Hetherington \& Jodl, 1994). Research suggests that adolescent stepchildren experience increased adjustment problems (Bray et al., 1994; Bray, Berger, Boethel \& Maymi, 1989; Hetherington, Cox \& Cox, 1982), which may be partly explained by the young person's increasing independence from the family.

Although adolescents in all families are in a developmental phase where their behaviour can be challenging, these problems appear to be particularly pronounced in stepfamilies (Hetherington \& Kelly, 2002). Explanations include adolescents' need to re-establish biological ties with non-resident biological parents, and increased loyalty 
conflicts and sexual anxieties for adolescent girls with stepfathers (Hetherington \& Kelly, 2002). In addition, adolescents from divorced and remarried families are more likely to disengage from parents at an earlier age than those in first families and this may increase risks to adjustment during these years (Hetherington \& Kelly, 2002). Adolescents from stepfamilies are also more likely to leave home at earlier ages, particularly female stepchildren (Kiernan, 1992). For instance, while $71 \%$ of female stepchildren living in stepfather families left home between the ages of seventeen and twenty, only $60 \%$ of male stepchildren did (Dharmalingam et al., 2004).

The higher risks for stepchildren can also be explained in terms of changes in family processes, such as parenting practices and family functioning. This is supported by research that process variables have more potent effects on child and adolescent adjustment than individual variables such as the child's gender or family structure (Demo \& Acock, 1996; Grych \& Fincham, 1990; Fine \& Kurdek, 1992). These findings have led stepfamily scholars to recommend that researchers examine processes within stepfamilies that are related to adjustment (Anderson, Greene, Hetherington \& Clingempeel, 1999; Coleman \& Ganong, 1990). However, it is only recently that researchers have focused on the processes that serve to hinder or promote coping in children experiencing family transitions (Pryor \& Trinder, 2004).

Research focusing on process variables has highlighted some important differences in stepfamilies compared to other families. Mothers in stepfather families may initially use more authoritarian parenting styles (i.e. behaviours high on 'control' and low on 'warmth') and more frequently initiate conflicts during the early stages of stepfamily life (Vuchinich, Hetherington, Vuchinich \& Clingempeel, 1991). While these levels eventually become comparable to those in first families (Hetherington \& Clingempeel, 1992; Pryor \& Rodgers, 2001) they may initially result in higher levels of externalising behaviours, especially for boys (Kim, Hetherington \& Reiss, 1999). The relationship between stepchildren and stepparents can be problematic (Nicholson, Phillips, Whitten, Halford \& Sanders, 2007) and there is evidence of deteriorating relations between children and biological parents (Cartwright, 2005; Cartwright \& Seymour, 2002). In addition, the parenting role that the stepparent exercises appears to be a crucial factor (Fine et al; 1997, 1998) with stepchildren's adjustment promoted when 
biological parents are the primary disciplinarians and stepparents play a less active role (Bray \& Berger, 1993; Bray \& Kelly, 1999) or support the biological parent in their parenting directives (Kurdek \& Fine, 1992).

Stepfamilies are also found to be less cohesive that first families, which may partially explain negative outcomes for stepchildren (Barber \& Lyons, 1994; Pink \& Wampler, 1985). Recent research notes that levels of family cohesion are positively associated with prosocial behaviour in children, and negatively associated with externalising behaviours (Pryor, 2004). Difficulties in the development of the stepparent-stepchild relationship might be one reason to explain the lower levels of cohesion generally found in stepfamilies. These lower levels of cohesion are particularly evident in the early stages of stepfamily life (Pryor \& Rodgers, 2001) and when adolescents are present in the household (Bray \& Berger, 1993; Smith, 1992). Furthermore, complex stepfamilies tend to be less cohesive than simple stepfamilies, at least in the early stages (Hetherington \& Kelly, 2002) since there are a multitude of relationships that must be developed.

There are other indications that family structure does not entirely explain outcomes for children. Longitudinal research has found that many of the negative effects children in stepfamilies experience are predicted by factors that preceded the parents' divorce and entrance into a stepfamily. For example, research following stepfamilies over time has found that negative child adjustment and strained parent-child relationships were evident a number of years prior to the parents' divorce (Aseltine, 1996; Cherlin et al., 1991; Hetherington \& Henderson, 1999). Amato and Booth (1996) found that problems in parent-child relationships were evident eight to twelve years prior to parental divorce. A study in New Zealand that examined the long term impact of living in a stepfamily concluded that while stepchildren were at increased risk for adjustment problems when compared to children in other family structures, these differences were related to "confounding social, contextual and individual factors that were present prior to the formation of the stepfamily" (Nicholson et al., 1999; p. 405).

Risks appear to be further enhanced when children have experienced several family transitions (Pryor \& Rodgers, 2001). For example, Hetherington \& Kelly (2002) report 
that while serious emotional or behavioural problems were found in only $20 \%$ of children experiencing one divorce, they occurred in $38 \%$ of those experiencing multiple divorces. In New Zealand, number of family transitions has been found to be positively associated with behavioural problems, such as levels of offending (Ferguson, Horwood \& Lynskey, 1992) and in the United States, with increased disruptive behaviour in school (Kurdek, Fine \& Sinclair, 1995). Similarly, in the United Kingdom, children in families that had experienced more than one parental divorce reported lower levels of happiness than children from other family types, and lower self-concepts than those in first families (Cockett \& Tripp, 1994).

The quality of parent-child relationships and parenting processes appear to be particularly affected, with multiple parenting transitions associated with increased levels of mother-initiated conflict (Kurdek et al., 1995) and lower monitoring behaviours by mothers (Degarmo \& Forgatch, 1999; Kurdek et al; 1995). These effects may persist into adulthood with children who have experienced multiple transitions showing an increased likelihood for early sexual intercourse and premarital childbearing (Cavanagh \& Huston, 2006; Fomby \& Cherlin, 2007; Woodward, Fergusson, \& Horwood, 2001; Wu \& Thomson, 2001). However, further research is needed to fully elucidate the impact of multiple transitions on children.

In conclusion, although research suggests that stepchildren are approximately twice as likely to experience adverse outcomes as children in first families, the majority experience stepfamily life as positive, and there are generally few differences between children in stepfamilies and stable sole parent homes. The sizes of these effects are greatly reduced when control variables are introduced, such as individual (e.g. child's age, gender) and process (e.g. parenting practices, stepparent role) variables. Finally, there is some evidence that multiple family transitions are associated with increased negative effects for children.

\subsubsection{Dissolution Rates in Stepfamilies}

The increased risks for children experiencing multiple transitions is concerning in light of evidence that stepfamilies are comparatively less stable than first families, particularly in the early years. According to statistics from the United States, $42 \%$ of 
first marriages and over $50 \%$ of remarriages with children end in divorce (AdlerBaeder \& Higginbotham, 2004; Ceglian \& Gardner, 1999; Coleman et al., 2000; Faber, 2004; Stokes \& Wampler, 2002; Visher \& Visher, 2003), and rates of separation are even higher in cohabiting stepfamilies (United States Census Bureau, 2000). This means that more than $50 \%$ of children who enter stepfamily life in the United States will experience the breakdown of their family at some stage.

Unfortunately, there is a lack of demographic data about stepfamilies in New Zealand and Australia. This is due, in part, to the complex nature of children's living arrangements, combined with a tendency for family statisticians to concentrate exclusively on relationships within household boundaries (Qu \& Weston, 2005). Whilst this makes the number of families more manageable for statistical purposes, it ensures there is limited national statistical information available on stepfamilies where children are likely to spend time in more than one household (De Vaus, 2004). There is some research, however, to suggest that stepfamily dissolution is high in stepfamilies. A longitudinal study in New Zealand found that approximately $53 \%$ of re-partnered relationships ended within five years (Christchurch Longitudinal Study; Fergusson, Horwood \& Dimond, 1985). More recently, Dharmalingam and colleagues (2004) reported that stepfamily life had ended within five years for $40 \%$ of children who were under ten years old when the stepfamily had formed, although the reasons for family dissolution were unclear.

Dissolution rates for stepfamilies appear to be particularly high in the early stages of the remarriage (Furstenberg \& Spanier, 1984), particularly in cohabiting stepfamilies. Longitudinal research reveals that nearly half of all second cohabiting relationships involving children end in separation within the first two years of the relationship (Fergusson, Horwood, \& Lawton, 1988). These higher dissolution rates do not appear to be due to lower partner satisfaction (Bray \& Berger, 1993; Landsford, Ceballo, Abbey \& Stewart, 2001; Vemer, Coleman, Ganong \& Cooper, 1989; Voydanoff, Fine \& Donnelly, 1994; White \& Booth, 1985) and have been attributed to the unique stressors stepfamily couples face, in particular the presence of stepchildren (Brown \& Booth, 1996; Jenkins, Simpson, Dunn, Rasbash, \& O’Connor, 2005; White \& Booth, 1985). 
In support of this, divorce is significantly higher in remarriages with stepchildren (Hetherington \& Kelly, 2002; O’Connor, Pickering, Dunn, Golding \& The ALSPAC Study Team, 1999) and stepchildren lower marital quality for remarried adults (Brown \& Booth, 1996), although there is similar evidence of this in first families (Kurdek, 1999). Other research suggests that stepchildren do not significantly reduce marital quality, although they do reduce the quality of parent-child relationships (White \& Booth, 1985). According to this research, it is this reduction in the quality of parentchild relationships that directly affects the stability of stepfamily couples and erodes marital satisfaction over time. Interestingly, the divorce rate for first marriages and remarriages become increasingly similar as individuals age (Clarke \& Wilson, 1994) with some indications that remarriages of older adults are more stable than first marriages (Wu \& Penning, 1997). The fact that stepchildren are less likely to live in the household in older remarriages might be one possible explanation for these findings.

Other explanations provided for the high dissolution rates emphasise the characteristics of stepfamily individuals. Selectivity arguments suggest that individuals who remarry are less willing to remain in unsatisfying relationships, and experience a form of 'conditional commitment' (Furstenberg \& Spanier, 1984) where future divorce is viewed as a more acceptable solution to an unhappy relationship (Hetherington \& Kelly, 2002). This may be one explanation for research indicating that it takes less deterioration in marital quality to precipitate divorce amongst those who have divorced previously (Booth \& Edwards, 1992). Other researchers suggest the existence of personality characteristics of stepfamily adults that make stable partnerships more difficult; such as poor conflict resolution skills and emotional instability (Booth \& Amato, 1991; Murphy, Glaser \& Grundy, 1997).

Remarriages may, too, show higher dissolution rates due to their incomplete institutionalisation in our society - a feature that may contribute to increased stress in stepfamilies. This deinstitutionalisation leads to ambiguity in roles and relationships in stepfamilies, so that the establishment of relationships must be more explicitly negotiated (Cherlin, 1978). While this hypothesis is widely acknowledged, research studies exploring its practical ramifications have yielded mixed results (Coleman, 
Ganong \& Cable, 1997). Other researchers have suggested that describing stepfamilies as 'deinstitutionalised' is not particularly helpful in developing satisfying stepfamily relationships (Pryor, 2008), nor may it be reflective of current attitudes toward stepfamilies, due to increased numbers (Cherlin, 2004). However, research that highlights the increased ambiguity of parenting roles in stepfamilies provides some support for the deinstitutionalisation hypothesis (Coleman et al., 2000).

In sum, there is evidence to indicate that stepfamilies are more unstable family structures than first families and that multiple family transitions are associated with increased risks for children. In comparison with those in first families and stable soleparent families, their behaviour, education, and future relationships are more likely to suffer. In this context, the factors that promote more stable stepfamilies is of prime importance.

\subsection{Determinants of Positive Stepfamily Functioning}

As noted earlier, stepfamily life can potentially be advantageous or disadvantageous to children's development. The identification of the factors that mediate and moderate stepfamily outcomes is important in better understanding stepfamily dynamics, and consolidating a knowledge base to better inform family policy and Government agencies concerned with stepfamilies. This section will outline the main factors associated with positive stepfamily functioning. These factors can be divided into four main groups: demographic, structural, individual and process factors.

\subsubsection{Demographic Factors}

$\underline{\text { Socioeconomic Status - Family Income and Education }}$

Researchers have frequently linked low socio-economic status with increased family stress and adjustment problems for children (Duncan \& Brooks-Gun, 2000; Hobcraft, 1998; Taylor \& McDonald, 1998; Wise, 2003). This is relevant to stepfamilies as research suggests that they are typically more financially strained than first families (Pryor \& Rodgers, 2001). In support of this, some research indicates that differences in children's adjustment in different family structures are partly mediated by socio- 
economic status (Amato \& Keith, 1991; Hetherington \& Clingempeel, 1992; Dunn, Deater-Deckard, Pickering \& O’Connor, 1998; O’Connor, et al., 2001). However, there are some indications that the importance of socio-economic status is reduced when family process variables are introduced, such as family functioning and parenting behaviours (Barrett \& Turner, 2005). Therefore, while socioeconomic status appears to have important effects on the adjustment of children, their importance may be overridden by family process variables.

\subsubsection{Structural Factors}

\section{Stepmother versus Stepfather Families}

The most common structural factor that has been examined is the difference between stepmother and stepfather families. There is some indication that, on average, stepchildren in stepfather families do better that those in stepmother families on some dimensions of adjustment (Fine \& Kurdek, 1992), and that stepmother-stepchild relationships are more problematic than those between stepfathers and stepchildren (Fellmann, Carrasco Galan, Roque \& Galan, 2008; Hobart, 1991). Two-thirds of young people interviewed in the United Kingdom reported actively disliking their stepmothers, compared to a third who reported disliking their stepfathers (GorrellBarnes, Thompson, Daniel \& Bruchardt, 1998). Stepmothers, also, report lower levels of positive engagement with stepchildren, and higher levels of stress and role dissatisfaction (Whitsett \& Land, 1992) when compared with women in other family structures (Thomson, McLanahan \& Curtin, 1992). It should be noted however, that differences between stepmother and stepfather families are often small, and not all researchers have found more negative relationships and adjustment in stepmother families (e.g. Ganong \& Coleman, 2001; Pryor, 2004). Other researchers emphasise the great diversity of stepmother households in the adjustment of stepchildren and relationships with stepmothers (Rodgers \& Pryor, 1998).

There have been various explanations provided for the increased difficulties stepmother families may experience. Since children usually live with their mothers after separation, the majority of stepmothers are non-residential parents (Ferri \& Smith, 1998; Nielson, 1999; Pryor \& Rodgers, 2001) making it difficult for 
stepmothers and stepchildren to form a close relationship. Furthermore, stepmother families may be more likely to have difficulties prior to stepfamily formation, resulting in fathers being awarded parental responsibility (Clingempeel et al, 1987; Ganong \& Coleman, 1994). Stepmothers are also more likely to face competition from the child's non-resident mother who is usually significantly more involved in the lives of their children than non-resident fathers are (Hetherington \& Henderson, 1997; Pryor \& Rodgers, 2001; Stewart, 1999). Although this involvement may be positive for children, it can present difficulties for stepmothers in building constructive relationships with their stepchildren (Hetherington \& Kelly, 2002).

\section{$\underline{\text { Simple and Complex Stepfamilies }}$}

Research examining differences between simple and complex stepfamilies was initially stimulated by clinical observations that life in a complex stepfamily is more difficult. Clinicians have emphasised problems with divided loyalties and family conflict, as stepfamily members struggle to establish roles and relationships in their families (Hetherington \& Kelly, 2002). Empirical research has generally concurred with these suggestions; with both adult and parent-child relationships found to be more problematic in complex stepfamilies (Clingempeel \& Brand, 1985; Schultz, Schultz \& Olson, 1991; Dunn, Davies, O’Connor \& Sturgess, 2000) and lower levels of family cohesiveness present (Hetherington \& Kelly, 2002; Pryor \& Rodgers, 2001). However, not all research has found more problematic functioning in complex stepfamilies. For example, Fine and Kurdek (1992) found there to be few differences in the adjustment of adolescents living in simple and complex stepfamilies. However, their study involved well-established stepfamilies and it is likely that differences may be more evident in the early stages, when new relationships and patterns of interaction are being developed.

\subsubsection{Individual Factors}

\section{$\underline{\text { Age and Gender of Stepchild }}$}

Individual characteristics of stepchildren, in particular their age and gender, have important associations with stepfamily well-being. Both researchers and clinicians suggest that stepfamily functioning, and relationships between stepparents and 
stepchildren, are more harmonious when stepchildren are younger when the stepfamily initially forms. For example, Hetherington and colleagues (1982) found that the most difficult age for a stepparent to enter a stepfamily was when the child was between the ages of ten and fifteen. Parenting roles may be more easily established when stepchildren are young when the stepparent enters the stepfamily since children may be more accepting of a stepparent's attempts at fulfilling a parental role than are adolescents (Bray, 1999; Hetherington, 1993; Hetherington \& Clingempeel, 1992; Rosin, 1987; Visher \& Visher, 2003). They will, too, have had a shorter experience of being parented by their biological non-resident parent, and so may find the adjustment to a third parenting figure comparatively easy. In contrast to younger stepchildren, those older than fifteen may view the entrance of a stepparent positively, as it relieves them of responsibilities for their biological parent as they prepare to leave the home (Hetherington \& Kelly, 2002).

There is other evidence to suggest that children's adjustment in stepfamilies is related to their gender Hetherington, 1989) although there is some uncertainty regarding the nature of differences between boys and girls. While there is some suggestion that stepfathers form more positive bonds with their stepsons as they bond over shared interests, other research suggests that boys find remarriage more difficult than girls (Amato, 1993; Brand et al., 1988; Coleman et al., 2000; Hetherington \& Clingempeel, 1992). Since the majority of children live with their mothers after parental separation, girls may form closer relationships with their mothers, thus viewing the entrance of a stepparent more negatively (Hetherington \& Kelly, 2002). While some research confirms these findings, others report few differences between male and female stepchildren (Coleman et al., 2000; Nicholson et al., 1999).

\section{Time since Stepfamily Formation}

Adjustment in stepfamilies is likely to change as the stepfamily spends more time together and stepparents and stepchildren develop and negotiate their relationship. In support of this, research has shown that parent-child interactions are more difficult in the early months of remarriage, and five years later, when children are adolescents (Bray et al., 1994). Similar findings are evident for aspects of family functioning, with family cohesion and conflict often found to more negative in stepfamilies in the 
beginning stages of cohabitation (Rodgers \& Pryor, 1998). Common explanations for more difficult functioning in the early years include the lack of history between family members, in particular stepparents and stepchildren, and children's need to adjust gradually to the family transitions they have experienced.

In light of this, clinicians have often encouraged biological parents in stepfamilies to introduce their new partner to children gradually before moving in together (Mills, 1984; Visher \& Visher, 1996). Despite these suggestions, much of the research suggests that stepparents are introduced to stepchildren relatively early in the relationship and often begin cohabitating quickly (Montgomery et al., 1992; Smith et al., 2001), ensuring there is often little time for bonds between stepparents and stepchildren to form. This may be particularly pronounced in stepmother families, where biological fathers, in comparison to biological mothers in stepfather families, may introduce their new partner to children more quickly (Gorrell-Barnes et al., 1998).

\subsubsection{Process Factors}

\section{The Stepparent-Stepchild Relationship}

The relationship between stepparents and stepchildren is one of the most salient relationships in a stepfamily. Some researchers suggest that the quality of this relationship is more important to family well-being than the marital relationship (Adler-Baeder \& Higgenbotham, 2004; Berstein, 2000; Brown et al, 1990; CrosbieBurnett, 1984; Pasley et al., 1994). There are other suggestions that the stepparentstepchild relationship has a greater effect on stepchildren's self-esteem and behavioural problems than their relationship with their non-resident parent (Furstenberg, Nord, Peterson \& Zill, 1983; White \& Gilbreth, 2001). Additional research indicates that children's relationships with stepparents and biological parents are equally important (Berg, 2003; Falci, 2006; Pryor, 2008; Schenck et al., 2006; White \& Gilbreth, 2001) although they may contribute to different aspects of wellbeing (Pryor, 2004).

Despite its importance, research indicates that stepchildren and stepparents may experience challenges in developing close relationships. These findings, however, may 
be partly explained by the large reliance on clinical samples, consisting of stepfamilies with more problematic stepparent-stepchild relationships. When relationships are studied in non-clinical populations, the majority of research has found that stepparents and stepchildren eventually form positive relationships, although they are generally rated of lower quality than relationships with biological parents, particularly in the early years (Hofferth et al., 2007; Pryor, 2004, 2008). For example, in a New Zealand study of one hundred stepfamilies, Pryor (2004) found that children rated relationships with stepparents as significantly lower than their relationships with resident and nonresident biological parents on affective dimensions of closeness, quality and security. Stepparents may rate the quality of this relationship even lower than stepchildren, and report more difficulties between themselves and their stepchildren (Ganong \& Coleman, 1993; Pryor, 2004) possibly due to their heightened awareness of their own behaviours, and those of their stepchildren.

More recently, research has focused on the ways in which stepparents develop positive relationships with their stepchildren. Several studies have shown that stepchildren prefer a stepparent who initially behaves in a friendly manner and does not engage in active disciplinary behaviours (Fine et al., 1998; Ganong, Coleman, Fine \& Martin, 1999; Golish, 2003; Moore \& Cartwright, 2005; Orchard \& Solberg, 1999; Russell \& Searcy, 1997; Visher, Visher \& Pasley, 2003). When stepparents initially develop friendships with stepchildren, stepparent-stepchild relationships are more often characterised by liking and affection (Ganong et al., 1999). There are various ways in which stepparents might do this, but the most effective way appears to be individual activities that are chosen by the child. When stepparents engage in these 'affinityseeking behaviours' (Ganong et al., 1999), relationships between stepparents and stepchildren are more likely to be mutually positive (Stern, 1982; Ganong et al., 1999). Affinity seeking behaviours are associated with relationship closeness in most relationships (Bell \& Daly, 1984) but they may be even more pertinent in stepfamilies where relationships are newly developing.

\section{The Stepparent Role}

Interest in the parenting role exercised by the stepparent initially stemmed from clinical recommendations that this was crucial to the positive development of the 
stepfamily (Mills, 1984; Visher \& Visher, 1996). Much of the clinical literature supports the view that stepfamilies may encounter problems when stepparents become prematurely involved in an active parenting role. Stepchildren may not believe that stepparents should act as parents (Visher \& Visher, 1988; Visher et al., 2003), and when stepparents do, this can lead to family conflict and relationship strain. Moore and Cartwight (2005) found that stepchildren expected biological parents to maintain primary responsibility for discipline and the stepparent to play a less involved role. Divided loyalties and feelings of betrayal may become evident when biological parents encourage stepparents to become involved parental figures (Cartwright, 2000). For these reasons, clinicians emphasise the value in stepparent roles that are not based on the biological parent role (Levin, 1997; Mills, 1984; Walker \& Messinger, 1979) and encourage stepfamily members in considering alternative parenting roles.

Despite these clinical insights, research has only recently begun to examine components of the stepparent role. While there have been over a hundred empirical publications on stepfamily life (between 1987 and 1998), only 5\% of these focused on the stepparent role (Pasley \& Ihinger-Tallman, 1994). More recently, there has been an increased focus on the stepparent role, and these results have generally confirmed clinical findings. A series of studies in the United States (e.g. Fine et al., 1997, 1998; Marsiglio, 1991, 1992) demonstrated that the way the stepparent role is constructed has a pertinent effect on relationship development and well-being in stepfamilies. The following chapter discusses research and clinical findings relating to the stepparent role. 


\section{Chapter Two}

\section{The Stepparent Role}

This chapter reviews research and clinical findings regarding the stepparent role. It begins by outlining the definition of a social role and the way the stepparent role has been defined for research purposes. Problems with previous definitions of the stepparent role are highlighted, leading to the definition to be used in this study. Research examining the stepparent role and stepfamily functioning is then reviewed; in addition to the confounding factors that affect the association between the two.

\subsection{Defining Roles}

Despite the frequency with which stepparent roles are cited as important, few clear definitions have been provided. This may be explained by the confusion regarding what constitutes a role, with role theorists providing conflicting definitions and assumptions regarding the operation and definition of roles (Biddle, 1986). This confusion is compounded in the stepfamily context by the ambiguity surrounding the role the stepparent should play in their stepchildren's lives (Fine \& Kurdek, 1994b; Schwebel, Fine \& Renner, 1991).

Role theorists have described a social role as consisting of "all the norms attached to a given social position" (Rodgers \& White, 1993; p.234). While it is assumed that roles provide guidance in social situations through the imposition of expectations or scripts (Jackson, 1998; Stark, 2007), the degree to which roles may change over time is contested. According to the Functionalist conception (Linton, 1936; Parsons \& Shils, 1951) roles are inflexible and universally agreed upon, with individuals accepting designated roles and fulfilling them as best they can. This conception has been

criticised by role theorists who argue that roles are not fixed and evolve over time (e.g. Jackson, 1998; LaRossa \& Reitzer, 1993). For example, some view roles as being 
constantly negotiated between individuals (Biddle, 1986; Mead, 1934, 2001) so that they are constantly modified as behaviours are tested in social situations.

The expectations that comprise social roles may stem from a variety of sources. According to Fine and colleagues (1997) expectations may stem from an individual's personal standards for behaviour, and perceptions of how others believe they should behave. Roles can be influenced by both external and internal components; for example, societal, cultural and situational influences may all have an important effect on the construction of roles. In light of these influencing factors, there is no guarantee that there will be agreement regarding role expectations, although role agreement is more likely when roles have been established for greater periods of time (Hollander, 1985).

Social roles are determined in two main ways; they may be achieved or they may be ascribed. An achieved social role is one that a person assumes voluntarily so that roles are not automatically imposed on an individual; rather there is a degree of choice regarding role definition. The stepparent role is often described as an achieved role as a stepparent does not automatically become a stepparent to their stepchild; rather they have to build this role over time (Bray, 1999; Visher \& Visher, 1990). In contrast, an ascribed role is a position that is assigned to an individual entirely because of certain traits beyond their control (Stark, 2007). The role of a biological (or adoptive) parent has been described as an ascribed role since they are instantly awarded parental status at the birth (or adoption) of a child, regardless of merit.

The construction of roles, therefore, may have a pervasive influence on family and individual functioning. For example, symbolic interactionists' view social roles as having pervasive effects on the quality of family life (LaRossa \& Reitzer, 1993) and researchers have frequently linked role stress with emotional exhaustion (Maslach \& Goldberg, 1998) reduced personal accomplishment (Kelloway \& Barling, 1991; Peiro, Gonzalez-Roma, Tordera \& Manas, 2001) and psychological distress (Fellmann et al., 2008). Furthermore, the degree to which roles are uncertain (role ambiguity) or in conflict with other role expectations (role conflict) have been shown to be associated with individual adjustment and family functioning (Biddle, 1986; Jackson, 1998). This 
is likely to be particular relevant in the stepfamily context, where roles are less clear and prescribed than is the case in first families. These studies, therefore, highlight the value in examining the stepparent role as an important determinant of stepfamily wellbeing.

\subsubsection{Defining the Stepparent Role}

The confusion that surrounds the conceptualisation and definition of roles has contributed to a lack of consistency in the measurement of the stepparent role across studies. The majority of previous research has narrowly measured the stepparent role, with reference to broad attitudes as opposed to behavioural aspects. For instance, the majority of research has focused on the degree to which the stepparent is perceived to be a 'parent' to their stepchild, without exploring the specific parenting behaviours that are entailed within this 'parental' role (Mason et al., 2002).

The stepparent role has rarely been measured in a uniform way, making it difficult to compare findings across research studies. In the United States, Hetherington and Clingempeel (1992) measured the stepparent role by examining the degree to which family members viewed a parental role to be appropriate for stepparents. They also examined perceptions of whether close relationships between stepparents and stepchildren were considered to be appropriate and the extent to which each spouse assumed responsibility for child-rearing and housekeeping tasks, although the individual child rearing tasks were not defined. In addition, Marsiglio (1992) examined stepfathers' perceptions of their role by measuring the degree to which they agreed with general statements regarding the nature of their role in their stepchildren's lives. In a study of Australian stepfather families, Funder (1996) measured the extent to which the stepparent was perceived to be functioning as a co-parent in the child's life. Stepparents' participation in custodial functions of day to day care and guardianship functions relating to decision-making and financial support were examined. Finally, in a study in the United Kingdom, Dunn and Deater- Deckard (2001) asked children to select the most appropriate label (e.g. parent, friend etc) to describe the role the stepparent should have. 
While these studies have increased current understandings regarding the stepparent role, their measurement was limited in several ways. Firstly, some of these studies (e.g. Dunn \& Deater-Deckard; Marsiglio, 1992) did not adequately measure stepfamily members' views regarding involvement in a variety of parenting behaviours. Measurement of a variety of behaviours is important since there are an array of parenting behaviours and child rearing responsibilities in which stepparents might be differentially involved. Furthermore, children's views may differ depending on the parenting behaviours that are examined. While children may not want stepparents to be involved in disciplinary behaviours, they may be happy for them to be involved in supportive behaviours, such as providing financial and emotional support. In addition, some of these studies only measured one family member's perceptions of the stepparent role (e.g. Marsiglio, 1992; Hetherington \& Clingempeel, 1992) and none examined the degree to which roles were discrepant among stepfamily members. Understanding how different components of the stepparent role relate to functioning and how all stepfamily members view this role is important in assisting stepparents in developing roles within their families.

The most comprehensive measurement of the stepparent role was undertaken by Fine and colleagues $(1997,1998)$ in their cross-sectional studies of the stepparent role and stepfamily functioning. These researchers define the stepparent role as consisting of the "cognitions and behaviours pertaining to how stepparents should and do act towards their stepchildren" (Fine et al., 1998; p 273). These cognitions are comprised of two dimensions; the actual and ideal stepparent role. While the actual role refers to the actual parenting behaviours performed by the stepparent, the ideal role reflects perceptions regarding how the stepparent should behave. While some previous research (e.g. Dunn \& Deater-Deckard, 2001) has examined the role the stepparent should play, most research explores the stepparent's actual role, and few have explored both components. These two components are important since views regarding how the stepparent should act may be discrepant with the actual behaviours performed by the stepparent, and this may be an important determinant of functioning (Fine et al., 1997). These dimensions of the stepparent role are illustrated in Figure 2.1. 
Figure 2.1

The Components of the Stepparent Role

\section{The Stepparent Role}

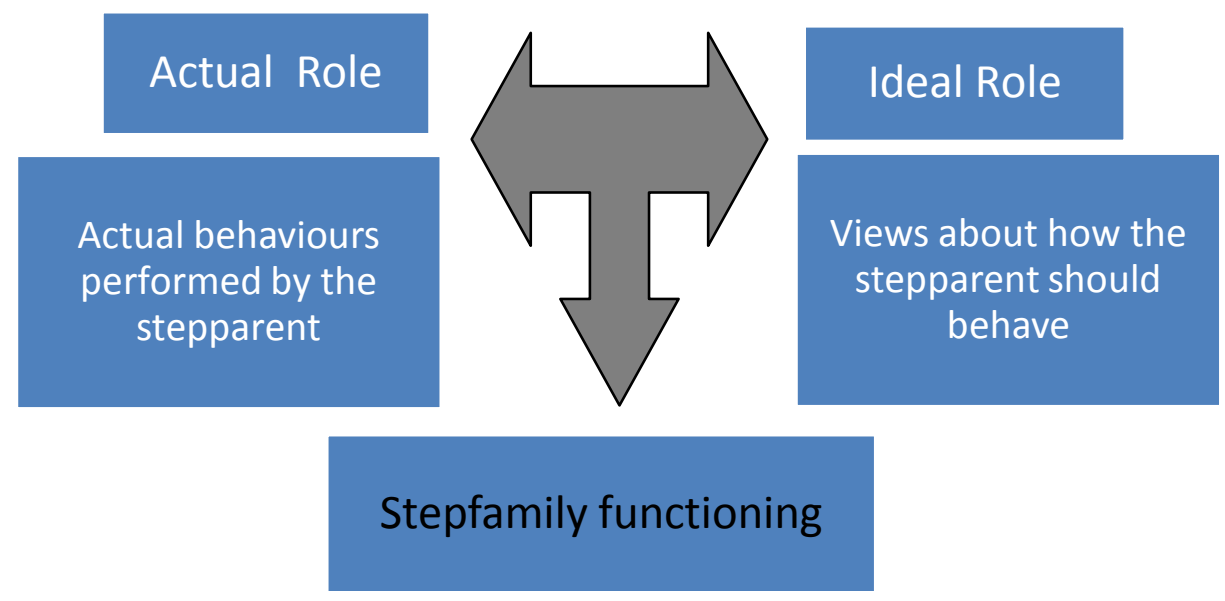

In addition, Fine and colleagues (1998) measured the stepparent role by assessing multiple stepfamily members' perceptions of the stepparent's involvement in a variety of parenting behaviours. Stepfamily members (resident biological parents, stepparents and stepchildren) assessed how involved their stepparent should be in various parenting behaviours (ideal stepparent role) constituting both warmth and control dimensions, and how involved they actually were (actual stepparent role). While warmth refers to the extent to which parents support, spend time and communicate with children, control refers to the degree to which rules and limits are set and enforced, and activities monitored (Glasgow, Dornbusch, Troyer, Steinberg \& Ritter; 1997). In this way, each individual received a score on the stepparent's actual and ideal role along both warmth and control dimensions and these could be compared between stepfamily members to measure discrepancies among stepfamily members.

This study uses the definition provided by Fine and colleagues (1998) although reframes its application to address additional components that are perceived to be important. The stepparent role is defined, then, as the cognitions and resulting behaviours relating to how stepparents should and do act towards their stepchildren. Particular attention is given to how these cognitions and resulting behaviours change over time, as well as how stepfamily members' role perceptions may differ. Since 
stepparents are likely to hold multiple roles in the family, for example the role of spouse and parent (Fine et al., 1998), this research is specifically focused on how stepfamily members' perceive the stepparent role in relation to the parenting of stepchildren. Parenting dimensions of warmth and control are examined since researchers have emphasised that these components need to be examined separately as they may be differentially associated with stepfamily functioning.

\subsection{Research on the Stepparent Role}

This section reviews research concerning the role stepparents play in stepchildren's lives, followed by research exploring the association between the stepparent role and stepfamily functioning. It begins to exploring the reasons why the stepparent role is so important in stepfamilies, in contrast to the development of parenting roles in first families.

\subsubsection{Issues Affecting the Establishment of the Stepparent Role}

Roles and responsibilities are particularly diffuse in stepfamilies because there is little consensus regarding what behaviours are considered appropriate for a stepparent to perform. This lack of consensus may be due to stepfamilies not yet being institutionalised within our society so that there are few normative expectations to guide the development of relationships. In support of this, there is considerable evidence to indicate that stepparent roles are less clear than biological parent roles, both within stepfamilies and in societal perceptions (Afifi, 2003; Church, 1999; Fine, 1997; Fine, Kurdek \& Hennigen, 1992; Fine et al., 1998; Gosselin \& David, 2005; Kurdek \& Fine, 1991). However, it is important to note that the ambiguous nature of parenting roles is not unique to stepfamilies as parenting roles in first families are also becoming less clear-cut, perhaps due to women's increased involvement in the workforce (Belsky, 1993; Edgar \& Glezer, 1992; Greif, 1995; Rustia \& Abbott, 1993). In addition, the changing roles and responsibilities associated with fatherhood further contribute to the increased ambiguity of parenting roles in all family types (Milligan, Fabian, Coope \& Errington, 2006). 
Without this normative framework, stepfamilies have to create roles and relationships in the family that work best for them. This potential difficulty is compounded by the fact that stepparent roles must also be developed while stepfamily relationships are simultaneously being developed, which creates a level of complexity that is not found in first families. While first families also face the task of establishing roles and relationships, this process occurs more gradually over time as the couple negotiate role content during the child's infancy. This is not the case in stepfamilies where the establishment of the couple bond occurs alongside the development of the steprelationship and the construction of the stepparent role.

Secondly, while in first families there is usually an implicit assumption that both parents will have equally significant, although different, roles to play, this may not be the case in stepfamilies. Since only one adult in a stepfamily is biologically related to the child, parenting roles involve a challenge that is not present in first families. This concerns the scope and nature of the stepparent's responsibilities to stepchildren as a parental figure that is not biologically related to them.

There is mixed evidence for the importance of biological relatedness. Some research suggests that biological relatedness is an important issue, particularly for children, and may affect who they categorise as family (Dunn \& Deater-Deckard, 1999; Mekos, Hetherington \& Reiss, 1996; Dunn et al., 2000; Dunn, 2004; Dunn, O’Connor \& Levy, 2002). However, there is also evidence that, rather than biological relatedness, affective factors (such as closeness) and who children live with are more important predictors of family membership (Anyan \& Pryor, 2002; Rigg \& Pryor, 2006; Schmeeckle, Giarrusso, Feng \& Bengtson, 2006).

There are some distinctions that need to be made regarding these findings. Firstly, children's perceptions of family membership do not necessarily correlate with perceptions of who is considered to be a 'parent'. For example, Schmeeckle and colleagues (2006) found that perceptions regarding family membership, or who is considered to be 'family', were different from perceptions regarding parental status. While biological relatedness may not affect who children consider to be family, it may have an effect on who is assigned parental status. There is some evidence that 
biological relatedness is an important concern for stepparents in deciding what role to adopt. For example, in a community study of stepfather households in the United Kingdom, stepfathers reported limiting or avoiding certain aspects of parenting, largely because of their status as a non-biological parent (Smith et al., 2001). Therefore, while studies may find that biological relatedness is not the primary qualification for describing family membership; this does not mean it does not have an effect on the way in which roles are ascribed in the stepfamily.

Since a large proportion of children enter stepfamilies when they are young and still living at home (Dunn et al., 1998; Haskey, 1994) children are more likely to be involved in the role definition process. For instance, most of the children $(72 \%)$ identified in U.K. data from the Office for National Statistics (ONS; Haskey, 1994) started stepfamily life before they were ten years old. In support of stepchildren's involvement in this process, there is research to illustrate the pertinent effect they have on the internal workings of the stepfamily. For example, stepchildren often have greater input in family decisions than stepparents, especially in the beginning stages (Banker et al., 2004; Gosselin \& David, 2005; Visher et al., 2003). Giles-Sims (1989) found that adolescents often had considerable decision-making power in stepfamilies, with $12 \%$ of stepfamilies reporting the adolescent to have equal or greater power than the adults in the stepfamily. The views of stepchildren, therefore, may be given considerable weight in determining how roles are assigned in stepfamilies.

\subsubsection{Roles Stepparents' play in their Stepchildren's Lives}

The last two decades have witnessed increased attention to the role stepparents' play in their stepchildren's lives. Perceptions regarding how the stepparent role is performed have typically been studied in two ways. Firstly, researchers have examined the labels that are used to describe the role the stepparent is playing in their stepchildren's lives. Researchers have often focused on the labels of 'parent', 'stepparent' and 'friend,' with the assumption that these labels correspond with differential involvement in parenting behaviours (Fine et al., 1998). The stepparent label represents the expectation that the stepparent should function in some parent-like ways, but assume a more detached role in other areas (Fine et al., 1998). For example, stepparents may not be entitled to make certain decisions or participate in major disciplinary actions. In 
contrast, the parent label represents the view that the stepparent should function like a biological parent, being actively involved in most parenting behaviours. Finally, the friend label represents the view that the stepparent should function in a supportive way, leaving active parenting to the biological parent (Fine et al., 1998).

There is currently no published research exploring the correlation between stepparent labels and parenting behaviours, therefore these research assumptions may not be justified. This means that stepparent labels may provide limited understanding regarding the stepparent role, as there is uncertainty regarding what these labels actually represent. Researchers have begun to address this issue by examining the stepparent role in more detail: in addition to the most appropriate label, the degree to which the stepparent is perceived to be involved in parenting behaviours is assessed (e.g. Fine et al., 1997, 1998). Since the study of stepparent role labels is based on the assumption that these labels reflect different parenting styles, further research that examines the association between the two is important.

The next section will focus on the labels that stepfamily members use to describe the stepparent role, followed by research examining the stepparent's involvement in various parenting behaviours. In line with the definitions provided by Fine and colleagues (1998), the actual stepparent role will be discussed first, followed by views regarding the ideal stepparent role.

\section{The Actual Stepparent Role}

\section{Stepparent Role Labels}

Some research has focused on the labels stepfamily members use to describe the stepparent role. In a New Zealand qualitative study, Fleming (1997) found that the most common label used by stepfamily adults and stepchildren was friends. Almost all the stepchildren in this study called stepparents by their first name, with the majority of children reserving the labels of 'Mum' and 'Dad' for their biological parents, whether or not they saw much of them, and whether or not they were still alive (Fleming, 1997). Similarly, most adolescents (55\%) in the Stanford Custody Project (1988) saw their new stepparent as a friend, with only $25 \%$ regarding them as a parent. 
In general, adult stepfamily members tend to view the stepparent role differently to their stepchildren. Some researchers have found that the majority of parents and stepparents view the stepparent as having taken on a parental role (Fine et al; 1998; Mason et al; 2002). Other research suggests that many stepfathers do not consider themselves to be stepparents as they consider themselves to be a 'normal' parent (Ahrons \& Wallisch, 1987; Smith et al., 2001), and that the parent role is more likely to be adopted by stepfathers than stepmothers (Ahrons \& Wallisch, 1987; EreraWeatherley, 1996). A parental role may be adopted in an attempt to reconstruct the nuclear family (Levin, 1997) although this is typically viewed by clinicians as problematic (Mills, 1984; Papernow, 2006; Visher \& Visher, 1996, 2003).

\section{Stepparent Role Behaviours}

When actual parenting behaviours of the stepparent are examined, there is some research to indicate that stepparents play an uninvolved role in the lives of their stepchildren, participating less frequently than biological parents in warmth and control parenting behaviours (Cooksey \& Fondell, 1996; Hetherington \& Kelly, 2002; Hetherington \& Clingempeel, 1992; Hetherington \& Jodl, 1994; Hofferth et al., 2007; Fisher, Leve, O’Leary \& Leve; 2003; Lansford et al., 2001). As a result, stepparents have been characterized as 'polite strangers' (Hetherington \& Henderson, 1997) and 'playful spectators' (Patterson, 1982) to their stepchildren (Degarmo \& Forgatch, 2007). Findings of this nature may have contributed to the assumption of stepparents having "little or no effect on child outcome" (White \& Gilbreth, 2001).

There is some evidence that these levels of involvement do not improve over time, particularly as stepchildren enter adolescence. For example, Hetherington and Clingempeel (1992) found that stepparents of early adolescents became more disengaged and demonstrated less positive behaviours over time, when compared with fathers in non-divorced homes (Pasley, Dollahite \& Ihinger-Tallman, 1993). While involvement and closeness with children declines during adolescence in all types of families (Stewart, 2005), this decrease may be more pronounced in stepfamilies (Anderson \& White, 1986; Bray, 1999; Hetherington \& Clingempeel, 1992) possibly due to the complexities in the relationship between stepparents and stepchildren. 
Stepparents in many cases cannot be held responsible for a less involved relationship with their stepchildren. There is some evidence to suggest that stepparents are less involved in the parenting of stepchildren because stepchildren do not accept them as parental figures (e.g. Hetherington and Clingempeel, 1992; Pasley et al., 1993). A qualitative study conducted by Erera-Weatherley (1996) of sixty-four remarried couples found that stepparents described their detachment as the result of hostile stepchildren, and reported that they would have preferred to be more involved in their stepchildren's lives. Other researchers have shown that the behaviours of stepchildren are equally, or more, likely to affect stepparent behaviour than vice versa (Hetherington \& Clingempeel, 1992; O’Connor, Hetherington \& Clingempeel, 1997). This feature of parent-child dynamics appears to be distinctive to newly formed stepfamilies since it is not found in other family types; such as first or sole-parent families, or in stepfamilies established for longer periods of time (Hetherington et al., 1999). Studies such as these emphasise the value in exploring bi-directional processes in stepfamilies (Baxter, Braithwaite, Bryant \& Wagner; 2004; Coleman et al., 2000; Dunn, 2004) although research of this nature has been limited.

Additional explanations for less active stepparent roles include cultural messages that convey the expectation that stepparents should be less involved in the lives of their stepchildren, engaging less frequently in warmth and control parenting behaviours (Claxton-Oldfield, 1992; Schwebel et al., 1991). Furthermore, stepparents might be disengaged at the direction of their spouse (Coleman, Ganong \& Weaver, 2001), although there is research to suggest that biological parents also actively encourage, rather than restrict, their parenting involvement (Fergusson \& Horwood, 1987; Papernow, 1993; Robertson, 2008).

However, not all research indicates that stepparents play an uninvolved role. Many stepparents are actively involved in the parenting of their stepchildren; with some sharing care-giving responsibilities with biological parents (Ahrons \& Wallisch, 1987; Smith et al., 2001). Other researchers have found that stepparents spend a similar amount of time as biological parents in parenting behaviours (Mason et al., 2002) although they are less involved in more intimate activities, such as helping with 
homework or advice-giving. Furthermore, when they are involved in these activities they are less often the leaders (Smith et al., 2001). Involvement in discipline appears to be more complex; while some stepparents are actively involved, others leave these responsibilities to the biological parent or support their partner in their directives (Fine \& Kurdek, date; Smith et al., 2001). Stepparents often support children financially (Ganong, Coleman \& Mistina, 1995), despite the lack of legal requirements to do so (Fine \& Fine, 1992; Redman, 1991) although these obligations tend to deteriorate if the stepfamily dissolves (Ganong et al., 1995).

A more accurate depiction of the role stepparents' play in stepchildren's lives may be reflected in studies that point to the immense variability in the stepparent role. While some researchers have found stepparents to be uninvolved in the parenting of their stepchildren, others find them to be highly involved (Crosbie-Burnett \& Giles-Sims, 1994). This variability in parenting may be heightened for stepparents when compared to biological parents. That is, research on stepfathers tends to show greater variability than biological fathers in their parenting involvement, either being disengaged and non-supportive of the mother, or being actively involved in raising stepchildren (Hetherington \& Clingempeel, 1992; Erera-Weatherley, 1996).

Some of these observed differences among studies may be due to differences in stepfamily samples and the era in which data was collected. For example, there is some indication that stepparents are becoming more involved in their stepchildren's lives (Ferri \& Smith, 1998) so that studies carried out in more recent times may report greater levels of stepparent involvement. In addition, research studies have not measured the stepparent role in a uniform way, nor have stepfamily samples been similarly defined across studies. This is important since much of the variability in the stepparent role can be explained by an assortment of individual, structural and process factors, and the stepparent's involvement in parenting behaviours may differ depending on the component of parenting that is assessed. The main factors affecting the stepparent role are discussed in section 2.4. 


\section{The Ideal Stepparent Role}

As outlined previously, there are two dimensions to the stepparent role - actual stepparent role behaviour (actual stepparent role) and desired stepparent role behaviour (ideal stepparent role). These dimensions were originally conceptualised by Fine and colleagues (1997) and examined in more depth in their later studies (Fine et al., 1998, 1999). However, since then, few research studies have focused on both actual and ideal components of the stepparent role. The following section will review the relevant research and clinical findings. Findings regarding role labels are presented first, followed by stepparent role behaviours.

\section{Stepparent Role Labels}

Researchers have frequently highlighted that stepchildren may desire stepparents to be friends to them, rather than parental figures. In a study conducted by Fine and colleagues (1998) $40 \%$ of stepchildren who were between the ages of ten and nineteen selected friend as the ideal stepparent role, while $29 \%$ selected parent. Similar results have been reported by Buchanan, Maccoby \& Dornbusch (1996), who found that stepchildren were more likely to want stepparents to be friends than to take on parenting roles. In New Zealand, Fleming (1997) found that stepchildren reported a preference for stepparents to be friends to them, although they did expect them to behave in some ways as a parent. Therefore, although there was a preference by children that stepparents be friends to them, they recognised that they might have to act in some ways as a parent.

Not all research has found that stepchildren prefer their stepparent to employ a less involved parental role. Dunn and Deater-Deckard (2001) asked younger children (aged between seven and fifteen) what role they felt the stepparent should have in their lives and found different results to those reported in previous studies. That is, 54\% described the ideal stepparent role as a parent, $19 \%$ as friends, $18 \%$ as both friends and parents, and 10\% thought stepparents should be neither parents nor friends. Therefore, the majority of stepchildren in this study felt that stepparents should exercise a parental role, which is inconsistent with previous research. A possible explanation for these findings is the younger age of the children, since researchers and clinicians suggest it 
is easier for stepparents to be parental figures to younger stepchildren, particularly when they enter their lives when the children are young (Bray, 1999; Hetherington \& Jodl, 1994).

Most research suggests that stepfamily adults describe the ideal stepparent role in different ways to children. In a study conducted by Fine and colleagues (1998), half of the stepparents and parents wanted the stepparent to be a parent to stepchildren. This could reflect the negative connotations associated with the term 'stepparent' or the reality that many stepparents do not consider themselves to be stepparents because they want to exercise a more parental role. This preference by adults to describe the ideal stepparent role as a 'parent' was in sharp contrast to stepchildren, who described the ideal role as parent only $29 \%$ of the time. As discussed in a later section, these findings are likely to vary when stepchildren of different ages are examined.

\section{Stepparent Role Behaviours}

Similar findings are evident when views regarding ideal parenting behaviours of the stepparent are examined. There is some evidence that the general public believe that stepparents should play a less active role in parenting stepchildren (Schwebel et al., 1991) and stepparents who engage in disciplinary and affectionate behaviours may be judged more negatively than biological parents acting in similar ways (ClaxtonOldfield, 1992). These studies were carried out more than twenty years ago now, so that there may have been some changes in more recent times. Yet, despite the increasing numbers of stepfamilies, there is some indication that negative stereotypes remain surrounding stepfather abuse and negative functioning for children in stepfamilies (Claxton-Oldfield, 1992; Claxton-Oldfield \& Whitt, 2003).

There have been few studies examining actual stepfamily members' perceptions of ideal stepparent role behaviours. One study conducted by Fine and colleagues (1998) examined the role stepfamily members wanted stepparents to play and found that they wanted them to be involved in both warmth and control dimensions of parenting. However, similar to role labels, stepchildren's views were different to that of their parents. Stepchildren reported wanting their stepparents to be less involved in warmth and control behaviours than adults and this difference was particularly striking for the 
control dimension. These findings suggest that stepfamily members may not agree on the most appropriate stepparent role, therefore highlighting the need to examine the perceptions of multiple stepfamily members.

Attitudes regarding ideal stepparent behaviours may depend on the behaviours that are examined. Some researchers highlight the reluctance of stepchildren to see their stepparent as having a right to set rules or administer discipline (Lutz, 1983; Pryor, 2004; Rosin, 1987). For example, approximately 50\% of adolescents in the Stanford Custody Project (Maccoby, Depner \& Mnookin, 1988) did not see their stepparents as having a right to set rules in the family (Buchanan \& Maccoby, 1996). Other research suggests that stepparents are expected to be less involved in warmth behaviours, such as providing emotional support, although they are equally obligated (as biological parents) to assist financially (Schwebel et al., 1991; Ganong et al., 1995). This research indicates that attitudes regarding the stepparent role may depend on the behaviours that are measured, and involvement in discipline may be a particularly contentious issue for stepfamilies.

\subsection{The Stepparent Role and Stepfamily Functioning}

The majority of research on the association between stepparent role labels and stepfamily functioning points to the adoption of a parent role as problematic in generating conflict between stepfamily members (Erera-Weatherley, 1996). For instance, adults in stepfamilies report more positive relationships when the stepparent is not expected to be a parent to stepchildren (Bray \& Berger, 1993) and problems may surface when stepparents are expected to assume a parental role too quickly (Bray, 1999; Fine et al., 1999). In contrast, some researchers have found that stepparents themselves may prefer to assume a parental role (Fine et al., 1998; Marsiglio, 1992) and find the role of stepparent to be inherently unsatisfying (Erera-Weatherley, 1996; Everett, 1998). Unfortunately, the cross-sectional nature of these studies precludes firm conclusions regarding the direction of these effects. That is, whether parental roles in stepfamilies lead to more positive functioning, or whether well functioning stepfamilies are more likely to develop parental roles with stepchildren remains 
unclear. Longitudinal research is needed to better elucidate the directionality of these effects.

The majority of stepfamily literature highlights the value in construing the stepparent role as a friend to stepchildren. The friend label may be the most effective as it best acknowledges the loyalty conflicts stepchildren may experience in having stepparents involved as a parent figure in their lives (Erea-Weatherley, 1996; Mills, 1984; Visher $\&$ Visher, 1990) and the lack of history between stepparents and children - features that may make a parental role more difficult for stepparents to enact. However, stepparents may not agree, preferring to play a more involved role due to the difficulties in ascertaining the boundaries of the friendship role and that of a responsible adult in the family (Everett, 1998). Since the majority of indications regarding the value in the friend role stem from small qualitative and clinical studies (e.g. Erera-Wetherley, 1996; Everett, 1998; Mills, 1984; Visher \& Visher, 1990) there is, so far, no strong empirical evidence for its effectiveness over other stepparent roles.

The results of research examining the association between stepparent role behaviours and stepfamily well-being are somewhat mixed. There is some evidence that stepchildren benefit from both warmth and control parenting behaviours (Hetherington \& Clingempeel, 1992; Rodgers \& Pryor, 1998; Kurdek \& Fine, 1993) thus suggesting that the association between children's adjustment and family processes are similar in first families and stepfamilies (Hetherington \& Clingempeel, 1992). Other research suggests that children may benefit from warmth behaviours (Crosbie-Burnett \& GilesSims, 1994), although biological parents should retain responsibility for disciplinary actions, with stepparents supporting these directives (Bray, 1999; Funder, 1996; Kurdek \& Fine, 1992). These findings are more supportive of clinical recommendations that stepparents initially focus on nurturing and befriending their stepchild, whilst trying not to control them (Mills, 1984, Visher \& Visher, 2003). 


\subsection{Factors Affecting the Stepparent Role and Stepfamily Functioning}

Much of the variability reported across studies of the stepparent role can be explained by the assortment of factors that affect the stepparent role and the association between the stepparent role and stepfamily well-being. The following section will outline the main individual, structural, relationship and measurement factors that affect the stepparent role and its association with stepfamily well-being.

\subsubsection{Individual Factors}

Time Availability

A predominant focus of research in the late twentieth century was on the gendered division of household tasks. This was stimulated by changes in traditional gender roles, partly due to significant increases in the proportion of women entering the workforce (Statistics New Zealand, 2008). An important component in determining the allocation of child-rearing tasks is time availability (Coverman 1985: England \& Farkas 1986; Hiller, 1984; Shelton 1992). Time availability is based on the principle that couples maximise family utility by assigning household tasks to the person with the most 'free time' (Aldous, Mulligan \& Bjarnasan, 1997) which is typically measured with reference to the number of hours spent in paid employment (IshiiKuntz \& Coltrane, 1992; Kamo, 1988). Research studies confirm that the degree of time spent in paid employment affects parenting involvement (Aldous et al., 1997). This suggests that stepparents who are employed for fewer hours each week might be more involved in the parenting of their stepchildren.

\section{Gender of Stepparent and Child}

Although recent studies have indicated that gender differences in family housework are diminishing (e.g. Pittman, Solheim, \& Blanchard, 1996), women remain primarily responsible for the majority of child-care and parenting tasks (Barnett \& Shen, 1997; Ishii-Kuntz \& Coltrane, 1992; Miller \& Garrison, 1982; Pleck, 1997; Wright, 1997). 
For example, Amato (1994) notes that, while attitudes towards gendered division of child-rearing behaviours have changed, they have not significantly changed at the behavioural level, so that women spend twice the amount of time in childcare activities even when working full-time. This suggests that stepmothers may play a more active parenting role because of the social demands encompassed in the mother role.

The majority of research suggests that, although most stepmothers are non-resident parents, they are expected to contribute to a large proportion of the childcare responsibilities when stepchildren are visiting. While stepmothers may prefer to become gradually involved in parenting behaviours, they are more likely to be encouraged to function as substitute parents by their partners (Gorrell Barnes et al., 1998). Parenting roles, then, often develop according to a gendered context (Walzer, 2004) with stepmothers significantly more involved in warmth and control behaviours than stepfathers (Ahrons \& Wallisch, 1987; Hetherington \& Kelly, 2002). This involvement may lead to conflict between stepchildren and stepmothers, particularly if stepchildren do not want their stepmothers to be active parental figures in their lives. This is supported by research indicating that stepchildren are less likely to perceive stepmothers as having the right to set rules in the household (Buchanan \& Maccoby, 1996) and rate their relationships with stepmothers more negatively than those with stepfathers (Pruett, Calsyn, \& Jensen, 1993).

The stepparent role may also be affected by the gender of the child. Some studies have found that stepfathers with boys play a more involved role than those with girls (Funder, 1996) and that the relationship with girls is more likely to be described as 'disengaged' (Clingempeel, Brand \& Ievoli, 1984; Hetherington \& Jodl, 1994). Explanations for these findings include the possibility of stepfathers forming more positive bonds with stepsons as they spend time together engaging in shared activities (e.g. sports, common interests). As positive bonds form, stepchildren may be more willing to accept greater levels of stepparent participation in parenting behaviours.

\section{Age of the Stepchild}

The majority of research indicates that stepparents are more likely to function in a parental role if they assume parenting responsibilities when their stepchildren are 
young (Bray \& Kelly, 1999; Dunn et al., 2000; Hetherington \& Jodl, 1994; Pasley \& Healow, 1987). It may be easier for stepchildren to accept the stepparent as a disciplinarian figure the younger they are when the stepparent enters the household (Rosin, 1987, Visher \& Visher, 2003). Hetherington and colleagues (1982) found that the most difficult age for a stepparent to be integrated into the household is when the stepchild is between the ages of ten and fifteen. Stepfamilies with stepchildren in between these ages tended to have more difficult stepparent-stepchild relationships and stepparents tended to play a less involved parenting role.

There are many reasons expressed in the empirical and clinical literature to explain these findings. Firstly, parenting younger stepchildren may necessitate greater involvement in daily child-care; for example activities such as bathing and getting children ready for school are likely to be less necessary as children get older. Secondly, younger stepchildren may form more positive bonds with stepparents, therefore allowing them to be more involved in parenting behaviours (Bray, 1999; Hetherington, 1993; Hetherington \& Clingempeel, 1992) whereas older adolescents (i.e. older than fifteen) may be relieved of concerns about emotional support for their parents as they prepare to lead their own lives (Hetherington \& Kelly, 2002). Stepparents might experience difficulties becoming actively involved in the parenting of early adolescent stepchildren due to their developmental need to develop an independence from the family.

\section{The Length of Time in the Stepfamily}

Most of the research and clinical literature suggests that stepparent roles and relationships are developmental, with stepparent role behaviours and stepfamily relationships changing as stepfamilies develop and spend more time together (Furstenberg et al., 1987; Ganong \& Coleman, 1992, Papernow, 1988; Stern, 1978). However, there is less consensus regarding the actual nature of changes in the stepparent role over time. While some researchers report that stepparents become more involved over time (Amato, 1987; MacDonald \& Demaris, 1996; Papernow, 1993) others suggest they become less involved and relationships deteriorate over time (Guisinger, Cowan \& Schuldberg, 1989; Hetherington \& Jodl, 1994). Rather than adopting a fixed parenting style, stepparents may engage in different behaviours at 
different stages of stepfamily development, partly in response to the behaviours and attitudes of stepchildren (Erera-Weatherley, 1996). Since the relationship between stepchildren and stepparents changes over time, modification of parental behaviours to reflect these changes may be a successful way to negotiate the parenting role.

The quality of the relationship between stepparents and stepchildren is likely to play an important moderating role in the stepparent's involvement in parenting behaviours. As the length of time in a stepfamily increases, stepparents and stepchildren spend more time together, and consequently, may develop more positive relationships. This may render stepchildren more receptive to their stepparent's parenting behaviours. This is one explanation for the finding that the parenting behaviours of the stepparent have different effects on stepchildren at different points in time (Hetherington, 1993). For example, children's adjustment is promoted when stepparents do not initially undertake an active role in discipline, although this may increase over time (Bray, 1999); possibly as stepparents and stepchildren develop more positive relationships.

The main problem with determining the effect the length of time in a stepfamily has on the stepparent role is that it is confounded with other factors. For instance, the length of time the stepfamily has existed is confounded with the child's age, both currently, and when the stepfamily first formed. Since these factors are also associated with stepparent involvement (Coleman et al., 2000), it is difficult to ascertain the independent effects of these factors. It is likely that both factors are important determinants of the parenting behaviours of stepparents, although it is difficult to establish the unique importance of each factor.

\section{Cohabitation versus Remarriage}

It is unclear whether there are significant differences in stepparent roles between cohabiting and married stepfamilies. It does appear that cohabitation is common for most stepfamilies, with many stepfamilies cohabiting prior to remarrying (Cherlin \& Furstenberg, 1994; De Vaus, 2004; Montgomery et al., 1992) and others never remarrying (Bumpass et al., 1995; Ganong \& Coleman, 1994; Statistics Canada, 2002). For example, studies in Australia indicate that $53 \%$ of stepfamilies are cohabiting, and 72\% cohabit before marrying (De Vaus, 2004; De Vaus, Qu \& 
Weston, 2005). These highs rates of cohabitation in stepfamilies are similarly evident in other Western countries with approximately one quarter of all stepfamilies in the United States, and one half of all stepfamilies in Canada, formed by cohabitation rather than marriage (Bumpass et al., 1995; Statistics Canada, 2002).

There is some research to suggest that there are few significant differences in the stepparent role between cohabiting and remarried stepfamilies. For example, although Marsiglio (1992) suggested that remarriage clarifies relationships which may "expand perceptions regarding the stepparent role" (pg 199), remarried stepfathers did not perceive their role differently to cohabiting stepfathers. It was posited that getting married does not strengthen a stepparent's parental role "beyond any changes resulting from the commitment to co-reside" (Marsiglio, 1992; p. 209). Since only stepfathers' perceptions were measured in this study, it is unclear whether marriage changes the perceptions of stepchildren. There is some evidence that this might be the case, with the Stanford Custody Project (1988) finding that children more readily accepted stepparent authority in remarried households in comparison to cohabiting households. In addition, stepchildren appear to be sensitive to issues of biological relatedness and whether their parents are legally remarried or not (Dunn et al., 2000; Dunn et al., 2002) which may affect a stepparent's enactment of a parenting role in cohabiting stepfamilies.

\subsubsection{Structural Factors}

\section{Stepparents' Biological Children in the Household}

Many stepparents have biological children of their own from a previous relationship, and the degree of time these children spend in the household may affect stepfamily dynamics. Stepparents with biological children in the household may adopt a more parental role towards stepchildren (Marsiglio, 1992, 2004) or adjust more easily to the parental functions of the stepparent role (Ambert, 1986). There is contrasting evidence to suggest that stepparents may experience difficulties in fulfilling the role of parent to their biological children and 'parent figure' to stepchildren, particularly if they have limited contact with biological children (Hetherington \& Stanley-Hagan, 2000). When stepparents have biological children that they see infrequently, they may feel reluctant 
to play a parental role to stepchildren, experiencing a form of cognitive dissonance (Rosin, 1987; Visher \& Visher, 1978) and withdrawing parenting involvement from stepchildren (Marsiglio, 1992).

Many step-couples will eventually have a biological (or adoptive) child together and this may affect the stepparent's role. Approximately 54\% of women who remarry will have a child in that marriage (Stewart, 2005; Thomson, 2003; Wineberg, 1990); therefore many stepparents are parenting stepchildren while concurrently developing their own biological parent role. This may increase parental involvement and commitment to stepchildren (Ambert, 1986; Hofferth \& Anderson, 2001; White, Brinkerhoff \& Booth, 1985). A half-sibling may, too, affect how stepchildren view their stepparent's authority to make parenting decisions (Cherlin, 1978), with some even beginning to call them 'Mum' or 'Dad' (Bernstein, 1989). These findings are in contrast to research that suggests that stepparents may withdraw attention from stepchildren in favour of biological children (Flinn, 1988; Lightcap, Kurlnad \& Burgess, 1982, Popenoe, 1994).

However, the majority of research highlights an alternative view - that a half-sibling has neither a positive nor a negative effect on a stepparent's role with stepchildren, and that there are few differences in parental involvement between stepfathers with and without biological children in the new relationship (Cooksey \& Fondell, 1996; Marsiglio, 1991; Stewart, 2005).

\subsubsection{Relationship Factors}

\section{The Non-Resident Parent - Child Relationship}

The majority of evidence suggests that children benefit from positive relationships and involvement with both stepparents and non-resident parents. Research indicates that children report more positive adjustment when they have close relationships with both stepfathers and non-resident fathers (Berg, 2003; Falci, 2006; King, 2006; White \& Gilbreth, 2001). Research examining associations between the parenting involvement of non-resident parents and stepparents has been less commonly studied than the quality of relationships. However, there are some indications that stepparents are more 
involved in the lives of their stepchildren when the non-resident parent continues to play an involved role. For example, Funder (1996) found that children tended to have more involvement with both fathers or less with either. This view complements the theoretical position that rather than substituting parental figures, children can accumulate parents and have positive and involved relationships with multiple parental figures (Pryor, 2004; Pryor \& Rodgers, 2001; White \& Gilbreth, 2001).

While the involvement of the non-resident parent may not significantly affect children's relationship with stepparents or the stepparent's actual involvement with stepchildren, it may affect children's perceptions of the stepparent role. When nonresident parents remain active parental figures, stepchildren may be less likely to accept their stepparent as an authority figure (Giles-Sims \& Crosbie Burnett, 1989; Macdonald \& Demaris, 2002). This may be particularly pronounced in the beginning stages and when stepchildren enter adolescence, when loyalty conflicts are more apparent. Although Funder (1996) did not find an overall association between stepparent and non-resident parent involvement, children's contact with the nonresident parent contributed to lower levels of stepparent involvement in guardianship decisions. Other researchers have found the stepparent role to be more ambiguous when the non-resident parent maintains regular contact with the child (Bray, 1999; Buchanan et al., 1996; White \& Gilbreth, 2001). In light of this evidence, children's levels of contact, involvement and closeness with non-resident parents may be important factors in predicting stepchildren's perceptions of the stepparent role.

\section{The Resident Parent-Child Relationship}

There are two perspectives offered in the literature to explain the effect a close relationship between resident parents and children have on the stepparent role. One perspective is that close relationships between resident parents and children may interfere with a stepparent's efforts to become involved due to a mother's desire to gate keep (Allen \& Hawkins, 1999; Robertson, 2008) or restrict her partner's involvement with the children (Coleman, Ganong \& Weaver, 2001). While there is some evidence of gate keeping behaviours by biological parents (primarily mothers), other research suggests parents are more likely to encourage (rather than restrict) stepparent involvement (Furstenberg, 1987; Robertson, 2008; Smith et al., 2001). In 
contrast, it may be stepfathers themselves who withdraw from engagement in parenting activities, which has been explained as due to their non-biological status (Smith et al., 2001).

The second perspective, which has received more empirical support, is that close parent-child relationships encourage the stepparent to play a more active parenting role in their stepchildren's lives (Marsiglio, 1992, 2004). For example, some researchers have found that close mother-child relationships do not restrict the stepfather's ability to develop a strong relationship with stepchildren. Rather, they may facilitate similarly positive relationships and levels of involvement between stepfathers and stepchildren (Buchanon et al., 1996; Marsiglio, 1992; Pryor, 2004; White \& Gilbreth, 2001). This highlights the pivotal role biological parents' play in the development of stepfamily relationships and the development of the stepparent's parenting role. However, the importance of this role and the relationship between parents and children has been underplayed in stepfamily research, with the general focus on relationships between stepparents and stepchildren (Solomon, 1992).

\subsubsection{Measurement Factors}

\section{$\underline{\text { Specific Parenting Behaviours Measured }}$}

The degree to which stepparents play an involved parenting role and the effect this has on stepfamily well-being may depend on the specific parenting behaviours that are measured in research studies. Research conducted on first families and stepfamilies suggests that warmth behaviours are positively associated with children's well-being (Fine, Voydanoff \& Donnelly, 1993; Hetherington \& Clingempeel, 1992; Maccoby \& Martin, 1983) while control behaviours are not consistently associated with positive adjustment for children. For example, studies have found that parental control and children's adjustment are positively (Astone \& McLanahan, 1991), and negatively (Fine et al., 1993) associated, and others have found no association between the two (Hetherington \& Clingempeel, 1992). In addition, stepfamily members' views regarding the appropriateness of various stepparent behaviours may differ depending on the parenting component measured. While children may be happy for stepparents to be involved in warmth behaviours such as providing for them financially, they may 
view control-related behaviours, in particular discipline, differently (Lutz, 1983, Fine et al., 1998).

The cross-sectional nature of these studies prevents an informed understanding regarding the direction of effects. That is, parents may become more involved in warmth behaviours in response to children's positive behaviours or adjustment, and similarly for control behaviours, where involvement may increase in response to problematic behaviours (Dunn, 2002; Fine et al., 1993; Hetherington et al., 1999). This idea is supported by Hetherington and colleagues (1999) who found that stepchildren's externalising behaviours were associated over time with later negativity from stepfathers. Studies such as these highlight the need to differentiate between warmth and control dimensions of the stepparent role, as they may be differently associated with children's adjustment. Furthermore, longitudinal designs are essential in better elucidating the direction of these effects.

\subsection{Summary}

This chapter outlined the research evidence concerned with the stepparent role, highlighting two components of the stepparent role that are deemed to be important the actual and ideal stepparent role. Evidence regarding how stepfamily members perceive the stepparent role highlights the fact that stepfamily members may hold discrepant views regarding the most appropriate stepparent role behaviours. The next chapter will explore these role discrepancies in more detail.

Research that examines the association between the stepparent role and stepfamily functioning has highlighted some inconsistencies across studies, which can be partly explained by the many confounding factors that play important moderating and mediating roles. These factors are important control variables in research examining the association between the stepparent role and stepfamily functioning. These factors are included in the research model that was examined in this model - and this will be outlined in the next chapter. 


\section{Chapter Three}

\section{Discrepancies in the stepparent role}

This chapter presents the evidence regarding the importance of role discrepancies on stepfamily functioning. Both inter and intra role discrepancies are conceived to be important components of stepfamily functioning and this chapter presents the relevant research and clinical evidence. It then outlines the strategies stepfamily members use to negotiate the stepparent role as a means of reducing role discrepancies. This chapter concludes with the research model that was examined in this study.

As outlined by Fine and colleagues (1998), stepparent role discrepancies can be measured in two ways. The first component is the degree of discrepancies among stepfamily members regarding the most appropriate stepparent role. The second component is the degree to which an individual's perceptions regarding ideal stepparent role behaviours are discrepant with the actual parenting behaviours performed by the stepparent. Discrepancies among stepfamily members will be discussed first. Since the majority of research studies have explored agreement among stepfamily members, rather than role discrepancies, the review will use both of these terms interchangeably.

\subsection{Discrepancies among Stepfamily Members}

The extent to which stepfamily members agree on the stepparent role is an important determinant of stepfamily functioning (Fine \& Kurdek, 1994a; Golish, 2003; Levin, 1997). According to Fine \& Kurdek's (1994a) model of stepfamily adjustment, a stepfamily is 'balanced' when stepfamily members' agree on the stepparent role and 'unbalanced' when discrepancies between stepfamily members are evident. These researchers posit that balanced stepfamilies are associated with higher quality relationships and more positive functioning. 
Research on inter-role discrepancies has largely focused on discrepancies between stepfamily adults. There are some indications that parents and stepparents agree on the degree of responsibility the stepparent should have in raising stepchildren (Bray \& Berger, 1993; Ganong \& Coleman, 1994). To explain this, stepfamily adults may be more likely to periodically discuss issues relating to the stepparent role (Fine, 1997) which may lead to lower discrepancies between adults.

As mentioned previously, the stepparent role has often been narrowly studied in research studies; which has similarly limited current understandings of role discrepancies. Rather than exploring agreement on the perceived appropriateness of specific stepparent role behaviours, research studies have typically examined discrepancies on broad attitudes, such as the degree to which the stepparent should be a parental figure to stepchildren. This is problematic since stepfamily members may agree on broad attitudes and not the more specific components of what is entailed within a parenting role. As Rosin (1987) states "there is a difference between agreement over sharing responsibilities of authority and discipline, and agreement over what should be done in a given situation" (p. 139). More recently, Fine and colleagues (1998) examined inter-role discrepancies in relation to more specific parenting behaviours and found that adults tended to agree on the extent to which the stepparent should be involved in warmth and control parenting behaviours.

Rarely have stepchildren's views of the stepparent role been measured, despite indications that their views are important determinants of stepfamily processes (Pryor, 2004). The importance of examining the views of children is further reinforced by research that illustrates the point that stepchildren often have different perceptions of family processes when compared to adults (Dunn, 2004). In particular, stepchildren may resist stepparent's efforts at discipline, and may not agree that stepparents should be actively involved in their lives (Hetherington \& Kelly, 2002; Mills, 1984). Research examining differences in perceptions among stepfamily members has found that parents and stepparents perceive the stepparent role in similar ways although stepchildren have different views (Fine et al., 1998). For example, while approximately $50 \%$ of stepfamily adults reported that the stepparent should be in a 
parental role, only $29 \%$ of stepchildren concurred. Instead, stepchildren were significantly more likely to want stepparents to be 'friends' to them.

The next section addresses the research examining the importance of inter-role discrepancies to stepfamilies: that is, are discrepancies between stepfamily members associated with increased problems in stepfamilies?

\subsubsection{Inter-Role Discrepancies and Stepfamily Functioning}

There is some evidence that inter-role discrepancies are associated with increased problems in stepfamilies. Failure to reach consensus on the stepparent role has been linked with marital conflict and adjustment problems for both parents and stepparents (Felker et al., 2002; Keshet, 1990, Keshet, Cath \& Shopper, 2001; Weaver \& Coleman, 2005). Furthermore, clinicians and researchers have both emphasised the importance of role agreement in leading to more positive relationships between stepparents and stepchildren (Quick, Newman \& McKenry, 1995) and higher levels of remarriage satisfaction (Kaplan \& Hennon, 1992; Palisi, Orleans, Caddell \& Korn, 1991).

However, there have been few studies that have examined associations between interrole discrepancies and stepfamily functioning by comparing stepfamily member's actual perceptions on identical measures. An exception to this is the study conducted by Fine and colleagues (1998) which compared stepfamily members' role perceptions on identical measures and found that agreement between adults was positively related to stepparent-stepchild closeness, family strengths and satisfaction with step parenting. As found in other research, discrepancies on the warmth dimension were more strongly associated with stepfamily functioning than discrepancies on the control dimension. Although there are theoretical reasons to hypothesise that discrepancies between stepparents and stepchildren are important, this study did not find it to be associated with functioning. Discrepancies between parents and stepchildren were not examined, possibly because researchers and clinicians have tended to highlight the salience of the relationship between stepparents and stepchildren; and the parenting role of the stepparent more directly concerns stepparents and stepchildren. 
In addition, inter-role agreement regarding the actual stepparent role was found to be more consistently associated with stepfamily well-being than agreement relating to the ideal role (Fine et al., 1998). However, it is likely that discrepancies on the ideal stepparent role become more evident over time, when expectations between stepfamily members are revealed. While discrepancies between stepfamily members on the actual stepparent role may be more indicative of reporting biases, which may be indicative of relationship difficulties or lower levels of cohesion; discrepancies on the ideal stepparent role are more likely to reflect differences in role expectations. It is likely that differences in expectations are more closely associated with stepfamily functioning, particularly over time, than differences in perceptions of how involved the stepparent actually is.

\subsection{Discrepancies within Individuals - Intra-Role Discrepancies}

The extent to which there are discrepancies between the actual and ideal stepparent role for a particular stepfamily individual (intra-role discrepancies) is also considered to be an important determinant of stepfamily functioning. As outlined previously, there are some indications that stepfamily adults and children view the ideal stepparent role differently. This highlights the possibility that stepparents may be participating in parenting behaviours which stepchildren do not consider to be appropriate. If this does occur, it may have a detrimental effect on the development of relationships and children's adjustment.

\subsubsection{Intra-Role Discrepancies and Stepfamily Functioning}

There have been few research studies that have examined intra-role discrepancies in stepfamilies. Similar to other research on the stepparent role, studies on intra-role discrepancies have tended to examine the perceptions of stepfamily adults without examining the perceptions of stepchildren. One of the first studies to explore intra-role discrepancies found that stepfamily adults who perceived the stepparent to be engaging in parenting behaviours as often as they felt was appropriate reported more satisfying parenting experiences (Fine \& Kurdek, 1994). Similar to the findings for inter-role discrepancies, discrepancies regarding the warmth dimension were more strongly associated with functioning than discrepancies regarding the control dimension. 
However, there were methodological problems with this study in that the sample was not representative, with participants recruited through the Stepfamily Association of America (SAA). Furthermore, only one dimension of stepfamily functioning was assessed. Despite these limitations, this study was one of the first to reinforce clinical observations that intra-role discrepancies have important effects on stepfamily functioning (Leslie \& Epstein, 1988; Visher \& Visher, 1988).

In order to better understand how intra-role discrepancies are associated with other components of stepfamily functioning, Fine and colleagues (1997) examined a variety of aspects of stepfamily functioning. In addition to parenting satisfaction, these researchers examined mental health symptoms, marital satisfaction and family strengths, as reported by stepfathers. This study provides further evidence that intrarole discrepancies for stepparents are negatively associated with stepfamily functioning. That is, small discrepancies between perceptions of how stepfathers do behave and how they would ideally like to behave were positively related to stepfathers' perceptions of their parenting involvement, satisfaction with the stepparent role, closeness with stepchildren, marital satisfaction, and family strengths. Similar to previous findings, discrepancies for the warmth dimension were more consistently associated with stepfamily outcomes than the control dimension. The main limitation of this study was that intra-role discrepancies for other stepfamily members were not examined; therefore the extent to which intra-role discrepancies for biological parents and stepchildren are associated with stepfamily functioning remains unclear. In addition, the cross-sectional nature of this study means that the direction of these effects is also unclear.

\subsection{Summary}

This review has highlighted the questions that exist regarding the association between role discrepancies and stepfamily functioning, despite the fact that both researchers and clinicians have highlighted its importance (Fine et al., 1998; Mills, 1984; Visher \& Visher, 1990). There is a need to further examine children's intra-role discrepancies, and the extent to which inter-role discrepancies between children and their parents are associated with stepfamily functioning. In addition, the effect role discrepancies have 
on stepfamily functioning has not been examined, after controlling for important control variables such as the stepparents actual involvement in parenting behaviours. It is possible that role discrepancies are not associated with stepfamily functioning beyond what can be explained by individual role perceptions, such as the stepparent's involvement in warmth and control behaviours. Previous studies have not examined these processes in this way and therefore this study aimed to do this by conducting hierarchical regression analyses to assess the independent contribution of role discrepancies in predicting stepfamily functioning.

The cross-sectional nature of previous research further limits our understanding of the direction of effects. That is, do role discrepancies lead to more problematic functioning in stepfamilies, or does more problematic functioning lead to higher role discrepancies? Questions of this nature require longitudinal data, measuring role discrepancies and stepfamily functioning at more than one point in time.

In light of suggestions that role discrepancies between stepfamily members may be reduced when stepfamily members actively negotiate the stepparent role (Fine 1997), the next section presents findings regarding role negotiation strategies used in stepfamilies.

\subsection{Role Negotiation in Stepfamilies}

Stepfamilies possess many unique features that point to the importance of role negotiation. As previously mentioned, there is some indication that parenting roles in stepfamilies are less clear than they are in first families (Coleman et al., 2000). Without this normative guidance, stepfamily members need to develop their own standards regarding parenting roles which may be complicated due to certain unique features of stepfamily life.

Firstly, stepfamily members have not lived together for the same length of time as a first family, where parents and children have established patterns of interaction during the child's infancy. This is compounded by the involuntary nature of many stepfamily relationships; in particular, the relationship between stepparents and stepchildren. That 
is, the shared connection to the biological parent is their reason for living in the same household, and they are often described as strangers with no common interests or feelings of mutual affection (Howden, 2007). Although the majority of stepparents and stepchildren eventually form supportive relationships (Robertson, 2008) the involuntary nature of this relationship, combined with the lack of history, can lead to difficulties in ascribing roles and relationships (Visher \& Visher, 1996).

These difficulties can be exacerbated by the complexity evident in the stepfamily household. There is a great deal of activity in the stepfamily; for instance, the composition of the household is likely to change regularly as children exit and return after spending time with their non-resident parent. If the stepparent has biological children, it is likely that they, too, will spend time in the household. This level of activity, combined with the newness of stepfamily relationships, ensures that more needs to be discussed and negotiated in order to function effectively as a family (Papernow, 2006; Peek, Bell, Waldren, \& Sorell, 1988).

The following section will outline the evidence for the value of role negotiation, which stems from three main sources; clinical accounts, research studies, and organisations providing assistance and advice to stepfamilies.

\subsubsection{Evidence for the Importance of Role Negotiation}

Clinicians working with stepfamilies initially highlighted the importance of role negotiation, particularly for newly formed stepfamilies (Mills, 1984; Visher \& Visher, 1988). It was generally recommended that stepfamily adults initially discuss expectations regarding the stepparent role, prior to the involvement of stepchildren (Visher \& Visher, 1988). For example, Mills (1984) suggests that stepfamily adults need to explore "the various possibilities of roles for the stepparent" (pg 368). Since a common problem reported by stepparents is the lack of clarity regarding their partner's expectations (Coleman et al., 2001; Whitsett \& Land, 1992) discussions are designed to develop a clearer understanding between stepfamily adults regarding the appropriate role of the stepparent. 
In response to these recommendations, organisations working with stepfamilies have often encouraged the discussion of the stepparent role in their educational and support programs. For example, a central task in the 'Personal Reflections' program (Kaplan \& Hennon, 1992) involves encouraging adults to discuss how the stepparent role will be enacted, and Gonzales (2009) highlights the need to achieve 'parental unification,' or agreement regarding the stepparent role, particularly regarding the stepparent's involvement in discipline. A similar content is evident in the 'Stepfamily Enrichment Program,' (Michaels, 2000, 2006) where stepfamily couples are encouraged to develop a parenting role contract, detailing the ways in which future parenting issues will be managed.

In addition, some researchers have highlighted the positive value in discussions of the stepparent role. In their research on the stepparent role, Fine and colleagues (1997, 1998) suggested that future research could better delineate the processes by which role agreement occurs in stepfamilies, with active negotiation of roles cited as a potentially important factor. Other researchers have emphasised the importance of role negotiation between stepfamily adults as a means of reducing discrepancies regarding role expectations (Nicholson et al., 2007) which have been found to foster a stronger marital relationship (Adler-Baeder \& Higginbotham, 2004; Bernstein, 2000; Dupuis, 2007; Pasley et al., 1993). Developing positive communication skills so that stepfamilies can successfully negotiate roles is commonly highlighted as a priority in work with stepfamily couples, with couples encouraged to conceptualise parenting roles that might challenge traditional gender roles (Bernstein, 2000; Dupois, 2007; Visher \& Visher, 2003).

Finally, there have been references made to the value of role negotiation in books developed for stepfamilies (i.e. 'how to' and self-help books), and educational resources for stepfamilies. In the United States, the Stepfamily Association of America has highlighted the importance of stepfamilies seeking clarity regarding parenting roles, particularly in relation to the appropriateness of the stepparent's involvement in discipline. In New Zealand, while there is no national stepfamily association, there is a Stepfamily Support and Education Group in Christchurch that assists stepfamilies through monthly support groups and access to educational resources. Don Rowlands 
(President) asserts that one of the recurring issues he observes in stepfamilies involves the resolution of the stepparent role (Don Rowlands; 2008, personal communication). These recommendations are consistent with advice in self-help books for stepfamilies, which encourage stepfamilies to develop a parenting team where parenting roles are actively communicated and negotiated (Ziegahn, 2002).

To conclude, there are plenty of indications that role negotiation may play an important role in clarifying role expectations in stepfamilies, particularly those in the early stages. Clinicians, researchers and authors of self-help books for stepfamilies frequently highlight role negotiation as playing a central role in the development of stepfamily relationships. Despite these indications, there has been little empirical research that has explored the extent to which stepfamilies negotiate the stepparent role, and the strategies that are used. The following section will address the research and clinical findings relating to the processes of role negotiation and the extent to which these occur in stepfamilies.

\subsection{Role Negotiation Strategies}

There are a wide range of strategies that may be used to negotiate the stepparent role. Strategies may differ in the extent to which the stepparent role is explicitly discussed, and the family members that are included in these discussions. While explicit strategies are discussions where the stepparent role is the prime focus, non-explicit strategies are more subtle in presentation. For example, in non-explicit strategies, the stepparent role may be negotiated through stepfamily members' behaviours (e.g. gate keeping behaviours) or through conversations where the stepparent role is not explicitly discussed (e.g. seeking feedback from family members). These strategies were considered to be important in light of indications regarding the ambiguity of roles in present society. That is, while stepfamilies may not identify having discussions regarding the stepparent role, they may report engaging in less explicit negotiation processes where the stepparent's role behaviours are addressed in a less explicit way.

Discussions on the stepparent role may also involve a range of family members. While the most common strategy may be discussions between stepfamily adults, stepfamilies 
may also negotiate roles amongst the whole family (family discussions) or between children and individual adults (parent-child discussions). These strategies are discussed in the following section.

\subsubsection{Role Negotiation Strategies Involving Stepfamily Adults}

\section{$\underline{\text { Adult Discussions }}$}

Discussions between stepfamily adults is the most commonly mentioned role negotiation strategy. These discussions might involve issues such as the type of stepparent-stepchild relationship the couple wants to nurture in the stepfamily, and/or the stepparent's role and responsibilities in parenting the stepchildren (Bray \& Kelly, 1999). Such discussions may take place before or after cohabitation, or at both stages. Bray and Kelly (1999) have suggested that discussions at both these times are important, since pre-cohabitation talks play an important role in revealing expectations, and post-cohabitation talks allow discussion of expectations that may not be revealed until living in the same household. Furthermore, post-cohabitation discussions enable adults to check in with each other periodically to discuss how the stepparent role is being enacted.

Both researchers and clinicians posit that a central task for adults in stepfamilies is the discussion of the stepparent role to avoid difficulties developing at a later stage (AdlerBaeder \& Higginbotham, 2004; Bernstein, 2000; Dupuis, 2007; Fine \& Everett, 1996; Gonzales, 2009; Nicholson et al., 2007; Pasley et al., 1993; Visher \& Visher, 2003). Discipline is highlighted as the most crucial issue to discuss, so that consensus is reached regarding how discipline will be handled by the stepparent. As previously mentioned, discipline can be a challenging issue in stepfamilies since biological parents and children may find stepparents involvement in discipline initially confronting. Negotiation between adults is likely to be particularly important when they have very different views regarding this role, since negotiation may play an important role in working through these differences.

Despite the value of discussions, the research indicates that couples do very little to prepare for stepfamily life, other than cohabiting (Ganong \& Coleman, 1989; Everett, 1998). Couples are more likely to discuss the stepparent role after moving in together, 
once they are exposed to a full range of their stepchild's behaviour (Robertson, 2008). In a study conducted by Smith and colleagues (2001), only $25 \%$ of stepfamily adults discussed parenting issues and childcare responsibilities before moving in together. In addition, despite the difficulties surrounding stepparent discipline, involvement in disciplinary behaviours was discussed by only $20 \%$ of couples prior to cohabitation, although this had risen to $50 \%$ after moving in together.

These findings indicate that stepparent role negotiation is more likely to occur when difficulties surface regarding the stepparent's role, which may become more apparent once living together. However, there has been no research, thus far, that has explored whether stepfamilies use role negotiation strategies in a preventative way, or whether they are used when the stepfamily are experiencing problems. The clarification of this is important in guiding practical recommendations for individuals in stepfamilies.

In addition, role negotiation may be limited in stepfamilies due to stepfamily adults avoiding discussing confronting issues such as the stepparent role. There is some research to suggest that stepfamily couples, compared to couples in first families, withdraw more from conflict-inducing discussions, such as the negotiation of parenting roles (Golish, 2000; Golish \& Caughlin, 2003; Halford, Nicholson \& Sanders, 2007) although communication between stepfamily couples has generally been linked with more positive stepfamily experiences (Beaudry, Boisvert, Simard, Parent \& Blais, 2004; Golish, 2000; Halford et al., 2007). Some researchers and clinicians suggest this avoidance stems from the desire to be seen as a first family, where active negotiation of roles is deemed to be less necessary (Levin, 1997; Visher and Visher, 1996).

However, while researchers frequently highlight the value in actively discussing the stepparent role, the actual value of role negotiation remains unclear. For example, a program developed for stepfamilies that encouraged the discussion of parenting roles actually reported higher separation rates amongst participating couples (Stepfamilies Preparation Program: Nicholson, Halford \& Sanders, 1996, 2007). Two explanations were proposed to explain these findings. Firstly, participating couples may have had more problems than non-participating couples at the outset which encouraged 
participation in this program, and secondly, discussing potentially stressful issues such as the stepparent role may have created conflict between couples. Future research needs to assess the value of discussions regarding the stepparent role so that stepfamilies can be best informed regarding how to enrich their stepfamily experiences.

\section{Less Explicit Discussions between Adults}

Stepfamily adults may be more likely to engage in less explicit discussions of the stepparent role. Rather than engaging in explicit talks about the stepparent role, stepparents may check in periodically with their partners for feedback regarding the appropriateness of their parenting behaviours. This may be expressed in a more general fashion, in response to a specific incident. For example, many of the stepparents interviewed in the pilot study mentioned that they would check in with their partner to clarify that their behavior was appropriate and whether they should have handled the situation differently. In this way, biological parents are likely to play a pivotal role in the development of the stepparent role through the feedback they provide (Berg, 2003; Bray, Berger \& Boethel, 1994; Cadolle, 2000; Coleman et al., 2000; Crosbie-Burnett \& Ahrons, 1985; Keshet et al., 2001).

\section{Discussions Involving the Non-Resident Parent}

While probably uncommon, non-resident parents may occasionally be involved in discussions between stepfamily adults regarding the stepparent's role. There have been two known studies that have alluded to the occurrence of talks of this nature. In a study by Marsiglio and Hinojosa (2007), stepfathers with positive relationships with their partner's ex-partner were more likely to talk openly about stepfamily issues, such as the stepparent role. One stepfather reported that "he and I have had some real serious talks on the phone, and he's really happy that I'm in her (stepchild's) life, because I'm a stable influence.... and he's also happy because I believe very strongly that as long as he's doing well, he needs to be involved too, that I'm never gonna try an replace him, even though he really has not raised her." (p. 854). Another study in the United Kingdom found that some stepfathers addressed the non-resident parent directly when they perceived him to be limiting their ability to act as a parent (Smith et al., 2001). It is likely that discussions of this nature may lead to increased understanding between 
stepfamily adults and more harmonious interactions between the child's two households.

\subsubsection{Role Negotiation Strategies Involving Children}

Although couple discussions are the most common types of discussions referred to in the literature, some researchers and clinicians emphasise the importance of inclusion of stepchildren in these discussions. While discussions should initially involve adults, researchers emphasise the importance of seeking stepchildren's input (Cissna, Cox \& Bochner, 1990; Fine, 1996; Mills, 1984; Visher \& Visher, 1988). This is important since the degree to which stepchildren agree with the stepfamily adults' conception of this role is likely to affect their success in implementing this role (Fine et al., 1997). Stepchildren may affect the stepparent role through their behavior towards the stepparent, and their acceptance of the enactment of a parenting role (Coleman, Fine, Ganong, Downs \& Paul, 2001; Stafford \& Bayer, 1993).

The extent of the stepchild's involvement in the role definition process depends on many factors, including the couples' values and the developmental stage of the child (Fine, 1996). For example, very young stepchildren may not be able to conceptualise and/or verbalise their expectations regarding the stepparent role which may limit their involvement. Adults may differ, too, in the extent to which they are child-centered and believe it is appropriate to actively seek children's views on the internal workings of the family.

The following section will outline the role negotiation strategies involving both stepchildren and adults in the stepfamily. Discussions between biological parents and children will be described first, followed by discussions between stepparents and stepchildren.

\section{Discussions between Resident Biological Parents and Children}

While infrequently discussed in the literature, resident biological parents may discuss the stepparent role with children directly. Parents may prefer discussing the stepparent role independently with children, particularly when their relationship with children is close, and when a significant period of time was spent in a sole parent family. 
Similarly, children may prefer to bring concerns to their biological parent rather than their stepparent, where relationships are still new and developing.

There has been some qualitative research alluding to the existence of role negotiation strategies involving biological parents and children. Many of the stepfamily couples in a study by Golish (2003) reported that stepchildren were more likely to talk directly to biological parents, than stepparents, about stepfamily issues such as the stepparent role. In a study designed to explore communication strategies in stepfamilies, Baxter, Braithwaite and Bryant (2006) found that most communication between children and stepparents occurred indirectly through the biological parent. That is, rather than discussing family issues directly with stepparents, children were more likely to approach their biological parent, who would play an intermediary role between children and stepparents. For example, one stepchild in the study by Golish (2003) reported "Bill...has no kids...so he's not used to how we work...so, a lot of times, he'll come up with his opinion on a particular matter...and so my Mum, we get her to explain to him that it doesn't really work that way." (p. 389).

However, while qualitative studies have highlighted the existence of discussions of this nature, no published studies were found that have explored the frequency with which these occur and to what extent they are associated with stepfamily functioning.

\section{Discussions between Stepparents and Stepchildren}

While discussions on the stepparent role between stepparents and stepchildren may be unusual, there is some indication that communication between the two is beneficial, and that some stepparents discuss their role with stepchildren directly (Bray \& Berger, 1993). A few stepparents in a study by Michaels (2007) reported providing clear explanations to stepchildren regarding their role in their life. In some cases, this involved reassuring stepchildren that they were not there to replace their non-resident parent. As one stepparent stated - "I talked with them all individually and there's a couple of things I made clear - that I wasn't trying to be their mother, I just wanted to be a caring adult in their lives" (Michael, 2006; p. 61). These stepparents felt that it was important to talk directly with stepchildren regarding these issues, partly because they were conscious of the loyalty conflicts they might experience. 
However, there are no known published studies that examine the frequency of these discussions in stepfamilies and the degree to which they are associated with positive functioning. It is likely, due to the relative newness of stepparent-stepchild relationships, that biological parent-child discussions are more common.

\section{Less Explicit Discussions between Adults and Children}

Furthermore, while some stepparents and biological parents will have explicit talks with children regarding the stepparent role, others may check in less directly for feedback regarding the stepparent's parenting behaviours. Therefore, in addition to explicit discussions about the stepparent role, non-explicit discussions between adults and children may be an important strategy used in stepfamilies to negotiate the stepparent role.

\section{Family Discussions}

The importance of family discussions, or family conferences, as they are often referred to in the American literature, is frequently emphasised by stepfamily researchers and clinicians. Qualitative studies have found newly formed stepfamilies to use family discussions to discuss important issues (Braithwaite et al., 2001; Golish, 2003). In a study by Coleman and colleagues (2001), some stepfamilies engaged in regular family meetings as a means of resolving family conflict. However, stepfamily individuals reported that these meetings needed to be maintained to be effective; therefore, frequency of stepfamily meetings may be important. In addition, many programs developed for stepfamily couples emphasise the value in family meetings. For example, 'Learning to Step Together' (LST; Carrier, 1982), and pre-blended family counseling (Gonzales, 2009) highlight the value in discussing the stepparent role as a family so that decisions can be made with the input of the entire family (Kaufman, 1993).

Yet, despite frequent references to the value of family discussions, research has rarely focused on how frequently these occur in stepfamilies. This study aimed to determine whether stepfamilies use family discussions to discuss the stepparent role, and to what extent they are associated with stepfamily functioning and the quality of relationships. 


\subsubsection{Gate Keeping Behaviours by the Biological Parent}

The research and clinical literature frequently refer to the powerful way in which the biological resident parent may discourage or gate keep the stepparent's involvement with children. According to Allen and Hawkins (1999) gate keeping is "a collection of beliefs and behaviours that ultimately inhibit a collaborative effort between men and women in family work." (p. 200). Although there is evidence of gate keeping behaviours in first families (Allen \& Hawkins, 1999), it is likely to be more pertinent in stepfamilies where only one parent is biologically related to the child. Biological parents may do this in a number of ways; by discouraging children and stepparents from spending time together, and expressing a desire for the stepparent to be minimally involved in parenting behaviours (Bray \& Kelly, 1999). It is suggested that these behaviours are unconscious, with parents adopting established patterns of behaviour acquired during the single parent phase (Bray \& Kelly, 1999) or attempting to protect close mother-child bonds (Coleman et al., 2001). While most researchers suggest that these behaviours are problematic in interfering in an independent relationship between stepparents and stepchildren (Bray \& Kelly, 1999; EreraWeatherley, 1996; Rosin, 1987; Whitsett \& Land, 1992), stepchildren may appreciate biological parents who encourage stepparents in limiting active parenting involvement (Cartwright, 2000) and gate keeping behaviours may be one way that biological parents do this.

There is some research evidence for the use of gate keeping behaviours in stepfamilies, particularly in the early stages. In a study by Erera-Weatherley (1996) some biological parents reported controlling the relationship between stepparents and children, and this appeared to interfere in the development of the step-relationship. In addition, Marsiglio (2004) highlighted the important role of mothers in gate keeping the stepparent's involvement by encouraging or restricting their access to stepchildren, which may occur before and after moving in together (Bray \& Kelly, 1998; Ganong \& Coleman, 2004). These behaviours may be more likely to occur in reference to disciplinary behaviours, since parents may feel that their partners are too strict or have unrealistic expectations regarding appropriate child behaviour (Coleman et al., 2001). 
However, not all researchers have found evidence for gate keeping behaviours of biological parents. There is some research to suggest that rather than discouraging their partner's parenting involvement, biological parents are more likely to actively encourage stepparents to play an involved role (Furstenberg et al., 1987; Smith et al., 2001; Robertson, 2008). In a study by Furstenberg et al (1987), many biological parents complained that the stepparent assumed too little responsibility for childrearing and did not have a great deal of influence over their children. Furthermore, Smith and colleagues (2001) found that parents were more likely to encourage stepparents to be more involved in parenting behaviours, rather than restrict their involvement (Robertson, 2008). Therefore, while research studies tend to focus on the extent to which parents restrict access to children, encouraging behaviours may be more common. These behaviours may not be met favorably by children, who may resent biological parents who encourage stepparents to play an involved parental role (Cartwright \& Seymour, 2002). In light of these indications, further research measuring gate keeping behaviours on a continuum representing restricting and encouraging behaviours is clearly needed.

\subsection{Conclusion of this Review}

This literature review has highlighted the factors that are considered to be important in positive stepfamily functioning. The research and clinical literature suggests that the stepparent role has important effects on the quality of relationships and overall functioning (Fine et al., 1998; Mills, 1984; Visher \& Visher, 1996). In extending previous research, the current study examines the association among perceptions of the stepparent role and stepfamily functioning over time, after controlling for relevant confounding factors. The research model examined is presented in Figure 3.1. This significantly extends previous research studies on the stepparent role, which have not adequately controlled for potential confounding variables, and have not examined the association between perceptions of the stepparent role and stepfamily functioning using longitudinal designs.

Two components of the stepparent role are assessed - perceptions regarding the stepparent's actual role behaviours (actual role) and how the stepparent role should be 
ideally performed (ideal role). Since researchers (Fine et al., 1998) have asserted that discrepancies in role perceptions have an important effect on stepfamily functioning, discrepancies between and within stepfamily individuals are examined. Discrepancy scores have not been adequately examined in research studies of the stepparent role, and this study is one of the first to examine the ability of role discrepancies to predict stepfamily functioning over time.

Finally, this study examines the process by which stepfamily members negotiate the stepparent role. In addition to the strategies used, this study examines whether role negotiation strategies are used more frequently when stepfamily functioning is more problematic, and whether they improve functioning and lead to lower inter-role discrepancies over time. This research is one of the first to address role negotiation in this detail, and therefore provides important information for organisations working with stepfamilies.

The next chapter details the research questions that are addressed, and the research design to address these questions.

Figure 3.1

Research Model of the Association between the Stepparent Role and Stepfamily Functioning

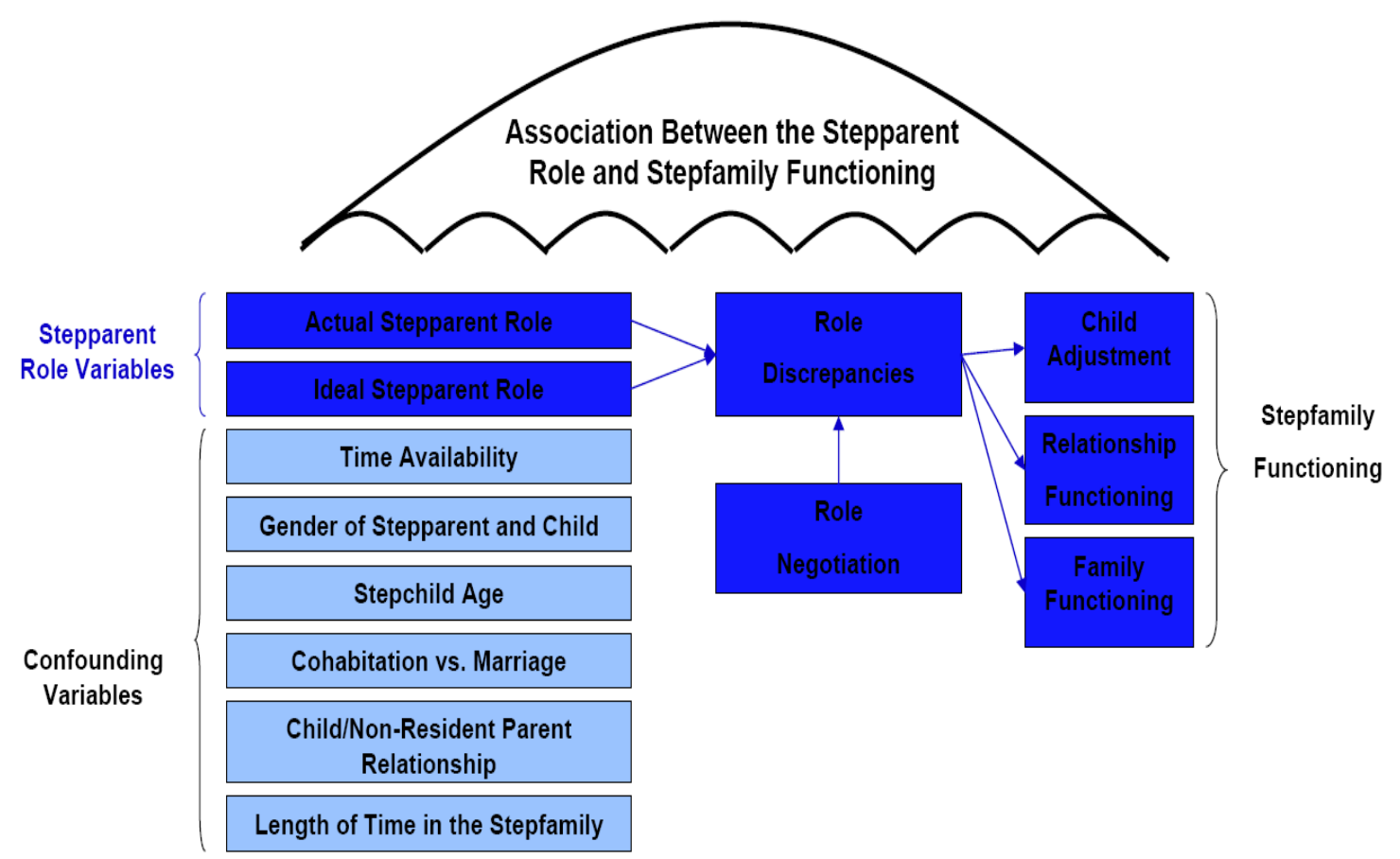




\section{RESEARCH QUESTIONS AND METHODOLOGY}

\section{Chapter Four}

\section{Research Questions and Design}

This chapter outlines the general aims of the research and the research questions that are addressed. This is followed by a description of the research design chosen to address these research questions.

\subsection{Research Aim}

This research sought primarily to explore different stepfamily member's perceptions of the stepparent role, and how these are associated with individual, relationship and whole family functioning. Two main aspects of the stepparent role were examined warmth and control parenting behaviours - both as they were reported to be actually performed and how they should ideally be performed. These two types of parenting behaviours were assessed for a particular stepchild, who was the designated target child for the study. A second aim was to assess the extent to which components of the stepparent role changed over time. Finally, the study sought to examine the effect that inter and intra role discrepancies and role negotiation had on stepfamily functioning.

\subsection{Research Questions}

This research was designed to address a number of specific questions. These research questions are presented in respect to three main themes; individual role perceptions, stepparent role discrepancies and stepparent role negotiation. These research questions lead to the regression analysis that examines the ability of role discrepancies to predict children's perceptions of stepfamily functioning over time. 


\subsubsection{Individual Role Perceptions}

1. How do stepfamily members perceive the actual and ideal stepparent role?

2. Do these perceptions change over time?

3. Are the labels used to describe the stepparent role associated with actual stepparent involvement in warmth and control behaviours?

4. To what extent is the actual stepparent role (at time 1) associated with stepfamily functioning at time 2 ?

\subsubsection{Stepparent Role Discrepancies}

\section{$\underline{\text { Intra-Role Discrepancies }}$}

5. To what extent are stepfamily members' perceptions of the actual stepparent role discrepant with their perceptions of the ideal stepparent role?

6. Do intra-role discrepancies change over time?

7. To what extent are intra-role discrepancies at time 1 associated with stepfamily relationships and functioning at time 2 ?

\section{$\underline{\text { Inter-Role Discrepancies }}$}

8. To what extent do adults and children agree on the ideal stepparent role?

9. Do inter-role discrepancies change over time?

10. To what extent are inter-role discrepancies at time 1 associated with stepfamily relationships and functioning at time 2 ? 


\subsubsection{Role Negotiation}

11. How is the stepparent role negotiated in stepfamilies?

12. Are stepfamilies more likely to engage in role negotiation strategies in the following twelve months when stepfamily functioning is more problematic at time 1 ?

13. Does role negotiation improve family functioning over time and/or lead to lower inter-role discrepancies between stepfamily members?

\subsubsection{Children's Views of Stepfamily Functioning and Role Discrepancies}

14. Are role discrepancies at time 1 associated with children's perceptions of stepfamily functioning at time 2 , after individual role perceptions and relevant demographic variables are controlled? Which are more important - inter role discrepancies or intra-role discrepancies?

The importance of this research rests on its potential to assess the impact of perceptions of the stepparent role on stepfamily functioning over time and to better understand how stepfamilies successfully negotiate the role of the stepparent. While previous research has illuminated some important issues concerning the stepparent role, this study further clarifies some of these issues and significantly contributes to the current knowledge base on the stepparent role.

\subsection{The Research Design}

A longitudinal, multi-informant research design was selected to best answer the research questions. In addition to the collection of quantitative data through the administration of questionnaires which all stepfamily members completed, adults in stepfamilies were interviewed about role negotiation strategies used in their families. The following section will outline why this research design was chosen. As the research aim was to explore differences in perceptions of the stepparent role amongst 
stepfamily members, it was not deemed necessary to obtain data from a comparison sample of first families.

\subsubsection{Longitudinal Design}

Longitudinal designs involve the collection of information from a group of informants at two or more points in time. This is in contrast to a cross-sectional design where participants are assessed on variables of interest at only one point of time. When research questions involve changes in variables over time, and/or exploration of issues relating to causality or the direction of effects, a longitudinal design is the best choice (Bechhofer \& Paterson, 2000). However, longitudinal research methods can be more expensive and time intensive to recruit and retain the desired numbers of participants.

There were two main reasons why a longitudinal design was chosen for this study. Firstly, one of the main deficiencies in previous research on the stepparent role (Fine, et al., 1997, 1998) is their cross-sectional nature, which limits understandings regarding the direction of effects and issues of causality. Longitudinal data provides a more accurate indication of cause and effect relationships between variables, since it can more accurately determine the pre-ceding factors (those measured at time one) and outcome factors (those factors measured at time two). For example, when stepparent role variables are collected at time one, and outcome variables at time two, it is more likely that the preceding variable (e.g. the stepparent role variable) has caused the effect on the outcome variable (e.g. family functioning). In this way, longitudinal designs enable a greater understanding of the association between variables than is the case with cross-sectional designs.

Secondly, while cross-sectional designs offer only a snapshot view of family life and how relationships and roles are functioning, longitudinal designs offer a more dynamic view. By measuring family members' perceptions at more than one point in time, changes in stepparent roles and relationships can be examined, which leads to greater insight into these components. Most of the previous research on the stepparent role has not examined how roles might change over time in the stepfamily, despite the fact that change is likely as stepfamily members develop relationships with one another and spend more time together as a family. This research incorporated a panel longitudinal 
design where the same sample of individuals is measured at more than one point in time to establish the nature of changes over time amongst the same group of stepfamilies.

This study can be described as a short term longitudinal study, since stepfamilies were surveyed at two points in time, twelve months apart. While changes in family dynamics may change more gradually over time, therefore benefiting from more longterm longitudinal research, a twelve month period was selected due to researcher time constraints and a desire to retain as many families as possible over the two waves. When longer time periods are used between stages of data collection, and when more than two stages are selected, there may be difficulties in maintaining contact with participants, so participant attrition may be a concern.

This research was carried out in two main stages:

\section{Time One}

At time one, 105 stepfamilies were visited in their homes where family members completed questionnaires and stepfamily adults (resident biological parents and stepparents) participated in independent interviews. These questionnaires contained measures that were designed to measure individual perceptions of the stepparent role and assessments of individual, family and relationship functioning. Semi-structured interviews were conducted with stepfamily adults to explore role negotiation strategies in more detail.

\section{$\underline{\text { Time Two }}$}

Twelve months later, stepfamilies were re-visited in their homes, where they completed similar questionnaires to those completed at time 1. No interviews were conducted at time 2 and role negotiation components were examined in questionnaire format. 


\subsubsection{Multi-informant Approach}

In stepfamily research, researchers are increasingly collecting data from multiple family members to gain a more complete understanding of the complex dynamics at play. Collecting data from multiple sources is particularly advantageous in research concerning the stepparent role, since stepfamily researchers and clinicians suggest that stepfamily members may not perceive the stepparent role in the same way and these differences may be closely related to stepfamily and individual adjustment (Fine et al., 1997, 1998). Unfortunately, there has been relatively little research that has examined multiple stepfamily members' perceptions, and children's views of the stepparent role have been measured infrequently.

Since the research questions were concerned with individual family members' perceptions, and how these might be different, perceptions of the stepparent role were collected from three stepfamily members - the biological resident parent, stepparent and a target stepchild between the ages of seven and eleven. The inclusion of preadolescent children in the sample is important since much of the research on stepparent roles has excluded children or collected data from older, adolescent children.

\subsection{Research Sample Criteria}

The target sample was limited in several ways. Since the prime aim of the study was to examine perceptions of the stepparent role in newly formed stepfamilies, factors that could be acting as confounding variables were partly controlled through limiting the sample of stepfamilies. As previously mentioned, variables such as the age of stepchildren and the length of time in the stepfamily can affect the nature of the stepparent role. When stepchildren are younger and when stepfamilies have existed for a greater period of time, stepparents may play a more involved parenting role in stepchildren's lives (Coleman et al., 2000). When confounding variables are controlled through placing limitations on the target sample, a more uniform group of stepfamilies can be examined. This makes it less necessary to separate the target sample into subgroups which generally reduces statistical power. The restrictions that were chosen are outlined in the following section. 


\subsubsection{Residential Stepfamily}

In this study a residential stepfamily was defined as a household with at least one stepchild, their parent and their parent's partner. Stepmother and stepfather families were combined, although differences on the variables of interest were examined. The stepchild had to spend at least $50 \%$ or more of their time living in the target household. This was important since living with stepchildren part-time is likely to affect the role of the stepparent since it limits their opportunities to parent stepchildren.

\subsubsection{The Age of the Target Stepchild}

To qualify for inclusion in the study, the target stepchild had to be between seven and eleven years of age. There were two main reasons for selecting this age range. Firstly, there has been limited research conducted on stepchildren of this age group, compared to teenage or adolescent stepchildren. This may be because adolescence has been found to be the most problematic age in terms of relationships between stepparents and stepchildren. By studying younger stepchildren this study sought to examine the processes preceding the problems and conflicts of adolescence. Secondly, the age of stepchildren when the stepfamily initially formed is deemed to be an important factor affecting stepfamily relationships and child adjustment. Therefore, by limiting the sample of stepchildren to those of a younger age in newly formed stepfamilies, the stepchild's age when the stepfamily initially formed was also partially controlled.

\subsubsection{Number of Children}

Secondly, it was decided to restrict data collection to only one stepchild in the appropriate age range in each family. When more than one stepchild qualified, the target child was selected by the adults, although this was relatively uncommon - there was generally only one eligible stepchild in each family. This decision was made so that parent-child dynamics could be examined more concisely. For all questions, adults were asked to answer questions in relation to the target child that was selected.

\subsubsection{Length of Cohabitation}

Couples were selected who were in a marriage or a permanent cohabiting relationship. Couples had to be living together for three months or more to qualify as permanently cohabiting, although they must not have been living together for more than four years. 
This criterion was selected for three key reasons. Firstly, it was considered that stepfamilies in these early stages of cohabitation would be more likely to be currently working through stepfamily relationships and parenting roles in their families (Bray \& Berger, 1993; Hetherington \& Henderson, 1997; Robertson, 2008). In contrast to retrospective research, family members would more accurately recall the key processes in developing roles and relationships in their families.

Secondly, stepfamilies of more than four years were excluded to minimise selection effects. That is, stepfamilies that have been together for longer periods of time are more likely to have successfully sorted through initial roles and relationship difficulties so that they are not representative of all stepfamilies.

Finally, stepfamilies of less than three months were excluded so as to minimise couple relationships that were more temporary, where the stepparent may be less likely to be perceived as a parenting figure, and/or less committed to an ongoing stepparent role.

\subsubsection{Community Sample}

In contrast to clinical samples, where families are recruited who are currently receiving clinical assistance, this research recruited stepfamilies from the larger community. Much of the previous research has tended to rely on clinical samples, which has contributed to a skewed understanding of stepfamily outcomes; with clinical research finding more problematic stepfamily relationships and family functioning (Ganong \& Coleman, 1986). One of the strengths of this research is that it sought to understand how 'ordinary' stepfamilies negotiate roles and relationships, without assistance from

clinicians and family counsellors. Therefore, only stepfamilies that were not currently undergoing stepfamily counselling were permitted to take part in the study. 


\section{Chapter Five}

\section{Research Methodology}

\subsection{Overview}

This research uses a longitudinal, multi-informant design to address the research questions outlined in section 4.2. Stepfamilies were recruited at time 1, and followed a year later. Various methods were used to recruit sufficient numbers of stepfamilies, since quantitative research with multiple independent and dependent variables requires a large sample to provide sufficient power to address the research questions. The various ways in which these families were recruited will be discussed in this chapter, in addition to the research procedure; from first contact with the researcher to the final interview, a year later. The measures that were selected to address these research questions are then presented. In general, the measures were similar at time 1 and time 2 , and where they were different, this is clearly noted.

\subsection{Recruiting Stepfamilies}

Recruitment took place over a period of 18 months, and involved a variety of methods. In the early stage of participant recruitment, it was identified that there may be difficulties in recruiting sufficient numbers of families, and additional recruitment strategies were therefore developed.

Most families (60\%) were recruited through advertisements in National and community newspapers and notices in Doctor's (General Practitioner) surgeries. A copy of this Information Flier is provided in Appendix A.

A significant proportion of families $(40 \%)$ were recruited through brief notices in school newsletters. Most full primary, contributing and intermediate schools across Greater Wellington area were contacted. In addition, twenty schools in Palmerston 
North and ten schools in the Hawkes Bay were contacted. Letters were sent to

Principals (see Appendix B) followed by a phone call two weeks later. Principals were asked their permission to place a brief notice in the schools newsletter. Notices outlined the main purpose of this study and the eligibility criteria, and provided contact numbers for interested families. An example of the Recruitment Notice is provided in Appendix C.

\subsection{Data Collection Procedure}

Participation in the study involved adults completing a questionnaire each, and taking part in an independent interview. Children completed a questionnaire that was verbally administered to them by the researcher, and contained some open-ended questions. The same process was repeated 12 months later. An outline of the data collection procedure is illustrated in Table 5.1.

Table 5.1

Procedure for Data Collection at Time One and Time Two.

Family Member

Biological Parents

Stepparents

Stepchildren
Time 1

Questionnaire

Interview

Questionnaire

Interview

Questionnaires

\section{Time 2}

Questionnaire

Questionnaire

Questionnaire

Families were asked where the most convenient and practical place was to complete the questionnaires and interviews. Most families completed the questionnaires and interviews in their own homes. In order to assure the safety of the researcher, a designated contact person knew at all times where and when interviews were taking place. The following provides an account of the research procedure at time one and two. 


\subsubsection{Procedure at Time One}

1. When contacted by an interested family, the study was explained to them and they were asked if they had any questions. Participants were reassured of the privacy and confidentiality of their responses, and that they could withdraw at any point without having to give reasons. Stepfamily members were all provided with an Information Sheet (see Appendix D), which was either emailed or sent to them by post, outlining the main aspects of the study.

2. For families that decided to participate, suitable meeting places and times were organised, which was usually at the stepfamilies' home. At this time, adults were given consent forms to sign. Consent forms for parents and stepparents are provided in Appendix E. The biological parent was asked to provide consent for the target child, although it was explained that this child would be asked to provide their assent prior to completion of the questionnaire, and that it would not proceed if the child was not in agreement. Adults were provided with their questionnaires, which they completed in separate rooms. A copy of the Background Information Form, for parents and stepparents, is provided in Appendix G. The Parent Questionnaire is provided in Appendix H. The stepparent measure is not provided since questionnaires for parents and stepparents were identical.

3. While adults were completing their questionnaires, the child completed their questionnaire with the researcher in a private room. Children had the assent form verbally explained to them and were asked to sign. They were reassured that anything they said would not be shared, and that if they did not want to answer any questions, they did not have to. A copy of the Child Assent Form is provided in Appendix F. The child and the researcher completed the questionnaire together; that is, the researcher read the questions and answers out verbally to the children and recorded the answers provided. A copy of the Child Questionnaire is provided in Appendix I. 
4. Once children had completed their questionnaire, the adults were interviewed individually in a private room. A copy of this interview is provided in Appendix J. Each adult was assured that their responses were confidential. Interviews were digitally recorded if they felt comfortable with this; if they did not, interview notes were taken. Almost all adults consented to interviews being digitally recorded; only two adults did not.

5. The family was thanked for their help, given a gift voucher and provided with a list of contact numbers of helping agencies if they were to require further assistance with personal or family issues in the future.

6. Families were contacted a week later, were thanked for their participation, and asked whether they had any questions or comments to make. The interviewer checked with adults that children had responded positively to the experience, and were not negatively affected in any way.

At the conclusion of time 1 data collection (December, 2007), families were sent Christmas cards, thanking them for their help, and wishing them a relaxing holiday season. This card also reminded the families that they would be contacted in the New Year, although they did not have to participate again if they did not want to.

\subsubsection{Procedure at Time Two}

Families were contacted approximately 12 months after data collection at time 1 and were invited to take part in the study for the second, and final, time. Of the 105 stepfamilies at time 1 , fourteen did not participate again at time 2 - one family did not want to take part, twelve stepfamilies had dissolved, and one was not contacted due to researcher safety concerns. Stepfamilies in which relationships had dissolved were not interviewed at time 2 , since this study was interested in the current parenting role of the stepparent in their stepchild's life. The data collection process was similar to that at time 1, although role negotiation was assessed through questionnaires at time 2. All families were sent a letter in February 2009, at the completion of the data collection, thanking them for their participation and informing them that summaries of the research would be sent to them once the research study was completed. 


\subsection{Research Measures}

Measures were chosen after a review of the relevant research literature. In light of the desire to measure the stepparent role in reference to specific parenting behaviours that could adequately be reported by both children and adults, the Stepparent Role Questionnaire (SRQ) was developed for this study. In addition, after an exploration of the main role negotiation strategies used by stepfamilies at time 1, the Role Negotiation Questionnaire (RNQ) was developed and administered at time 2.

A small pilot study on ten stepfamilies was conducted, in order to test the suitability of the measures. In addition to testing the comprehensibility of the new measures developed for this study, it was important to test pre-established measures that were not originally developed for use on children aged between seven and eleven years old. These ten families were recruited through friends and colleagues. The pilot study confirmed that the questionnaire length was suitable for children, stepparents and biological parents, and that the physical layout and wording made sense. The remainder of this chapter presents the measures that were used in the study.

\subsubsection{Background Information}

Demographic and background information was obtained from biological parents and stepparents, in order to provide a more comprehensive understanding of the history of each family. Adults in stepfamilies were asked to report on a variety of demographic variables, including their age, gender, family income, ethnicity, education, and hours worked outside the home.

In addition, adults were asked questions about their previous experiences in relationships, including how many cohabiting relationships they had had (of three months or more), whether they had children from previous relationships, and, if so, whether these children spent time in the target household. Both adults were also asked how long they had been dating and cohabitating and whether they were cohabiting, married, or in a civil union at the time of the initial data collection. 
Biological parents were also asked how often the target child saw their biological (non-resident) parent, and the status of their relationship with the child's other biological parent (i.e. separated/divorced/widowed).

The following section will outline the measures used in this study.

\subsubsection{Child Adjustment}

\section{Strengths and Difficulties Questionnaire (SDQ)}

Children's positive and negative behaviours were assessed using the Strengths and Difficulties Questionnaire (SDQ), developed by Goodman (1997). The SDQ is a brief questionnaire that measures behavioural and emotional problems in children, in addition to positive (prosocial) behavioural attributes. There are versions that can be completed by young people, their parents, and teachers, and researchers have found moderate levels of cross-informant agreement (Hawes \& Dadds, 2004). The scale is composed of 25 items that measure five domains of behaviour - emotional symptoms, conduct problems, hyperactivity, peer relationship problems, and prosocial behaviour. The first 4 of the 5 subscales add to generate a Total Difficulties score, with the Prosocial subscale generating a representation of positive behavioural attributes. Items consist of statements such as "I fight a lot and bully people" and "I finish the work I am doing, my attention is good" (child version) which are rated on a 0 (not true), 1 (sometime true), or 2 (certainly true) scale.

The SDQ's emphasis on strengths and difficulties makes it particularly acceptable for use with community samples, and it has been used in British nationwide surveys on the mental health of children (including the Avon Longitudinal Study of Parents and Children; Dunn et al; 1999) in addition to a state-wide data collection protocol in New South Wales with patients in mental health services (NSW Mental Health Outcomes and Assessment Training; MH-OAT). The measure reports good validity, with scores correlating in a theoretically meaningful way with other measures of psychopathology (Goodman, 1997, 2001; Goodman, Meltzer \& Bailey, 1998), and discriminating well between children with and without psychopathological symptoms (Goodman, 1999; Goodman et al., 1998; Klasen et al., 2000; Mullick \& Goodman, 2001). Researchers 
report strong internal reliability scores for the Total Difficulties score and the Prosocial domains, although other subscales can be somewhat lower; in particular the conduct and peer problems subscales (Muris, Meesters \& Eijkelenboom, 2004). Since lower reliability scores have been reported when used on children younger than 11 years, it is recommended that researchers ensure the child comprehends the items and the rating scale before administration, and ideally use the self-report version in combination with versions completed by other informants (e.g. parents).

In this study three informants completed the SDQ - stepparents, biological parents, and the children themselves, and reliability coefficients were adequate. Internal consistency scores for the Total Difficulties score (Chronbach alpha $(\alpha)=.79$ ) and for most of the subscales were satisfactory, although the subscales for peer problems $(\alpha=$ $.42)$ and conduct problems $(\alpha=.60)$ were low. Internal consistency scores for the other subscales were $.71, .65$, and .69 for emotional symptoms, hyperactivity and prosocial behaviour, respectively. These Chronbach alpha scores are those reported by children; stepparents and parents scores are not provided since they were very similar. These lower internal consistency scores for some of the subscales were not problematic, since only Total Difficulties was used in statistical analyses. Internal consistency scores at time 2 were similar to those at time 1 , and are presented in Appendix L.

\section{About Myself Self-Concept Scale}

Children's self-concept was assessed using the About Myself self-concept scale, developed by Song \& Hattie (1983). This measure of self-concept is based on a hierarchical model of self-concept, as originally defined by Shavelson, Bolus and Keesling (1980). About Myself is a 35 item self-report questionnaire using a seven point scale response format in which children indicate to what extent each statement is true of them. Seven facets of self-concept are assessed and descriptions of these facets are provided in Table 5.2. The measure was originally constructed for early adolescent children, and therefore some wording changes were made in order to increase comprehension with the younger children in this study. Items consist of statements such as "I think I am able to get good grades in school" and "Kids my age enjoy 
spending time with me." Only children completed this measure. The original measure, in addition to wording changes, are presented in Appendix M.

Table 5.2

Facets Measured in the About Myself Scale (Song \& Hattie, 1982)

\begin{tabular}{|c|c|}
\hline Domain & Interpretation \\
\hline Ability & $\begin{array}{l}\text { The ability to which an individual believes he/she is capable of } \\
\text { achieving }\end{array}$ \\
\hline Achievement & The product of a person's actual academic achievement \\
\hline Classroom & Confidence in classroom activities \\
\hline Peer & An individual's popularity and interaction with friends \\
\hline Family & $\begin{array}{l}\text { An individual's perception of acceptance or non-acceptance by } \\
\text { his/her family }\end{array}$ \\
\hline Confidence & Emotional aspects of self-concept \\
\hline Physical & An individual's attitude toward his/her physical appearance \\
\hline
\end{tabular}

Song and Hattie (1982) have reported adequate test-retest reliability scores, reasonable internal consistency scores and low levels of socially desirable responses. The authors have demonstrated internal consistency scores of .68 for Classroom, 92 for Achievement, .87 for Peer, .87 for Family, .66 for confidence and .82 for Physical selfconcept. Similarly, this study found relatively lower internal consistency scores for the Classroom and Confidence subscales with alphas of .56 and .66, respectively. Internal consistency scores for the other subscales in this study were $.80, .71, .79, .79$, and .66 for the peer, physical, ability, achievement and family domains, respectively. These lower internal consistency scores for some of the subscales were not problematic, since only composite scores (Total Self-Concept) were used in statistical analyses to reduce the number of statistical analyses. Internal consistency scores for the Total SelfConcept scale were high with a Chronbach alpha of .90. Chronbach alpha scores at time 2 are presented in Appendix L (Self-Concept). 


\subsubsection{Quality of the Couple Relationship}

\section{Warmth and Hostility Scale (IYPRS)}

The quality of the couple relationship was assessed by the warmth and hostility (quality) scales in the Iowa Youth and Families Project Rating Scales (IYPRS; Melby, Conger, Conger \& Lorenz, 1993). The IYPRS was developed by a team of researchers at Iowa State University to measure the behavioural characteristics of individual family members and the quality of behavioural exchanges between family members (Melby \& Conger, 2001).

This measure focuses on dimensions of interpersonal conflict and warmth that exist between stepparents and biological parents. Each adult answered thirteen items ( 7 for hostility, 6 for warmth), asking them to indicate the frequency with which their partner had engaged in various positive and negative behaviours over the past week, such as "shouted at you because he/she was angry with you," "Argued with you" and "let you know he/she cares about you." Responses to these items are measured on a four point scale, from 1 (Never/Rarely), 2 (Sometimes), 3 (Often) and 4 (Most of the Time/Always). Previous research by Melby, Ge, Conger and Warner (1995), using items from the warmth subscale, reported alpha levels of .89 for fathers and .90 for mothers. Negative items can be recoded so that the total score reflects the degree of positive behavioural exchanges between the couple, and this was used in this study. This study found both stepparents' $(\alpha=.92)$ and parents' $(\alpha=.91)$ total scores to have good reliability. Chronbach alpha scores at time 2 are presented in Appendix L (Partner RQ).

\section{$\underline{\text { Satisfaction with Partner }}$}

Both stepparents and biological parents were asked to report on their current level of satisfaction with their relationship with their partner. This was measured by a single item, "Overall, how satisfied are you with the relationship you have with your partner?" with response options forming a seven point scale from 1 (not at all satisfied) to 7 (very satisfied). 


\subsubsection{Quality of the Parent-Child Relationship}

\section{Warmth and Hostility Scale (IYPRS)}

The quality of the stepparent-stepchild and biological parent-child relationships were assessed by the warmth and hostility scales of the IYPRS (Melby et al., 1993). For the stepparent-child relationship, both stepparents and children reported the frequency with which the other person had acted in positive and negative ways towards them. For the biological parent-child relationship (both resident and non-resident parents), only the child's account of this relationship was measured. Items were identical to those used to assess the couple relationship. For the stepparent-child relationship, both children's and stepparents' accounts reported adequate levels of reliability, with internal consistency scores of .87 for children, and .85 for stepparents. For the biological-parent child relationships, children's accounts reported adequate reliability with a Chronbach alpha of .86 for relationships with biological parents and .85 for relationships with non-resident parents. Chronbach alpha scores for these relationships at time 2 are presented in Appendix L.

\section{(Step)parent-Child Closeness}

Both stepparents and children were asked to report on the level of closeness they felt for each other. This was measured by a single item, "How close do you feel to this child/your stepparent?" with response options forming a seven point scale from 1 (not close at all) to 7 (very close indeed). Children also answered similar questions in reference to their biological parents.

\subsubsection{The Stepparent Role}

The stepparent role was measured in two main ways - by examining the labels used by stepfamily members to describe the stepparent role and by a questionnaire that examined the extent to which the stepparent is involved in warmth and control parenting behaviours. 


\section{$\underline{\text { Stepparent Role Labels }}$}

All stepfamily members were provided with a list of ten labels to describe the role stepparents may play in stepchildren's lives. Stepfamily members were asked to inspect this list and indicate what label, or combination of labels, they would use to best describe the actual and ideal stepparent role. If the most appropriate label was not provided in this list, there was an 'other' category, where individuals could provide their own label to describe the stepparent role. The labels that were provided are based on those provided by Fine and colleagues (1998) although there were some amendments made based on the New Zealand (not American) context. That is, 'camp counselor' was not included since this has little relevance for New Zealand children. In contrast to parents, who were asked to report on the ideal stepparent label, children were asked to indicate the label(s) that they would use to describe the role they would like the stepparent to play in their lives. Identical labels were provided for all stepfamily members, and these are provided in Appendix I, page 299.

\section{Stepparent Parenting Behaviours}

Both adults and children were asked to report on the degree to which the stepparent was involved in a range of parenting behaviours, and to what degree they felt he/she should be involved in these behaviours. This measure was developed by the author for this study and was designed to capture a greater range of parenting behaviours than existing measures, while remaining relatively simple so that young children could understand the questions. The aim was to create a parenting measure that asked individuals to report the frequency of more concrete, every-day parenting behaviours. Behaviours were designed to cover two overarching concepts of warmth (daily care, emotional support and financial support) and control (discipline, monitoring, social guidance) behaviours. These domains were selected after an examination of the parenting domains covered in other measures of parenting, such as the Stepparent Behaviour Inventory (Fine et al., 1998), the Weinberger Parenting Inventory (Feldman $\&$ Weinberger, 1994) and the Family Climate Inventory (Kurdek et al., 1995).

Each individual answered questions asking them to indicate how involved the stepparent is in a particular parenting behaviour from 1 (not at all involved) to 5 (very involved). For example, individuals were asked to report how involved their 
stepparent/partner/yourself is in "helping them with their homework", "telling them off when they have been naughty", and "helping them get ready in the morning." Following each individual item, participants were asked to assess the degree to which this is their ideal level of stepparent involvement. Ideal scores were again rated on a five point scale from 1 (not at all involved) to 5 (very involved), with stepfamily members advised to indicate whether they would like the stepparent to be more or less involved, relative to their score for the stepparent's actual involvement.

An excerpt from the Stepparent Role Questionnaire from the Parent Questionnaire is provided in Figure 5.1. For example, if an individual selected a score of 1 for actual involvement and wanted their stepparent to be much more involved in making sure the child is ready for school in the morning, they were asked to circle a number on the desired involvement scale (up to 5) that indicated how much more involved they would like him/her to be. Children's instructions conveyed similar instructions although rather than being asked if this was the ideal level of involvement, they were asked, 'Are you happy with [your stepparent] doing this, or would you prefer them to do this less or more?' and the researcher helped the child select the best number to reflect their views.

Figure 5.1

Excerpt from the Stepparent Role Questionnaire - Parent Version

The following section asks you how involved your partner is currently in various parenting tasks, and how involved you feel they should be at this point in time (desired involvement). Please answer these questions in reference to the target child.

Not at all

Involved
Very

Involved

Making sure that this child is ready

for school in the morning

口 My partner is currently............ $1124 \quad 3 \quad 4 \quad 5$

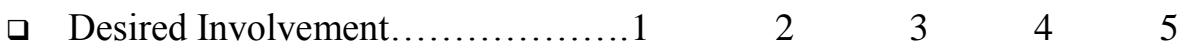


Responses formed two dimensions of the stepparent role: the actual and the ideal role. That is, the items that corresponded to how the stepparent is actually behaving formed the actual role, and items corresponding to how the stepparent should ideally act formed the ideal role. Composite scores for each of these components (actual and ideal) were formed for both the warmth and control dimensions of parenting, for each stepfamily member. An illustration of the various dimensions of the stepparent role is provided in Appendix O.

Internal consistency scores were very good for this measure, with all Chronbach alpha scores for warmth and control scales over .8. A complete list of Chronbach alpha scores for stepparents, parents and children for the two components of warmth and control are displayed in Table 5.3. Similarly high scores were reported at time 2 and these scores are provided in Table 2, Appendix L.

Table 5.3

Internal Consistency Scores for the Stepparent Role Questionnaire.

\begin{tabular}{lcccc}
\hline \multicolumn{1}{c}{ Stepfamily Member } & \multicolumn{2}{c}{ Warmth } & \multicolumn{2}{c}{ Control } \\
\hline \hline & Actual & Ideal & Actual & Ideal \\
Parents $(n=105)$ & .88 & .87 & .94 & .94 \\
Stepparents $(n=103)$ & .87 & .91 & .93 & .94 \\
Children $(n=105)$ & .82 & .83 & .81 & .82 \\
\hline
\end{tabular}

\subsubsection{Family Functioning}

Two measures of family functioning were chosen to assess two components of family functioning: family cohesion and conflict.

\section{Family Cohesion}

Family cohesion was measured by the Cohesion subscale of the Family Adaptation and Cohesion Scales (FACES III), developed and modified by Olson, Portner and Lavee (1985). Cohesion refers to the emotional bonding that family members feel toward one another (Olson \& Gorall, 2003). The theoretical framework of FACES III is the Family Circumplex Model, which views high levels of cohesion as indicative of 
balanced family functioning. FACES III was selected over other measures of family functioning as it has been widely used, and has received considerable research evidence regarding its adequate psychometric properties. For example, scores on the FACES III cohesion dimension have been found to correlate positively with child and adolescent development (Henry, Sager \& Plunkett, 1996; King, 1989) marital satisfaction (James \& Hunsley, 1995) and negatively with child behavioural problems (Kashani, Allan, Dahlmeier, Rezvani \& Reid, 1995). FACES III cohesion has also been found to correlate well $(r=.84)$ with the Self Report Family Inventory (SFI; Hampson, Hulgus \& Beavers, 1991), which is another widely used measure of family cohesion.

The family cohesion scale consists of ten items, which are measured on a true/false scale where stepfamily members estimate the truth of each statement (e.g. "people in my family feel very close to each other," "We can easily think of things to do together as a family"). The measure is recommended for children aged twelve years or over; therefore, some wording changes were implemented to aid comprehension for the younger aged children in this study. These wording changes are presented in Appendix N. Olson and colleagues (1985) report adequate internal consistency scores for this scale, with an internal consistency score of .77. This was higher than the reliability found in the current study, with scores of .50 for stepparents, .60 for parents and .55 for children. However, these lower reliabilities were essentially due to the scoring format, with the true/false format leading to low variability in the measure. Therefore, the scoring format was changed at time 2 to a five point scale where participants' assessed the relative truth of each statement from 1 (not at all true) to 5 (certainly true). These changes led to significant improvements in internal consistency scores at time 2, with scores of $.88, .82$, and .83 for stepparents, parents and stepchildren, respectively. The low internal consistency scores at time 1 were not problematic since family cohesion at time 2 was used in the majority of statistical analyses.

\section{Family Conflict}

Family Conflict was measured by the Conflict subscale in the Survey of Family Climate (SFC; Kurdek \& Fine, 1993b). The SFC is designed to measure young adolescents' perceptions of the emotional and structural environment of their home. 
(Touliatos, Perlmutter \& Straus, 2001). A revised version of this measure has been found to discriminate between rejected and popular fifth and sixth graders (Baker, Barthelemy \& Kurdek, 1993). In addition, Kurdek, Fine and Sinclair (1993) measured the goodness of fit of the four dimensions, using a confirmatory factor analysis, and report a reasonable index of .91 .

All family members indicated how much they agreed $(1=$ strongly disagree, $7=$ strongly agree) with each of six statements regarding the family they live with most of the time (i.e. the target family). Small wording changes were made; for example, the word 'fighting' was replaced with 'arguing,' as it was felt that young children might interpret this word in a physical way (i.e. physical fighting). Kurdek and Fine (1995) report excellent internal reliability scores for this scale, with a Chronbach alpha of .91. Similarly, this study found good internal reliability scores, with Chronbach alpha scores of .89 for stepparents, .89 for parents and .81 for children. Chronbach alpha scores at time 2 were similarly high and are presented in Appendix L.

\subsubsection{Role Negotiation}

Stepfamily adults and children reported on different components of role negotiation. The strategies reported by parents and stepparents are presented first, followed by children's reports on role negotiation.

\section{$\underline{\text { Stepfamily Adults }}$}

At time 1, both parents and stepparents participated in independent structured interviews that were designed to examine the processes by which the stepparent role was negotiated in their family. These role negotiation interviews are provided in Appendix J. Questions were developed through a thorough review of the research and clinical literature relating to stepparent roles and role negotiation processes in stepfamilies (eg Fine et al., 1998; etc). As outlined earlier, while clinicians and researchers have emphasised the importance of role negotiation strategies in stepfamilies, there has been no published research on role negotiation or published measures to assess role negotiation processes. The role negotiation strategies examined in this study can be categorised as explicit and less explicit role negotiation strategies and are discussed in the following section. 


\section{Explicit Role Negotiation Strategies}

These refer to active discussions of the stepparent role that may involve a diverse set of family members. These may differ based on the stepfamily members that are included in these discussions. These explicit discussions may take the following forms:

1. Discussions between the stepfamily couple (stepparent and biological parent).

2. Discussions between stepfamily adults and the non-resident parent.

3. Discussions amongst the whole family (that is, resident parents, stepparents and children): Family Discussions.

4. Discussions between parents and children, individually.

Stepfamily adults were asked to assess whether these talks had occurred both before and after living together. Individuals were asked to indicate how often these different talks occurred in each time period, from 1 (not at all) to 5 (very often). They were also asked to report on additional aspects of these talks such as whether they were spontaneous or planned, who initiated them, and whether decisions were reached in these talks. If decisions were reached, stepfamily members were asked to provide details regarding these decisions. While this qualitative information is invaluable in further exploring role negotiation in stepfamilies, only frequency data was used in this study, and additional role negotiation data will be explored in future studies by the author.

\section{Less Explicit Role Negotiation Strategies}

The key distinction between explicit and less explicit role negotiation strategies is that the stepparent role is negotiated in a less direct way, with the most appropriate role not explicitly discussed. The following less-explicit strategies were measured in this study:

1. Biological parents and stepparents individually 'checking in' with stepchildren for feedback regarding the parenting behaviours of the stepparent in relation to a particular incident.

2. Stepparents 'checking in' with their partner for feedback regarding their parenting behaviours, and

3. Biological parents engaging in gate keeping behaviours that may serve to restrict a stepparent's parenting involvement. 
To measure the frequency with which less explicit discussions (that is, $1 \& 2$ ) occurred in stepfamilies, parents and stepparents were asked to indicate how often these talks occurred from 1 (not at all) to 5 (very often). Stepfamily adults were asked to assess whether these talks had occurred since living together; the period of time prior to cohabitation was not examined since it was assumed that less explicit talks such as these would not be as easily recalled retrospectively.

The frequency with which biological parents engaged in gate keeping behaviours (3) was measured by a questionnaire developed for this study, based on descriptions provided by Bray and Kelly (1998) in their Development in Stepfamilies (DIS) project. Parents and stepparents assessed the degree to which they perceived their partner/themselves to participate in eight behaviours that served to restrict or encourage the stepparent's parenting involvement, from 1 (not at all) to 7 (very much so) such as "I ask my partner to care for this child on their own" (encourage) and “although I listen to my partner's suggestions, I know what's best for this child" (restrict). These items are provided in Appendix H, page 288. The items corresponding to behaviours that encourage the stepparents parenting role were reverse scored so the measure represented the extent of participation in gate keeping behaviours.

At the second stage of data collection, stepfamily adults completed self-report questionnaires designed to measure the frequency of the same role negotiation strategies that were measured, through interviews, at time 1. Interviews were not conducted again, since the interest at time 2 was whether these role negotiation strategies were still being used, rather than exploring these strategies in greater detail. Adults were asked to think about the period of time between the first visit until now (the last year period), and provide information regarding the frequency (from $1=$ not at all to $5=$ very frequently) of these discussions. They were also asked questions regarding who these talks were initiated by, whether they were spontaneous or planned, and whether decisions were made in these talks. As mentioned previously, this information was not analysed in this study, and will be used in subsequent studies on role negotiation in stepfamilies. A copy of the Role Negotiation Questionnaire, for parents and stepparents, is provided in Appendix K. 


\section{Children}

Children were not asked to report on role negotiation strategies to the same extent as parents. Instead, children were asked to report on whether the following two discussions occurred:

1. Discussions with either a family member or a non-family member about how they felt about their stepparent and the ways in which he/she is acting towards them. If these talks had occurred, children were asked whom it was they had talked to.

2. Discussions with their resident parent, where their resident parent checks in with them to see how they are feeling about living with their stepparent. If this had occurred, children were asked to report on what was said and how they felt about their parents engaging in these discussions with them.

These questions were asked in the Child Questionnaire and can be found in Appendix I, page 300. Children were asked the same questions regarding role negotiation at time 2 as they were at time 1 , in relation to the last year period.

\subsection{Ethical Considerations}

This research involved children and their families answering questionnaires and (for adults) taking part in interviews that enquired about personal aspects of their family lives. Therefore, there were some important ethical matters to consider.

Firstly, considering the relatively young age of the children in the study, and the nature of the issues discussed, efforts were taken to ensure that children felt comfortable with research participation. These precautions formed the basis for the following procedures:

1. Although biological parents provided consent for children's participation, children were clearly asked before starting the questionnaire whether they wanted to complete it. It was clearly explained to them that they did not have to answer any questions if they did not want to. 
2. They were told to say 'pass' to the researcher if they were not comfortable with an answer, or did not know the answer to the question, and it was explained that they would not be in trouble if they did so.

3. It was also clearly stated in the Child Assent Form that their answers were confidential, and would not be divulged to anyone else, unless their answers indicated that they were a concern to themselves or to others.

4. Children were told that although their parents were also doing similar questionnaires, this did not mean that they had to participate, and that they would not be in any trouble if they decided to withdraw or not continue with the questionnaire.

5. To protect children's privacy, questionnaires were completed with the researcher in a private room.

6. Families were contacted a week after the initial data collection (at time 1) and asked for feedback regarding the research procedure, and whether children had expressed any concerns. No children had reported any concerns to their parents, and, in general, expressed positive feelings about participation in the research.

To show that they understood these issues, children were asked to sign an assent form, at both stages of the study. They were also provided with a list of helping agencies at the conclusion of each stage of data collection and explained that these were free agencies that could help them if they needed to talk about any problems they might be experiencing. As illustrated in Appendix I, helping agencies provided were Kids Line, What's Up, Youth Line and Skylight.

Similar precautions were taken with adults, in light of the personal and potentially distressing subject matter of the interviews and questionnaires. Adults were assured that the interviews and questionnaires were confidential, and that they did not have to continue with them if they felt uncomfortable. Interviews were recorded, although it was checked that individuals felt comfortable with this. If they did not (as two individuals indicated) no recordings were taken and notes were written instead. All interview recordings were stored on the researcher's computer, in a passwordprotected file to which only the researcher had access. Questionnaires and other 
written notes relating to participants' responses or identity were also kept in a locked filing cabinet. Adults, too, were provided with a list of family organisations that they could contact if they needed further assistance.

This study was approved by the Victoria University of Wellington Human Ethics Committee on the $1^{\text {st }}$ March, 2005.

\subsection{Data Storage and Analysis}

Questionnaire data were entered directly into SPSS (Version 16) and interview recordings covering relevant material were transcribed. Once interview transcripts were complete, the interview data were coded and entered into SPSS.

\subsubsection{Data Checking}

Prior to the calculation of composite scores for variables, the data were checked and cleaned for potential errors. This was done by calculating the frequencies for variables and ensuring the maximum and minimum scores were within range. The presence of univariate outliers was examined, and conditional checks conducted in order to identify data entry errors. Once data checking was complete, the quantity and distribution of missing data was evaluated; in particular whether there was evidence of any non-randomness or bias in the missing data. There was little missing data, and no evidence of systematic bias.

\subsubsection{Creating Composite Scores}

Once the questionnaire data were checked and any errors corrected, composite scores were created. Firstly, manuals for the measures were consulted and appropriate item scores were reverse coded. Once the reverse coding had taken place, composite measures were created and their distributions examined. For numeric data, this involved inspection of histograms and box plots, and an examination of the skewness and kurtosis statistics. If necessary, extreme scores or outliers were re-coded so that scores were within two standard deviations from the mean score, while retaining their relative rank in reference to other scores (in line with suggestions by Tabachnick \& Fidell, 2007). To ensure that adjustment of these scores did not change the results of 
subsequent analyses, results were compared for analyses using the original scores, and the adjusted scores. If there was a significant difference between the two analyses, this is reported where relevant. Nominal or ordinal frequency distributions were examined and coding categories combined where necessary.

Internal consistency of each measure was examined using Chronbach alpha scores and items were deleted if they lowered the reliability of a measure considerably. Inter-item correlations were inspected to examine the correlation of individual items with the underlying construct of the measure.

Bivariate relationships were assessed using Pearson's correlations; however Spearman correlations were used when at least one of the variables was significantly skewed. Differences between actual and ideal roles for each stepfamily member were assessed using paired t-tests, and the Wilcoxon Rank test if variables were not normally distributed. The selection of parametric or non-parametric tests was based on an examination of the distributions of the difference scores for the variables being compared. If distributions did not depart significantly from normality, parametric tests were used.

\subsubsection{Creating Role Discrepancy Scores}

Role discrepancy scores (inter and intra) were developed for each stepfamily member by creating difference scores. Inter-role discrepancy scores were developed by subtracting children's ideal stepparent role from stepparent's ideal role, to create a measure of Stepparent-Stepchild inter-role discrepancy. Variables were created in a similar way for Parent-Stepparent and Parent-Child inter-role discrepancies. Absolute values of difference scores were taken since this study was interested in the magnitude of the differences between stepfamily members rather than the direction of the difference (in line with Fine et al., 1998). In a similar way, intra-role discrepancy scores were computed for each stepfamily member. That is, a variable measuring children's intra-role discrepancies (for both the warmth and control dimensions) was created by subtracting their score for the ideal role from the actual role. Absolute values were again taken and parents and stepparents intra-role discrepancy scores were 
created in a similar way. A conceptualisation of these role discrepancy scores is provided in Appendix P.

After creating these discrepancy scores, the normality of these variables was assessed by examining descriptive statistics, histograms and box-plots. It was expected to some extent that these variables would depart from normality since taking the absolute value of scores reduces the tails of the distribution. Extreme scores and outliers were recoded to form less extreme scores that were within two standard deviations from the mean. To ensure that the same pattern of results was upheld before modification of these scores, analyses were conducted both ways. If these results were inconsistent, they are highlighted in the Results chapters, where relevant.

Associations between stepparent role discrepancies and stepfamily functioning were then examined longitudinally by examining bivariate relationships using role variables at time 1 and stepfamily functioning measures at time 2. A longitudinal design was chosen in order to best address the limitations of cross-sectional studies, such as ambiguity regarding the direction of effects. Role discrepancy scores that correlated significantly with stepfamily outcomes were then entered into a two-step hierarchical regression analysis, designed to examine the ability of children's role discrepancies to predict their perceptions of stepfamily functioning twelve months later. Key control variables, such as a stepparent's actual involvement and certain demographic and individual variables were statistically controlled if they correlated significantly with stepfamily functioning measures at time 2 and relevant stepparent role discrepancies at time 1. Demographic variables and stepparent's actual involvement were entered in the first step of the regression analysis, followed by children's role discrepancies in the second step. Prior analyses included checks for multivariate outliers, unequal variances (heteroscedasticity), non-normally distributed errors, and multicollinearity (Field, 2000). The next chapter presents the results from the data collected at time 1 . 


\section{RESULTS}

\section{Chapter Six}

\section{Results - Time One}

This chapter begins by presenting the results regarding the characteristics of the stepfamilies that participated in this study at time 1. This is followed by the presentation of results of the outcome variables measured in this study: that is, the quality of stepfamily relationships, whole family functioning and children's adjustment. The last section will present the results regarding stepfamily members' perceptions of the stepparent role and strategies used to negotiate the stepparent role.

\subsection{The Research Sample}

The results presented in this section are gathered from the information stepparents and biological parents provided in the Background Information Forms. This information is used to describe the demographic profile of the stepfamilies; their income, employment status, education, marital status, history of personal relationships, ethnicity, age and household composition. Results refer to findings from data collection at time 1; however it will be noted if there were significant changes at time 2.

The final sample consisted of the parent, stepparent and stepchild in 105 stepfamilies, who had been living together for less than four years. The demographic characteristics of these stepfamilies are outlined below, and provided in Table 6.1.

\subsubsection{Household Demographic Characteristics}

As is common to stepfamily research, the majority of stepfamilies (84\%) were stepfather families, and $16 \%$ were stepmother families. Mothers generally obtain custody of the children after divorce and separation (Rodgers \& Pryor, 1998; Statistics 
New Zealand, 2007) therefore children are much less likely to be resident in a stepmother household. These families were relatively new to stepfamily life; they had been living together an average of 26 months at the initial interview, and (including the cohabitation period) dating for approximately 35 months. This means the average time stepfamily adults had been dating prior to cohabitation was 9 months.

The majority of stepfamily couples (58\%) were cohabiting at time 1 , although this had reduced by time 2 (to $28 \%$ ) due to many couples getting married (28\%) between the two stages of data collection.

The average ages and numbers of males and females for stepparents and biological parents are illustrated in Table 6.1 and frequencies for the age of stepchildren are provided in Figure 6.1. As indicated in the graph, one stepchild celebrated her $12^{\text {th }}$ birthday in the time period between recruitment and data collection, therefore this family was included in the study. The average age of the stepchildren at time 1 was 9.4 years and there were slightly more female stepchildren $(56 \%)$ than male stepchildren $(44 \%)$.

Figure 6.1

Ages of Stepchildren Interviewed $(n=105)$

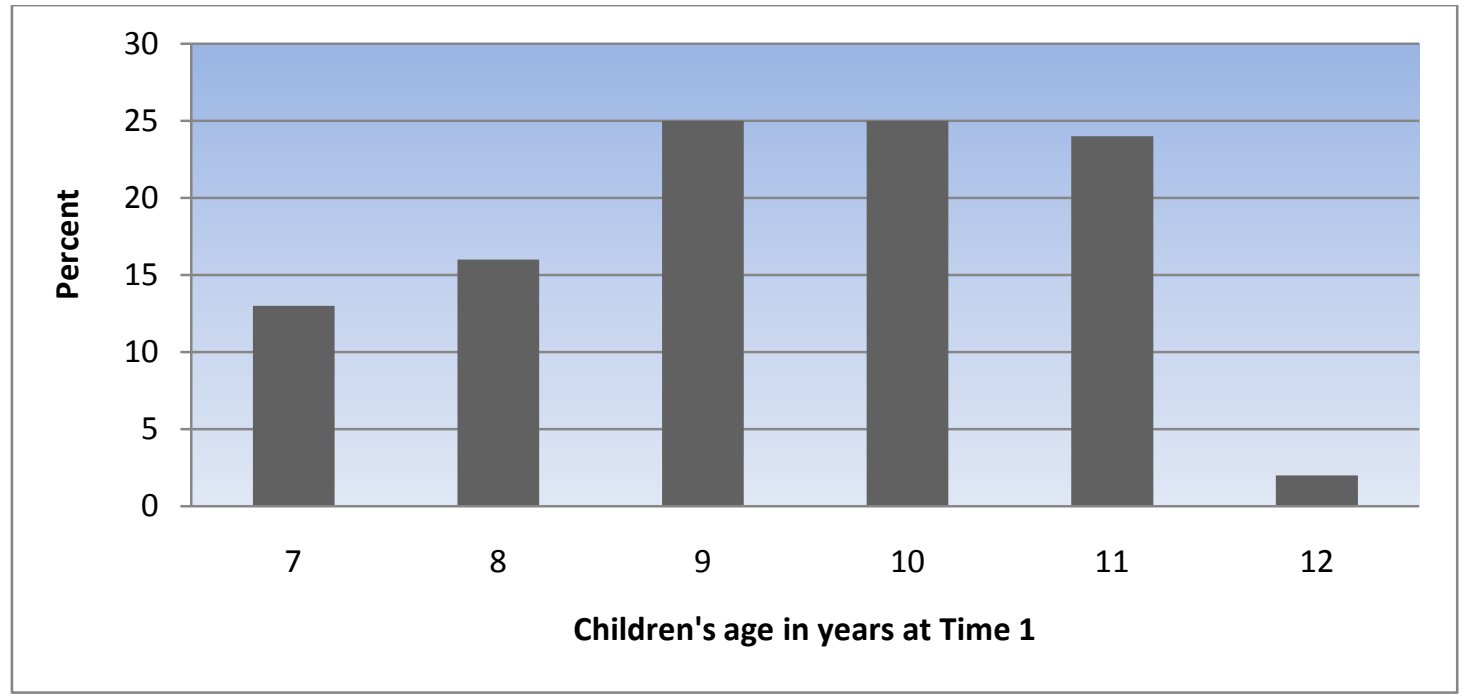

Common to stepfamily research, most of the adults in these families were of New Zealand European ethnicity, and reported high levels of educational achievement, with 
$36 \%$ of stepparents and $46 \%$ of parents holding university degrees. Similarly, average annual income levels were higher than expected in the general population, with $31 \%$ of families earning $\$ 100,000$ or more. Only biological parents were asked to report on family income levels.

All of the participating stepfamilies lived in the North Island of New Zealand, with the majority living in Wellington.

Table 6.1

Characteristics of the Stepfamily Sample at Time One

\begin{tabular}{llcc}
\hline Characteristics & & $\begin{array}{c}\text { Parents } \\
(n=105)\end{array}$ & $\begin{array}{c}\text { Stepparents } \\
(n=103)\end{array}$ \\
\hline \hline Mean age (years) & Male & 38 & 40 \\
Gender (\%) & Female & 16 & 84 \\
Ethnicity (\%) & NZ European & 84 & 16 \\
& Maori & 83 & 85 \\
& Samoan & 11 & 9 \\
& Nuiean & 2 & 4 \\
& Chinese & 0 & 1 \\
& Indian & 0 & 2 \\
& Other & 1 & 0 \\
& None & 12 & 6 \\
Education (\%) & $5^{\text {th }}$ form & 10 & 16 \\
& $6^{\text {th }}$ form & 18 & 22 \\
& $7^{\text {th }}$ form & 18 & 19 \\
& Uni degree & 6 & 3 \\
& & 46 & 36 \\
Employment status & & & \\
(mean hours a wk) & & 25 & 39 \\
\hline
\end{tabular}

\subsubsection{Relationship Histories of Parents}

All the couples were heterosexual, except for one lesbian couple. Most of these families $(95 \%)$ were formed due to the separation and/or divorce of the child's biological parents. Only $5 \%$ of the families were formed due to the death of the child's biological parent.

Stepparents were asked to report on the number of their previous cohabiting relationships of three months or more duration, not including that with their present 
partner. Only $16 \%$ of stepparents reported that they had not been in a previous cohabiting relationship. Of the stepparents who had - 36\% had one, $27 \%$ had two and $17 \%$ had three previous cohabiting relationships. There were also two stepparents (4\%) who reported six previous cohabiting relationships.

\subsubsection{Family Composition}

Stepfamilies in this study came in a diversity of forms and family membership changed regularly as family members exited and entered the household. Most stepparents $(60 \%)$ had at least one child from a previous relationship. Fourteen percent of stepparents had one child, $24 \%$ had two children, $18 \%$ had three, and $4 \%$ had four children from a previous relationship.

There were a variety of arrangements in place regarding the amount of time the stepparent's biological children spent in the household. While $21 \%$ had children that spent very little to no time in the stepfamily household, an equal proportion $(20 \%)$ reported that children visited once every week or two. In addition, $11 \%$ had stepchildren that lived in this household half-time or full-time. This meant many target stepchildren not only had to adjust to a new parental figure, they also had to adjust to a new relationship with step-siblings. In addition, $24 \%$ of stepparents reported having a child with the biological parent; an occurrence that had increased to $33 \%$ by time 2 .

Parents were asked to report on the number of cohabiting relationships they had experienced since the dissolution of their relationship with the child's biological parent. Prior to the present partner (and not including the child's biological parent) $30 \%$ reported at least one other cohabiting relationship of three months or more, which means that many children may have had previous experience with a stepparent. One biological parent reported having seven previous cohabiting relationships.

In general, parents waited about 30 months (from their last cohabiting relationship) until the present partner moved into the house, with a minimum of 0 months, to a maximum of 96 months (8 years). Therefore, many children in this sample had spent a substantial portion of time in a single-parent household before the formation of the stepfamily. 


\subsection{Summary}

As is common to stepfamily research, this sample is not representative of the general population, and is comprised predominantly of stepfather families of high socioeconomic status (high education and income) and of New Zealand European ethnicity. Almost all stepfamilies were formed due to the separation/divorce of the child's biological parents. While all stepchildren (except for one) were between seven and eleven years of age, many children had experienced life with a stepparent before the present one. Furthermore, many stepchildren had to adjust to having their stepparent's children in the household, from time to time, and the presence of a new half-sibling.

The remainder of Chapter 6 presents the results from analyses conducted using time 1 data to address the research questions. It begins by outlining the results for the outcome variables measured and follows with an examination of the independent variables measured; including individual role perceptions, role discrepancies and role negotiation.

\subsection{Relationships in the Stepfamily}

This section will present the descriptive statistics for all the relationship variables, with differences between stepparents, parents and children examined. For the following analyses, descriptive statistics and histograms were inspected prior to the calculation of statistical tests, and outliers and extreme scores modified where necessary (as indicated in section 5.6.2). These modifications are provided in Appendix Q.

\subsubsection{The Couple Relationship}

Biological parents and stepparents were asked to report on the degree to which their partner acted in positive and negative ways towards them. Items corresponding to negative qualities and behaviours were reversed scored, creating a composite score of relationship quality for each adult, with high scores reflecting more positive relationships. Relationship quality scores for both stepparents and parents were high that is, both stepparents $(\mathrm{M}=3.41 ; \mathrm{SD}=.57)$ and parents $(\mathrm{M}=3.55 ; \mathrm{SD}=.49)$ 
reported that their partner frequently acted in positive ways towards them (possible mean scores $=1-4)$.

To examine whether there were differences between parents and stepparents in relationship quality scores, a paired-samples t-test was conducted. Results suggested there were significant differences between stepparents and parents in relationship quality scores $(\mathrm{t}(102)=3.65, \mathrm{p}=.00)$. Specifically, parents rated their partners as acting in more positive ways towards them, than stepparents rated biological parents acting towards them.

Biological parents and stepparents were also asked to rate their satisfaction with their relationship with their partner, from 1 (not at all satisfied) to 7 (very satisfied). Results indicated there were no significant differences between stepparents $(M=6.24 ; \mathrm{SD}=$ $1.11)$ and parents $(M=6.18 ; S D=1.11)$ in relationship satisfaction scores. The mean scores indicated that both stepparents and biological parents were highly satisfied with their relationship with their partner. When relationship quality scores were correlated with partner satisfaction, the resulting correlations $(r=.70 ; p=.00$ for stepparents, $r=$ $.86 ; \mathrm{p}=.00$ for parents) indicated that these two dimensions were highly correlated.

\subsubsection{Children's Relationship with their Biological Parents}

Children reported high quality relationships with their resident biological parents $(\mathrm{M}=$ $3.42 ; \mathrm{SD}=.40$; possible mean scores $=1-4)$. Children were also asked to report on the level of closeness they felt to their resident parent from 1 (not close at all) to 7 (very close). Children reported feeling very close to resident parents $(M=6.16 ; \mathrm{SD}=1.19)$. When relationship quality scores were correlated with relationship closeness, the resulting correlation $(\mathrm{r}=.41 ; \mathrm{p}=.00)$ indicated that these two dimensions of the parent-child relationship were moderately correlated.

Similar to ratings of relationship quality with resident parents, children reported high quality relationships with their non-resident parents $(\mathrm{M}=3.48 ; \mathrm{SD}=.48)$. Children also reported feeling close to non-resident parents $(\mathrm{M}=5.68 ; \mathrm{SD}=1.54)$ and closeness and quality scores were significantly moderately correlated $(\mathrm{r}=.55 ; \mathrm{p}=.00)$. 


\subsubsection{The Stepparent-Stepchild Relationship}

Children and stepparents both rated this relationship as of moderate quality and results indicated that there were significant differences between stepparents and stepchildren $(\mathrm{t}(102)=3.51, \mathrm{p}=.001)$. Specifically, children rated their stepparents as acting in more positive ways towards them $(\mathrm{M}=3.22 ; \mathrm{SD}=.59)$, than stepparents rated children acting towards them $(\mathrm{M}=3.02 ; \mathrm{SD}=.48)$. Stepparents and stepchildren were also asked to report on the degree of closeness they felt to each other. To examine whether there were any differences between children's and stepparents' ratings of closeness in this relationship, a paired-sample t-test was conducted. Although children reported feeling less close to stepparents $(M=4.71 ; S D=1.88)$ than stepparents reported feeling to them $(\mathrm{M}=5.04 ; \mathrm{SD}=1.33)$, this did not quite reach significance. Aspects of relationship quality and closeness were moderately to highly correlated for children ( $\mathrm{r}$ $=.70 ; \mathrm{p}=.00)$, and stepparents $(\mathrm{r}=.68 ; \mathrm{p}=.00)$.

Table 6.2

Mean Scores for Stepfamily Relationships

\begin{tabular}{llllc}
\hline Relationships & \multicolumn{3}{c}{ Means for Stepfamily Members } & Sig. \\
\hline \hline & $\begin{array}{l}\text { Parents } \\
(n=105)\end{array}$ & $\begin{array}{l}\text { Stepparents } \\
(n=103)\end{array}$ & $\begin{array}{l}\text { Children } \\
(n=105)\end{array}$ & \\
\cline { 2 - 4 } & & & \\
& $3.55(.49)$ & $3.41(.57)$ & - & $\mathrm{P}=.00$ \\
BP-SP Quality & $6.18(1.11)$ & $6.24(1.11)$ & - & $\mathrm{NS}$ \\
BP-SP Satis & - & $3.02(.48)$ & $3.22(.59)$ & $\mathrm{P}=.00$ \\
SP-SC Quality & - & $5.04(1.33)$ & $4.71(1.88)$ & $\mathrm{NS}$ \\
SP-SC Close & - & - & $3.42(.40)$ & - \\
BP-SC Quality & - & - & $6.16(1.19)$ & - \\
BP-SC Close & - & - & $3.48(.48)$ & - \\
NRP-SC Quality* & - & - & $5.68(1.54)$ & - \\
NRP-SC Close* & - & & & \\
\hline
\end{tabular}

NB. NS $=$ not significant at $\mathrm{p}<0.05$ level; Satis $=$ Satisfaction,

$\mathrm{BP}=$ biological parent, $\mathrm{SP}=$ stepparent, $\mathrm{SC}=$ stepchild, $\mathrm{NRP}=$ non-resident biological parent Standard deviation provided in brackets $*_{n}=81$ 


\subsection{Family Functioning}

Two aspects of family functioning were assessed - family cohesion and family conflict, with all stepfamily members completing identical measures. The following section presents the descriptive statistics for these results.

\subsubsection{Family Cohesion}

As can be seen in Figure 6.2, stepfamily members reported very high levels of family cohesion, with a range of scores across all stepfamily members of 7 to 10 . Descriptive statistics for cohesion scores are provided in Table 6.3. Distributions were significantly positively skewed, and therefore results for cohesion should be considered with caution. The highly skewed distribution was largely due to the nature of the scoring used - that is, items were scored according to a yes/no format and this led to low variability within the measure. As previously mentioned, this was addressed at time 2 by scoring cohesion on a five point likert scale.

Figure 6.2

Comparison of Family Cohesion Scores for Stepfamily Members

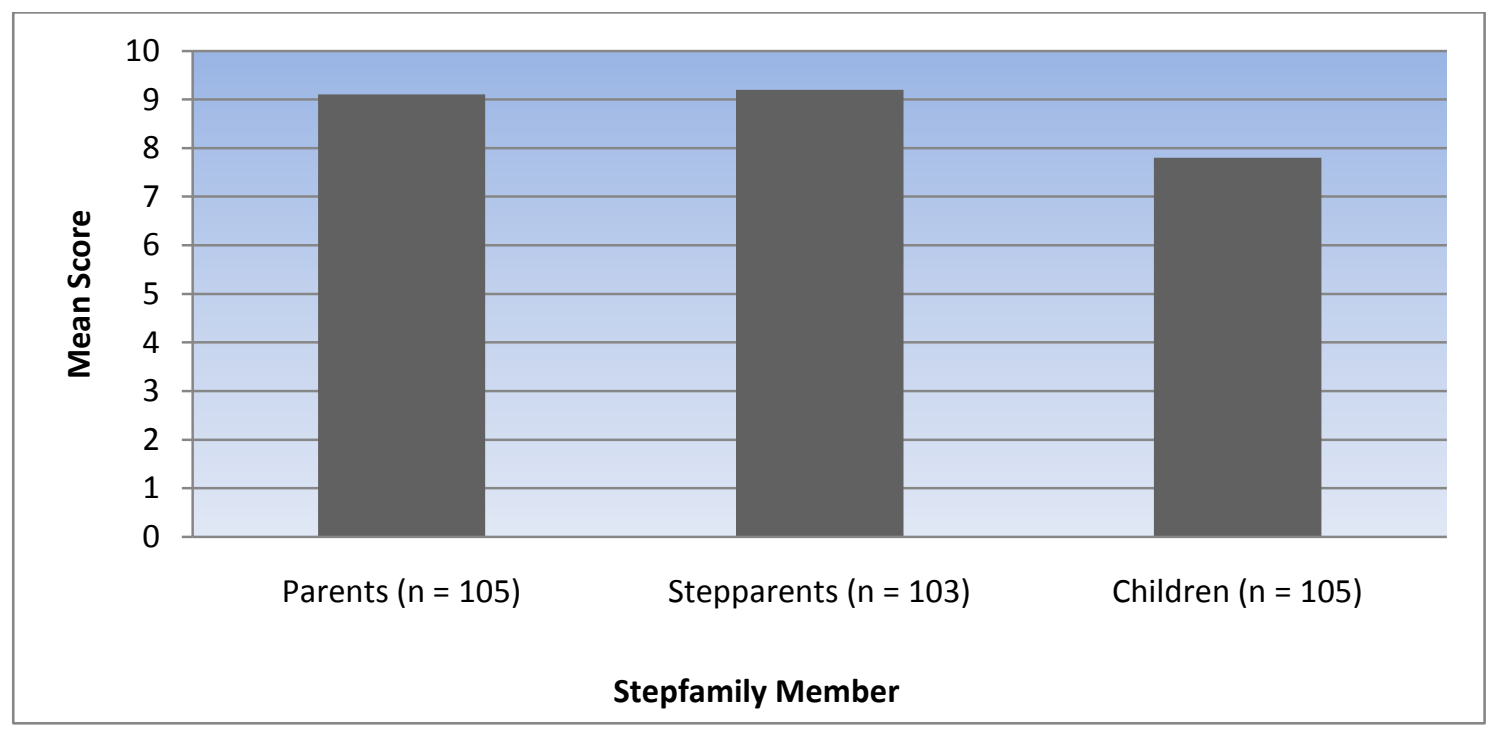


Table 6.3

Mean Scores for Stepfamily Members for Family Functioning

Family Functioning

Mean Scores

\begin{tabular}{lccc}
\hline \hline & $\begin{array}{c}\text { Parents } \\
(n=105)\end{array}$ & $\begin{array}{c}\text { Stepparents } \\
(n=103)\end{array}$ & $\begin{array}{c}\text { Children } \\
(n=105)\end{array}$ \\
\cline { 2 - 4 } Family Cohesion & $9.1(1.5)$ & $9.2(1.4)$ & $7.8(1.8)$ \\
Family Conflict & $15.6(7.2)$ & $15.9(7.8)$ & $18.6(8.9)$ \\
\hline
\end{tabular}

Standard deviation provided in brackets

Post-hoc tests were conducted using the Wilcoxon Rank Test. Since parents and stepparents reported the same mean scores, only two comparisons were examined and a Bonferroni adjustment was made with the alpha level set at .025. Comparisons were made to compare children with parents and with stepparents, and these results indicated that children rated levels of family cohesion significantly lower than both their parents $(\mathrm{z}=-5.14, \mathrm{p}=.00)$, and their stepparents $(\mathrm{z}=-4.94, \mathrm{p}=.00)$.

\subsubsection{Family Conflict}

As can be seen in Figure 6.3, stepfamily members reported low levels of family conflict, with mean scores for parents, stepparents and children all between 15 and 19 (possible mean scores $=6-42$ ). After closer examination of the distribution of scores for family conflict, some outliers were adjusted for biological parents and stepparents. There were no outliers reported from children's scores, as this distribution did not depart significantly from normality. These outliers were all extremely high scores, and were more than three standard deviations from the mean. A decision was made to keep these scores in the analysis, although they were adjusted to a less extreme score that retained their ranking in relation to the distribution of scores. For example, one parent had a score on family conflict that was an extreme score (37) and this was adjusted to 35, so that it was within two standard deviations from the mean, but remained the highest score for parents. These changes are detailed in Appendix Q (Table 1). 
To examine whether there were any differences between children and stepfamily adults, two paired t-tests were performed comparing children's scores with each of their parent's scores. Children reported higher family conflict than both parents $(\mathrm{t}(102)=-$ $3.15, \mathrm{p}=.002)$ and stepparents $(\mathrm{t}(102)=2.47, \mathrm{p}=.02)$. Descriptive statistics for conflict scores are provided in Table 6.3.

Figure 6.3

Comparison of Family Conflict Scores for Stepfamily Members

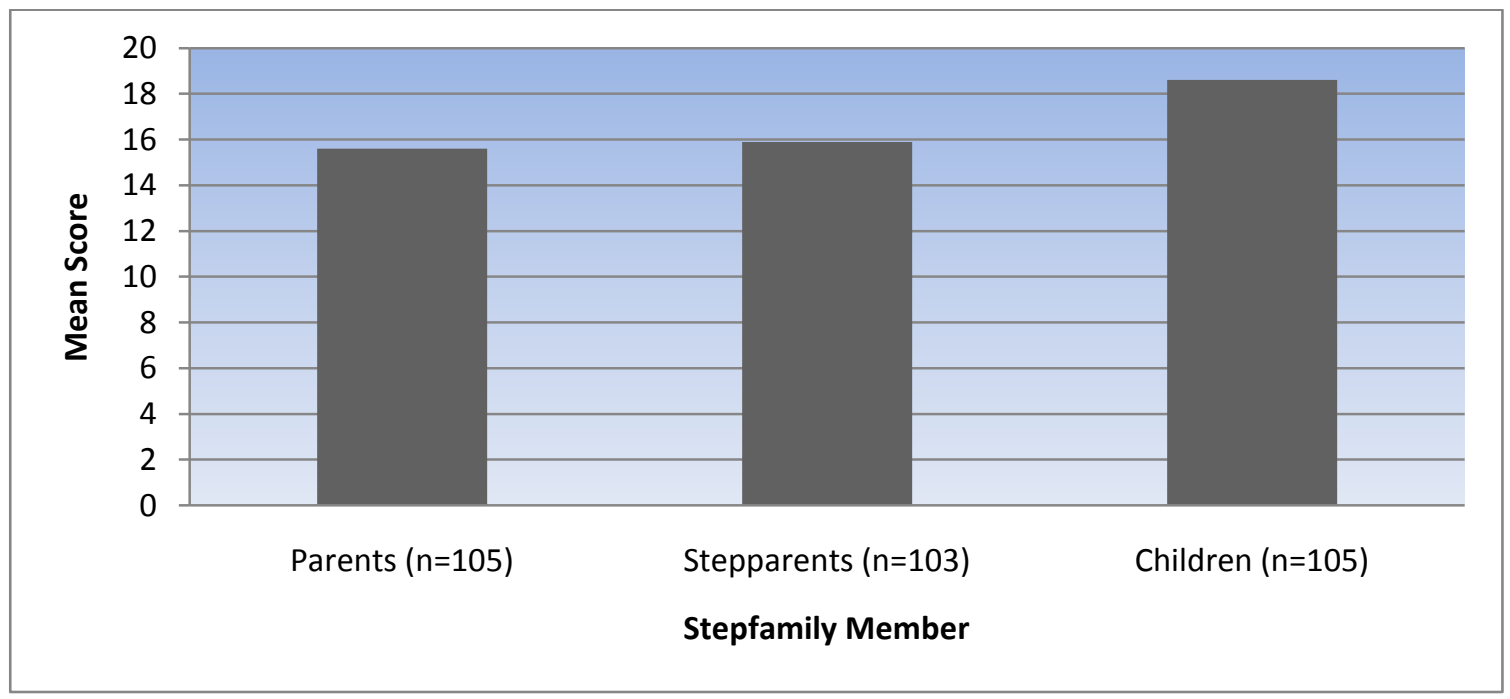

\subsection{Child Adjustment}

Two aspects of child adjustment were assessed; children's strengths and difficulties (as measured by the SDQ), and their self-concept (as measured by 'About Myself'). For children's strengths and difficulties, all stepfamily members completed identical measures. For self-concept, only children completed this measure as it was assumed they would be the most accurate reporters of self-concept. The following section will present the descriptive statistics for these results.

\subsubsection{Children's Strengths and Difficulties}

As illustrated by the mean scores in Table 6.4, stepfamily members reported a wide variety of scores regarding children's strengths and difficulties. Table 6.4 presents mean scores for total SDQ and sub-scale scores. Descriptive statistics and histograms were inspected for total scores and none departed significantly from normality. 
Table 6.4

Mean Scores for the SDQfor Stepfamily Members

\begin{tabular}{lccc}
\hline \multicolumn{1}{c}{ SDQ Subscales } & \multicolumn{3}{c}{ Mean and Standard Deviation } \\
\hline & Parents & Stepparents & Children \\
& $n=105$ & $n=103$ & $n=105$ \\
\cline { 2 - 4 } Total Difficulties & $8.9(5.8)$ & $10.4(6.3)$ & $14.2(6.3)$ \\
Emotional Symptoms & $2.4(2.1)$ & $2.5(2.1)$ & $4.1(2.6)$ \\
Conduct Problems & $1.6(1.6)$ & $2.1(2.0)$ & $2.6(1.9)$ \\
Peer problems & $1.7(1.9)$ & $1.9(1.8)$ & $2.9(1.8)$ \\
Hyperactivity & $3.2(2.5)$ & $3.9(2.7)$ & $4.7(2.4)$ \\
Prosocial behaviours & $8.3(1.7)$ & $7.9(2.0)$ & $8.0(1.8)$ \\
\hline
\end{tabular}

Standard deviation provided in brackets

In general, across most of the domains, parents reported the lowest number of child difficulties, children reported the highest and stepparents scored somewhere in between. Differences between stepfamily members are illustrated in Figure 6.4.

Figure 6.4

SDQ Subscale Scores for Stepfamily Members

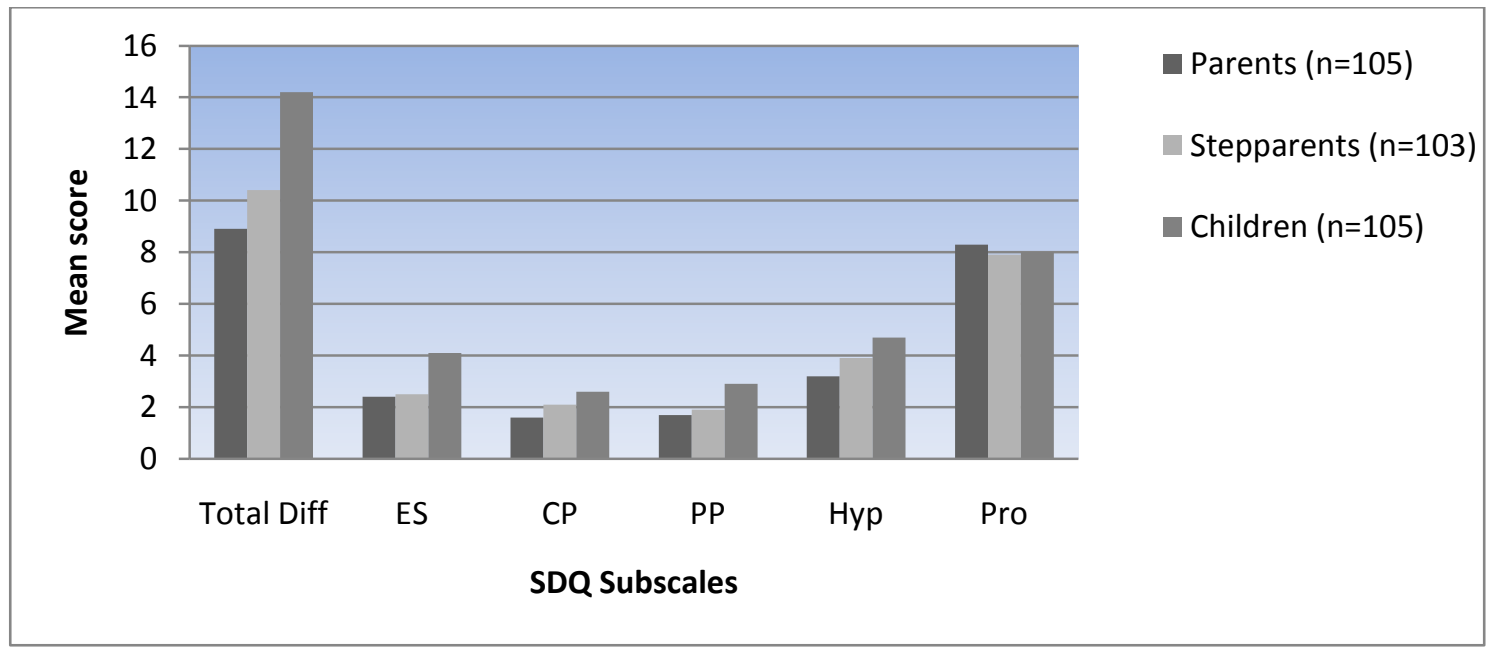

In addition, scores were compared with norm scores provided by Mellor (2005) based on Australian (non-clinical) children aged between 7 and 17. These scores are provided in Appendix R. These graphical comparisons indicated that the current sample had a higher proportion of children in the borderline and abnormal ranges 
(across all dimensions of child difficulties) and a lower proportion of children in the normal range. For the positive dimension of adjustment (the prosocial domain) there were a higher proportion of children in the normal range and lower proportions in the borderline and abnormal ranges. This was particularly the case when children's perceptions were compared with the norms provided by Mellor (2005). Parents' and stepparents' scores were more similar to the norms provided by Mellor (2005).

\subsubsection{Children's Self-Concept}

Children generally reported high levels of self-concept $(\mathrm{M}=4.73 ; \mathrm{SD}=.68$; possible range $=1-6$ ) across all seven domains of self-concept. Scores on these seven domains are illustrated graphically in Figure 6.5. Descriptive statistics and histograms were inspected and total scores did not depart significantly from normality. Similar to that found by Hattie (1982) the highest self-concept scores were for the achievement domain $(\mathrm{M}=5.29 ; \mathrm{SD}=.80)$ and the lowest scores for the physical domain $(\mathrm{M}=4.10, \mathrm{SD}=$ 1.21). Mean scores were found to be similar to those provided by Hattie (1982) that are based on Australian children in Year 7 (aged between 12 and 13). Comparison of these two samples is provided in Appendix R

Figure 6.5

Mean Self-concept Scores for Children $(n=105)$

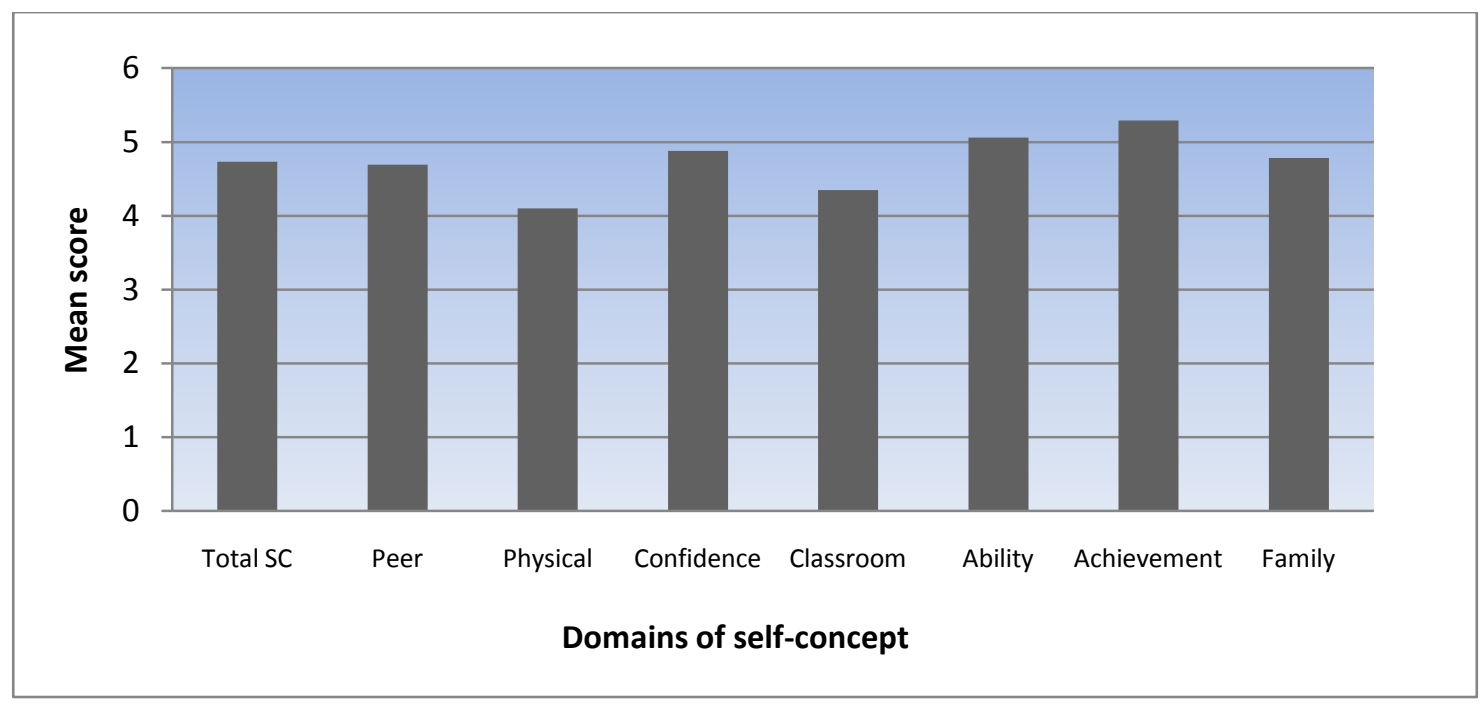




\subsection{The Stepparent Role}

The stepparent role was measured in two ways - by asking stepfamily members to report on the label they would use to describe the actual and ideal stepparent roles, and by asking them to indicate the stepparent's actual and ideal parenting behaviours along warmth and control dimensions. These are discussed separately in the following section.

\subsubsection{Labels to Describe the Stepparent Role}

Stepfamily members were asked to select the most appropriate label, or labels, to describe the role they felt the stepparent was actually playing in the children's lives, and the role they would ideally like him/her to play.

Family members were provided with a variety of labels, such as friend, stepparent, parent, mum/dads partner, and close relative, and could choose one or more of these, or could specify an alternative label as 'other' if the most appropriate label was not provided.

Cross-tabulations were calculated for the actual and ideal stepparent role, to explore the most common labels (whether single or combination labels) used to describe the stepparent role; these are provided in Appendix S. A particular label, or combination of labels, was described as commonly chosen if it was selected by more than $10 \%$ of stepfamily individuals. These commonly selected labels were then compared among stepfamily members. The most commonly selected combinations across all stepfamily members, for the actual and ideal role, are presented in Table 6.5.

\section{The Actual Stepparent Role}

The three most commonly selected labels, or combinations of labels, used by parents to describe the actual stepparent role were stepparent (18\%), partner (12\%) and stepparent and mum/dads partner (12\%). For stepparents, the three most commonly selected labels were stepparent (22\%), mum/dads partner (13\%) and friend and stepparent (12\%). Finally, for children, the three most popular labels selected were parent (25\%), stepparent (17\%) and friend and stepparent (11\%). Therefore, while stepparent alone was selected equally commonly by all stepfamily members, stepchildren were much 
more likely than either parents $(9 \%)$ or stepparents $(8 \%)$ to describe the actual stepparent role as solely like a parent $(25 \%)$.

Table 6.5

Commonly Selected Labels for the Stepparent Role - Percents

\begin{tabular}{llccc}
\hline Dimension & Combinations & Parents & Stepparents & Children \\
\hline \hline \multirow{3}{*}{ Actual Role } & $n=105$ & $n=103$ & $n=105$ \\
\cline { 2 - 4 } & Parent & 9 & 8 & 25 \\
& Stepparent & 18 & 22 & 17 \\
& Partner & 12 & 13 & 4 \\
& Friend + stepparent & 9 & 12 & 11 \\
& Stepparent + partner & 12 & 7 & 4 \\
& & & 14 & 18 \\
& Parent & 11 & 11 & 16 \\
& Stepparent & 15 & 2 & 11 \\
& Friend & 3 & 11 & 11 \\
& Friend + stepparent & 11 & 12 & 5 \\
\hline
\end{tabular}

The Ideal Stepparent Role

There were four labels, or label combinations, commonly selected by parents to describe the ideal stepparent role: these were like a stepparent (15\%), friend and parent (14\%), parent (11\%), and friend and stepparent (11\%). For stepparents, the four most commonly selected labels were parent (14\%), friend and parent (12\%), stepparent (11\%), and friend and stepparent (11\%). For stepchildren, four labels were commonly selected: these were like a parent (18\%), a stepparent $(16 \%)$, a friend $(11 \%)$ and a friend and stepparent (11\%). It appears, therefore, that while mum/dads partner was frequently provided to describe the actual stepparent role by adults in the stepfamily, it was not frequently chosen to describe the ideal role. While parent was used more commonly by children to describe the ideal stepparent role, it was less commonly selected than it was for the actual role.

\section{Summary}

To describe the actual and ideal stepparent role, the label of stepparent was commonly selected by all stepfamily members. Although stepchildren were more likely to select alternative labels to parent to describe the actual and ideal role, they were more likely 
to select parent than parents and stepparents. In general, parents and stepparents showed high levels of agreement regarding most of the commonly selected labels. In addition to differences for the parent label, stepchildren were much less likely than stepfamily adults to describe the actual stepparent role as like mum/dads partner and were much more likely to describe the ideal role as a friend. However, these differences were not found for the label combinations that included friend, such as friend and parent, and friend and stepparent; where parents, stepparents and children used friend equally often.

These findings partly address Research Question 1 and show that stepfamily members use a variety of labels to describe the actual and ideal stepparent role, although one of the key findings is that children were more likely (than stepfamily adults) to describe the stepparent role as like a parent. The next section addresses the second aspect of this research question which refers to perceptions of the stepparent's involvement in parenting behaviours.

\subsubsection{Stepparent Parenting Behaviours}

Before the warmth and control dimensions of the stepparent role were assessed, a factor analysis was performed to assess whether it was appropriate to separate the Stepparent Role Measure (SRQ) into two sub-scales of warmth and control dimensions. The results of this factor analysis are presented below.

\section{Factor Analysis of Warmth and Control Scales for the SRQ}

The 25 items of the Warmth and Control scales of the Stepparent Role Questionnaire (SRQ) were subjected to principal components analysis (PCA) using SPSS Version 16. Data for stepparents for the actual stepparent role scale were inspected, although results were also inspected for parents and children, and across ideal scales, to ensure a similar pattern occurred. Prior to performing PCA, the suitability of the data for factor analysis was assessed. Inspection of the correlation matrix revealed the presence of many coefficients of .3 and above. The Kaier-Meyer-Oklin value was .87 , therefore exceeding the recommended value of .6 (Kaiser, 1970, 1974) and Bartlett's Test of Sphericity (Bartlett, 1954) reached statistical significance $(\mathrm{p}=.00)$, thus supporting the factorability of the correlation matrix. 
Principal components analysis revealed the presence of four components with eigenvalues exceeding 1, explaining $44.9 \%, 11.6 \%, 6.1 \%$ and $5.1 \%$ of the variance respectively. An inspection of the scree-plot revealed a break after the second component. Using Catell's (1966) scree test, it was decided to retain two components for further analysis. This was further confirmed by the Component Matrix which suggested that the majority of the items loaded moderately (above .3) on the first two components. The Scree-plot and Component Matrix are provided in Appendix T.

The two component solution explained a total of $56.4 \%$ of the variance, with component 1 contributing $44.9 \%$ and component 2 contributing $11.6 \%$. The rotated solution revealed the presence of a fairly simple structure (Thurstone, 1947) with both components showing a number of strong loadings and all variables loading generally on only one component. There was a moderate correlation between the two $(\mathrm{r}=.51)$ therefore the oblique rotation was used which is more suitable for correlated factors. The results of this factor analysis are provided in Table 6.6.

Based on these results, warmth and control subscales were computed for all stepfamily members for both the actual and ideal dimensions, using the relevant items as indicated above. The warmth scale was composed of the items in the top half of Table 6.6 , and the control scale contained those items in the bottom half.

Before descriptive statistics were performed, the distribution of actual and ideal scores was explored for each of the warmth and control dimensions of the stepparent role. As a result, two outliers were adjusted (from parents scores) that were significantly low scores of more than three standard deviations from the mean on both warmth and control dimensions. These scores were not deleted from the analysis, but were adjusted to a score within two standard deviations from the mean that retained their relative ranking. Results of these changes are provided in Table 2 in Appendix Q. 
Table 6.6

Factor Analysis of the Stepparent Role Questionnaire $(n=103)$ - Stepparents' Questionnaire

\begin{tabular}{|c|c|c|c|c|c|}
\hline \multicolumn{6}{|c|}{ Coefficients } \\
\hline \multirow[t]{2}{*}{ SRQ Item } & \multicolumn{2}{|c|}{ Pattern } & \multicolumn{2}{|c|}{ Structure } & \multirow[t]{2}{*}{ Communalities } \\
\hline & Control & Warmth & Control & Warmth & \\
\hline Take to school & -.04 & .57 & .26 & .55 & .31 \\
\hline Hug child & -.15 & .84 & .27 & .76 & .60 \\
\hline Help with homework & .01 & .71 & .37 & .72 & .51 \\
\hline Discuss problems & .12 & .69 & .47 & .75 & .57 \\
\hline Take to activities & -.07 & .68 & .27 & .64 & .41 \\
\hline Talk about friends & .05 & .78 & .44 & .80 & .64 \\
\hline Stand up for child & .21 & .60 & .51 & .70 & .52 \\
\hline Drive child places & .05 & .72 & .41 & .74 & .55 \\
\hline Ask about day & .06 & .72 & .43 & .75 & .57 \\
\hline Teacher interviews & .22 & .37 & .41 & .48 & .27 \\
\hline Monitor TV shows & .44 & .31 & .59 & .53 & .42 \\
\hline $\begin{array}{l}\text { Tell off when } \\
\text { naughty }\end{array}$ & .81 & -.03 & .79 & .38 & .63 \\
\hline Teach to be polite & .83 & -.02 & .82 & .41 & .67 \\
\hline Make new rules & .77 & .15 & .85 & .54 & .74 \\
\hline Teach to & .82 & -.12 & .76 & .30 & .59 \\
\hline say "please" & & & & & \\
\hline Punish child & .90 & -.06 & .86 & .40 & .75 \\
\hline $\begin{array}{l}\text { Teach child to take } \\
\text { turns }\end{array}$ & .72 & .19 & .82 & .56 & .69 \\
\hline $\begin{array}{l}\text { Make sure don't } \\
\text { stay up too late }\end{array}$ & .64 & .17 & .72 & .49 & .54 \\
\hline Tell off when rude & .85 & -.12 & .79 & .32 & .64 \\
\hline $\begin{array}{l}\text { Teach to consider } \\
\text { others feelings }\end{array}$ & .65 & .25 & .78 & .59 & .66 \\
\hline
\end{tabular}

$\underline{\text { Actual and ideal stepparent role }}$

This section will present the results relating to stepfamily members' perceptions regarding the actual and ideal stepparent role. Descriptive statistics are based on original scores, prior to the adjustment of outliers. 


\section{Biological Parents}

Parents reported their partners were involved in both the warmth $(\mathrm{M}=3.58, \mathrm{SD}=.79)$ and control $(\mathrm{M}=4.05, \mathrm{SD}=.95)$ dimensions of the stepparent role (possible mean range $=1-5)$. When parents were asked how involved they would like the stepparent to be (ideal role), they reported wanting their partner to play an involved role. That is, they wanted him or her to be involved in both warmth $(\mathrm{M}=4.00, \mathrm{SD}=.79)$ and control $(\mathrm{M}=4.15, \mathrm{SD}=.81)$ behaviours.

\section{Stepparents}

When stepparents were asked to report on their own role, they reported that they were involved in both warmth $(\mathrm{M}=3.25, \mathrm{SD}=.94)$ and control $(\mathrm{M}=3.83, \mathrm{SD}=.93)$ behaviours. Scores for the ideal role across warmth and control domains were slightly higher - stepparents reported ideally wanting to be moderately involved in warmth (M $=3.83, \mathrm{SD}=.82)$ and control $(\mathrm{M}=3.97, \mathrm{SD}=.85)$ behaviours.

\section{Children}

Children reported that their stepparents were involved in both warmth $(\mathrm{M}=2.92, \mathrm{SD}=$ $.93)$ and control $(\mathrm{M}=3.28, \mathrm{SD}=.90)$ behaviours. Similar findings were evident for the ideal stepparent role. Children reported desiring stepparents to be moderately involved in both warmth $(\mathrm{M}=3.21, \mathrm{SD}=.92)$ and control $(\mathrm{M}=3.00, \mathrm{SD}=.90)$ behaviours.

These results address the second component of Research Question 1 and indicate that stepfamily members perceived stepparents to be involved in both warmth and control parenting behaviours (actual stepparent role) and wanted them to be involved in these components (ideal stepparent role). These findings also suggest that all stepfamily members perceived stepparents to be more involved in control behaviours than warmth behaviours, and wanted them to be more involved in these behaviours. 


\subsection{Role Labels and Role Behaviours}

As previously mentioned, research on the stepparent role often uses labels to measure the stepparent role, based on the assumption that these labels are associated with different levels of stepparent involvement in both control and warmth behaviours. This study was interested in examining the association between role labels and parenting behaviours, to assess the accuracy of this assumption.

A one-way between-groups analysis of variance was conducted to explore whether there were significant differences in warmth and control scores for different stepparent role labels. Since stepfamily members could select multiple labels, only singular cases were used; that is, where a particular label was selected singularly and not in combination with other labels. All stepfamily members were divided into four groups based on the label they had given for the actual stepparent role; that is, parent, stepparent, friend or partner. These labels were used as they were the most commonly selected labels. However, after an examination of the frequencies, only three labels were included in the analysis (parent, stepparent and partner) as these were the most commonly selected singular labels. These frequencies are provided in Table 7, Appendix S. Results for parents, stepparents and children were combined $(n=133)$ to increase statistical power. Descriptive statistics and histograms for warmth and control scores were inspected and these variables did not depart significantly from normality.

For the warmth dimension, there were significant differences between the three labels: $\mathrm{F}(2,130)=8.85 ; \mathrm{p}=.00$. Post-hoc comparisons using the Tukey HSD test indicated that the mean score for warmth behaviours for parent $(\mathrm{M}=3.53, \mathrm{SD}=.99)$ was significantly higher than partner $(\mathrm{M}=2.55, \mathrm{SD}=.90)$. Similarly, the mean score for warmth behaviours for stepparent $(\mathrm{M}=3.14, \mathrm{SD}=1.09)$ was significantly higher than partner $(\mathrm{M}=2.55, \mathrm{SD}=.90)$. There were no significant differences in warmth scores for parent or stepparent, although (as illustrated in Figure 6.6) mean scores indicated the parent label was associated with higher involvement in warmth behaviours. 
For the control dimension, there were significant differences between the three labels: $\mathrm{F}(2,130)=4.24, \mathrm{p}=.02$. Post-hoc comparisons using the Tukey HSD test indicated that the mean score for control behaviours for parent $(\mathrm{M}=4.05, \mathrm{SD}=.77)$ was significantly higher than partner $(\mathrm{M}=3.43, \mathrm{SD}=1.05)$. However, although the stepparent label $(\mathrm{M}=3.72, \mathrm{SD}=.91)$ was associated with more control behaviours than partner $(M=3.43, S D=1.05)$ this did not reach significance. Similarly, there was no significant difference in involvement in control behaviours for the labels of parent $(\mathrm{M}=4.05, \mathrm{SD}=.77)$ and stepparent $(\mathrm{M}=3.72, \mathrm{SD}=.91)$, although the mean scores indicated the parent label was associated with higher control behaviours (as illustrated in Figure 6.6).

Figure 6.6

Comparison of Mean Warmth and Control Scores for Stepparent Labels $(n=133)$

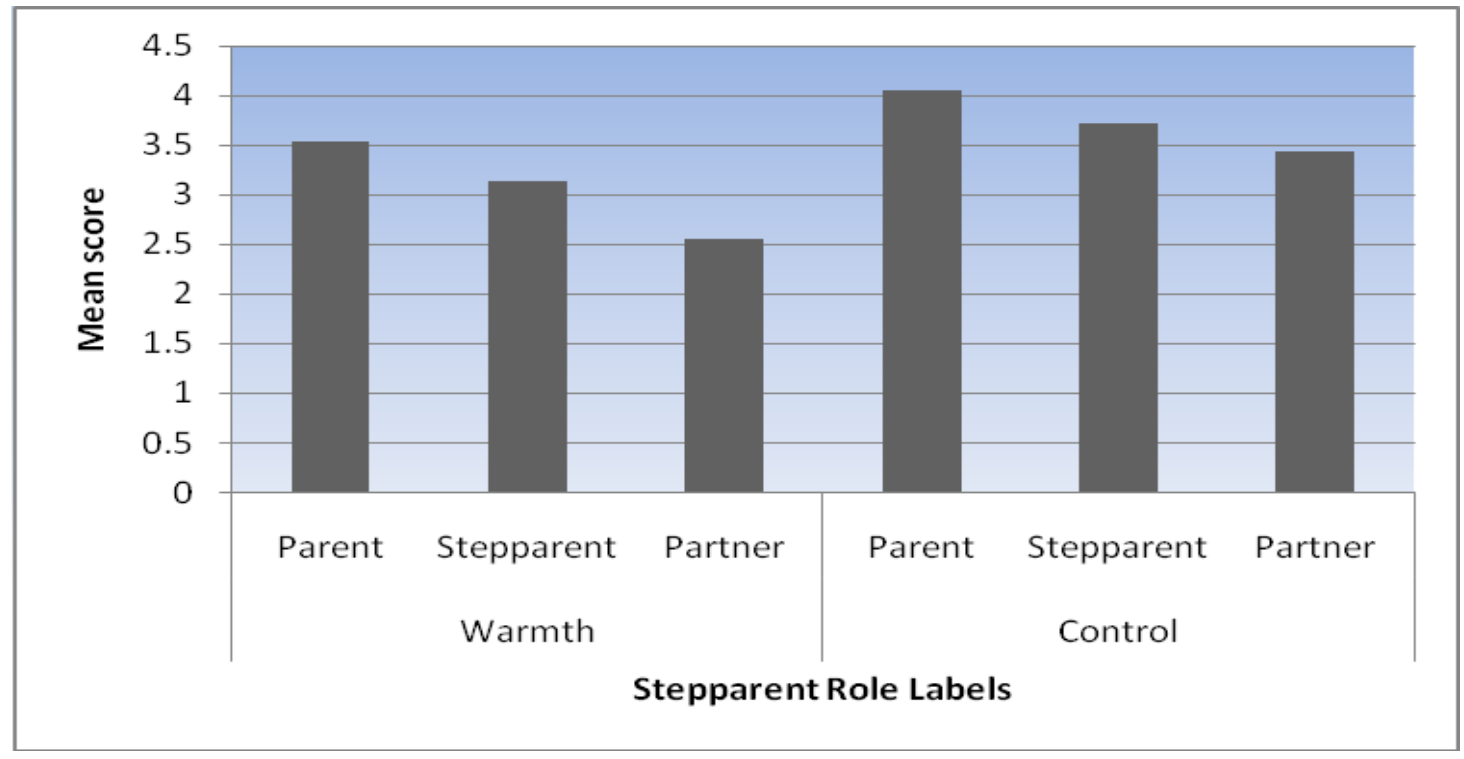

\subsubsection{Summary}

Overall, the results indicate that the parent label is associated with the highest involvement in warmth and control behaviours, and the partner label the least. Although warmth and control scores for the stepparent label were in between those for parent and partner, statistical tests did not indicate significant differences between the parent and stepparent labels. These results address Research Question 3 and indicate that different stepparent role labels were associated with different levels of involvement in warmth and control parenting behaviours. 


\subsection{Discrepancies in Stepparent Role Perceptions}

This section will present the results relating to discrepancies in role perceptions - both differences between the actual and ideal role scores for a particular stepfamily individual (intra-role discrepancies) and differences for the ideal stepparent role between stepfamily individuals (inter-role discrepancies).

\subsubsection{Intra-Role Discrepancies}

To evaluate whether there were significant differences between actual and ideal roles, six paired t-tests were performed comparing actual and ideal scores for the warmth and control dimensions of the stepparent role for all stepfamily members. Despite the fact that some of the stepparent role variables departed significantly from normality (as indicated earlier) parametric tests were used as distributions of the difference scores were examined and were found to be normally distributed. Results for these tests are provided in Table 6.7 and displayed graphically in Figure 6.7.

Table 6.7

Comparison of the Actual and Ideal Stepparent Role for Stepfamily Members

\begin{tabular}{|c|c|c|c|c|c|c|}
\hline \multirow[t]{2}{*}{ Dimension } & \multirow[t]{2}{*}{ Member } & \multicolumn{2}{|c|}{ Actual Role } & \multicolumn{2}{|c|}{ Ideal Role } & \multirow[t]{2}{*}{ Sig (p) } \\
\hline & & Mean & SD & Mean & SD & \\
\hline \multirow[t]{3}{*}{ Warmth } & Parents $(n=105)$ & 3.59 & .98 & 4.01 & .74 & $\mathrm{P}=.00$ \\
\hline & Stepparents $(n=103)$ & 3.25 & .95 & 3.83 & .82 & $\mathrm{P}=.00$ \\
\hline & Children $(n=105)$ & 2.92 & .93 & 3.21 & .92 & $\mathrm{P}=.00$ \\
\hline \multirow[t]{3}{*}{ Control } & Parents $(n=105)$ & 4.07 & .94 & 4.17 & .76 & $\mathrm{P}=.03$ \\
\hline & Stepparents $(n=103)$ & 3.81 & .94 & 3.97 & .85 & $\mathrm{P}=.02$ \\
\hline & Children $(n=105)$ & 3.28 & .90 & 3.00 & .90 & $\mathrm{P}=.00$ \\
\hline
\end{tabular}

When differences between actual and ideal roles scores were compared for biological parents, analyses revealed that biological parents wanted their partners to be significantly more involved in warmth $(\mathrm{t}(103)=-7.97, \mathrm{p}=.00)$ and control $(\mathrm{t}(103)=-$ 
2.25; $\mathrm{p}=.03$ ) behaviours than they actually were. Similarly, stepparents wanted to be significantly more involved in warmth $(\mathrm{t}(101)=-8.74, \mathrm{p}=.00)$ and control $(\mathrm{t}(101)=-$ 2.37; $\mathrm{p}=.02$ ) behaviours than they actually were. For children, results revealed that they wanted their stepparents to be significantly more involved in warmth $(\mathrm{t}(104)=-5.47, \mathrm{p}$ $=.00)$, although less involved in control $(\mathrm{t}(104)=5.08 ; \mathrm{p}=.00)$ behaviours than they actually were.

Figure 6.7

Comparison of Actual and Ideal scores for Warmth and Control Dimensions of the Stepparent Role

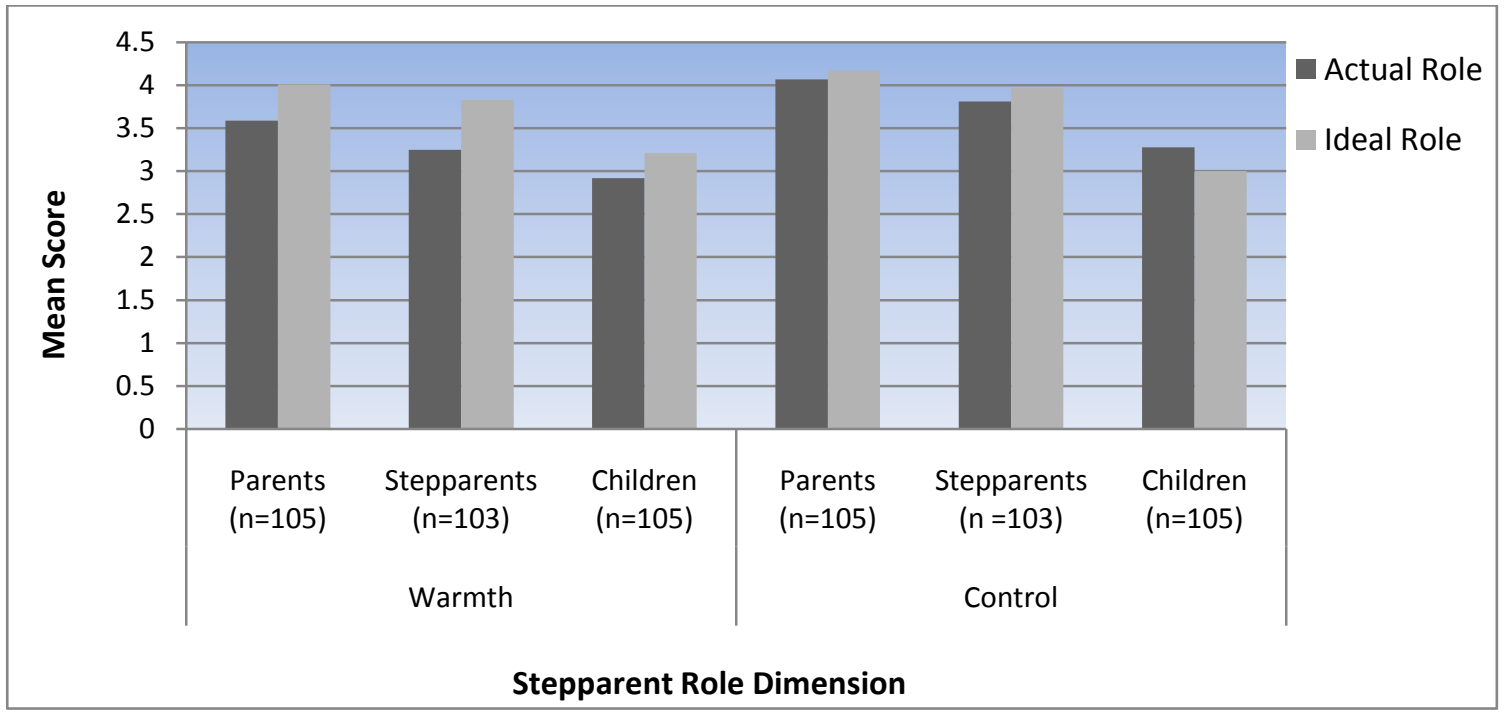

\subsubsection{Inter-Role Discrepancies}

To evaluate whether there were significant differences on the ideal role between stepfamily members, six paired t-tests were performed comparing warmth and control dimensions of the stepparent role for all combinations of stepfamily members. Although some of the stepparent role variables departed significantly from normality (as indicated earlier) parametric tests were used as the distributions of the difference scores were all normally distributed.

For the warmth dimension, there were significant differences between the ideal role between parents and children $(\mathrm{t}(101)=8.38 ; \mathrm{p}=.000)$, stepparents and parents $(\mathrm{t}(101)=$ 2.28; $\mathrm{p}=.02)$ and between stepparents and children $(\mathrm{t}(101)=6.30 ; \mathrm{p}=.000)$. Inspection of mean scores indicated that both parents $(\mathrm{M}=4.00 ; \mathrm{SD}=.77)$ and stepparents 
$(\mathrm{M}=3.83 ; \mathrm{SD}=.82)$ reported ideally wanting stepparents to be more involved in warmth behaviours than children did $(\mathrm{M}=3.23$; $\mathrm{SD}=.91)$. Parents $(\mathrm{M}=4.00 ; \mathrm{SD}=$ .77) wanted stepparents to be more involved in warmth behaviours than stepparents (M $=3.83 ; \mathrm{SD}=.82$ ) themselves did. Differences between stepfamily members for the warmth dimension are illustrated graphically in Figure 6.8.

For the control dimension, there were significant differences between the ideal role between parents and children $(\mathrm{t}(101)=10.84 ; \mathrm{p}=.000)$, stepparents and parents $(\mathrm{t}(101)$ $=-9.09 ; \mathrm{p}=.000)$, and stepparents and children $(\mathrm{t}(101)=-2.19 ; \mathrm{p}=.03)$. Inspection of mean scores indicated that both parents $(M=4.16 ; \mathrm{SD}=.79)$ and stepparents $(\mathrm{M}=3.97$; $\mathrm{SD}=.85)$ reported ideally wanting stepparents to be more involved in control behaviours than children $(\mathrm{M}=3.00 ; \mathrm{SD}=.88)$ did, and parents $(\mathrm{M}=4.16 ; \mathrm{SD}=.79)$ wanted stepparents to be more involved in control behaviours than stepparents themselves did $(\mathrm{M}=3.97 ; \mathrm{SD}=.85)$. Differences between stepfamily members for the control dimension are illustrated graphically in Figure 6.8.

These results address Research Question 8 and show that stepfamily members viewed both the warmth and control dimensions of the ideal stepparent role in different ways. Children wanted stepparents to be the least involved in these behaviours, parents the most, and stepparents scored in the middle.

Figure 6.8

Comparison of the Ideal Stepparent Role among Stepfamily Members

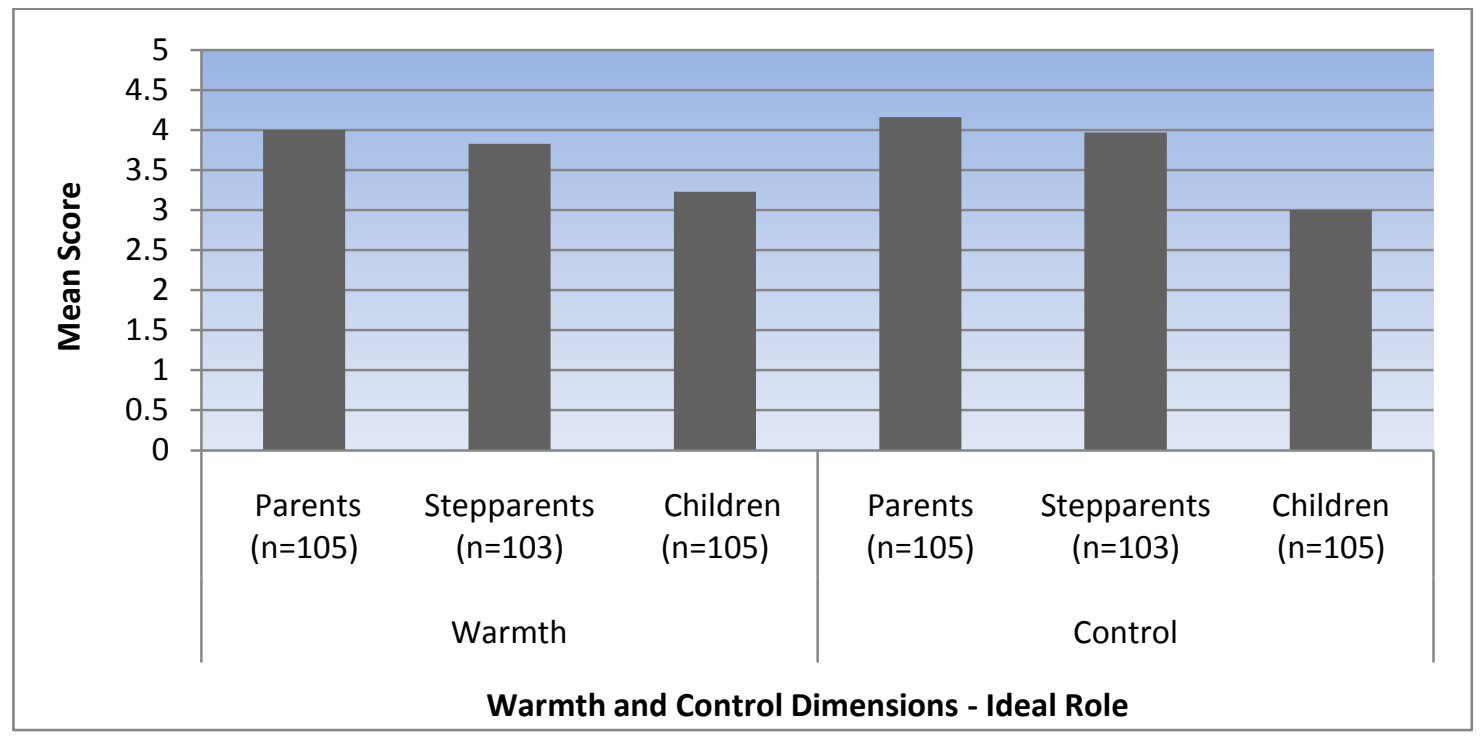




\subsection{Stepparent Role Negotiation}

This section will address the negotiation strategies that stepfamily members reported using to negotiate the stepparent role. Adults were asked questions regarding the frequency with which role negotiation strategies were used, both before and after the formation of the stepfamily ${ }^{2}$. Although children were not asked about role negotiation in the same detail, they were asked some open-ended questions of this nature in the questionnaires.

Preliminary analyses of the distributions of frequency scores for role negotiation strategies reported at time 1 suggested that they were not behaving as continuous variables, and were more categorical in nature. This was due to the high ceiling effects for most of the role negotiation strategies, with most adults reporting low levels of role negotiation, particularly for the period of time prior to cohabitation. Results relating to the distributions of these variables for parents are provided in Appendix U. As a similar pattern was evident for both parents and stepparents, only descriptive statistics for parents are provided in the appendix. A decision was made to convert each variable into a categorical variable, where $0=$ no talks of this nature, and $1=$ talks of this nature. An exception to this was for the frequency of gate keeping behaviours which was continuous in nature and normally distributed.

The following analysis outlines the role negotiation strategies reported by parents and stepparents, and how their views were different. Children's views regarding role negotiation are then examined.

\subsubsection{Adults' Perceptions of Role Negotiation}

Percentages were calculated for role negotiation strategies for parents and stepparents and are presented in Table 6.8. These percentages reflect the proportion of parents and stepparents who reported using these role negotiation strategies, before moving in together (pre-cohabitation) and after moving in together (post-cohabitation). A dash (-) indicates that this strategy was not measured at this point in time.

${ }^{2}$ I.e. when the stepfamily first started living together full-time 
Table 6.8

Percentages for Role Negotiation Strategies for Adults at Time One

\begin{tabular}{lcccc}
\hline Strategies & \multicolumn{2}{c}{ Pre-cohabitation } & \multicolumn{2}{c}{ Post-cohabitation } \\
\hline \hline & $\begin{array}{c}\text { Parents } \\
n=105\end{array}$ & $\begin{array}{c}\text { Stepparents } \\
n=103\end{array}$ & $\begin{array}{c}\text { Parents } \\
n=105\end{array}$ & $\begin{array}{c}\text { Stepparents } \\
n=103\end{array}$ \\
\cline { 2 - 5 } & & & & \\
& 39 & 36 & 56 & 38 \\
Partner talks & 6 & 0 & 7 & 3 \\
Ex-partner talks & 30 & 5 & 27 & 8 \\
Child talks & 7 & 8 & 21 & 10 \\
Family talks & - & - & 42 & 54 \\
Partner check-in & - & - & 48 & 19 \\
Child check-in & & &
\end{tabular}

Parents' perceptions of role negotiation strategies will be discussed first, followed by stepparents' perceptions of role negotiation strategies.

\section{Parents' Reports of Role Negotiation}

For parents, the most common role negotiation strategy, both pre (39\%) and post (56\%) cohabitation were talks with their partner. This was followed by talks with children about the stepparent's role, with $30 \%$ and $27 \%$ of parents reporting engaging in these talks before and after living together, respectively. Talks with their ex-partner less commonly occurred, both pre $(6 \%)$ and post $(7 \%)$ cohabitation. Family talks were reported with low frequency by parents' pre-cohabitation (7\%), although they had increased after living together to $21 \%$.

Post cohabitation, almost half the parents (42\%) reported that their partners checked in with them for feedback regarding their parenting behaviours with stepchildren. Slightly more $(48 \%)$ reported that they checked in with their children to see how they were feeling about the stepparent's behaviour towards them.

Parents were asked to what extent they believed they had acted in certain ways that may gate keep the child's relationship with the stepparent. Parents reported that they did engage in gate keeping behaviours with a mean of $2.60(\mathrm{SD}=.86$, possible mean scores $=1-5)$. 


\section{Stepparents' Reports of Role Negotiation}

Percentages were calculated for role negotiation strategies for stepparents and are presented in Table 6.8. These percentages reflect the proportion of stepparents who reported using these role negotiation strategies both before and after cohabitation.

Similar to parents, the most common role negotiation strategy engaged in, both pre $(36 \%)$ and post $(38 \%)$ cohabitation were talks with their partner. As can be seen in Table 6.8, the other kinds of discussions (talks with their stepchild, talks as a family and talks with their partner's ex-partner) were much less commonly reported by stepparents. Only $5 \%$ and $8 \%$ of stepparents reported talking to their stepchild about their role, either before or after living together, respectively. Although slightly more common, only $8 \%$ of stepparents reported engaging in family talks pre-cohabitation, and only $10 \%$ post cohabitation. The least common strategy used by stepparents was talks with their partner's ex-partner about their role. No stepparents reported talking with their partners' ex-partner about their role before cohabitation and this had increased to only $3 \%$ after living together. After cohabitation, approximately 1 in 5 stepparents (19\%) reported checking in with their stepchild regarding how they felt about their behaviour towards them. They were much more likely to check in with their partner for parenting feedback (54\%).

These findings indicate, in comparison to parents, stepparents were much less likely to report engaging in talks with their partner and having talks as a family (for post cohabitation period only) or checking in with the target child.

Stepparents were asked to what extent they believed their partner had acted in ways that aimed to gate keep the child's relationship with them. Similar to parents, stepparents believed their partners engaged in gate keeping behaviours to a certain degree $(\mathrm{M}=$ 2.60, $\mathrm{SD}=0.86$; possible mean scores $=1-5$ ). 


\subsubsection{Children's Perceptions of Role Negotiation}

Finally, this section will address the findings in relation to children's views on role negotiation. These views are considered separately from parents and stepparents as they were asked about different aspects of role negotiation. Children were asked to report on whether role negotiation strategies had occurred in their families. In addition, they were asked open-ended questions regarding why certain discussions did not occur in their families and how these negotiation strategies made them feel (refer to Question 97 \& 98, page 299).

\section{Talking to a Family or Non-Family Member about their Stepparent's Behaviour}

The majority of children (62\%) reported that they had not spoken to anyone about their stepparent's behaviour towards them. A variety of reasons were given regarding why they had not done this, such as feeling like it was not needed, or not wanting to discuss these sorts of issues. For example, one girl said she would "Never, ever, ever talk about this with anyone. I never tell my feelings to anyone but then it keeps me sad" (female, aged 11). Another boy felt that he lacked the support to discuss issues like this: "They usually don't listen, and I don't like to talk to people about it” (male, aged 10).

Of the $38 \%$ of children who reported that they had talked to someone, a variety of people were approached. In most cases (70\%) it was the resident parent; non-resident parents were approached only $8 \%$ of the time. For many children, siblings were an important source of support with $10 \%$ reporting they had spoken to their sibling about their stepparent's behaviour. Other children had talked to a stepsibling (3\%), a grandparent $(5 \%)$ or some other person $(5 \%)$, such as a "friend at school who also lived in a family like ours" (female, aged 11) or "a teacher" (male, aged 9).

\section{The Resident Parent Checking in with the Target Child}

The majority of children (63\%) reported that their resident parent had checked in with them and sought their feedback regarding how they were feeling about their stepparent. However, there were a sizeable minority of children (37\%) whose resident parents did not check in with them in this way. When children were asked what their resident parents had said to them, they reported discussing issues concerning the stepparent moving in, and how they felt about the stepparent living with them. For example, many 
children were asked "Would you like (stepparent) to move in with us?" or "Are you happy with (stepparent) living here?" A few children were asked whether they liked their stepparent, and sometimes this feedback was very important. For example, one child reported "She told me that if I didn't like him, she wouldn't marry him." (male, aged 8).

Of the children whose feedback was sought, there were different views reported regarding how they felt about being asked. While the majority of children expressed positive feelings about being asked; for example "I feel like she cares for me" (female, aged 9) and "it makes me feel like I have a say" (male, aged 8), others expressed concerns. One child revealed that she wished "she wouldn't ask me" (female, aged 9), and another said that she was "nervous because maybe I said something that Mum didn't like." (female, aged 10).

\section{Summary}

These findings addressed Research Question 11 and indicate that stepfamily members report engaging in a variety of role negotiation strategies. Partner talks were the most commonly used strategy, and many biological parents had explicit talks with their children about the stepparent role. In addition, many stepfamily adults' reported that the stepparent had checked in with the biological parent regarding actual parenting behaviours and that parents engaged in gate keeping behaviours. Role negotiation strategies were more likely to occur after cohabitation than before living together and non-explicit strategies were more commonly used than explicit-strategies.

\subsection{Overview of Chapter Six}

The results presented in this chapter suggest that stepfamily members perceive the stepparent role in a variety of ways. While stepfamily adults were more likely to describe the actual stepparent role as like a stepparent, children were more likely to describe it as like a parent. However, the majority of stepchildren did not select parent as the ideal role - while $18 \%$ selected parent as the ideal role for the stepparent, $82 \%$ did not see the ideal role as a parent. The association between stepparent role labels and role behaviours was explored and, in agreement with assumptions of previous 
researchers (Fine et al., 1998) and clinicians (Visher \& Visher, 1988) the parent role was associated with the highest involvement in warmth and control behaviours, the partner label the least, and the stepparent label somewhere in the middle.

However, although stepparent role labels were associated with role behaviours, this did not mean that stepchildren wanted stepparents to be more involved in a parenting role. When perceptions regarding the stepparent's ideal involvement in warmth and control behaviours were examined, all stepfamily members reported that stepparents were, and should be, involved in these behaviours. However, stepchildren wanted stepparents to be less involved in warmth and control behaviours than their stepparents and biological parents.

While all stepfamily members wanted the stepparent to be more involved in warmth behaviours than they actually were, only stepchildren wanted them to be less involved in control behaviours. In addition to highlighting the need to explore both warmth and control dimensions of the stepparent role, these findings emphasise the need to examine all stepfamily members' perceptions, since they may be different. The extent to which these differences affect stepfamily functioning is explored in Chapter Seven. Longitudinal correlations are conducted to best examine how role perceptions at time 1 affect stepfamily functioning 12 months later (time 2).

Stepfamily members' report negotiating the stepparent role in a variety of ways. Role negotiation was more common after moving in together and non-explicit role negotiation strategies were more commonly used than explicit negotiation strategies. The next chapter will address to what extent these role negotiation strategies are associated with improvements in stepfamily functioning, and higher levels of agreement between stepfamily members regarding the stepparent role.

Similar to previous research on the stepparent role, the results outlined in this chapter are cross-sectional, and therefore it is unclear to what extent the stepparent role changes over time. The next chapter will explore the nature of change in role perceptions to provide a richer understanding of the stepparent role. 


\section{Chapter Seven \\ Results -Time Two}

The changes that occurred in the research sample over the two stages of data collection are initially discussed, followed by an analysis of the changes over time in stepparent role variables. Role negotiation strategies are then examined, to assess whether stepfamilies are more likely to engage in role negotiation when they were experiencing problems, and whether these strategies lead to improvements in functioning over time. Longitudinal correlations are then presented that assess the association between the actual stepparent role and stepparent role discrepancies at time 1 with stepfamily functioning twelve months later. This is followed by hierarchical regression analyses which sought to determine the comparative importance of inter and intra role discrepancies for children's reports of stepfamily functioning, after controlling for the stepparent's actual involvement and important demographic and individual variables.

\subsection{Changes to Sample}

The main change to the sample was that data were collected from fewer stepfamilies at the second stage. The main reason for sample attrition was that some of the stepfamilies were no longer together at time 2 as they had separated during the twelve month period. While $86 \%$ of the stepfamilies at time 1 were still in a relationship together at time $2,11 \%$ had dissolved the relationship. In addition, one family did not want to participate again at time 2 , and two families could not be re-contacted. This left 88 stepfamilies from whom data were collected at time 2 .

Many of the stepfamilies had experienced other family changes in the past year. Firstly, $28 \%$ of stepfamily couples had married in the time between time 1 and 2, so that there were significantly fewer cohabiting couples at time 2. In addition, approximately $10 \%$ of stepfamily couples had a biological child together between times 1 and 2 . 
Stepparents were asked whether there had been changes in their level of contact with their biological children over the previous 12 month period. Of the stepparents who were interviewed at time 2 (who had biological children), 33\% reported changes in contact with biological children. When stepparents were asked to report on the nature of the changes that had occurred, $18 \%$ reported a decrease in contact with their biological children and 14\% reported an increase. These changes are likely to have an impact on stepfamily functioning, such as a stepparent's happiness with their relationships with their stepchildren. Many stepparents commented in interviews that they had found it difficult to enjoy spending time with their stepchildren when contact with their own biological children had decreased.

There had been no significant changes in family income, biological parent and stepparent employment status, or the frequency of contact between children and nonresident parents.

Stepfamily adults were asked whether they had used counselling services in the past year. Parents and stepparents reported that approximately 13-14\% of stepfamilies had received family or couple counselling in the past year (13\% for parents, $14 \%$ for stepparents). Some children had also received counselling to address abandonment issues concerning the non-resident parent. Other stepparents reported undertaking counselling services themselves to better address past relationship and personal issues that were interfering with their current relationship.

Ten percent of biological parents reported having contact with the Family Court in the past year. There were many reasons reported for doing this, including issues related to "adoption and name change," applications for "full guardianship" and negotiation of "child care arrangements." Parents were also asked whether there had been any changes in the household over the past year. The nature of these changes was not specified by the researcher, although parents were asked to provide examples of the changes that had occurred. A large proportion of parents (41\%) reported that there had been changes of some nature in their family in the past year. When parents were asked what type of changes had taken place, a variety of responses were given; older children 
had left the home, new children were born into the stepfamily, and visiting arrangements with the stepparents' biological children had changed.

Finally, children were one year older, with the average age of stepchildren at time 2 being eleven years. This means that adolescence was closer at the second stage of data collection, and this developmental change has the potential to play an important role in the functioning of stepfamily relationships.

\subsection{The Stepparent Role: Changes over Time}

This section outlines changes over time in stepfamily members' perceptions of the actual and ideal stepparent role. Before statistical tests were performed, the distribution of actual and ideal scores at time 2 were explored for each of the warmth and control dimensions of the stepparent role. As a result, some outliers were adjusted that were significantly low scores of more than three standard deviations from the mean scores. These scores were not deleted from the analysis, but were adjusted to a score within two standard deviations from the mean that retained their relative ranking. Results of these changes are provided in Table 2 in Appendix Q.

\subsubsection{The Actual Stepparent Role}

To establish whether stepfamily members reported changes in the stepparent role over time, paired t-tests were performed on the warmth and control scores. For parents, results indicated there were significant changes over time in warmth behaviours, $(\mathrm{t}(87)$ $=2.18, \mathrm{p}=.03$ ), but no changes in control behaviours. The descriptive statistics

(provided in Table 7.1) indicate that parents perceived their partners to be less involved in warmth behaviours over time. There were no significant changes over time for stepparents' or children's perceptions of the stepparent's involvement in warmth and control behaviours. 
Table 7.1

Changes over Time for the Actual Stepparent Role

\begin{tabular}{clccccc}
\hline \multirow{2}{*}{ Role } & \multicolumn{1}{c}{ Member } & \multicolumn{2}{c}{ Time 1 } & \multicolumn{2}{c}{ Time 2 } & Sig (p) \\
\hline \hline \multirow{4}{*}{ Warmth } & Pean & SD & Mean & SD & \\
\cline { 3 - 7 } & Parents $(n=88)$ & 3.75 & .90 & 3.59 & .95 & P $=.03$ \\
& Stepparents $(n=85)$ & 3.30 & .97 & 3.29 & 1.04 & NS \\
& Children $(n=89)$ & 2.94 & .99 & 2.87 & .95 & NS \\
\multirow{4}{*}{ Control } & Parents $(n=88)$ & 4.20 & .83 & 4.13 & .87 & NS \\
& Stepparents $(n=85)$ & 3.92 & .88 & 3.87 & .97 & NS \\
& Children $(n=89)$ & 3.36 & .91 & 3.39 & .74 & NS \\
\hline
\end{tabular}

\subsubsection{The Ideal Stepparent Role}

To establish whether stepfamily members reported changes in the ideal stepparent role over time, paired t-tests were performed on the warmth and control scores. For all stepfamily members, results indicated that there were no significant differences over time in warmth or control ideal dimensions. Descriptive statistics are provided in Table 7.2 .

Table 7.2

Changes over Time for the Ideal Stepparent Role

\begin{tabular}{clccccc}
\hline Role & Member & Time 1 & \multicolumn{2}{c}{ Time 2 } & Sig (p) \\
\hline \hline \multirow{3}{*}{ Warmth } & & Mean & SD & Mean & SD & \\
\cline { 3 - 7 } & Parents $(n=88)$ & & & & & \\
& Stepparents $(n=85)$ & 3.88 & .82 & 3.76 & .87 & NS \\
& Children $(n=89)$ & 3.23 & .96 & 3.07 & .95 & NS \\
\multirow{3}{*}{ Control } & Parents $(n=88)$ & 4.27 & .72 & 4.24 & .73 & NS \\
& Stepparents $(n=85)$ & 4.03 & .82 & 3.93 & .85 & NS \\
& Children $(n=89)$ & 3.03 & .92 & 3.18 & .80 & NS \\
\hline
\end{tabular}


These results address Research Question 2 and illustrate that there were, in general, few changes in individual role perceptions (actual and ideal role) over time. There was only one significant change - parents reported stepparents to be less involved in warmth behaviours over time.

\subsection{Stepparent Role Discrepancies: Changes over Time}

Although there were few significant changes in perceptions of the actual or ideal stepparent role over time, this does not mean that role discrepancy scores have not changed. The next section examines whether intra-role discrepancies changed over time for stepfamily members, followed by an examination of changes in inter-role discrepancies among stepfamily members.

\subsubsection{Intra-Role Discrepancies}

Six intra-role discrepancy scores were created at time 1 and 2 by calculating difference scores between the ideal role and the actual role for each stepfamily member. These were calculated for each of the warmth and control dimensions. The absolute value of these discrepancy scores was taken, as it was the magnitude of the difference that was considered to be important, rather than the direction of this difference (in line with Fine et al., 1998). The original variables (before modification of outliers) were used to create these difference scores and distributions of the discrepancy scores were then examined. In light of the skewed nature of some of these discrepancy scores, some outliers and extreme scores were re-coded for parents' and children's scores so that all scores were within two standard deviations from the mean score. These modified scores are provided in Appendix Q. No scores were changed for stepparents' intra discrepancy scores at either time 1 or 2.

To evaluate whether there were significant differences over time for intra-role discrepancy scores, six paired t-tests were performed. Results for these tests are given in Table 7.3 and discussed in the following sections. 
Table 7.3

Changes over Time for Intra-Role Discrepancies

\begin{tabular}{llccccc}
\hline Role & Member & \multicolumn{2}{c}{ Time 1 } & \multicolumn{2}{c}{ Time 2 } & Sig (p) \\
\hline \hline \multirow{3}{*}{ Warmth } & Parents $(n=88)$ & .29 & .26 & .29 & .25 & NS \\
\cline { 2 - 7 } & Stepparent $(n=85)$ & .43 & .30 & .38 & .29 & $\mathrm{P}=.04$ \\
& Children $(n=89)$ & .23 & .22 & .19 & .21 & NS \\
\multirow{3}{*}{ Control } & Parents $(n=88)$ & .22 & .25 & .23 & .26 & NS \\
& Stepparent $(n=85)$ & .26 & .27 & .26 & .28 & NS \\
& Children $(n=89)$ & .28 & .27 & .19 & .20 & $\mathrm{P}=.00$ \\
\hline
\end{tabular}

For parents, results revealed no change over time for intra-role discrepancy scores for the warmth or control dimensions of the stepparent role. For stepparents, there were significant changes over time for the warmth dimension $(\mathrm{t}(84)=2.08 ; \mathrm{p}=.04)$ although no significant differences for the control dimension. Descriptive statistics indicated that intra-role discrepancy scores for the warmth dimension decreased over time. For children, results revealed there were no significant changes over time in intra-role discrepancies for the warmth dimension although there were for the control dimension $(\mathrm{t}(88)=3.06 ; \mathrm{p}=.003)$. The mean scores indicate that children's intra-role discrepancy scores for the control dimension decreased over time.

\subsubsection{Inter-Role Discrepancies}

Variables measuring role discrepancies between stepfamily members were created for time 1 and 2. Six role discrepancy variables were created for each possible combination of family members (stepparent-stepchild, parent-stepparent and parent-child) for the two dimensions of the stepparent role (warmth and control). These discrepancy scores were represented by difference scores between stepfamily members based on the original scores. Again, the absolute value of the discrepancy scores was taken, as it was the magnitude of the difference that was considered to be important. Initial inspection of the data indicated that some of these variables had scores that were acting as outliers and extreme scores. These values were adjusted in a similar way to that discussed previously and are provided in Appendix Q. 
To determine whether inter-role discrepancies changed over time, paired t-tests were performed for each possible dyadic combination of stepfamily members for both the warmth and control dimensions of the stepparent role. Descriptive statistics and results of these tests are provided in Table 7.4. The following section outlines the results for stepparent-stepchild, biological parent-child and stepparent-parent inter-role discrepancies.

Table 7.4

Changes over Time for Inter-Role Discrepancies

\begin{tabular}{ccccccc}
\hline Dimension & Role Discrepancy & \multicolumn{2}{c}{ Time 1 } & \multicolumn{2}{c}{ Time 2 } & Sig (p) \\
\hline \hline \multirow{2}{*}{ Warmth } & Sean & SD & Mean & SD & \\
\cline { 3 - 7 } & SP_BP $(n=85)$ & .60 & .48 & .61 & .48 & NS \\
& BP_Ch $(n=88)$ & 1.05 & .71 & 1.10 & .76 & NS \\
& SP_SC $(n=85)$ & .98 & .68 & .84 & .65 & P=.04 \\
& SP_BP $(n=85)$ & .64 & .53 & .71 & .62 & NS \\
& BP_Ch $(n=88)$ & 1.44 & .82 & 1.26 & .76 & NS \\
& SP_SC $(n=85)$ & 1.22 & .85 & .99 & .73 & $\mathrm{P}=.02$ \\
\hline
\end{tabular}

There were no changes over time for inter-role discrepancies between parents and stepparents, or between parents and children. However, stepparents and stepchildren reported significant changes over time for both the warmth $(\mathrm{t}(84)=2.06 ; \mathrm{p}=.04)$ and control $(\mathrm{t}(84)=2.39 ; \mathrm{p}=.02)$ dimensions. An inspection of the mean scores indicates that role discrepancies between stepparents and stepchildren decreased over time.

\section{Summary}

These results address Research Question 6 and illustrate that children's intra-role discrepancies for the control dimension, and stepparents' intra-role discrepancies for the warmth dimension, decreased over time. In addition, inter-role discrepancies between stepparents and stepchildren (for both warmth and control dimensions) decreased over time. These findings address Research Question 9. These findings indicate a general pattern of reduced role discrepancies (both inter and intra) over time. 


\subsection{Frequency of Stepparent Role Negotiation}

The association between frequency of role negotiation and stepfamily functioning was examined in two steps. Firstly, stepfamily functioning scores (as reported by stepfamily adults) at time 1 were correlated with their reported frequency of role negotiation strategies in the following 12 months. This was designed to assess whether role negotiation more commonly occurred in those stepfamilies that were experiencing more problematic functioning at time 1 (Research Question 12). Secondly, correlations between role negotiation at time 2 and change in stepfamily functioning variables were examined to examine whether role negotiation was effective in improving stepfamily functioning over time (Research Question 13). The first section presents results investigating whether role negotiation was more likely to be reported (at time 2) in stepfamilies with more problematic functioning at time 1.

Prior to the calculation of correlations, descriptive statistics were examined for the role negotiation variables. As a result, the variable measuring the extent to which stepparents reported having discussions with their partners' ex-partner was excluded as only three stepparents reported using this strategy. Descriptive statistics were then inspected for these variables, which revealed that many of the role negotiation strategies at time 2 were significantly skewed. This led to the adjustment of some outliers in a similar way to that explained previously. These modifications are provided in Appendix Q. In light of the skewed distributions of these variables after adjustment of outliers, Spearman correlations were used in the following analyses.

Correlations between frequency of role negotiation strategies at time 2 and stepfamily functioning scores at time 1 are displayed in Table 7.5. Correlations were not calculated for cohesion scores based on the problems with this variable at time 1. These correlations represent the association between each adult's perception of role negotiation strategies and their perception of stepfamily functioning. Results regarding parents and stepparents are presented separately. 


\subsubsection{Parents' Role Negotiation and Stepfamily Functioning}

Role negotiation variables for parents at time 2 were correlated with scores on family conflict, partner relationship quality, children's difficulties, and parent-child relationship quality at time 1. Results of these correlations are provided in Table 7.5.

Table 7.5

Correlations between Role Negotiation Strategies for Parents at Time Two and Stepfamily Functioning at Time One $(n=88)$

\begin{tabular}{lcccc}
\hline Strategies Time 2 & \multicolumn{4}{c}{ Stepfamily Functioning Time 1 } \\
\hline \hline & Conflict & Partner RQ & Tot Diff & BP_Ch RQ \\
\cline { 2 - 5 } Partners Talks & .14 & .03 & .03 & .19 \\
Child Talks & $.30^{* *}$ & -.03 & .11 & -.01 \\
Ex Talks & -.02 & .07 & -.19 & .03 \\
Family Talks & .16 & .05 & -.11 & .17 \\
Partner Check In & .06 & .09 & .00 & -.06 \\
Child Check In & $.25^{*}$ & -.17 & .03 & .08 \\
Gate Keeping & .11 & $-.40^{* *}$ & -.15 & -.14 \\
\hline
\end{tabular}

These findings suggest that parents who perceived more negative stepfamily functioning at time 1 , reported more frequent use of role negotiation strategies in the following 12 months. Family conflict at time 1 was positively associated with the frequency with which parents' had explicit talks with children and checked in with them for feedback. Partner relationship quality at time 1 was negatively associated with the frequency with which biological parents' engaged in gate keeping behaviours. This indicates that certain role negotiation strategies were more frequently used in the following twelve months in stepfamilies with lower partner relationship quality and higher family conflict scores at time 1. 


\subsubsection{Stepparents' Role Negotiation and Stepfamily Functioning}

Role negotiation variables for stepparents at time 2 were correlated with scores at time 1 for family conflict, partner relationship quality, stepparent-stepchild quality and children's difficulties. Results of these correlations are provided in Table 7.6.

Table 7.6

Correlations between Role Negotiation for Stepparents at Time Two and

Stepfamily Functioning at Time One $(n=85)$

\begin{tabular}{lcccc}
\hline Strategies Time 2 & \multicolumn{4}{c}{ Stepfamily Functioning Time 1 } \\
\hline \hline \multirow{2}{*}{ Partner Talks } & Conflict & Partner RQ & SP_SC RQ & Tot Diff \\
\cline { 2 - 5 } Child Talks & .05 & -.03 & -.18 & .15 \\
Family Talks & -.03 & -.05 & .02 & .13 \\
Partner Check In & -.00 & -.01 & -.14 & .06 \\
Child Check In & .03 & -.08 & -.13 & .04 \\
Gate Keeping & -.08 & .07 & -.04 & .13 \\
\hline
\end{tabular}

Stepparents reported more frequent use of gate keeping by biological parents in the following 12 months when they perceived stepfamily functioning to be more negative at time 1 . The quality of their relationship with their partner and the stepparentstepchild relationship at time 1 were both negatively correlated with gate keeping behaviours at time 2 . In addition, family conflict at time 1 was positively associated with gate keeping behaviours at time 2. This suggests that when stepfamily relationships were of lower quality and family conflict was higher at time 1, stepparents perceived their partners to engage more frequently in gate keeping behaviours.

\section{$\underline{\text { Summary }}$}

These findings address Research Question 12 and indicate that stepparents and parents report more frequent use of role negotiation strategies, particularly gate keeping behaviours, when stepfamily functioning is more problematic at time 1 . 


\subsection{Role Negotiation and Changes in Stepfamily Functioning}

To determine whether role negotiation led to changes over time in stepfamily functioning (Research Question 13), difference scores (using original scores) were created to reflect the difference between stepfamily functioning scores at time one and two. For parents, the difference scores that were examined were family conflict, partner relationship quality, parent-child relationship quality and children's difficulties. For stepparents, the difference scores examined were family conflict, partner relationship quality, stepparent-stepchild relationship quality and children's difficulties. In contrast to difference scores calculated for inter-role and intra-role discrepancies, absolute values were not taken as this research question concerned the degree to which stepfamily functioning had improved, or become worse, over time. Therefore, difference scores were created so that a positive score reflected an increase in stepfamily functioning (i.e. family conflict, relationship quality) over time, and negative scores reflected a decrease in stepfamily functioning over time. As previously mentioned, difference scores were not calculated for cohesion scores because of the highly skewed nature of this variable at time 1 .

Prior to the calculation of correlations, descriptive statistics and histograms were examined for the stepfamily functioning difference scores. Some outliers and extreme scores were identified and modified; these are provided in Appendix Q. Despite these changes to outliers, difference scores remained significantly skewed; therefore Spearman Correlations were conducted in the following analyses.

\subsubsection{Parents' Role Negotiation and Changes in Stepfamily Functioning}

Role negotiation variables for parents were correlated with changes in family conflict, parent-child relationship quality, partner relationship quality and children's difficulties. Results of these correlations are provided in Table 7.7. These correlations represent the association between parents' perceptions of role negotiation and their perception of changes in functioning. 
Table 7.7

Correlations between Role Negotiation at Time Two and Changes in Stepfamily

Functioning over Time $(n=88)$ - for Parents

\begin{tabular}{lcccc}
\hline Strategies Time 2 & \multicolumn{4}{c}{ Change Over Time in Stepfamily Functioning } \\
\hline \hline & Conflict & Partner RQ & Tot Diff & BP_Ch RQ \\
\cline { 2 - 5 } Partner Talks & -.03 & .08 & -.05 & -.16 \\
Child Talks & -.02 & -.01 & .06 & -.03 \\
Ex Talks & .16 & -.02 & .20 & .03 \\
Family Talks & -.12 & .07 & .10 & -.11 \\
Partner Check In & -.11 & .06 & -.02 & -.05 \\
Child Check In & .01 & -.05 & .08 & -.09 \\
Gate Keeping & .05 & .07 & -.05 & .04 \\
\hline
\end{tabular}

As illustrated in Table 7.7, frequency of role negotiation strategies reported by parents was not significantly correlated with any changes in stepfamily functioning over time.

\subsubsection{Stepparents' Role Negotiation and Changes in Stepfamily Functioning}

Role negotiation variables for stepparents at time 2 were correlated with changes in family conflict, partner relationship quality, stepparent-stepchild relationship quality and children's difficulties. Results of these correlations are provided in Table 7.8. These correlations represent the association between stepparents' perceptions of role negotiation and their perception of changes in functioning.

Table 7.8

Correlations between Role Negotiation at Time Two and Changes in Stepfamily

Functioning over Time $(n=87)$ - for Stepparents

\begin{tabular}{lcccc}
\hline Strategies Time 2 & \multicolumn{4}{c}{ Change over Time in Stepfamily Functioning } \\
\hline \hline & Conflict & Partner RQ & SP_SC RQ & Tot Diff \\
\cline { 2 - 5 } Partner Talks & -.13 & .04 & .12 & .16 \\
Child Talks & -.12 & .02 & .18 & .06 \\
Family Talks & -.04 &. $\mathbf{2 3 *}$ & $\mathbf{. 2 6 *}$ & .03 \\
Partner Check In & -.04 & .02 & .11 & .03 \\
Child Check In & -.12 & .05 & $\mathbf{. 3 7 * *}$ & .01 \\
Gate Keeping & .02 & .02 & $\mathbf{- . 2 6 *}$ & .12 \\
\hline
\end{tabular}


There were more significant correlations between role negotiation strategies and changes in stepfamily functioning for stepparents, than for parents. Family talks and the extent to which stepparents checked in with stepchildren were all significantly positively associated with an improvement in the quality of the stepparent-stepchild relationship, and (for family talks) an improvement in relationships with their partners over time. This finding was particularly prominent for stepparents' checking in with target stepchildren, which was moderately correlated with an improvement in the stepparentstepchild relationship quality over time $\left(\mathrm{r}=.37^{* *}\right)$. In addition, gate keeping behaviours were significantly correlated with a decrease in the quality of the stepparent's relationship with their stepchild over time.

\section{Summary}

These results address Research Question 13 and indicate that some role negotiation strategies were associated with improvements in stepfamily functioning. While parents' reports of the frequency of role negotiation were not associated with any improvements in stepfamily functioning, stepparents' reports were associated with improvements in several aspects of functioning. In particular, the frequency of family talks and stepparents checking in with the target stepchild were associated with improvements in the relationship between stepparents and children. In contrast, use of gate keeping behaviours was associated with a decrease in the quality of the stepparent-stepchild relationship.

\subsection{Role Negotiation and Changes in Inter-Role Discrepancies}

This section addresses the extent to which role negotiation strategies are associated with a decrease in inter-role discrepancies over time. Difference scores were created that represented the difference in inter-role discrepancies between time one and two. Differences scores were calculated so that a positive score reflected an increase in interrole discrepancies over time, while a negative score reflected a decrease in role discrepancies over time. Distributions of these change scores showed that these variables were not significantly skewed although Spearman correlations were conducted since role negotiation strategies were significantly skewed. Role negotiation strategies at time 2 were correlated with change in inter-role discrepancy scores for both warmth and 
control dimensions of the stepparent role, to further address Research Question 13. The results for parents and stepparents are presented separately.

\subsubsection{Parents' Role Negotiation and Changes in Inter-Role Discrepancies}

Role negotiation variables for parents at time 2 were correlated with changes in interrole discrepancy scores between stepparents and parents, and parents and children, for the warmth and control dimensions of the stepparent role. Results of these correlations are provided in Table 7.9 .

Table 7.9

Correlations between Role Negotiation Strategies for Parents at Time Two and Changes in Inter-Role Discrepancies over Time

\begin{tabular}{|c|c|c|c|c|}
\hline \multirow[t]{2}{*}{ Strategies Time 2} & \multicolumn{2}{|c|}{$\begin{array}{c}\text { BP_SP Discrepancies } \\
(n=85)\end{array}$} & \multicolumn{2}{|c|}{$\begin{array}{c}\text { BP_SC Discrepancies } \\
(n=87)\end{array}$} \\
\hline & Warmth & Control & Warmth & Control \\
\hline Partner Talks & .01 & -.02 & -.04 & -.01 \\
\hline Child Talks & .07 & -.03 & .03 & -.00 \\
\hline Ex Talks & -.03 & -.11 & .05 & -.21 \\
\hline Family Talks & -.01 & -.19 & .14 & .05 \\
\hline Partner Check In & -.18 & -.17 & -.08 & -.07 \\
\hline Child Check In & -.08 & .02 & $.21 *$ & -.12 \\
\hline Gate Keeping & .03 & -.05 & -.01 & -.01 \\
\hline
\end{tabular}

Overall, there were few significant correlations between use of role negotiation strategies at time 2 and changes in inter-role discrepancies. There was only one significant correlation and this involved the extent to which stepparents checked in for feedback with their target stepchild: this was associated with increased discrepancies over time (i.e. lower agreement) on the warmth dimension of the stepparent role between parents and children (BP-SC). Role negotiation strategies were not significantly associated with any changes in role discrepancies between parents and stepparents. 


\subsubsection{Stepparents' Role Negotiation and Changes in Inter-role Discrepancies}

Role negotiation variables for stepparents at time 2 were correlated with changes in inter-role discrepancies between stepparents and parents, and stepparents and stepchildren, for both the warmth and control dimensions of the stepparent role. Results of these correlations are provided in Table 7.10. As illustrated in this table, stepparents' reports of role negotiation strategies at time 2 were not associated with any changes in inter-role discrepancies over time.

Table 7.10

Correlations between Role Negotiation Strategies for Stepparents at Time Two and Changes in Inter-Role Discrepancies over Time $(n=88)$

\begin{tabular}{|c|c|c|c|c|}
\hline \multirow[t]{2}{*}{ Strategies T2 } & \multicolumn{2}{|c|}{$\begin{array}{c}\text { BP_SP Discrepancies } \\
(n=85)\end{array}$} & \multicolumn{2}{|c|}{$\begin{array}{c}\text { SP_SC Discrepancies } \\
(n=84) \\
\end{array}$} \\
\hline & Warmth & Control & Warmth & Control \\
\hline Partner Talks & -.06 & -.02 & .09 & .04 \\
\hline Child Talks & -.12 & -.11 & .09 & -.04 \\
\hline Family Talks & .08 & -.19 & .19 & .07 \\
\hline Partner Check In & -.07 & .04 & .09 & -.10 \\
\hline Child Check In & -.14 & -.21 & .10 & -.01 \\
\hline Gate Keeping & .18 & .04 & .12 & .19 \\
\hline
\end{tabular}

\section{Summary}

These findings address Research Question 13 and indicate that there were few correlations between role negotiation in the last 12 months (time 2) and changes in inter-role discrepancies over time. This indicates that, in general, role negotiation does not lead to a reduction in inter-role discrepancies among stepfamily members. There was one exception to this: the extent to which biological parents report checking in with children over the last 12 months (time 2) was positively associated with increased discrepancies between biological parents and children over time. These findings appear to be contrary to suggestions that role negotiation is useful in improving role agreement between stepfamily members, and possible explanations for this finding are discussed in Chapter 8. 


\subsection{Longitudinal Analyses}

This section presents the results relating to stepfamily members intra and inter role discrepancy scores at time 1 and their view of stepfamily functioning, twelve months later (at time 2). Results regarding the actual stepparent role and stepfamily functioning are presented first (Research Question 4). This is followed by the presentation of the results for the association between intra-role discrepancies and stepfamily functioning (Research Question 7) and inter-role discrepancies and stepfamily functioning (Research Question 10).

\subsubsection{The Actual Stepparent Role and Stepfamily Functioning}

Distributions of scores were inspected and as a result, some outliers and extreme scores were adjusted for stepfamily functioning scores at time 2. These changes are provided in Appendix Q. Since many of the stepfamily functioning scores remained significantly skewed after re-coding the outliers, Spearman correlations were performed between warmth and control actual stepparent role scores for stepfamily members (at time 1) and their perceptions of stepfamily functioning (at time 2). These are provided in Table 7.11. Perceptions of the ideal role were not examined as this study was interested in how the stepparent's actual role behaviours at time 1 were associated with stepfamily functioning so that significant variables could be controlled statistically in subsequent regression analyses. 
Table 7.11

Correlations between the Actual Stepparent Role at Time One and Stepfamily Functioning at Time Two $(n=87)$

\begin{tabular}{lcccccc}
\hline Functioning T2 & \multicolumn{5}{c}{ Actual Stepparent Role Time 1 } \\
& \multicolumn{2}{c}{ Children } & \multicolumn{2}{c}{ Parents } & \multicolumn{2}{c}{ Stepparents } \\
& Warmth & Control & Warmth & Control & Warmth & Control \\
\cline { 2 - 7 } & & & & & & \\
Ch_RP RQ & $.34^{* *}$ & .01 & .09 & .10 & - & - \\
Ch_SP RQ & $.48^{* *}$ & .05 & - & - & $.38^{* *}$ & $.28^{*}$ \\
Partner RQ & - & - & .17 & .21 & .14 & .12 \\
Cohesion & $.36^{* *}$ & .01 & $.28^{* *}$ & $.33^{* *}$ & $.36^{* *}$ & $.31^{*}$ \\
Conflict & $-.26^{*}$ & .05 & -.20 & -.09 & -.08 & .05 \\
Self-Concept & $.29 * *$ & -.05 & - & - & - & - \\
Total Diff & -.15 & .14 & -.02 & .16 & -.09 & -.03 \\
\hline
\end{tabular}

These findings illustrate that the actual stepparent role was significantly associated with many aspects of stepfamily functioning at time 2. For children, the warmth dimension of the stepparent role was associated with all aspects of stepfamily functioning (except for total difficulties), while the control dimension was not. That is, the warmth dimension was positively associated with children's perceptions of the quality of their relationships with stepfamily adults, family cohesion and their selfconcept. In addition, the warmth dimension was negatively associated with family conflict.

For both parents and stepparents, the warmth and control dimensions were positively associated with their perceptions of family cohesion. In addition, the warmth and control dimensions for stepparents were positively associated with their perceptions of the quality of the stepparent-stepchild relationship.

These results address Research Question 4 and suggest that the actual stepparent role at time 1, particularly for the warmth dimension, is significantly associated with many aspects of stepfamily functioning twelve months later. This is particularly the case for children, where the actual stepparent role was more consistently associated with their perceptions of stepfamily functioning than for other stepfamily members. 


\subsubsection{Intra--Role Discrepancies and Stepfamily Functioning}

Correlations were performed between warmth and control intra-role discrepancy scores for each stepfamily member (at time 1) and measures of stepfamily functioning (at time 2), and these are provided in Table 7.12. In light of the significantly skewed nature of the role discrepancy and stepfamily functioning scores, Spearman correlations were used. Correlations represent the association between each individual's role discrepancy scores (for warmth and control) and their perception of stepfamily functioning. Results are presented separately for stepfamily adults and children.

Table 7.12

Correlations between Intra-Role Discrepancies at Time One and Stepfamily

Functioning at Time Two $(n=85)$

\begin{tabular}{lcccccc}
\hline $\begin{array}{l}\text { Stepfamily } \\
\text { Functioning T2 }\end{array}$ & \multicolumn{7}{c}{ Intra-Role Discrepancies Time 1 } \\
\hline \hline & Warmth & Control & Warmth & Control & Warmth & Control \\
& \multicolumn{7}{c}{ Children } & \multicolumn{7}{c}{ Parents } & & \\
Ch_RP RQ & $-.44^{* *}$ & $-.31^{*}$ & - & - & - & - \\
Ch_SP RQ & $-.27^{*}$ & $-.42^{* *}$ & - & - & $-.24^{*}$ & $-.43^{* *}$ \\
Partner RQ & - & - & -.04 & -.13 & -.10 & -.20 \\
Cohesion & -.13 & $-.30^{* *}$ & -.11 & -.13 & $-.32^{* *}$ & $-.48^{* *}$ \\
Conflict & $.35^{* *}$ & $.31^{* *}$ & .15 & .17 & .17 & .21 \\
Self-Concept & $-.34^{* *}$ & $-.33^{* *}$ & - & - & - & - \\
Total Diff & $.31^{* *}$ & $.29^{* *}$ & -.02 & -.05 & .04 & $.36^{* *}$ \\
\hline
\end{tabular}

\section{Adults' Intra-Role Discrepancies}

Overall, higher intra-role discrepancies for stepparents at time 1 were associated with less positive stepfamily functioning at time 2. In particular, stepparents with higher intra-role discrepancies on the warmth and control dimensions reported lower family cohesion and lower quality relationships with stepchildren. These associations were higher for those involving the control dimension than the warmth dimension. In addition, stepparents' intra role discrepancies for the control dimension were positively associated with higher levels of child difficulties at time 2 . 
There were no significant associations between parents' intra-role discrepancy scores at time 1 and their perceptions of stepfamily functioning at time 2 .

\section{Children's Intra-Role Discrepancies}

Similar to stepparents, higher intra-role discrepancies for stepchildren at time 1 were associated with less positive stepfamily functioning at time 2. For both the warmth and control dimensions of the stepparent role, higher intra role discrepancies (at time 1) were associated with lower quality stepparent-stepchild, parent-child relationships and self-concepts at time 2. Intra role discrepancies for both dimensions were also positively associated with family conflict and children's total difficulties at time 2. For the control dimension of the stepparent role, higher role discrepancies (at time 1) were negatively associated with family cohesion. For children, intra-role discrepancies for warmth and control dimensions were equally significantly associated with stepfamily functioning.

\section{Summary of Findings for Intra-Role Discrepancies}

These results address Research Question 7 and indicate that there were many significant correlations between intra-role discrepancy scores and stepfamily functioning, particularly for stepchildren. Higher intra-role discrepancy scores for stepchildren were

significantly associated with most aspects of stepfamily functioning. Similarly, higher role discrepancy scores for stepparents were associated with some aspects of adjustment, although not as many as for stepchildren. Intra-role discrepancies for both the warmth and control dimensions were equally significantly associated with stepfamily functioning although, for stepparents, correlations were higher for those involving the control dimension. These results indicate that greater discrepancies between actual and ideal stepparent roles are associated with perceptions of problematic functioning at time 2. This was not the case for parents, whose intra role discrepancies were not associated with any aspects of stepfamily functioning twelve months later.

\subsubsection{Inter-Role Discrepancies and Stepfamily Functioning}

Correlations were conducted between inter-role discrepancies scores (at time 1) for all possible combinations of stepfamily members and perceptions of stepfamily functioning (at time 2). Again, Spearman correlations were conducted in light of the skewed nature 
of the variables. Analyses are presented separately for stepparent-stepchild, parentstepparent and child-parent role discrepancies.

\section{Stepparent-Stepchild Role Discrepancy}

As illustrated in Table 7.13, there were no significant associations between stepparentstepchild discrepancy scores and stepfamily functioning.

Table 7.13

Correlations between Stepparent-Stepchild Inter-Role Discrepancies at Time One and Stepfamily Functioning at Time Two $(n=87)$

\begin{tabular}{lcc}
\hline Stepfamily Functioning T2 & \multicolumn{2}{c}{ SP_SC Ideal Role Discrepancy Time 1 } \\
\hline \hline & Warmth & Control \\
\cline { 2 - 3 } Family Cohesion (SP) & -.15 & .06 \\
Family Cohesion (SC) & -.20 & .05 \\
Family Conflict (SP) & .18 & -.04 \\
Family Conflict (SC) & .06 & -.06 \\
Child Difficulties (SC) & .02 & -.07 \\
Child Self-concept (SC) & -.12 & .04 \\
SP-SC RQ (SP) & -.18 & .03 \\
SP-SC RQ (SC) & -.14 & -.02 \\
\hline
\end{tabular}

$\mathrm{SC}=$ stepchild, $\mathrm{SP}=$ stepparent; $\mathrm{RQ}=$ relationship quality

\section{Stepparent-Parent Role Discrepancy}

As can be seen in Table 7.14, there were few significant correlations between stepparent-parent role discrepancies and stepfamily functioning. Discrepancies between stepparents and parents for both the warmth and control dimensions at time 1 were negatively associated with stepparents' reports of the quality of the stepparent-stepchild relationship, twelve months later. That is, the greater the difference between stepparents' and parents' views of ideal warmth and control behaviours, the lower stepparents' rated the quality of their relationship with the target stepchild. 
Table 7.14

Correlations between Stepparent-Parent Inter-Role Discrepancies at Time One and Stepfamily Functioning at Time Two $(n=89)$

\begin{tabular}{lcc}
\hline Stepfamily Functioning T2 & \multicolumn{2}{c}{ SP_BP Ideal Role Discrepancy Time 1 } \\
\hline \hline & Warmth & Control \\
\cline { 2 - 3 } Family Cohesion (SP) & -.17 & -.19 \\
Family Cohesion (BP) & .02 & -.13 \\
Family Conflict (SP) & .11 & .07 \\
Family Conflict (BP) & -.08 & .00 \\
Partner RQ (SP) & -.17 & -.10 \\
Partner RQ (BP) & .10 & .17 \\
SP-SC RQ (SP) & $-.26^{*}$ & $-.32^{* *}$ \\
\hline
\end{tabular}

\section{Parent-Stepchild Role Discrepancy}

As can be seen in Table 7.15, parent-child role discrepancies were associated with more aspects of stepfamily functioning, although only for warmth behaviours. Discrepancies between children and parents on the stepparent's ideal warmth behaviours were negatively associated with family cohesion and stepchildren's relationships with their resident parents and stepparents. That is, the greater the difference between children and parents' views of the ideal role (warmth) at time 1, the lower children rated family cohesion and the quality of their relationships with their resident parents and stepparents at time 2. In addition, discrepancies between parents and children (for the warmth dimension) at time 1 were associated with increased levels of family conflict at time 2 , as perceived by stepchildren. 
Table 7.15

Correlations between Parent-Child Inter-Role Discrepancies at Time One and Stepfamily Functioning at Time Two $(n=89)$

\begin{tabular}{lcc}
\hline Stepfamily Functioning T2 & & SC_BP Ideal Role Discrepancy Time 1 \\
\hline \hline & Warmth & Control \\
\cline { 2 - 3 } Family Cohesion (SC) & $-.33^{* *}$ & -.03 \\
Family Cohesion (BP) & -.07 & .09 \\
Family Conflict (SC) & $.25^{*}$ & .17 \\
Family Conflict (BP) & .09 & -.14 \\
Child Difficulties (SC) & .01 & -.05 \\
Child Self-concept (SC) & -.14 & .03 \\
SC_RP RQ (SC) & $-.33^{* *}$ & -.09 \\
SP-SC RQ (SC) & $-.33^{* *}$ & -.04 \\
\hline
\end{tabular}

\section{Summary of Findings for Inter-Role Discrepancies}

These results address Research Question 10 and indicate that greater inter-role discrepancies at time 1 are associated with less positive stepfamily functioning at time 2, particularly for the quality of the stepparent-stepchild relationship. Discrepancies between children and parents appear to have the greatest effect on stepfamily functioning, and stepchildren's views of stepfamily functioning were the most affected by inter-role discrepancies. Greater differences between children and their resident parents at time 1 were associated with children's perceptions of lower quality relationships with stepparents and parents, and lower levels of family cohesion. They were also associated with higher levels of family conflict. There were fewer positive associations found for discrepancies between stepparents and biological parents although discrepancies between stepfamily adults were associated with lower quality relationships between stepparents and stepchildren, as reported by stepparents. There were no significant associations found for discrepancies between stepparents and stepchildren and stepfamily functioning. In general it was discrepancies regarding the warmth dimension of the stepparent role that were more significantly associated with stepfamily functioning. 


\subsection{Summary}

As illustrated in the previous section, it is clear that role discrepancies are associated with a variety of aspects of stepfamily functioning, particularly for children. It is unclear however, which role discrepancies are making unique contributions to children's views of stepfamily functioning, after controlling for key variables. This section examines the association between children's inter and intra role discrepancies at time 1 and their functioning twelve months later in more detail, through a series of hierarchical regression analyses. These regression analyses allow for further examination in regard to which role discrepancies (i.e. intra or inter) are making significant unique contributions to children's adjustment. In addition, the children's perceptions of the stepparent's actual involvement in warmth and other key demographic and individual variables are statistically controlled where relevant.

\subsection{Multiple Regression Analyses}

A series of multiple regression analyses were performed in order to address Research Question 14. One of the prime aims of this analysis was to uncover which discrepancy scores for children were most important in predicting their assessments of stepfamily functioning twelve months later, once relevant demographic variables and actual stepparent involvement were controlled. The quality of children's relationships with parents and stepparents, and family functioning (e.g. cohesion and conflict) were included in regression analyses since they were significantly correlated with both intra and inter-role discrepancies for children. Children's total difficulties and self-esteem were not included in regression analyses since they were only associated with intra-role discrepancies, and not with inter-role discrepancies. It was envisaged that role discrepancies would have a greater effect on the quality of relationships and whole family functioning as opposed to children's individual functioning.

In order to establish which demographic/individual factors to control (of those highlighted in Figure 3.1), two sets of correlations were performed prior to the 
conduction of regression analyses. Demographic and individual variables (at time 1) were correlated with children's intra and inter role discrepancies at time 1 and with stepfamily outcome variables at time 2 . These analyses revealed that no demographic or individual variables were significantly correlated with both role discrepancies at time 1 and stepfamily functioning at time 2 ; therefore none were included in subsequent regression analyses. The results of these correlations are provided in Appendix V.

Children's perception of actual stepparent involvement in warmth was correlated with all outcome and role discrepancy variables and therefore was entered in step 1 in all subsequent regression analyses. Therefore, four hierarchical regression analyses were conducted with actual stepparent involvement (for the warmth dimension) entered in block 1. Role discrepancy variables were selected for regression analyses based on the results of the longitudinal correlations conducted previously. Prior to each analysis, preliminary analyses were conducted to ensure no violation of the assumptions of normality, linearity, multicollinearity and homoscedasticity.

\subsubsection{Family Cohesion}

Longitudinal correlations were inspected and as a result the role discrepancy scores entered into the regression analysis were children's intra role discrepancies for control (intra-control), and inter-role discrepancies between parents and children for the warmth dimension (BP_Ch Warmth). Hierarchical multiple regression was used to assess the ability of these two role discrepancy variables (at time 1) to predict children's views of family cohesion, twelve months later (time 2), after controlling for the stepparent's actual involvement in warmth behaviours.

Stepparents' actual involvement in warmth was entered at Step 1, explaining $15.2 \%$ of the variance in family cohesion. After entry of the three role discrepancy variables at Step 2 the total variance explained by the model as a whole was $22.7 \%$, F $(3,86)=8.40$; $\mathrm{p}=.00$. The two role discrepancy variables explained an additional $7.4 \%$ of the variance in family cohesion, after controlling for actual stepparent involvement in warmth. This contribution was significant: $\mathrm{R}$ squared change $=.074, \mathrm{~F}$ change $(2,86)=4.14, \mathrm{p}=.02$. The beta statistics indicate that a one unit increase in discrepancies between parents and children (for warmth) at time 1 is associated with a .25 unit decrease in family cohesion 
at time 2. The results of the individual contributions of each of these variables in predicting Family Cohesion is provided in Table 7.16.

Table 7.16

Multiple Regression Summary Table for Family Cohesion ( $n=87$ )

\begin{tabular}{lcccccc}
\hline Predictor & \multicolumn{3}{c}{ Model 1 } & \multicolumn{3}{c}{ Model 2 } \\
\hline & Beta & $\mathrm{t}$ & $\mathrm{P}$ & $\mathrm{Beta}$ & $\mathrm{t}$ & $\mathrm{P}$ \\
\cline { 2 - 7 } Control Variable & & & & & & \\
Actual-Warmth & .39 & 3.98 & .00 & .22 & 1.90 & $\mathrm{NS}$ \\
$\begin{array}{l}\text { Role Discrepancies } \\
\text { Intra-Control }\end{array}$ & & & & & & \\
BP-Ch Warmth & & & -.17 & -1.70 & $\mathrm{NS}$ \\
& & & -.25 & -2.29 & .03 \\
& $\mathrm{R}^{2}=.15, \mathrm{~F}(1,88)=15.80^{* *}$ & $\mathrm{R}^{2}=.23, \mathrm{~F}(3,86)=8.40^{* * *}$ \\
\hline
\end{tabular}

${ }^{*} P<.05,{ }^{* *} P<.01$

\subsubsection{Family Conflict}

Longitudinal correlations were inspected and as a result the role discrepancy variables entered into the regression analysis were children's intra-role discrepancies for control and warmth, and inter-role discrepancies between parents and children for the warmth dimension. Hierarchical multiple regression was used to assess the ability of these three role discrepancy variables (at time 1) to predict children's' views of family conflict, twelve months later (time 2), after controlling for stepparents' involvement in warmth.

Actual stepparent warmth was entered at Step 1, explaining 5.6\% of the variance in family conflict. After entry of the three role discrepancy variables at Step 2 the total variance explained by the model as a whole was $18.6 \%, F(4,85)=4.86 ; \mathrm{p}=.001$. The three role discrepancy variables explained an additional $13 \%$ of the variance in family conflict, after controlling for actual stepparent involvement in warmth, $\mathrm{R}$ squared change $=.13, \mathrm{~F}$ change $(3,85)=4.53, \mathrm{p}=.005$. In the final model, children's intra-role discrepancies for warmth and inter-role discrepancies between parents and children (for warmth) were significant predictors of family conflict. The beta statistics indicate that a one unit increase in children's intra-role discrepancy for warmth at time 1 is associated with a .28 unit increase in family conflict at time 2, as reported by children. In addition, a one unit increase in inter-role discrepancies between parents and children (for warmth) 
at time 1 is associated with a .26 increase in family conflict at time 2 . The results of the individual contributions of each of these variables in predicting Family Conflict are provided in Table 7.17.

Table 7.17

Multiple Regression Summary Table for Family Conflict $(n=89)$

\begin{tabular}{lcccccc}
\hline Predictor & \multicolumn{3}{c}{ Model 1 } & \multicolumn{3}{c}{ Model 2 } \\
\hline \hline & & & & & \\
& Beta & $\mathrm{t}$ & $\mathrm{P}$ & Beta & $\mathrm{t}$ & $\mathrm{P}$ \\
\cline { 2 - 7 } $\begin{array}{l}\text { Control Variables } \\
\text { Actual-Warmth }\end{array}$ & -.24 & -2.28 & $.03^{*}$ & -.02 & -.16 & $\mathrm{NS}$ \\
$\begin{array}{l}\text { Role Discrepancies } \\
\text { Intra-Control }\end{array}$ & & & & & & \\
Intra-Warmth & & & .06 & .50 & $\mathrm{NS}$ \\
BP-Ch Warmth & & & .28 & 2.24 & $.03^{*}$ \\
& & & .26 & 2.26 & $.03^{*}$ \\
& & & & & \\
& $\mathrm{R}^{2}=.06, \mathrm{~F}(1,88)=5.20^{*}$ & $\mathrm{R}^{2}=.19, \mathrm{~F}(4,85)=4.86^{* *}$ \\
\hline
\end{tabular}

\subsubsection{Quality of Stepparent - Stepchild Relationship}

Longitudinal correlations were inspected and as a result the role discrepancy variables entered into the regression analysis were children's intra-role discrepancies for warmth and control and inter-role discrepancies between parents and children for the warmth dimension. Hierarchical multiple regression was used to assess the ability of these three role discrepancy variables (at time 1) to predict children's views of the quality of the stepparent-stepchild relationship, twelve months later (time 2), after controlling for stepparent's actual warmth.

Stepparents' actual warmth was entered at Step 1, explaining $21 \%$ of the variance in stepparent-stepchild relationship quality. After entry of the three role discrepancy variables at Step 2 the total variance explained by the model as a whole was $34 \%, \mathrm{~F}$ (4, $85)=10.93 ; \mathrm{p}=.000$. The three role discrepancy variables explained an additional $13 \%$ of the variance in stepparent-stepchild relationship quality, after controlling for stepparent's actual involvement in warmth, R squared change $=.13$, F change $(3,85)=$ $5.58, \mathrm{p}=.002$. In the final model, only intra-control (beta $=-.37 ; \mathrm{p}=.001)$ and actual warmth (beta $=.29 ; \mathrm{p}=.01$ ) were statistically significant. The beta statistics indicate 
that a one unit increase in children's intra-role discrepancy for control at time 1 is associated with a .37 unit decrease in stepparent-stepchild relationship quality at time 2 . In addition, a one unit increase in stepparent's actual warmth at time 1 is associated with a .29 unit increase in the quality of the stepparent-stepchild relationship at time 2 . The results of the individual contributions of each of these variables in predicting stepparentstepchild relationship quality are provided in Table 7.18.

Table 7.18

Multiple Regression Summary Table for Stepparent-Stepchild Relationship Quality

\begin{tabular}{|c|c|c|c|c|c|c|}
\hline \multirow[t]{2}{*}{ Predictor } & \multicolumn{3}{|c|}{ Model 1} & \multicolumn{3}{|c|}{ Model 2} \\
\hline & Beta & $\mathrm{t}$ & $\mathrm{P}$ & Beta & $\mathrm{t}$ & $\mathrm{P}$ \\
\hline \multicolumn{7}{|c|}{ Control Variables } \\
\hline Actual-Warmth & .46 & 4.83 & .00 & .29 & 2.75 & .01 \\
\hline \multicolumn{7}{|c|}{ Role Discrepancies } \\
\hline Intra-Control & & & & -.37 & -3.32 & .00 \\
\hline Intra-Warmth & & & & .05 & .42 & NS \\
\hline \multirow[t]{2}{*}{ BP-Ch Warmth } & & & & -.15 & -1.46 & NS \\
\hline & \multicolumn{3}{|c|}{$\mathrm{R}^{2}=.21, \mathrm{~F}(1,88)=23.33 * *$} & \multicolumn{3}{|c|}{$\mathrm{R}^{2}=.34, \mathrm{~F}(4,85)=10.93 * *$} \\
\hline
\end{tabular}

\subsubsection{Quality of Biological Parent - Child Relationship}

Longitudinal correlations were inspected and as a result the role discrepancy variables entered into the regression analysis were children's intra-role discrepancies for warmth and control, and inter-role discrepancies between parents and children for the warmth dimension. Multiple regression was used to assess the ability of these three role discrepancy variables (at time 1) to predict children's views of the quality of their relationship with their biological parent twelve months later (time 2), after controlling for stepparents' involvement in warmth at time 1.

Stepparents' actual warmth was entered at Step 1, explaining $8.8 \%$ of the variance in parent-child relationship quality. After entry of the three role discrepancy variables at Step 2 the total variance explained by the model as a whole was $24.8 \%, F(4,84)=6.92$; $\mathrm{p}=.000$. The three role discrepancy variables explained an additional $16 \%$ of the 
variance in parent-child relationship quality, after controlling for stepparents actual warmth: $\mathrm{R}$ squared change $=.16, \mathrm{~F}$ change $(3,84)=5.95, \mathrm{p}=.00$. When the individual contributions of the role discrepancies were inspected, children's intra-role discrepancies for warmth (beta $=-.31 ; \mathrm{p}=.01$ ) and parent-child inter-role discrepancy for warmth (beta $=-.36 ; \mathrm{p}=.00$ ) were statistically significant predictors of the quality of the parent-child relationship at time 2 . The beta statistics indicate that a one unit increase in children's intra-role discrepancies for warmth at time 1 is associated with a .31 unit decrease in parent-child relationship quality at time 2 . In addition, a one unit increase in discrepancies between parents and children (for warmth) at time 1 is associated with a .36 unit decrease in parent-child relationship quality at time 2 . The results of the individual contributions of each of these variables in predicting parent-child relationship quality are provided in Table 7.19.

Table 7.19

Multiple Regression Summary Table for Parent-Child Relationship Quality

\begin{tabular}{|c|c|c|c|c|c|c|}
\hline \multirow[t]{2}{*}{ Predictor } & \multicolumn{3}{|c|}{ Model 1} & \multicolumn{3}{|c|}{ Model 2} \\
\hline & Beta & $\mathrm{t}$ & $\overline{\mathrm{P}}$ & Beta & $\mathrm{t}$ & $\overline{\mathrm{P}}$ \\
\hline \multicolumn{7}{|l|}{ Control Variables } \\
\hline Actual-Warmth & .30 & 2.90 & $.00 * *$ & .04 & .38 & NS \\
\hline \multicolumn{7}{|l|}{ Role Discrepancies } \\
\hline Intra-Control & & & & .03 & .25 & NS \\
\hline Intra-Warmth & & & & -.31 & -2.63 & .01 \\
\hline \multirow[t]{2}{*}{ BP-Ch Warmth } & & & & -.36 & -3.26 & .00 \\
\hline & \multicolumn{3}{|c|}{$\mathrm{R}^{2}=.09, \mathrm{~F}(1,87)=8.39 * *$} & \multicolumn{3}{|c|}{$\mathrm{R}^{2}=.25, \mathrm{~F}(4,84)=6.92 * *$} \\
\hline
\end{tabular}

$N=89$

${ }^{*} P<.05,{ }^{* *} P<.01$

Summary of Regression Analyses

These results addressed Research Question 14 and indicate that children's role discrepancies were significant predictors of the quality of their relationships with their stepparents and parents, and their perceptions of family functioning twelve months later. 
Increased role discrepancies between children and parents for the warmth dimension had a negative effect on the quality of children's relationships with their biological parents, family cohesion and conflict. That is, role discrepancies between parents and children significantly predicted lower quality relationships between children and their biological parents, lower levels of family cohesion and higher levels of family conflict, as perceived by target stepchildren.

Children's intra-role discrepancies were also important predictors of children's assessments of stepfamily functioning twelve months later. They were found to be significant predictors of the quality of their relationship with stepparents and parents, and their assessments of family conflict. In particular, increased intra-role discrepancies for the control dimension predicted a decrease in stepparent-stepchild relationship quality, and increased discrepancies for the warmth dimension predicted a decrease in parent-child relationship quality. Increased intra-role discrepancies for the warmth dimension also predicted an increase in children's perceptions of family conflict. Children's intra role discrepancies were not, however, significant predictors of family cohesion, above what could be explained by inter-role discrepancies between parents and children, and after stepparent's actual involvement in warmth was statistically controlled. These findings suggest that both inter and intra role discrepancies are important predictors of stepfamily functioning for children, and that they may be associated with different aspects of functioning. 


\section{DISCUSSION}

\section{Chapter Eight}

\section{Discussion of Findings}

This chapter discusses the key findings of this study, and relates it to previous research and clinical recommendations regarding the stepparent role. This concludes with a discussion of the strengths and limitations of the study and implications for policy and future research.

\subsection{Overview of Main Findings}

This research sought to examine the association between a variety of stepparent role variables and stepfamily functioning over time. Both cross-sectional and longitudinal date were used to answer a number of research questions, and multiple stepfamily members completed questionnaires regarding role perceptions so that comparisons could be made among stepfamily members.

These analyses revealed several key findings:

1. Stepparents, biological parents and children viewed the stepparent role in different ways.

2. Individual perceptions of the stepparent role did not change over the twelve month period, although role discrepancies did. When changes did occur, role discrepancy scores (for both intra and inter) decreased over time.

3. Individual perceptions of the stepparent role and role discrepancies were associated with aspects of stepfamily functioning, twelve months later.

4. Intra-role discrepancies had more significant effects on stepfamily functioning over time, than discrepancies among stepfamily members (inter-role discrepancies; although, 
5. Discrepancies between parents and children (for the warmth dimension) were associated with aspects of stepfamily functioning.

6. Role discrepancies (both intra and inter) were associated with children's assessments of stepfamily functioning above what could be explained by stepparents actual parenting involvement.

7. Stepfamily members used a variety of strategies to negotiate the stepparent role, and they were more likely to use some of these strategies when stepfamily functioning was more problematic at time 1.

8. Role negotiation strategies were associated with some improvements in stepfamily functioning over time, although they were not associated with improvements in inter-role discrepancies. The reverse was true for gate keeping behaviours, which was associated with a decrease in the quality of the relationship between stepparents and stepchildren over time.

The remainder of this thesis will discuss these key findings, with reference to previous research and clinical evidence and the policy implications of these findings. Prior to this discussion, an overview of the stepfamily outcomes is presented.

\subsection{Overview of Stepfamily Outcomes}

Overall, stepfamily members reported positive functioning in their families. Positive functioning was reflected at individual, relationship and whole family functioning levels. Firstly, stepparents and parents reported high quality relationships with one another, although parents rated the quality of this relationship as higher than stepparents. It is possible that stepparents may assess their relationships with their partner more negatively due to the anxieties they experience in establishing relationships with stepchildren while simultaneously maintaining a close relationship with their partner. These anxieties, particularly in the early stages, may lead stepparents to view their relationships as less positive when compared to the biological parents' perception of the same relationship.

Secondly, children reported high quality relationships with the parental figures in their lives. That is, they reported high quality relationships with their biological parents and 
stepparents, although relationships with biological parents were reported to be of higher quality than relationships with stepparents. These findings are similar to other research on New Zealand stepchildren (e.g. Pryor, 2004) that has found children's assessments of relationships with stepparents to be more negative than relationships with biological parents. However, it is important to note that in neither study were relationship quality scores low and there were no indications that stepparent-stepchild relationships were overly problematic. Therefore, while the development of the stepparent-stepchild relationship may be initially challenging, the majority of stepparents in this study were able to build a reasonably satisfactory relationship with their stepchildren.

Children, however, rated the quality of this relationship as higher than their stepparents did. Similar findings were reported by Pryor (2004) who found that children assessed the quality, closeness and security of their relationships with stepparents higher than did their stepparents. This could indicate actual differences in perceptions of relationship quality, or may be due to stepparents actually acting in more positive ways towards stepchildren than stepchildren acted towards them. The relationship quality measure examined the degree to which the other person acted in positive and negative ways towards them. Stepparents may be more likely to engage in positive behaviours due to a desire to form a close relationship with stepchildren or in response to their partner's encouragement regarding the importance in building a close and mutually supportive relationship with their stepchildren. In a study by Ganong and colleagues (1999) stepparents reported engaging in a variety of affinity seeking behaviours in order to develop a positive relationship with stepchildren, despite the fact that these behaviours were often not reciprocated by their stepchildren.

Stepfamily members reported high levels of family cohesion and low levels of family conflict, although children rated these family dynamics more negatively than their parents. Pryor (2004) also found that children viewed family dynamics more negatively than stepfamily adults, rating aspects of family functioning such as cohesion and expressiveness lower than both parents and stepparents. While these findings may indicate substantive differences between the views of adults and children, they may also be due to younger children providing a more accurate portrayal 
of family dynamics due to less social desirability bias. In contrast to children, adults may be more motivated to present their family like an 'ordinary' family, and so report close relationships between family members and low levels of conflict.

Although stepchildren endorsed a healthy self-concept and frequent engagement in positive behaviours, they also reported a number of adjustment difficulties. Children's total difficulties across behavioural, emotional, and social domains were higher than the norms provided for the SDQ, based on Australian children aged seven to fourteen. However, scores for the SDQ were comparable to those found by Pryor (2004) in her community study of seven to eleven year old children in stepfamilies. Therefore, these findings may support those of previous researchers that children in stepfamilies, especially in the early years, are at increased risk for adjustment problems than children in other families (Hetherington \& Jodl, 1994; Kiernan 1992; Pryor \& Rodgers 2001). Additionally, the higher adjustment problems in these studies may be due to the younger age of the children, although it might be expected that children aged 7 to 14 would show higher difficulties as they are closer to adolescence where more difficulties are generally reported.

\subsection{Research Questions}

This research addressed a number of research questions, using both cross-sectional and longitudinal data. This section will discuss the findings in relation to the research questions outlined in Chapter 4.

\subsubsection{Perceptions of the Actual and Ideal Stepparent Role}

When stepfamily members were asked to report on the label they would use to describe the actual role of the stepparent, there were some discrepancies among stepfamily members. While the stepparent label was most commonly selected by adults to describe the actual stepparent role, stepchildren were more likely to describe the role as like a parent. Children were also more likely to describe the ideal stepparent role as like a parent, although discrepancies for the ideal role were less apparent that for the actual role. In addition, children were much less likely than adults to describe the stepparent role as similar to their mum or dads partner. 
These findings suggest that while adults report similar labels to describe the stepparent role, children view the stepparent role differently. That is, children in this study were more likely to view their stepparent as currently acting like a parent, and furthermore, described this as the ideal role. These findings are slightly different to those reported in other studies which highlight a preference by stepchildren for stepparents to be friends to them rather than acting as parents; in contrast to stepfamily adults who are more likely to want stepparents to perform a parental role (Buchanon \& Maccoby, 1996; Fine et al., 1998). However, there were some differences between the current study and that conducted by Fine and colleagues, in that this study measured the stepparent role with reference to both singular and combination labels; whereas Fine and colleagues only measured single labels. These measurement differences ensure that differences between the two studies need to be regarded with caution.

These different findings could be explained by the age differences in stepchildren between these studies. While Fine and colleagues (1998) collected data from early adolescents with an average age of fourteen years, this study examined role perceptions of younger stepchildren, with an average age of nine years old. In further support for this explanation, the current findings are similar to those reported by Dunn and Deater-Deckard (2001) who also found that younger stepchildren (aged between 7 and 15) were more likely to describe the ideal stepparent role as a parent. Therefore, these findings may be in line with clinicians and researchers who have suggested that younger children may more readily accept the stepparent in a parental role when compared to their adolescent counterparts (Bray, 1999; Hetherington, 1993; Hetherington \& Clingempeel, 1992; Rosin, 1987; Visher \& Visher, 2003).

There are several possible reasons to explain this finding. First, older stepchildren may not want their stepparent to be a parental figure in their lives, because of their age. This idea had been suggested by stepfamily researchers (eg Hetherington et al., 1982) who have suggested that the most difficult age for a stepparent to be integrated into the household is when the stepchild is aged between ten and fifteen. It may be easier for stepchildren to accept the stepparent as a disciplinarian figure when they are younger when the stepparent enters the household (Rosin, 1987, Visher \& Visher, 2003) and 
children older than fifteen may view the entrance of a stepparent positively as it relieves them of concerns for their biological parent as they prepare to leave the home (Hetherington et al., 1982).

Second, younger stepchildren may be more likely to describe the stepparent role as a parental figure as it is a more familiar term, in contrast to other role labels, such as 'mum/dads partner.' The term 'parent' might, for younger children, simply represent the relationship between adult and child, especially when they live together. In contrast, older adolescents and adults might have the cognitive maturity to consider the subtle nuances in labels to describe parental roles. Similar explanations have been provided by Fine and colleagues (1998) who suggest that differences in labels selected by stepchildren and adults may be due to the fact that these labels may hold different meanings for stepchildren and adults. This is one of the main reasons why stepparent role labels were examined in addition to perceptions regarding the appropriateness of stepparent parenting behaviours. Findings regarding stepparent role behaviours will be discussed in section 8.3.3. In the following section, the association between stepparent role labels and behaviours is discussed.

\subsubsection{Role Labels and Role Behaviours}

Stepparent role labels were initially studied by researchers, based on the assumption that these labels were associated with different levels of involvement in parenting behaviours. For example, the parent role was considered to be associated with more involvement in warmth and control behaviours than the labels of stepparent or friend (Fine et al., 1998; Visher \& Visher, 1988). The results of the current study support these assumptions, and indicate that the parent label is associated with higher involvement in warmth and control parenting behaviours than the partner label. As hypothesised, the stepparent label was associated with moderate involvement in warmth and control behaviours, with levels in between those for parent and partner. Unfortunately, the friend label could not be examined since there were insufficient singular cases for this label. So, while this study provides some confirmation that stepparent role labels are associated with different level of involvement in parenting behaviours, further studies using larger samples are needed to replicate these results. 


\subsubsection{Perceptions of Stepparent Role Behaviours}

Perceptions of stepparents' involvement in a variety of parenting behaviours were examined. The results confirm that many stepparents play an involved parenting role in their stepchildren's lives. Stepparents were involved in both the warmth and control aspects of parenting (actual role) and family members wanted them to be involved in these domains (ideal role). Stepparents were involved in a range of behaviours; including providing emotional and financial support and help with daily child care (warmth dimension) and involvement in providing discipline, monitoring behaviours and social guidance (control dimension). As previously mentioned, the examination of specific behaviours of the stepparent role is one of the advantages of this study since previous researchers have tended to examine the stepparent role in reference to broad attitudes (Mason et al., 2002), such as whether stepparents should have equal roles to that of a biological parent, without examination of the perceived appropriateness of the specific behaviours performed by the stepparent.

Although this study did not include comparative data from family members in first families, the results do not support the view that stepparents play an uninvolved role in the parenting of their stepchildren (Cooksey \& Fondell, 1996; Hetherington \& Clingempeel, 1992; Fisher et al., 2003; Shucksmith, 1995), or are disengaged from stepchildren (Hetherington \& Jodl, 1994). In contrast, these findings are in accordance with studies that highlight the involved role of stepparents in a variety of parental behaviours (Ahrons \& Wallisch, 1987; Funder, 1996; Smith et al., 2001) such as warmth and control parenting behaviours (Fine et al., 1998). As noted earlier, an important variable is the age of the stepchild in the stepfamily, since the majority of research has found that stepparents are less involved in the parenting of their adolescent stepchildren. The reasons for this are twofold - younger children call for more immediate parenting on a day to day level, and adolescent children are likely to resist stepparents' parenting efforts, partly as an expression of the general developmental need for teenagers to develop independence.

These findings conflict with research indicating that the general public believe that stepparents should be less involved in parenting behaviours than biological parents. 
For example, studies examining societal attitudes regarding the stepparent role support the view that stepparents are expected to engage less frequently in supportive and disciplinary parental behaviours (Claxton-Oldfield, 1992; Schwebel et al., 1991). While these studies were carried out more than ten year ago, they do suggest a disjuncture between societal views concerning stepfamilies, and the actual behaviours of stepparents as reported by those living in stepfamilies. These divergences highlight the need for stepfamily research to continue to study stepfamily dynamics from the perspectives of stepfamily members as they may be the most accurate reporters of the internal dynamics within their families. They suggest, too, the need for alignment between social attitudes and the day to day realities of stepfamily living.

These high rates of stepparent involvement may, too, reflect the increased involvement of stepparents in their stepchildren's lives. Ferri and Smith (1998) compared the involvement of stepfathers across two generations in the United Kingdom and found that men in the latest generation expected, and wanted, to be more involved than those in the first generation (Pryor, 2004). Other research suggests that father involvement, in all family types, has changed considerably in the last twenty years, with participation in childcare increasing significantly (Lamb \& Tamis-Lemonda, 2004; Pleck, 1997). Some researchers have suggested that the last twenty years has witnessed an expansion of the roles of fathers in children's lives, a period that has been termed the 'androgynous' period (Edgar \& Glezer, 1992). This period may have been partially stimulated by women's increased entrance into the workforce, and has led to a broadening of the expectations encompassed within the 'father' role (Belsky, 1993; Greif, 1995; Rustia \& Abbott, 1993).

In addition, these results could reflect the fact that's stepfamilies are becoming increasingly socially recognized, or 'institutionalized' (Cherlin, 1978) in our society. As the proportion of children living in stepfamilies has increased there are likely to be clearer guidelines regarding how stepparents should best parent their stepchildren (Cherlin, 2004). This is further supported by research studies that have found the concept of 'family' to be more fluid and less determined by biological status (Anyan \& Pryor, 2002; Rigg \& Pryor, 2006; Schmeeckle et al., 2006) when compared to perceptions of family in less recent times. This shift in societal perceptions might lead 
to higher recognition of non-biological parents (e.g. stepparents) in children's lives and contribute to the development of more normative behaviours for the stepparent role.

\subsection{Discrepancies in Perceptions of the Stepparent Role}

In addition to individual role perceptions held by stepfamily members, this study examined the extent to which role discrepancies were associated with stepfamily functioning over time. Findings relating to two types of role discrepancies (intra-role and inter role discrepancies) are discussed in the following section.

\subsubsection{Intra-Role Discrepancies}

Stepfamily members reported on the actual and ideal parenting behaviours of the stepparent to enable a comparison of how the stepparent role is currently functioning (actual stepparent role), with how the stepparent role should function (ideal stepparent role). The importance of examining both of these components was originally conceptualised by Fine and colleagues (1997) and continued in their later studies (Fine et al., 1998, 1999). Fine and colleagues were among the first researchers to go beyond discussing the importance of role discrepancies to examining empirically the association between role discrepancies and stepfamily functioning. Similar to the findings of Fine and colleagues (1998), this study found differences between perceptions of the actual and ideal stepparent role, and these differences were evident across both warmth and control dimensions.

One of the notable findings in this study was that the nature of these discrepancies was different for stepchildren and stepfamily adults. Stepparents and parents wanted stepparents to play a more involved role in warmth and control parenting behaviours than they actually were. However, this was not the case for stepchildren where results differed for the warmth and control dimensions of the stepparent role. While stepchildren reported wanting stepparents to be more involved in warmth behaviours than they actually were, the opposite was found for control behaviours - where they wanted them to be less involved in these behaviours. 
These findings are consistent with research that highlights the discrepancies between stepfamily adults and stepchildren regarding appropriate stepparent behaviours. For example, an examination of the mean scores presented by Fine and colleagues (1998) suggest that stepchildren (in contrast to parents and stepparents) did not want stepparents to be more involved in control behaviours than they actually were, although they were happy for them to be more involved in warmth behaviours. One aspect of control behaviours is discipline, which is frequently described to be a contentious issue in stepfamilies. Researchers and clinicians generally concur that stepparent involvement in discipline may be challenging for stepchildren (Lutz, 1983; Pryor, 2004) since they may find it difficult to adjust to another adult figure involved in a disciplinary role. Consequently, many clinicians suggest that stepparents need to become gradually involved in disciplinary behaviours, and to initially focus on forming a friendly relationship with stepchildren (Mills, 1984; Visher \& Visher, 1988). These findings, therefore, may highlight a feature of stepfamily life that has been commonly supported by research and clinical accounts - that stepchildren find their stepparent's involvement in disciplinary behaviours challenging.

As previously mentioned, this study extends current understandings of the stepparent role by examining the views of younger stepchildren, rather than adolescents. In relation to disciplinary behaviours, the age of stepchildren may be an important factor since there may be key differences between younger stepchildren's and adolescents' acceptance of stepparent discipline, with younger stepchildren more accepting of these behaviours since they are not at a developmental age where challenging parental authority is common. They also might be more likely to form close bonds with stepparents (Bray, 1999; Hetherington, 1993; Hetherington \& Clingempeel, 1992; Rosin, 1987, Visher \& Visher, 2003), thus allowing stepparents to become more involved in disciplinary behaviours. This study is one of the first to suggest that younger stepchildren, like their adolescent counterparts, hold different views regarding their stepparent's involvement in the control dimension of parenting, such as involvement in disciplinary behaviours.

A possible explanation for these findings is that children may want parents to be more involved in warmth (the positive aspects) and less involved in control (the negative 
aspects) whether parents are step or biological parents. For example, Fine and colleagues (1998) have suggested that discrepancies between stepfamily members may be explained due to stepchildren holding different views from adults about what should be done in families, regardless of family structure. If this is the case, there may be nothing intrinsic to the stepfamily that leads to different views between children and adults. Rather, views relating to control behaviours, such as discipline, may be more reflective of children's reluctance to be disciplined by adults, and may not be unique to stepfamilies. At present, however, there has been no published research that examines children's views in first families, and whether they also want parents to be less involved in control behaviours than warmth behaviours.

There are several indications, however, that these findings might not be solely explained by children's reluctance for parents, whether step or otherwise, to be involved in control behaviours. Firstly, stepchildren frequently asserted during data collection that control behaviours, particularly active disciplinary behaviours, were to be performed by biological parents, not stepparents, thus indicating a preference for stepparents to be less involved in these behaviours than biological parents. This point was alluded to in a study conducted by Cartwright and Seymour (2002) who found that stepchildren often preferred biological parents to remain their primary disciplinarian. Other researchers have emphasised the ambivalence and conflict experienced by children, and biological parents, when stepparents become prematurely involved in active disciplinary behaviours (Bray, 1999; Cartwright, 2000; Funder, 1996; Mills, 1984; Moore \& Cartwight, 2005; Visher et al., 2003). Findings of this nature suggest that stepchildren hold different views regarding their stepparent's involvement in discipline when compared to biological parent's involvement. However, comparison studies using larger samples which measure stepchildren's views of stepparents and biological parents in the same families could be conducted to better examine this possibility.

\subsubsection{Inter-Role Discrepancies}

Stepfamily members' views of the ideal stepparent role were compared to better understand whether stepfamily members hold different views regarding ideal stepparent role behaviours. When comparing stepfamily members' views, results 
revealed a similar pattern across both the warmth and control domains. While all stepfamily members reported ideally wanting stepparents to be involved in both warmth and control behaviours, children wanted them to be the least involved, parents the most, and stepparents were somewhere in the middle.

However, although there were differences between stepfamily members in ideal views, all stepfamily members reported wanting stepparents to be involved in both warmth and control aspects of parenting. In fact, stepfamily members reported that stepparents were, and should be, more involved in control related behaviours than warmth behaviours. This finding appears somewhat inconsistent with previous contentions that involvement in control behaviours may be difficult for stepparents to perform, and might be best left for the biological parent, at least in the early years. For example, Kurdek \& Fine (1992) found that an adjunctive parenting style where stepparents support their partner in their parenting and engage in monitoring, rather than active disciplinary, behaviours was the most effective in newly formed stepfamilies. However, as mentioned previously, it is important to note that the current study measured control behaviours, of which disciplinary behaviours was only one component. Therefore, it does not necessarily follow that stepfamily members want stepparents to be more involved in disciplinary behaviours than warmth behaviours. Rather, they may want stepparents to be more involved in the other aspects of control that were measured - monitoring and social guidance behaviours. Future research could separate these sub-dimensions to better explore this finding.

The differences among stepfamily members' regarding the ideal stepparent role are consistent with stepfamily literature that identifies biological parents as actively encouraging stepparent involvement; in contrast to stepchildren who may prefer stepparents to be less involved in a parental role than their parents. Many researchers and clinicians have emphasised that this active encouragement by biological parents may lead to conflict with their children, who may prefer biological parents to retain primary parenting responsibility, particularly for discipline (Bray, 1999; Cartwright, 2000; Cartwright \& Seymour, 2002; Moore and Cartwright; Funder, 1996) and prefer their parents to encourage their stepparents to do so. Biological parents may do this for a variety of reasons, such as a desire to encourage parenting assistance after exhaustion 
from the single parent phase (Hetherington \& Kelly, 2002), or to be seen as an 'ordinary' family with two involved parental figures (Levin, 1997). Despite these suggestions, many stepfamily researchers and clinicians have emphasised the value in biological parents remaining the primary parenting figure in the initial stages of stepfamily life (Bray, 1999; Mills, 1984; Cartwright, 2000; Cartwright \& Seymour, 2002; Funder, 1996; Moore and Cartwight; 2005; Visher \& Visher, 2003).

These results suggest that stepparents want to be less involved in role behaviours than their partners want them to be. Stepparents may be more conscious of the most appropriate parenting behaviors to exercise as they are personally implementing this role and therefore more conscious of how these behaviours are received by stepchildren. Therefore, while they may want to perform a more involved role than they currently are, they may be more aware of the constraints affecting the enactment of a more involved parenting role and may tailor their expectations to reflect more realistic goals. This is suggested by Fine and colleagues (1998) who found that stepparents were less certain of the most appropriate parenting behaviours than biological parents or stepchildren. Other researchers have suggested that stepparents are more aware of the complexities and ambiguities inherent in their role (Fine \& Kurdek, 1994b; Fine, Coleman \& Ganong, 1999), since they constantly have to modify their behaviours with their stepchildren. In support of this, many stepparents in the current study commented that although they would like to function in a parental role with stepchildren, they were aware that this might not be well received by their stepchildren.

The finding that biological parents want their partners to be more involved in parenting behaviours than other stepfamily members is in contrast to research findings that parents engage in gate keeping behaviours. There is some previous research to suggest that biological parents (particularly mothers) gate keep or restrict access to their children, particularly in the early stages of stepfamily life (Bray \& Kelly, 1998; Coleman, Ganong \& Weaver, 2001; Erera-Wetherley, 1996; Ganong \& Coleman, 2004; Marsiglio, 2004). In support of this, this study found evidence of moderate involvement in gate keeping behaviours at both stages of data collection; that is, both parents and stepparent reported that the biological parent acted in ways that potentially 
interfere with the development of an independent relationship between stepparents and children.

Although evidence for biological parents' gate keeping behaviours may appear to conflict with their desire for their partner to be actively involved, the two may not be mutually exclusive. For instance, parents in stepfamilies might engage in behaviours that serve to control or restrict the stepparent's interactions with their children, while simultaneously wanting their partners to eventually undertake an involved parenting role once stepfamily relationships become more established. In separate analyses not described here, these two factors were found to be only moderately correlated, thus indicating that gate keeping and ideal stepparent role behaviours were not mutually exclusive. This finding may offer additional insight regarding how gate keeping behaviours are conceptualised across both the empirical and clinical spheres.

\subsection{The Stepparent Role and Stepfamily Functioning}

To better understand the importance of stepparent role perceptions on stepfamily functioning, associations were examined between stepparent role perceptions at time one and stepfamily functioning twelve months later. Regression analyses were then performed to examine the unique importance of inter and intra-role discrepancies in predicting children's perceptions of stepfamily functioning over time. While many stepparent role discrepancies were found to be correlated with stepfamily functioning variables, only some role discrepancies actually predicted children's perceptions of stepfamily functioning after key variables were taken into account. Results relating to the correlations between stepparent role variables and stepfamily functioning are discussed first, followed by results of the regression analyses performed.

\subsubsection{The Actual Stepparent Role}

The degree to which stepparents are involved in warmth and control behaviours was positively associated with many aspects of stepfamily functioning twelve months later. Involvement in warmth behaviours was associated with most aspects of children's perceptions of stepfamily functioning, although control behaviours were not associated with aspects of stepfamily functioning. Fewer associations were found between 
stepfamily adults' perceptions of actual stepparent role behaviours and stepfamily functioning. However, in contrast to stepchildren, involvement in control behaviours (in addition to warmth behaviours) at time one were associated with perceptions of stepfamily functioning twelve months later. Perceptions of the ideal stepparent role were not included in analyses since this study was interested in the extent to which the stepparent's actual behaviour affected stepfamily so that this could be statistically controlled in regression analyses. In contrast, perceptions of the ideal stepparent role were considered to be important to the extent they were discrepant with other stepfamily members' expectations (inter-role discrepancies), or the stepparent's actual behaviour (intra-role discrepancies).

While warmth behaviours may be viewed by children as "uniformly positive behaviours to exhibit" (Fine et al., 1997; pg 521), there may be more ambivalence surrounding the control dimension of parenting (Fine \& Kurdek, 1994). Previous research has also found that perceptions regarding the warmth dimension are associated more consistently with stepfamily functioning than the control dimension (Fine \& Kurdek, 1994; Fine et al., 1997). In contrast to warmth behaviours, children's happiness with their stepparent's participation in control behaviours may be dependent on an assortment of factors, such as the quality of their relationship with stepparents, the timing of control behaviours, and the specific control behaviours that are performed. In contrast, parents may view active involvement in warmth and control behaviours as universally positive as both are viewed to be necessary components of effective parenting. This is in line with theoretical ideas and empirical findings that an authoritative parenting style, with active participation in warmth and control parenting behaviours, is the most effective parenting style (Baumrind, 1968; Hetherington \& Clingempeel, 1992); a finding that adults may be cognisant of, than children.

It is likely that the association between the actual stepparent role and stepfamily functioning is bidirectional, so that stepparents become more involved in warmth behaviours when relationships and stepfamily functioning are more positive. The bidirectional nature of the development of relationships between stepparents and stepchildren has been illustrated by O'Connor and colleagues (1997) who showed that adolescent behaviours towards stepparents had an equally robust effect on their 
adjustment outcomes as did stepparents' behaviours towards adolescents. While the longitudinal nature of this study was designed to examine these processes, a one year period may be insufficient to enable firm conclusions regarding the direction of effects. In addition, other analytic approaches, such as structural equation modelling (SEM) may be more effective in better examining bidirectional processes.

Therefore, in light of these limitations, these findings do not necessarily indicate that stepparents should be encouraged to be involved in an active role as this will lead to more positive functioning. In addition to the potential for bidirectional effects, there are factors that may play important roles in the association between a stepparent's actual parenting involvement and adjustment in stepfamilies. The extent of discrepancy between the behaviours the stepparent is actually performing and the perceived appropriateness of these behaviours (intra-role discrepancies) and discrepancies with others stepfamily members (inter-role discrepancies) may both be important factors. The association between intra and inter role discrepancies and stepfamily functioning, after taking into account the stepparents' actual involvement was explored through a series of regression analyses. Results of the correlations between role discrepancies and stepfamily functioning will be discussed first, followed by a discussion of the findings from the regression analyses.

\subsubsection{Intra-Role Discrepancies}

The extent to which the actual role is consistent with the ideal role is considered to be an important determinant of stepfamily functioning. Results from the current study confirmed this, indicating that intra-role discrepancies were associated with many aspects of stepfamily functioning for stepchildren and stepparents. Lower intra-role discrepancies were consistently associated with higher quality relationships and stepfamily functioning twelve months later. While children's intra-role discrepancies for warmth and control were similarly associated with stepfamily functioning, this was not the case for stepparents where intra-role discrepancies for control were more highly associated with their perceptions of stepfamily functioning. In addition, children's intra-role discrepancies for the control dimension were highly associated with the quality of the stepparent-stepchild relationship. 
To explain the higher correlations between stepparents' intra-role discrepancies for the control dimension and stepfamily functioning, stepparents may experience frustration at not being able to be involved in control behaviours in the way they would like to, and this may lead to difficulties in their relationships with stepchildren and lower levels of family cohesion. Discrepancies in the control dimension may be more important than the warmth dimension because control is a more controversial issue in stepfamilies and therefore discrepancies are more likely to have an effect on stepfamily functioning. This may be particularly salient for the stepparent-stepchild relationship, where intra-role discrepancies for the control dimension may have a crucial effect on the quality and development of this relationship.

In contrast to stepparents and stepchildren, parents' intra-role discrepancies were not associated with any aspects of stepfamily functioning twelve months later. While parents will hold expectations regarding their partner's behaviour which may be discrepant with actual behaviours, discrepancies are unlikely to affect their adjustment in the same way as they do stepparents and stepchildren who are directly involved in the interaction. For example, stepparents may experience frustration and therefore perceive stepfamily functioning more negatively when they are not as involved as they would like to be in the parenting of stepchildren. For children, the extent to which they believe certain role behaviours to be appropriate, or in line with their expectations, are likely to affect the degree to which they are accepting or rejecting of the stepparent's parenting behaviours.

\subsubsection{Inter-Role Discrepancies}

This study also examined the extent to which discrepancies between stepfamily members regarding the ideal stepparent role were associated with stepfamily functioning twelve months later. In general, discrepancies between stepfamily members had a less consistent effect on stepfamily functioning than intra-role discrepancies. However, agreement between biological parents and children was important and was found to be associated with some aspects of stepfamily functioning; such as, increased family cohesion and the quality of the parent-child relationship, and lower levels of family conflict. The stepfamily outcome variable most consistently associated with inter-role discrepancies was the quality of the stepparent-stepchild 
relationship. Discrepancies between stepfamily adults (i.e. parents and stepparents) and between biological parents and children were both associated with lower quality relationships between stepparents and stepchildren. Possible reasons for why discrepancies between parents and children appear to be more important than discrepancies among other stepfamily members are discussed in section 8.5, in relation to the results from the regression analyses.

In general, only stepchildren's views of family functioning were affected by inter-role discrepancies in their families. This suggests that children may be more affected by different views with other stepfamily members regarding the stepparent role. Since children reported that they wanted stepparents to be less involved in both warmth and control behaviours than adults, they may be more likely to be negatively affected by these differences in views. It is possible that ideally wanting stepparents to be less involved in parenting behaviours than other stepfamily members is more problematic than ideally wanting stepparents to be more involved than other stepfamily members. A similar argument can be advanced for intra role discrepancies - where ideally wanting a stepparent to be less involved (than they actually are) in parenting behaviours may be more problematic than wanting them to be more involved. However, this may differ for the warmth and control dimensions of the stepparent role. That is, in light of the contentious nature of discipline, wanting stepparents to be less involved than other family members may be more problematic than wanting them to be less involved in warmth. Analyses of these issues were beyond the scope of this study, and suggestions for future research in this area are outlined in section 8.11.

While intra-role discrepancies were associated with children's individual functioning, as measured by total difficulties and self-concept scores, inter-role discrepancies were not and therefore aspects of children's individual functioning were not included in subsequent regression analyses. This suggests that the degree to which children and stepfamily adults agree on the ideal stepparent role has more potent effects on the quality of parent-child relationships and whole family functioning than on children's individual adjustment. This is not surprising since role discrepancies among stepfamily members are more likely to affect the dyadic interactions between stepfamily members, and how the family is functioning as a group (family functioning). Aspects 
of children's individual functioning may be more affected by other aspects of stepfamily functioning, such as the quality of their relationship with their non-resident parents; and individual variables, such as children's age and gender. Alternatively, since the effect of inter-role discrepancies on children's individual functioning was only assessed over a one year period; inter-role discrepancies might not yet have affected children's individual adjustment. This may occur more gradually over time, as the negative effects on parent-child relationships and family functioning increasingly affect children's individual functioning.

These findings indicate that discrepancies between parents and children have the greatest effect on stepfamily functioning. Role discrepancies between parents and children for the warmth dimension were negatively associated with family cohesion and the quality of children's relationships with both their parents, and positively associated with family conflict. In contrast, inter-role discrepancies between stepparents and parents were only associated with one aspects of stepfamily functioning, the stepparent-stepchild relationship; and discrepancies between stepparents and stepchildren were not associated with any aspects of stepfamily functioning. This appears to be contrary to clinical recommendations which typically encourage discussions between stepparents and biological parents in order to reach consensus between stepfamily adults regarding the most appropriate stepparent role (Kaplamn \& Hennon, 1992; Michaels, 2006; Mills, 1984; Visher \& Visher, 1988). It is also unclear why discrepancies between parents and stepparents affect the stepparentstepchild relationship, and not other relationships in the stepfamily. It is conceivable that agreement among stepfamily adults regarding the stepparent role leads to less conflict between adults regarding role issues which may then have a positive impact on parent-child relationships. However, it is unclear why discrepancies between stepfamily adults affect the stepparent-stepchild relationship and not other aspects of stepfamily functioning; in particular the relationship between stepfamily adults.

In light of the salience of the relationship between stepparents and stepchildren, it is also unclear why discrepancies between stepparents and stepchildren were not associated with any aspects of stepfamily functioning. These findings are in agreement with Fine and colleagues (1998) who also found that stepparent-stepchild role 
discrepancies were not associated with stepfamily functioning, despite the fact that stepparents reported that they should engage in parenting behaviours more often than stepchildren reported. These authors suggested that stepparents and stepchildren may be unaware of discrepancies regarding ideal role behaviours, so that these discrepancies are less likely to lead to difficulties in relationship functioning. In contrast, discrepancies between parents and children may be more apparent as they are more likely to discuss their expectations regarding the stepparent role. In support of this, parents and children were more likely to have explicit talks about the stepparent's role behaviour than stepparents and stepchildren.

However, while stepparents and stepchildren may be less aware of conflicting perceptions, it does not automatically follow that discrepancies will not affect stepfamily functioning. For instance, if stepparents believe they should be more involved in discipline than stepchildren, actual disciplinary behaviours performed by the stepparent are likely to be perceived more negatively by stepchildren. This may create difficulties in this relationship, despite the fact that stepchildren and stepparents are not consciously aware of these differences in views. Another explanation is that parents and children have a longer history than stepparents and stepchildren; therefore, different expectations may be more contentious than divergences between stepparent and stepchildren where they are more expected. In support of this, Cartwright and Seymour (2002) found that one of the central issues stepchildren reported to be difficult in their stepfamilies was biological parents who openly encouraged the stepparent to be involved in parental behaviours that they did not considered to be appropriate. These findings highlight the need for parents and children to discuss and negotiate the stepparent role so that some level of agreement can be attained.

In general, inter-role discrepancies regarding the warmth dimension were more strongly associated with stepfamily functioning than the control dimension. This lies in contrast with pronouncements in stepfamily literature regarding the pertinence of agreement regarding how control behaviours of the stepparent are to be performed, particularly in relation to the stepparent's involvement in discipline. For example, in a popular book written for stepfamilies, Leman (1994) states that "you and your spouse will stand or fall, sink or swim, together, and if there is anything the two of you need 
to work through and agree upon it's who will discipline the kids and how it will be done" (p. 208). As previously mentioned, discipline can be a dividing issue for stepfamilies since it can be difficult for biological parents to allow another adult to discipline their child, and children may respond unfavourably to stepparent discipline, particularly when they are adolescents.

There are many plausible reasons why discrepancies relating to warmth may be more pertinent than discrepancies relating to control. First, as suggested by Fine and colleagues (1998), stepfamily members may be less likely to discuss issues relating to the control dimension of parenting as it may be more conflict-inducing than the warmth dimension, and therefore discussion may be avoided. This avoidance may lead to stepfamily members having little understanding of the differences in expectations with other stepfamily members regarding control behaviours whereas warmth behaviours may be more openly discussed and discrepancies more easily identified. Second, since warmth behaviours are considered to be universally positive for children, discrepancies may be more consistently associated with more positive stepfamily functioning, whereas control behaviours may be more dependent on additional variables; for instance, individual factors such as the length of time in the stepfamily, and the stepparent's current involvement in warmth. Regression analyses were designed to examine this possibility, and results from these will be discussed in the following section.

\subsection{Results of Regression Analyses}

This research sought to extend the cross-sectional findings of Fine and colleagues (1998) by examining the importance of children's inter and intra role discrepancies as predictors of their perceptions of functioning over time. In addition, the stepparent's actual involvement at time one was included in regression analyses to examine whether role discrepancy scores predicted stepfamily functioning beyond what could be explained by the stepparent's actual involvement. Previous research has not controlled for this potential confounding variable. Only discrepancy scores that were associated with stepfamily functioning over time were included in the regression analyses. 
The results of these analyses generally confirmed those results discussed previously; that children's intra-role discrepancies and inter role discrepancies between parents and children have important effects on children's assessments of functioning. However, results from the regression analyses extend these findings in indicating that role discrepancies for children are important predictors of their functioning twelve months later after stepparent's actual involvement is controlled. In addition, they provide additional insights into which role discrepancies (intra or inter) are most important in terms of specific components of stepfamily functioning for children. Previous research has not conducted hierarchical regression analyses on role discrepancy variables and therefore the independent importance of role discrepancies on stepfamily functioning has remained unclear. The following section will discuss the key findings from the regression analyses

\subsubsection{Key Findings}

Inter-Role Discrepancies between Parents and Children

Similar to the results from the longitudinal correlations, the extent to which stepchildren agree with their biological parents regarding the ideal stepparent role (for warmth) was found to be an important predictor of the quality of children's relationships with their biological parents twelve months later. In particular, lower discrepancies between parents and children were predictive of higher quality relationships between children and biological parents. It is likely that when parents and children agree on the most appropriate role of the stepparent, this leads to more positive interactions between the two, due to lower levels of conflict regarding discrepant role expectations. As outlined by Fine and Kurdek (1994b) the stepfamily system is described as 'balanced' when stepfamily members' perceptions regarding the stepparent role are consistent. Balanced cognitions between parents and children may be particularly salient as they have the most established relationship, and biological parents are often described as playing a pivotal role in their children's adjustment to the new stepfamily (Cartwright, 2005; Solomon, 1996). 
Discrepancies between parents and children were also found to be important predictors of whole family functioning; that is family cohesion and family conflict. In addition to creating difficulties in relationships between parents and children, parent-child role discrepancies are likely to have pertinent effects on how the stepfamily is functioning as a group. Researchers have emphasised the important role biological parents' play in promoting positive relationships and a sense of family 'togetherness' within the family (Coleman, Ganong \& Weaver, 2001; Mariglio, 1992; Solomon, 1992). Agreement between parents and children may also reduce conflict within the family since agreement on salient issues such as parenting roles may lead to reduced negative interactions between stepfamily members.

These results from the regression analyses extend the current findings in highlighting the importance of inter role discrepancies between parents and children, over and above what can be explained by children's intra-role discrepancies, and after controlling for the stepparent's actual involvement. Therefore, these results significantly extend previous understandings regarding the importance of role discrepancies, and highlight the salience of agreement between parents and children regarding the ideal role, particularly for the warmth dimension of parenting.

\section{Children's Intra-Role Discrepancies}

Children's intra-role discrepancies were found to be predictive of the quality of their relationships with their parents and stepparents. In particular, lower intra-role discrepancies were associated with higher quality relationships with their parents and stepparents, twelve months later. It is likely that when stepchildren view their stepparent's actual involvement as appropriate they are more likely to respond to their behaviours in a positive way thereby forming a mutually positive relationship. Previous research highlights the powerful role stepchildren play in the acceptance or rejection of stepparent behaviours (Hetherington \& Clingempeel, 1992; O'Connor et al., 1997; Speers \& Trees, 2007) - behaviours that have a significant effect on the role enacted by the stepparent. Therefore, children's intra role discrepancies are likely to be an important component in influencing how children respond to stepparents' actual behaviours. 
However, while children's intra-role discrepancies regarding control were more closely associated with stepparent-stepchild relationships, discrepancies regarding warmth behaviours were more closely associated with parent-child relationships. While the importance of the control dimension for the stepparent-stepchild relationship is comprehensible, it is less clear why intra-role discrepancies for the warmth dimension affected children's relationships with their parents. Since associations between many variables were examined in this study, this finding may have occurred by chance. However, future research could examine this finding in more detail in order to better examine its validity.

It is interesting to note that children's intra role discrepancies for warmth significantly predicted family conflict while intra-role discrepancies for control did not. Although longitudinal correlations suggested that both warmth and control intra role discrepancies were associated with family conflict, only warmth was a significant predictor over and above discrepancies for control and a stepparent's actual involvement. This may appear contrary to speculations that children experience increased difficulties when they perceive their stepparents to be participating in control behaviours that they do not consider to be appropriate. In line with this, we might expect control behaviours to be more closely associated with increased levels of family conflict since children may hold particularly strong views regarding how involved they feel their stepparents should be in control behaviours, particularly disciplinary behaviours. This may then lead to heightened difficulties for children when these expectations are not reflected in actual behaviours.

However, as previously mentioned, while warmth behaviours may be perceived as a universally positive behaviour to exhibit, control behaviours may be more complex, and depend on other important factors. Intra-role discrepancies for warmth may be one of these important factors, which may explain why discrepancies for control were not significant beyond what could be explained by warmth intra-role discrepancies. Furthermore, this study measured a variety of components of control behaviours such as social guidance, monitoring and disciplinary behaviours. Findings may differ, therefore, when only intra-role discrepancies relating to disciplinary behaviours are examined. 
Finally, although children's intra role discrepancies for control were significantly correlated with family cohesion, these discrepancies were not significant predictors above what could be explained by discrepancies between parents and children. This indicates that discrepancies between parents and children are more important indicators of family cohesion than children's intra-role discrepancies, for both warmth and control dimensions. This is not surprising considering that family cohesion refers to the emotional closeness and sense of togetherness between stepfamily members, which may be more significantly affected by discrepancies between stepfamily members, than discrepancies between an individual's actual and ideal views.

\subsubsection{Summary}

These findings indicate that both inter-role discrepancies and intra role discrepancies were significantly associated with children's perceptions of stepfamily functioning. However, there is some indication that different types of role discrepancies may be associated with different aspects of stepfamily functioning. That is, while children's intra role discrepancies for warmth may be more predictive of the quality of the parentchild relationship, intra-role discrepancies for the control dimension may have a greater effect on the stepparent-stepchild relationship. Agreement between parents and children was associated with most aspects of stepfamily functioning; that is, family cohesion, and the quality of parent-child relationships; and negatively associated with family conflict. However, it was not associated with the quality of the stepparentstepchild relationship, beyond what could be explained by children's intra-role discrepancies. Finally, children's intra role discrepancies were not associated with family cohesion, above what could be explained by inter-role discrepancies between parents and children. These findings highlight several significant new findings. 


\subsection{Role Negotiation in Stepfamilies}

Role negotiation strategies in stepfamilies were examined in order to better understand the strategies newly formed stepfamilies use to negotiate the stepparent's role and responsibilities. The scant empirical attention given to role negotiation in stepfamilies is surprising, since previous qualitative studies (e.g. Braithwaite, 1998; Braithwaite et al., 2001; Braithwaite, McBride \& Schrodt, 2003; Golish, 2000, 2003; Golish \& Caughlin, 2002) and stepfamily clinicians have emphasised (eg Mills, 1984) the importance of these discussions. The next section will outline the main findings regarding role negotiation in stepfamilies.

Firstly, role negotiation was considerably more likely to occur in stepfamilies once they were living together than beforehand. These findings are in agreement with other researchers who have highlighted that discussion of parenting roles, particularly regarding the stepparent's role in discipline, are increasingly common after cohabitation (Smith et al., 2001). This is despite recommendations from stepfamily researchers and clinicians that discussions at both times are important, since precohabitation talks play an important role in revealing stepfamily members expectations and post-cohabitation talks allow discussion of those role expectations that are not easily identifiable beforehand (Bray \& Kelly, 1999).

There are several possible reasons to explain why role negotiation is more common once stepfamily members are living in the same household. Firstly, before stepfamily members live together, they are unlikely to have had sufficient time together to gain an understanding of the issues requiring negotiation. In particular, the discipline of stepchildren may become more salient after cohabitation, as stepparents are exposed to the full range of their stepchildren's behaviour (Robertson, 2008). These findings may indicate that the stepparent role is discussed explicitly only when key differences in role expectations become apparent, which may be more likely to occur once living in the same household.

Secondly, there are indications that stepfamily couples cohabit relatively quickly (Anderson \& Greene, 2005; Montgomery et al., 1992), thus leaving little time for role 
negotiation beforehand. The majority of couples in an English study (83\%) cohabited within a year of beginning the relationship (Smith et al., 2001). In fact, some couples began cohabiting soon after meeting, leaving little time for stepparents and stepchildren to get to know each other (Robertson, 2008). In this study, the average time of dating prior to cohabitation was nine months. These findings, therefore, confirm those of previous studies that stepfamily couples cohabit relatively quickly, leading to fewer opportunities for role negotiation prior to cohabitation.

This study suggests that stepfamilies negotiate the stepparent role in a variety of ways. The most common strategy used was partner discussions, although many biological parents also discussed the stepparent role explicitly with their children. In general, non-explicit strategies were more frequently used to negotiate roles than explicit strategies, particularly gate keeping behaviours. In contrast, very few adults in stepfamilies discussed roles with the child's other biological parent or participated in family discussions. In general, biological parents were more likely than stepparents to check in with children for feedback, while stepparents were more likely to approach their partners for feedback regarding their role. This is not surprising considering the 'newness' of the relationship between stepparents and stepchildren, and the pivotal role biological parents play in guiding the development of the relationship between their children and their partner (Coleman et al., 2001; Solomon, 1996).

Stepparents reported less commonly engaging in role negotiation strategies than biological parents, such as discussions with their partner, family discussions, or checking in with the target child. There are two possible explanations for this finding. First, this may indicate that stepparents are less likely to use role negotiation techniques than biological parents, possibly because they are the newest members of the family and may find discussion of challenging issues such as parenting roles difficult to initiate. Second, since the majority of stepparents were males (ie. stepfathers) these findings could represent gender differences regarding the perceived use of communication strategies, such as role negotiation strategies. In contrast to women, men may be less likely to report engaging in communication strategies, regardless of the nature of these discussions. Women are often described as playing an important communicative role in mediating and negotiating harmony between family 
members (Fine et al., 1999). Although not discussed in this thesis, role negotiation interviews conducted in the current study revealed that women were more commonly the instigators of role negotiation discussions, and this might provide partial support for this explanation.

Stepchildren were asked whether resident parents had checked in with them about their stepparent's behaviours and whether they had spoken to anyone about the stepparent's role in their life. In general, when children did discuss the stepparent role, they were most likely to discuss it with their resident biological parent. These findings are in accordance with Dunn and Deater-Deckard (2001) who reported that children prefer to confide in resident parents than stepparents in regards to stepfamily issues. The results of the current study suggest that children may prefer to discuss the stepparent's role in their life with their parents; rather than their stepparents, where relationships are still developing.

The majority of children also reported that their resident parent had checked in with them to discuss their views regarding their interactions with stepparents. It seems that many resident parents in this study actively sought children's views regarding family dynamics, something which is seen to have a positive effect on children's adjustment. It is assumed that it is helpful for children undergoing family transitions to have opportunities to talk about what is happening, or has happened, within their families (Gorell Barnes et al., 1998). Clinical work with children suggests that they may benefit from explanations regarding the changes that have occurred, and future changes that are to be expected (Dowling \& Gorrell Barnes, 2000). Therefore many resident parents in this study appeared to be acting in positive ways as suggested by stepfamily clinicians.

\subsubsection{Role Negotiation and Stepfamily Functioning}

This study examined whether role negotiation was more likely to occur in stepfamilies that were experiencing problems. The dearth of research on role negotiation means that little is known about why stepfamilies engage in role negotiation strategies: for example, do they use these strategies as preventative measures or are they more likely to use them when there are specific problems to be resolved? 
These findings indicated that role negotiation was used more frequently in the following twelve months in stepfamilies that were experiencing more problematic functioning. In particular, biological parents reported engaging in role negotiation strategies more frequently when family conflict was high and when the relationship between stepfamily adults was of lower quality. For stepparents, only one role negotiation strategy was more frequently used when there were problems in stepfamily functioning; gate keeping behaviours. Stepparents reported that their partners were more likely to engage in gate keeping behaviours when family conflict was higher, and when they had lower quality relationships with their partners and with their stepchildren. Similarly, biological parents perceived that they more frequently engaged in gate keeping behaviours when they had a lower quality relationship with their partner. Family conflict and negative stepfamily relationships may be seen as particularly concerning and therefore requiring intervention. This study suggests that biological parents may have engaged in gate keeping behaviours as a way of dealing with these problems in stepfamily functioning.

However, gate keeping behaviours did not appear to be effective in improving stepfamily functioning. That is, the extent to which biological parents engaged in gate keeping behaviours was associated with a decrease in the quality of the stepparentstepchild relationship over time. This finding is consistent with previous research that highlights the negative effect gate keeping behaviours have on the development of an independent relationship between stepparents and stepchildren (Bray \& Kelly, 1999; Coleman, Ganong \& Weaver, 2001; Erera-Weatherley, 1996; Rosin, 1987). It should be noted, however, that this association was not found for biological parents' perceptions of gate keeping behaviours. Biological parents' reports of their own gatekeeping behaviours were not associated with a decrease in the quality of the stepparent-stepchild relationship over time. However, it is likely that stepparents will provide the most accurate reports regarding the nature of their relationships with their stepchildren since they are experiencing these interactions first hand.

In contrast to gate keeping behaviours, there was some evidence that other role negotiation strategies led to improvements in stepfamily functioning. While role 
negotiation, as reported by parents, was not associated with any changes in stepfamily functioning, stepparents' reports were associated with some improvements in stepfamily functioning. In particular, the frequency with which stepparents' reported having family talks and checking in with stepchildren were both associated with an improvement in the quality of the stepparent-stepchild relationship, and (for family talks only) in their relationships with their partners. This finding was even more significant for checking in with stepchildren, which was strongly associated with an improvement in the quality of the relationship between stepparents and stepchildren over time. These findings, therefore, highlight the value in stepparents periodically checking in with stepchildren to discuss their feelings regarding the development of this relationship.

Role negotiation strategies are likely to be particularly beneficial in the development of the relationship between stepparents and stepchildren since there are few normative guidelines to assist in the development of the stepparent role. This role ambiguity is compounded by that fact that children do not choose to be in a relationship with their stepparents (Pryor, 2004), and stepparents and stepchildren have less history than other relationships in the stepfamily. For example, children's relationship with biological parents, and the relationship between stepfamily adults, both precede stepfamily formation. In addition, the presence of stepparents may trigger loyalty conflicts for children in their relationships with their non-resident parents, and stepparents may be seen as competing with children for the attention of their biological parents (Pryor, 2004). These factors lead to complexities in developing an appropriate stepparent role that are not necessarily found in other stepfamily relationships.

There are several possible reasons why stepparents' reports of role negotiation were associated with stepfamily functioning, while parents' reports were not. Firstly, stepparents may perceive the usefulness of these strategies because they are more conscious of the lack of clarity regarding their role and therefore more actively seek role clarification (Fine et al., 1998; Marsiglio, 1992; Whitsett \& Land, 1992). Gate keeping behaviours are more likely to be perceived negatively by stepparents as they may be more aware of the difficulties these behaviours create in their interactions with their stepchildren. In contrast, role negotiation for parents may serve a less important 
purpose as they are not faced on a daily basis with the ambiguities surrounding the most appropriate ways to act towards children. Many of the biological parents in this study held firm expectations at the outset regarding the most appropriate stepparent role, and these expectations may have rendered the negotiation of roles less necessary.

While role negotiation did lead to some improvements in family functioning, further improvements may become evident as the stepfamily develops. When stepfamily relationships are new and evolving, explicitly discussing challenging issues such as the stepparent role might be avoided (Golish, 2000; Halford et al., 2007), and are more likely to occur in more established stepfamilies. Instead, in the early stages, more subtle processes that are less verbal and explicit may be more commonly used, and these strategies may be more effective in improving stepfamily functioning. In support of this, this study found that the extent to which stepparents checked in with children for feedback in response to a particular incident, without explicitly discussing their parenting role, was associated with improvements in functioning.

Although gate keeping behaviours had a negative effect on some aspects of stepfamily functioning (e.g. the relationship between stepparents and stepchildren), there are likely to be other less explicit strategies used by stepfamily members that lead to improvements in stepfamily functioning. For example, Speers and Trees (2007) found that stepchildren negotiated the stepparent role through their expressions of autonomy and connection-seeking in their interactions with stepparents. These behaviours, and other less explicit strategies that have not been examined here, may play an important role in the development of stepfamily relationships, and may lead to improvements in functioning over time.

\subsubsection{Role Negotiation and Inter-Role Discrepancies}

This study also explored the extent to which role negotiation led to lower role discrepancies between stepfamily members over time. This was considered to be important since role negotiation may be beneficial for stepfamilies to the extent that it leads to increased role agreement among stepfamily members. 
Overall, these findings indicate that role negotiation had very little effect on inter-role discrepancies. This indicates, therefore, the likelihood that other reasons have had a large part to play in explaining the association between role negotiation and improvements in stepparent-stepchild relationships over time; excluding higher levels of agreement between stepparents and stepchildren. Through checking in with stepchildren, stepparents may have formed more positive relationships with their stepchildren. It is possible, too, that stepparents who check in more frequently with their stepchildren may have different characteristics from those who do not. For example, stepparents who communicate with their stepchildren about these issues may be more child-focused, and may have a more positive relationship with children at the outset. It may be these features that are more important in leading to improvements in stepfamily functioning over time.

The one significant association that was found suggests that the extent to which parents report checking in with their target child is associated with increased discrepancies at time two between parents and children. This appears to be contrary to predictions that role negotiation strategies would lead to higher levels of agreement in the ideal stepparent role over time, not lower levels of agreement. However, it should be noted that this correlation was low and, since a number of correlations were performed, may have merely occurred by chance. It is also possible that the limited time between stages of data collection may have led to ambiguity with regards to which variable preceded the other. That is, it may indicate that parents are more likely to check in with children when there are greater discrepancies present, where it is perceived that more negotiation is required. Longitudinal research that examines role negotiation at additional time periods may be useful in better examining this finding. 


\subsection{Changes over Time in the Stepparent Role}

In general, results revealed few changes over time in stepfamily member's perceptions of the stepparent role. However, there were some differences over time in stepfamily members' intra and inter-role discrepancies and these will each be discussed in the following section.

\subsubsection{Individual Role Perceptions}

The stepparent role remained relatively stable over the one-year period. That is, stepfamily members generally reported that stepparents were similarly involved in warmth and control dimension at time one and two, and reported wanting them to be similarly involved. One exception to this was that parents reported their partners to be less involved in warmth behaviours over time. While this seems contrary to expectations that stepparents might become more involved in parenting behaviours as relationships with stepchildren develop, the age of the target stepchild may play an important role in this regard. As previously mentioned, target stepchildren were one year closer to adolescence at time two, and this may have resulted in stepparents' being less involved in warmth behaviours, possibly to respect the wishes of their stepchildren. However, this decreased involvement was not found for stepparents' or children's perceptions, therefore this finding might have occurred by chance.

These minimal changes in the stepparent role over time are in agreement with other research studies that have found the stepparent role to remain relatively stable over time (e.g. Bray \& Berger, 1993). These findings may be explained by the fact that the stepparent role may change more gradually over time so that a one year period is insufficient to provide an accurate assessment of role changes.

\subsubsection{Role Discrepancies}

There were two changes over time in intra-role discrepancies, and the general pattern was for intra-role discrepancies to decrease over time. That is, warmth discrepancies for stepparents and control discrepancies for children decreased over time. This means that at the second stage of data collection, stepparents' participation in control behaviours were more in line with children's wishes. Similarly, stepparents' 
participation in warmth behaviours at time two were more in accordance with their ideal views. These results were not evident for biological parents, where there was no evidence of change over time in intra-role discrepancies.

These findings suggest that stepchildren and stepparents were happier with the stepparent role at the second stage of the study, since actual parenting behaviours were less discrepant with their ideals. Stepparents and children may have reduced their expectations regarding the stepparent's role and these reduced expectations may have led to lower intra-role discrepancies. However, ideal stepparent roles for children and stepparents did not change over time; therefore, there may be other explanations for this finding. Stepchildren may have negotiated a relationship with their stepparent to suit their needs, although the way in which this occurred is unclear. Although role negotiation strategies involving children were measured (e.g. family meetings, child check in) these were not measured from the perspective of children. In addition, there may be other less explicit role negotiation strategies that decrease children's intra-role discrepancies that were not examined in this study.

Furthermore, children and stepparents may be happier with the stepparent role over time as they have had more opportunities to form a mutually positive relationship. Stepfamily scholars frequently emphasise the involuntary nature of the stepparentstepchild relationship, since children do not 'choose' to have this person live with them (Pryor, 2004), nor do they necessarily want stepparents to play a parenting role in their lives. As a result, as their relationship develops over time, stepchildren may be more comfortable with the stepparent's actual role behaviours, despite the fact that they have not actually significantly changed.

A similar explanation can be offered for the finding that inter-role discrepancies between children and stepparents decreased over time. While discrepancies between stepfamily adults, and parents and children, did not change over time, stepchildren reported considerably fewer discrepancies over time with their stepparents. By the second stage of data collection, stepparents and stepchildren will have had more time to negotiate a mutually agreed upon relationship. This time together may have led to changes in the way the ideal stepparent role is viewed by stepparents and stepchildren, so that stepparent role behaviours may be deemed to be more acceptable. 


\subsection{Study Limitations}

This section provides an overview of the strengths and limitations of the study, covering issues such as the representativeness of the sample, methodological issues and significant new findings.

\subsubsection{Representativeness of the Sample}

Although a large number of stepfamilies participated in this study $(\mathrm{N}=105)$ the present sample was not representative of all New Zealand stepfamilies. Firstly, these findings are largely based on stepfather families that have formed through the separation and divorce (rather than death) of one of the child's biological parents. There were few stepmother families (16\%) and even fewer stepfamilies formed as a result of the death of the child's biological parent (5\%). Previous researchers and clinicians have noted the increased difficulties stepmothers face in the enactment of their role (Hetherington \& Kelly, 2002; Levin, 1997; Whitsett \& Land, 1992). Since participation in this study required the target child to live at least $50 \%$ of the time in the participating stepfamily, many non-residential stepmother families where stepchildren live part-time would have been excluded. While there were no differences between stepmother and stepfather families on important variables; the low numbers of stepmother families may have made any difference hard to detect. Therefore, these results should not necessarily be generalised beyond stepfather families and those formed due to the separation or divorce of the child's biological parents.

In contrast to the majority of previous research that has focused on remarried couples, this study included both remarried and cohabiting stepfamilies. While cohabitation is often a precursor to remarriage, many stepfamily couples in New Zealand remain in long term cohabiting relationships rather than legally remarrying (Bumpass et al., 1995; Ganong \& Coleman, 1994). In support of this, more than half of the participating stepfamilies (56\%) were not legally remarried. Cohabiting and remarried couples were included together in light of research suggesting there are no differences in the stepparent role between cohabiting and remarried stepfamilies (Marsiglio, 1992). 
Stepfamilies in the early stages of development were selected because it is assumed the majority of role negotiation occurs in the first few years (Bray \& Berger, 1994; Hetherington, 1993; Robertson, 2008). However, these findings may not be relevant to stepfamilies that have been together longer than four years.

The sample was overrepresented by stepfamilies of New Zealand European ethnicity, and those of high education and family income. Eighty-five percent of stepfamily adults were New Zealand European and a large proportion of stepfamilies (31\%) reported family incomes of over $\$ 100,000$. This is not uncommon to stepfamily research (Hetherington, 1993), or to research conducted in New Zealand, with Pryor (2004) finding similar patterns in relation to the socio-economic characteristics of stepfamilies in her study. While it enables comparisons across studies, it does restrict the applicability of the findings to other stepfamily types. These biases are largely due to self-selection recruitment processes, as it is likely that those with higher incomes and education would be most interested in participation. Recruitment of low-socioeconomic stepfamilies and minority ethnic groups, may require methods not used in this study.

The lack of knowledge about stepfamilies of different ethnicities is problematic in the New Zealand context, where Maori and Pacific families constitute a large proportion of the population. Recent New Zealand census (2006) information indicates that $14.6 \%$ of New Zealanders are Maori, and $14.7 \%$ are Pacifica. There is, too, some data from Statistics New Zealand (2006) that suggests that there are high proportions of Maori and Pacific children living in alternative family forms. For example, Maori children $(29 \%)$ are more likely than non-Maori children $(18 \%)$ to have lived in a blended family (New Zealand Women: Family, Work and Study, 1995). Since Maori and Pacific children are represented disproportionately in stepfamilies, further research about these family types is needed. In this study, only five Maori stepfamilies and four Pacific families participated so that analysis by ethnicity was not possible.

Stepchildren between the ages of seven and eleven were targeted for this research to better understand how younger children view the role of the stepparent. The majority of previous research has focused on adolescent stepchildren, ensuring that we have little understanding regarding how younger children view the stepparent role. Since 
there is evidence that factors such as the stepchild's age when the stepfamily formed and their current age are important determinants of stepfamily functioning (e.g. Hetherington et al., 1999) results cannot automatically be generalised to stepfamilies with stepchildren of different ages. This is particularly relevant in reference to the stepparent role, where the child's age, both currently, and when the stepfamily initially formed, are found to be key determinants of the stepparent's parenting role (Bray, 1999; Hetherington, 1993; Hetherington \& Clingempeel, 1992).

Finally, all stepfamilies were from the North island of New Zealand, with the majority living in Wellington. These results therefore cannot necessarily be generalised to stepfamilies in other regions.

\subsubsection{Methodological Limitations}

There are a number of methodological issues that need to be considered when interpreting the results of this study. This section will cover issues regarding the nature of the measures employed, and the limitations in interpretation of these results.

Similar to previous research, the stepparent role was measured entirely by self-report questionnaires and semi-structured interviews. While this has the advantage of more accurately measuring perceptions regarding the stepparent role, it may have inflated associations between variables due to shared method variance. Shared-method variance is an association between variables that is partially due to similar methods of measurement (Ritchey, Fishbein \& Harold, 2001) rather than an actual association between two variables. This is a common concern in cross-sectional research where an association between two variables may be explained by extraneous variables; such as the individual's current mood, or environmental factors. Although this problem is partially addressed by the longitudinal design, future researchers should gain behavioural observations of the stepparent role and stepfamily functioning to further validate these research findings.

Secondly, while the study design was longitudinal, the amount of time between stages of data collection was relatively short and data was only collected at two points in time. This restriction was largely due to researcher constraint and funding issues; so 
that it was not possible for one researcher to follow over one hundred stepfamilies for two years. Although this research extends previous knowledge of roles in stepfamilies by examining the stepparent role longitudinally, future research could incorporate additional stages of data collection to examine role changes and the direction of effects in more detail. While this study found that the stepparent role changed very little over time, changes may become more evident over a greater period of time. In addition, while role negotiation did not appear to lead to lower inter-role discrepancies among stepfamily members, this association may become more evident over time.

In addition, while longitudinal designs are useful in examining changes over time and causal dynamics, participation in the study may have an effect on outcome variables. That is, participation in interviews and questionnaires at time one may have an effect itself on the results, with the research experience instigating discussions about parenting roles that might not otherwise have occurred. Although this is an important factor that needs to be considered in interpreting results regarding changes in the stepparent role, the advantages of longitudinal designs were considered to outweigh this potential limitation.

Twelve stepfamilies had dissolved by the second stage of data collection and this meant that the stepfamilies at time two may have been composed of more 'successful' or less problematic stepfamilies. Since paired tests and other statistical analyses using the longitudinal data compared mean scores for stepfamilies at time one with those who were still together at time two, this may mean that roles discrepancies are less, or more, important for stepfamilies that separate, since they were not included in the analysis. While analyses to compare stepfamilies that remained together with those that dissolved was beyond the scope of this study, future research could address whether separating stepfamilies report more problematic functioning and higher role discrepancies prior to separation.

The final comments to be made regarding this study's limitations concerns the number of analyses performed and the variables included in these analyses. First, since many correlations and statistical tests were conducted, some of these significant findings will have occurred by chance. This needs to be considered in interpreting the significant 
results in this study. Second, many of the distributions for the independent and dependent variables were significantly skewed. This largely concerned the role discrepancy scores with the majority of stepfamily members reporting low discrepancy scores. This is to be expected when difference scores are created by using absolute values since it effectively reduces the tails of the distribution. Skewed variables are relatively common in social research, with other researchers reporting stepparent involvement to be significantly skewed (Hetherington et al., 1982). To deal with this, variables are often transformed to meet the assumptions required for correlational and regression analysis which require normally distributed scores. This study, however, addressed skewed variables by adjusting extreme scores and outliers, and using nonparametric statistical methods if still required after the modification of variables.

\subsection{Study Strengths and Significant New Findings}

The results of this study extend our understanding of the stepparent role in many important ways. Firstly, most of the previous research conducted on the stepparent role has focused on American stepfamilies and therefore we have limited understanding of New Zealand stepchildren's views of the stepparent role and the extent to which these are associated with stepfamily functioning. American stepfamilies may be different from stepfamilies in New Zealand since American divorce and remarriage rates are significantly higher than those in New Zealand and Australia (Pryor \& Rodgers, 2001). In line with Cherlin's hypothesis $(1978,2004)$ this difference may lead to clearer expectations regarding stepparent roles and responsibilities. Nonetheless, this study validates findings from American studies (e.g. Fine et al., 1997, 1998), showing that the stepparent role has an important effect on stepfamily functioning in New Zealand stepfamilies.

The stepparent role was measured at two points in time thereby building on previous understandings of how stepfamily members perceive the stepparent role. Previous researchers (e.g. Fine et al., 1997, 1998; Smith et al., 2001 etc) have used crosssectional designs to examine the stepparent role, limiting our understanding of more complex processes, such as how the stepparent role changes over time. Longitudinal studies are particularly useful in examining causal dynamics in relationship and role 
development. This study is one of the first to examine empirically the stepparent role using a longitudinal design with a large number of stepfamilies involved. The sample size obtained was relatively large compared to other studies of stepfamilies, providing sufficient statistical power to explore associations between variables.

A further strength of this study concerns the way in which the stepparent role was measured. In contrast to previous research on the stepparent role (Mason et al., 2002), this study focused on specific parenting tasks performed by the stepparent. Specific, everyday behaviours were studied so that both adults and young children could report accurately on these behaviours and so that perceptions of role behaviours could be compared. Stepparent role perceptions were measured with reference to both warmth and control parenting behaviours since previous research suggests that these have critical, although potentially different, effects on stepchildren's adjustment. This also enables comparisons with the research conducted by Fine and colleagues (1998) who examined warmth and control dimensions of the stepparent role.

Multiple components of stepfamily functioning were measured which increases our understanding of stepfamily dynamics. The majority of previous research on the stepparent role has focused on one aspect of stepfamily functioning; usually measuring marital quality or children's adjustment. In contrast, this study examined multiple dimensions, including marital quality, child adjustment, the quality of parent-child relationships and whole family functioning (cohesion and conflict). This is important since there are indications that relationships and family processes in stepfamilies are more independent than in first families (Bray et al., 1994); in particular, that the marital subsystem may function somewhat independently from the parent-child subsystem in stepfamilies (Bray et al., 1994). Therefore, while functioning in one subsystem may be positive, this does not necessarily mean that functioning in another is also positive (Fine \& Kurdek, 1994a). This study found stepparent role variables to be predictive of different aspects of adjustment and therefore supports the value in examining multiple components of adjustment.

While previous research has measured only one stepfamily member's perceptions of functioning, this study incorporated a multi-informant approach. Data were collected 
from stepparents, parents and target stepchildren, thus providing a deeper understanding of stepfamily functioning and the nature of the stepparent role. A multiinformant approach is important in light of research suggesting that stepchildren view the stepparent role differently to adults (Fine et al., 1998). As discussed in Chapter Two, many of the previous studies on the stepparent role have relied solely on adults reports of the stepparent role, leaving the views of stepchildren relatively uncharted. This is problematic since stepchildren have a powerful effect on the success of the stepfamily, and researchers and clinicians have emphasised that children's views have important effects on stepfamily functioning.

This study supports findings of previous researchers that stepchildren view the stepparent role differently from stepfamily adults. However, these findings extend previous understandings by showing that younger children also view the stepparent role in different ways from adults. Adolescent stepchildren have been more frequently studied possibly because of indications that adolescents have more problematic responses to stepfamily life and relationships with stepparents. In addition to highlighting discrepancies between children's and adults' views in stepfamilies, this study highlights the need to examine both stepparent role labels and parenting behaviours since they may each provide independent information.

The stepparent role has often been measured with reference to the labels that are used to describe the stepparent role with the assumption that these labels correspond with differential involvement in parenting behaviours. Despite these assumptions, there was no published research found which empirically examines the accuracy of this assumption; that is, whether stepfamily members' role labels are associated with differential parenting involvement. This study is one of the first to do this, and the results partly validate the view that stepparent labels are correlated with differential parenting behaviours. It may be worthwhile, however, for future researchers to examine this association using larger sample sizes, in addition to observational studies that examine actual role behaviours as opposed to perceived role behaviours.

These findings highlight the complexity of the stepparent role and the need to examine a multitude of components. As outlined by Fine and colleagues (1998), in addition to 
perceptions of the stepparent's actual role behaviours, views regarding ideal stepparent behaviour are considered to be important. Measurement of both these components is important since there is no guarantee that the two are consistent, yet degree of consistency may have important effects on stepfamily functioning (Fine et al., 1998; Mills, 1984). Despite indications by clinicians that role discrepancies are important, few researchers have measured these two components of the stepparent role and associations with stepfamily functioning. One exception was Fine and colleagues (1998) who measured both components of the stepparent role and showed that consistency in perceptions of the stepparent role are important determinants of stepfamily functioning. The results of this study further highlight the importance in examining both actual and ideal components of the stepparent role to examine role discrepancies, in order to better understand how actual and ideal views are differentially associated with stepfamily functioning.

This study is one of the first to indicate that discrepancies in the stepparent role predict stepfamily functioning over time. Separating discrepancy scores from stepparent's actual involvement is important in determining the unique contribution role discrepancies make in predicting stepfamily functioning. Previous studies (e.g. Fine et al., 1998) have not separated these two components, nor have regression analyses been conducted which enable an assessment of the independent contribution of particular variables over time.

Finally, this study serves an important role in bringing to the forefront a communication strategy in stepfamilies that has received inadequate attention. Role negotiation has only recently been discussed by researchers and clinicians as being an important communication strategy whereby stepfamily members negotiate the most appropriate stepparent role. While there have been some qualitative studies by communication scholars (e.g. Braithwaite, 1998; Braithwaite et al., 2001; Braithwaite, McBride \& Schrodt, 2003; Golish, 2000, 2003; Golish \& Caughlin, 2002) focused on components of role negotiation, there has been no published research that has explored the strategies used by stepfamilies and the degree to which these are associated with stepfamily functioning. 
This study was one of the first to study role negotiation quantitatively and to examine its association with stepfamily functioning. A more detailed understanding regarding the strategies used by stepfamilies to resolve the stepparent role has the potential to be of considerable practical value for organisations working with and advising stepfamilies. The current results highlight the usefulness in further research that focuses on providing a more detailed understanding of role negotiation, in particular the more subtle ways in which negotiation occurs.

\subsection{Future Research}

These results highlight several fruitful areas for further research. Firstly, although this study was important in examining perceptions of the stepparent role and stepfamily functioning using a longitudinal design, future researchers could collect data at additional stages and with greater lengths of time between data collection points. This might better address whether there are changes in the stepparent role over greater periods of time, and assess the degree to which role discrepancies and role negotiation strategies lead to improvements in stepfamily functioning over time.

Second, while this study examined some role negotiation strategies used in stepfamilies, it is likely that there are additional strategies that have not been measured in this study. Particularly in the early years, when relationships between members are new and developing, role negotiation strategies that are more subtle and less explicit may be more effective in increasing agreement between stepfamily members regarding the stepparent role, and improving stepfamily functioning. Future research might explore the more subtle processes used in stepfamilies to negotiate roles, excluding those measured in this study.

Additional research might focus on why gate keeping behaviours are problematic for stepparent-stepchild relationships, and why parents engage in these behaviours when they lead to heightened problems between stepparents and children. This study indicates that parents are more likely to engage in these behaviours when their relationship with their partner is of lower quality. Future research could focus on the other conditions that lead to increased gate keeping behaviours, and whether there are 
some gate keeping behaviours that are more problematic than others. Better understanding the processes by which gate keeping behaviours lead to less positive stepparent-stepchild relationships is important in light of the salience of the relationship between stepparents and stepchildren.

These findings indicate that stepparents who check in with stepchildren for feedback regarding their parenting role have higher quality relationships with their stepchildren. However, the process through which this occurs is unclear since there was no evidence that checking in with children led to lower inter-role discrepancies between stepparents and stepchildren. Through checking in with stepchildren, stepparents may have formed more positive relationships with them. It is possible, too, that stepparents who check in more frequently with their stepchildren may have different characteristics from those who do not. While examination of these processes was beyond the scope of this study, future research might focus on the association between stepparents' role negotiation with children and relationship quality, after controlling for the individual characteristics of stepparents and the closeness of the stepparentstepchild relationship.

In light of the salience of the stepparent-stepchild relationship, it was surprising that discrepancies between stepparents and stepchildren did not lead to increased problems in stepfamily functioning, particularly in the quality of the relationship between stepparents and stepchildren. Future research might focus on the reasons why discrepancies between the two do not appear to have a negative effect on stepfamily functioning. Additional research might benefit from individually examining the different sub-dimensions of control related behaviours, as discrepancies between stepparents and stepchildren on disciplinary behaviours may have a detrimental effect on the quality of their relationship. As previously mentioned, this study measured three components of the control dimension (social guidance, monitoring behaviours and discipline), so that the effect of differences in regards to disciplinary behaviours may have been masked.

The current study examined the magnitude of role discrepancies between (inter-role discrepancies) and within (intra-role discrepancies) stepfamily members, and did not 
measure the direction of these discrepancies. It is possible, and highly likely, that additional information can be attained by examining the direction of discrepancy scores, rather than the magnitude of these differences. This would enable the following questions to be addressed: Do role discrepancies have more pertinent effects on children's functioning when stepparents are more, as opposed to less, involved than children ideally want them to be? Are inter-role discrepancies between parents and children more problematic when parents ideally want stepparents to be more (rather than less) involved in parenting behaviours than children believe to be appropriate? Additionally, results may differ for the warmth and control dimensions of parenting. That is, children may experience heightened problems when stepparents are more involved in control behaviours than children want them to be; and this may be more challenging than having stepparents more involved (than desired) in warmth behaviours. This was not explored in the current study since the focus was on the magnitude of role discrepancies, rather than the direction of these discrepancies. Future research could explore these complexities to build a better understanding of the association between role discrepancies and stepfamily functioning.

In addition to children's role discrepancies, future analyses could examine the predictive power of stepparents' role discrepancies on their perceptions of stepfamily functioning. As outlined previously, parents' role discrepancies were not significantly associated with stepfamily functioning twelve months later, while stepparents' role discrepancies were. Future research might address the extent to which role discrepancies for stepparents are predictive of stepfamily functioning twelve months later, and which are more important - agreement with their partners regarding the ideal stepparent role (parent-stepparent inter-role discrepancies) or discrepancies between their actual and ideal roles (intra-role discrepancies)? Research of this nature might play an important role in developing a better understanding of the stepparents' role perceptions and its affect on stepfamily functioning.

Finally, it is important to note that these results are based on a community sample of seven to eleven aged stepchildren. Therefore, these findings may be different when samples of stepchildren with various psychological disorders, such as Attention deficit Hyperactivity Disorder (ADHD) or Oppositional Defiance Disorder (ODD) are 
examined. For example, the presence of psychopathology might affect aspects of the stepparent role, such as how the role is developed and assigned and how it is negotiated within these families. In addition, aspects of family functioning in these stepfamilies are likely to be different in terms of parental relationships and parent-child relationships and these may contribute to different role processes. Future research might focus on children with psychopathology present to better examine whether the present findings are upheld in diverse populations.

\subsection{Implications for Policy and Practice}

The results of this study have several important implications for organisations that work with stepfamilies. Firstly, they provide an evidence base for Government and non-Government agencies in New Zealand that work with stepchildren and their families. This study shows that many stepparents are playing active roles in their stepchildren's parenting, and that aspects of the stepparent role have important effects on stepfamily functioning and children's adjustment.

Clinicians working with stepfamilies may be encouraged to focus more attention on perceptions of the stepparent role. There may be particular value in focusing on children's views of the stepparent role, since their perceptions were powerfully associated with their adjustment. This lies in contrast to research studies and clinical recommendations that have largely focused on the importance of adults' perceptions of the stepparent role.

The study also highlights additional content areas that might be addressed by clinicians in their work with stepfamilies. While role agreement between stepfamily adults is typically encouraged by researchers and clinicians (e.g. Bray \& Kelly, 1999; Cissna et al., 1990; Kaplan \& Hennon, 1992; Mills, 1984; Nicholson et al., 2007; Visher \& Visher, 1988) agreement between parents and children was found to be more predictive of positive functioning. It might be important to encourage parents and children to discuss their expectations regarding the stepparent role so that some agreement can be reached. While stepparents should certainly be involved at some stage of the role negotiation process, clinicians might be best advised to initially 
involve children and biological parents, with parents later discussing issues with their partners. Stepparents and children lack the shared history of parents and children, therefore discussion of contentious issues, like the stepparent role, might best initially involve parents and children.

While explicit talks between children and stepparents may not be beneficial, stepparents should be encouraged to check in with stepchildren regarding their perceptions of their parenting behaviours. This process of checking in was associated with more positive relationships between stepparents and stepchildren over time. Interestingly, although gate keeping behaviours were more likely to occur in stepfamilies that were experiencing problems, these behaviours actually led to a reduction in the quality of the relationship between stepparents and children. Biological parents might be best advised to engage in role negotiation strategies, other than gate keeping behaviours, when there are problems in stepfamily functioning. In addition, if further research finds similar findings regarding the detrimental effect of gate keeping behaviours, it may be advantageous for clinicians to educate parents in regards to the potential negative effects of these behaviours on the relationship between their partners and children. This might be useful information for biological parents in stepfamilies; enabling them to strengthen their stepfamily experiences.

In addition, these results suggest that clinicians should pay attention to the extent to which children's and stepparents' ideal role perceptions are consistent with the stepparent's actual behaviour. In contrast to parents, children's and stepparents' intrarole discrepancies were associated with many aspects of stepfamily functioning. While this study provides evidence for the importance of children and stepparent intra-role discrepancies, it is unclear how these issues might be best resolved in stepfamilies. While future research might focus on the processes by which intra-role discrepancies for stepparents and children improve over time, it is likely that informing stepparents of children's expectations may play some role in reducing role discrepancies and improving stepfamily dynamics.

This study provides further support that many stepparents in New Zealand are playing involved and valued roles in children's lives. As other studies have found (e.g. Ahrons 
\& Wallisch, 1987; Fine et al., 1998; Smith et al., 2001) stepparents were involved in an assortment of parenting behaviours, such as emotional and financial support, daily child care, social guidance and monitoring, and disciplinary behaviours. This suggests that the social status of stepparents may be inconsistent with the legal recognition of stepparents which has generally failed to recognise the relationship between stepparents and stepchildren (Atkin, 2004). For instance, stepparents are rarely required to support their stepchildren financially and it is often difficult for stepparents to maintain contact with stepchildren in the event of the separation or death of the child's biological parent (Fine, 1997). Furthermore, stepparents who are involved in their stepchildren's schooling frequently find that the customs of school systems provide little allowance for the presence of stepparents (Ganong \& Coleman, 1994).

To address these concerns there have been recent changes in the law in New Zealand concerning stepfamilies as a means of empowering the role of the stepparent. In 2004, the Guardianship Act 1968 was replaced by the Care of Children Act 2004, which created an avenue for a stepparent to be appointed as a guardian to his or her stepchild, without a decision made by a Family Court Judge. These new guidelines, which have been labeled the 'Do it Yourself' (or DIY procedure) were designed as a means of giving legal effect to care arrangements already in existence, while saving the costs of time and money involved in a decision by a Family Court Judge (Watt, 2004). The findings from this study, therefore, provide validation and support for legal and policy procedures (like the DIY procedure) that seek to extend stepparents' responsibilities to stepchildren.

Finally, findings regarding the nature of role negotiation and the stepparent role components that are associated with positive functioning provide important information for individuals living in stepfamilies. Many of the adults who participated in this study emphasised the need for practical information concerning how to best develop stepfamily relations. Stepfamily individuals often reported feeling poorly prepared and hesitant about entering stepfamily life, and were concerned about the lack of practical information available to assist in this process. In fact, many stepfamilies intentionally decided to take part in this study to help other families, like themselves, who are anticipating or experiencing stepfamily life. 


\subsection{Conclusions}

Many children in New Zealand grow up in stepfamilies and this is likely to increase further as adults create new ways of forming families other than the nuclear family model. The majority of previous research has been based on comparison studies, which contributes to the perception of stepfamilies as deficient family structures for children. While there are indications of increased risks for children in stepfamilies and evidence that stepparents may be less involved in the parenting of stepchildren, outcomes depend on a variety of structural, individual and family process variables. In contrast to perceptions of stepparents as uninvolved or abusive to their stepchildren, this study suggests that many stepparents are actively involved in a variety of parental behaviours and the majority of stepchildren experience relatively close relationships with stepparents.

Although many stepparents play active roles in their stepchildren's lives, this study highlights the importance of children's perceptions of the stepparent role and the degree to which these are consistent with other stepfamily members (inter-role discrepancies). In particular, children's agreement with biological parents regarding the stepparent role appears to be more important than agreement with stepparents in predicting stepfamily functioning. The extent to which children's role expectations are consistent with the stepparent's actual role behaviours (intra-role discrepancies) was found to have important effects on children's functioning.

The research also extends present understandings of role negotiation that has continued to receive scant empirical attention. This study is one of the first to show quantitatively that stepfamily members employ a variety of strategies to negotiate the stepparent role, although role negotiation is more common after moving in together. In general, non-explicit strategies were more commonly used than explicit strategies, in

particular gate keeping behaviours by biological parents. However, partner talks were commonly used by stepfamily adults to negotiate roles and many biological parents also discussed roles explicitly with their children. There was some evidence that role negotiation was used when stepfamilies were experiencing difficulties, and that these 
strategies led to some improvement in stepfamily dynamics over time, although gate keeping behaviours may deteriorate relationships between stepparents and stepchildren.

Finally, this study is the first to provide quantitative evidence that role discrepancies are significantly associated with children's perceptions of stepfamily functioning over time, beyond the stepparent's actual level of involvement. These findings extend previous cross-sectional studies on the stepparent role that have linked the stepparent role with stepfamily functioning at one point in time. This study is important in showing that role discrepancies for children (both inter and intra) are positively associated with less positive stepfamily functioning over time. It also provides empirical support for many clinical observations, especially the importance of intrarole discrepancies and role negotiation strategies. This research suggests that role discrepancies are important to stepfamilies, particularly for stepchildren. Further research needs to further examine the impact this has on the stepfamily over greater periods of time and how these issues are best negotiated in their families. The importance of further elucidating these complex processes is clear: it has the potential to be of immense use to those working with stepfamilies, and stepfamily members themselves. 
"I tried to cultivate the role for the first 3 years........ I tried to cultivate this role, And I was all over the shop. I didn't know what it was or what I was doing, and that's why when I heard about this study, I was like this is what I needed, some resources..."

(Stepparent interviewed in this study) 


\section{THE IMPORTANCE OF PERCEPTIONS..........}

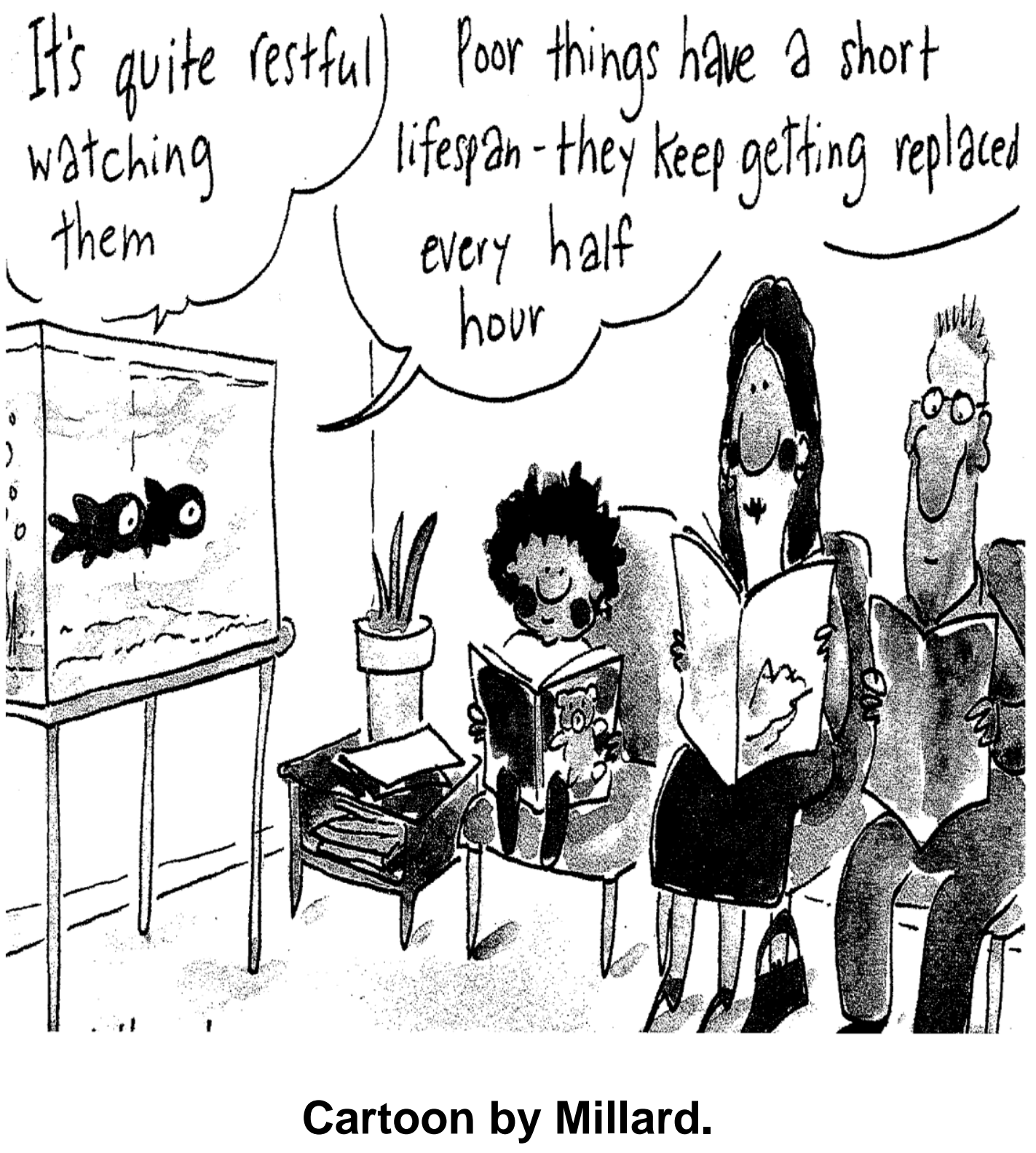


Adler-Baeder, F; \& Higginbotham, B. (2004). Implications of remarriage and stepfamily formation for marriage education. Family Relations, 53(5), 448-458.

Afifi, T.D. (2003). "Feeling caught" in stepfamilies: Managing boundary turbulence through appropriate communication privacy rules. Journal of Social and Personal Relationships, 20(6), 729-755.

Ahrons, C. R; \& Wallisch, L. (1987). Parenting in the binuclear family: Relationships between biological and stepparents. In K. Pasley; \& M. Ihinger-Tallman. (Eds.) Remarriage and step parenting: Current research and theory (pp. 225-256). Publication?

Aldous, J; Mulligan, G; \& Bjarnason, T. (1998). Fathering over time: What makes the difference? Journal of Marriage \& the Family, 60(4), 809-820.

Allen, S.M; \& Hawkins, A.J. (1999). Maternal gate keeping: Mothers' beliefs and behaviours that inhibit greater father involvement in families. Journal of Marriage and the Family, 61(1), 199-212.

Ambert, A. (1986). Being a stepparent: Live-in and visiting stepchildren. Journal of Marriage and the Family, 48, 795-804.

Amato, P. R. (1987). Family process in one-parent, stepparent, and intact families: The child's point of view. Journal of Marriage and the Family, 49, 327-337.

Amato, P. R. (1993). Children's adjustment to divorce: Theories, hypotheses, and empirical support. Journal of Marriage and the Family, 55, 23-38.

Amato, P. R. (1994). Father-child relations, mother-child relations, and offspring psychological well-being in early adulthood. Journal of Marriage and the Family, 56, 1031-1042.

Amato, P.R. (2000). The consequences of divorce for adults and children. Journal of Marriage and the Family, 62, 1269-1287.

Amato, P.R. (2010). Research on divorce: Continuing trends and new developments. Journal of Marriage and the Family, 72(3), 650-666.

Amato, P. R; \& Booth, A. (1996). A prospective study of parental divorce and parentchild relationships. Journal of Marriage and the Family, 58, 356-365.

Amato, P. R; \& Keith, N. (1991). Parental divorce and the well-being of children: A meta analysis. Psychological Bulletin, 110, 26-46. 
Anderson, E.R; Greene, S.M; Hetherington, E.M; \& Clingempeel, W.G. (1999). The dynamics of remarriage: Adolescent, parent and sibling influences. In E.M. Hetherington (Ed). Coping with divorce, single parenting and remarriage: $A$ risk and resiliency perspective. Lawrence Erlbaum Publishers, NJ, 295-319.

Anderson, E. R; \& Greene, S. M. (2005). Transitions in parental re-partnering after divorce. Journal of Divorce and Remarriage, 43(3), 47-62.

Anderson, J; \& White, G. (1986). An empirical investigation of interactive and relationship patterns in functional and dysfunctional nuclear families and stepfamilies. Family Process, 25, 407-422.

Anyan, S; \& Pryor J. (2002). What is in a family? Adolescent perceptions. Children and Society, 16, 1-12.

Aquilino, W.S. (1996). The life course of children born to unmarried mothers: childhood living arrangements and young adult outcomes. Journal of Marriage and the Family, 58(2), 293-310.

Aseltine, R. H. (1996). Pathways linking parental divorce with adolescent depression. Journal of Health and Social Behavior, 37, 133-148.

Astone, N.M; \& McLanahan, S.S. (1991). Family structure, parental practices and high school completion. American Sociological Review, 56, 309-20.

Atkin, B. (2004). Stepfamilies: Their inconclusive place in the law at Stepfamilies: research, legal, and clinical perspectives. An update (Roy McKenzie Centre for the Study of Families) (Wellington, August, 2004).

Retrieved 9 September, 2008, from http://www.victoria.ac.nz/mckenziecentre/news/pastevents/presentations/stepfamilies-atkin.pdf

Australian Bureau of Statistics. (1998). Family Characteristics, Australia. (No. 4442.0). Canberra, ACT: Author.

Baker, A; Barthelemy, K.J; \& Kurdek, L.A. (1993). The relation between classroom social status and family and neighbourhood factors in fifth and sixth graders. Journal of Applied Developmental Psychology. The rest?

Banker, B.S; Gaertner, S.L; Dovidio, J.F; Houlette, M; Johnson, K.M. \& Riek, B.M. (2004). Reducing stepfamily conflict: The importance of inclusive social identity. In M. Bennett \& F. Sani (Eds.). The development of the social self. (pp. 267-288). New York: Psychology Press. 
Barber, B. L; \& Lyons, J. M. (1994). Family processes and adolescent adjustment in intact and remarried families. Journal of Youth and Adolescence, 23(4), 421436.

Barnett, R. C; \& Shen, Y. (1997). Gender, high- and low-schedule-control housework tasks, and psychological distress: A study of dual-earner couples. Journal of Family Issues, 18, 403-428.

Barrett, A.E; \& Turner, R.J. (2005). Family structure and mental health: the mediating effects of socioeconomic status, family process, and social stress. Journal of Health and Social Behaviour, 46, 156-169.

Bartlett, M.S. (1954). A note on the multiplying factors for various $\mathrm{x}^{2}$ approximation. Journal of the Royal Statistical Society, Series B16, 296 - 298.

Baumrind, D. (1968). Authoritarian vs. authoritative parental control. Adolescence, 3, 255-272.

Baxter, L. A; Braithwaite, D. O; \& Bryant, L. (2006). Types of communication triads perceived by young-adult stepchildren in established stepfamilies. Communication Studies, 37, 381-400.

Baxter, L. A; Braithwaite, D. O; Bryant, L; \& Wagner, A. (2004). Stepchildren's perceptions of the contradictions in communication with stepparents. Journal of Social and Personal Relationships, 21(4), 447-467.

Beaudry, M; Boisvert, J.M; Simard, M; Parent, C; Blais, M.C. (2004). Communication: a key component to meeting the challenges of stepfamilies. Journal of Divorce and Remarriage, 42, (1/2), 85-104.

Bechhofer, F; \& Paterson, L. (2000). Principles of research design in the social sciences. Routledge.

Bell, R.A; \& Daly, J.A. (1984). The affinity-seeking function of communication. Communication Monographs, 51, 91-114.

Belsky, J. (1993). Promoting father involvement-An analysis and critique: Comment on Silversteen. Journal of Family Psychology, 7(3), 287-292.

Berg, E.C. (2003). The effects of perceived closeness to custodial parents, stepparents and non-resident parents on adolescent self-esteem. Journal of Divorce and Remarriage, 40(12), 69-86.

Berger, R. (1998). The experience and issues of gay stepfamilies. Journal of Divorce and Remarriage, 29(2), 93-102.

Bernstein, A. C. (1989). Yours, mine, and ours. New York: Norton. 
Bernstein, A.C. (2000). Remarriage: redesigning couplehood. In P. Papp (Ed.), Couples on the Fault Line: New Directions for Therapists (pp. 284-311). New York: Guilford Press.

Biddle, B.J. (1986). Recent development in role theory. Annual Review of Sociology, $12,67-92$.

Booth, A; \& Amato, P. (1991). Divorce and psychological stress. Journal of Health and Social Behaviour, 32, 396-407.

Booth A; \& Edwards J.N. (1992). Starting over: why remarriages are more unstable. Journal of Family Issues, 13, 179-194.

Braithwaite, D. O; McBride, M. C; \& Schrodt, P. (2003). "Parent teams" and the everyday interactions of co-parenting in stepfamilies. Communication Reports, 16(2), 93-109.

Braithwaite, D. O; Olson, L. N; Golish, T. D; Soukup, C; \& Turman, P. (2001). "Becoming a family": Developmental processes represented in blended family discourse. Journal of Applied Communication Research, 29(3), 221-247.

Brand, E; Clingempeel, W. G; \& Bowen-Woodward, K. (1988). Family relationships and children's psychological adjustment in stepmother and stepfather families. In E. M. Hetherington \& J. D. Arasteh (Eds.). Impact of divorce, single parenting, and step parenting on children.

Bray, J. H. (1988). Children's development in early re- marriage. In E. M. Hetherington \& J. Arasteh (Eds.). The impact of divorce, single-parenting and step-parenting on children (pp. 279-298). New York: Lawrence Earlbaum.

Bray, J. H. (1999). Stepfamilies: the intersection of culture, context and biology. Monographs of the society for research in child development, 64(4) 210-218.

Bray, J. H. (1999). From marriage to remarriage and beyond: Findings from the Developmental Issues in Stepfamilies research project. In E. M. Hetherington (Ed.). Coping with divorce, single-parenthood and remarriage: A risk and resiliency perspective (pp. 253-271). Mahwah, NJ: Erlbaum.

Bray, J. H; \& Berger, S. H. (1993). Developmental issues in stepfamilies research project: Family relationships and parent-child interactions. Journal of Family Psychology, 7, 76-90.

Bray, J. H; Berger, S. H; \& Boethel, C. L. (1994). Role integration and marital adjustment in stepfather families. In K. Pasley \& M. Ihinger-Tallman (Eds.). Step-parenting: Issues in theory, research, and practice (pp. 15-32). Westport, CT: Greenwood Press.

Bray, J. H; Berger, S. H; Boethel, C. L; \& Maymi, J. R. (1989). Behavioural observations of developing stepfamilies. Paper presented at the 97th Annual Convention of the American Psychological Association: New Orleans, LA. 
Bray, J. H; \& Kelly, J. (1998). Stepfamilies: Love, marriage, and parenting in the first decade. New York: Broadway.

Bray, J. H; \& Kelley, J. (1999). Stepfamilies: Love, marriage, and parenting in the first decade. New York: Random House.

Breivik, K; \& Olweus, D. (2006) Children of divorce in a Scandinavian welfare state: are they less affected than US children? Scandinavian Journal of Psychology, 47, 61-74.

Brown, S; \& Booth, A. (1996). Cohabitation versus marriage: A comparison of relationship quality. Journal of Marriage and the Family, 58, 668-678.

Brown, A. C; Green, R.J; \& Druckman, J. (1990). A comparison of stepfamilies with and without child-focused problems. American Journal of Orthopsychiatry, 60, $556-566$.

Buchanan, C. M; Maccoby, E. E; \& Dornbusch, S. M. (1996). Adolescents after divorce. Cambridge: Harvard University Press.

Bumpass, L; Raley, R. K; \& Sweet, J. (1995). The changing character of stepfamilies: Implications of cohabitation and nonmarital childbearing. Demography, 32, 425-436.

Burgoyne, J; \& Clark, D. (1982a). From father to step-father. In L. McKee \& M. O'Brien (Eds.). The father figure (pp. 196-207).

Burgoyne, J; \& Clark, D. (1982b). Reconstituted families. In? (Ed.). Families in Britain (pp. 286-302). London: Routledge and Kegan Paul.

Burgoyne, J; \& Clark, D. (1984). Making a go of it: A study of stepfamilies in Sheffield. London: Routledge and Kegan Paul.

Cadolle, S. (2000). Etre parent, être beau-parent: La recomposition de la famille. Paris: Odile Jacob.

Carlson, M. J. (2006). Family structure, father involvement, and adolescent behavioural outcomes. Journal of Marriage and the Family, 68(1), 137-154.

Cartwright, J. (2000). Evolution and human behaviour. London: MacMillan.

Cartwright, C. (2005). Stepfamily living and parent-child relationships: an exploratory investigation. Journal of Family Studies, 11(2), 267-283. 
Cartwright, C; \& Seymour, F. (2002). Young adults' perceptions of parents' responses in stepfamilies: What hurts? What helps? Journal of Divorce and Remarriage, 37(3/4), 123-141.

Cattell, R. B. (1966). The scree test for the number of factors. Journal of Multivariate Behavioural Research, 1, $245-276$.

Cavanaugh, S; \& Huston, A. (2006). Family instability and children's early problem behaviour. Social Forces, 85, $575-605$.

Ceglian, C. P; \& Gardner, S. (1999). Attachment style: a risk for multiple marriages? Journal of Divorce \& Remarriage, 31(1/2), 125-139.

Ceglian, C. P; \& Gardner, S. (2000). Attachment style and the 'wicked stepmother' spiral. Journal of Divorce \& Remarriage, 34, 111-129.

Cherlin, A. (1978). Remarriage as an incomplete institution. American Journal of Sociology, 84(3), 634-650.

Cherlin, A. J. (2004). The deinstitutionalization of American marriage. Journal of Marriage and the Family, 66 (4), 848-861.

Cherlin, A. J; \& Furstenberg, F. F. (1994). Stepfamilies in the United States: a reconsideration. Annual Review of Sociology, 20, 359-381.

Cherlin, A. J; Furstenberg, F. F; Chase-Lonsdale, P. L; Kiernan, K. E; Robbins, P. K; Morrison, D. R; \& Teitler, J. (1991). Longitudinal studies of effects of divorce on children in Great Britain and the United States. Science 253, 1386-88.

Church, E. (1999). Who are the people in your family? Stepmothers' diverse notions of kinship. Journal of Divorce \& Remarriage, 31(1/2), 83-105.

Cissna, K. N; Cox, D. E; \& Bochner, A. P. (1990). The dialectic of marital and parental relationships within the stepfamily. Communication Monographs, 57, 44-61.

Clarke, S. C; \& Wilson, B. F. (1994). The relative stability of remarriages- a cohort approach using vital statistics. Family Relations, 43, 305-310.

Claxton-Oldfield, S. (1992). Perceptions of stepfathers: Disciplinary and affectionate behaviours. Journal of Family Issues, 13(3), 378-389.

Claxton-Oldfield, S \& Voyer, S. (2001). Young adults' perceptions of stepchildren. Journal of Divorce and Remarriage, 35 (1\&2), 107-114.

Claxton-Oldfield, S. \& Whitt, L. (2003). Child abuse in stepfather families: Do people think it occurs more often than it does in biological father families? Journal of Divorce and Remarriage, 40(1/2), 17-33. 
Clingempeel, W. G \& Brand, E. (1985). Quasi-kin relationships, structural complexity, and marital quality in stepfamilies: a replication, extension, and clinical implications Family Relations, 34(3), 401-409.

Clingempeel, W. G; Brand, E; \& Ievoli, R. (1984). Stepparent-stepchild relationships in stepmother and stepfather families: A multimethod study. Family Relations, $33(3), 465-473$.

Clingempeel, W. G; Brand, E; \& Segal, S. (1987). A multilevel-multivariabledevelopmental perspective for future research on stepfamilies. In K. Pasley \& M. Ihinger-Tallman (Eds.). Remarriage and step parenting: Current research and theory (pp. 225-256).

Cockett, M; \& Tripp, J. (1994). The Exeter family study. Exeter: University of Exeter Press.

Coleman, M. A; Fine, M. A; Ganong, L. G; Downs, K. M; \& Pauk, N. (2001). When you're not the Brady bunch: Identifying perceived conflicts and resolution strategies in stepfamilies. Personal Relationships, 8, 57-73.

Coleman, M; \& Ganong, L. (1990). Remarriage and stepfamily research in the 1980s: Increased interest in an old family form. Journal of Marriage and the Family, $52,925-940$.

Coleman, M; Ganong, L; \& Cable, S. (1997). Perceptions of stepparents: An examination of the incomplete institutionalization and social stigma hypotheses. Journal of Divorce and Remarriage, 26, 25-48.

Coleman, M; Ganong, L; \& Fine, M. (2000). Reinvestigating remarriage: Another decade of progress. Journal of Marriage and the Family, 62(4), 1288-1307.

Coleman, M; Ganong, L; \& Weaver, S. (2001). Relationship maintenance and enhancement in remarried families. In J. Harvey, \& A. Wenzel (Eds.). Close romantic relationships: Maintenance and enhancement (pp. 255-276). Mahwah, NJ: Lawrence Erlbaum.

Cooksey, E. C; \& Fondell, M. M. (1996). Spending time with his kids - effects of family-structure on fathers' and children's lives. Journal of Marriage and the Family, 58(3), 693-707.

Coverman, S. (1985). Explaining Husbands' Participation in Domestic Labour. Sociological Quarterly, 26, 81-97.

Crosbie-Burnett, M. (1984). The centrality of the step relationship: A challenge to family theory and practice. Family Relations, 33, 459-463. 
Crosbie-Burnett, M; \& Ahrons, C. R. (1985). From divorce to remarriage: implications for therapy with families in transition. Journal of Psychotherapy and the Family, 1, 121-137.

Crosbie-Burnett, M; \& Giles-Sims, J. (1994). Adolescent adjustment and step parenting styles. Family Relations, 43(4), 394-399.

Currier, C. (1982). Learning to step together: A course for stepfamily adults. Palo Alto, CA: Stepfamily Association of America.

Deater-Deckard, K; \& Dunn, J. (1999). Multiple risks and adjustment in young children growing up in different family settings: A British community study of stepparent, single mother, and non-divorced families. In E. M. Hetherington (Ed.). Coping with divorce, single parenting, and remarriage: A risk and resiliency perspective (pp. 47-65). Mahwah, NJ: Lawrence Erlbaum Associates, Inc.

De'Ath, E. (1992). Stepfamilies: What do we know? What do we need to know? London: Stepfamily.

Degarmo, D. S; \& Forgatch, M. S. (1999). Contexts as predictors of changing parenting practices in diverse family structures: A social interactional perspective to risk and resilience. In Hetherington, E. M. (Ed) Coping with Divorce, Single Parenting, and Remarriage: A Risk and Resiliency Perspective. (pp. 227 -252). Mahwah, NJ: Erlbaum.

DeGarmo, D. S; \& Forgatch, M. S. (2007). Efficacy of Parent Training for Stepfathers: From Playful Spectator and Polite Stranger to Effective Step fathering. Science and Practice, 7(4), 1-41.

Demo, D. H; \& Acock, A. C. (1996a). Family structure, family process, and adolescent well-being. Journal of Research on Adolescence, 6, 457-488.

De Vaus, D. (2004). Diversity and change in Australian families: Statistical profiles. Melbourne: Australian Institute of Family Studies.

De Vaus, D; Qu, L; \& Weston, R. (2005) The disappearing link between premarital cohabitation and subsequent marital stability, 1970-2001. Journal of Population Research, 22, 99-118.

Dharmalingam, A; Pool, I; Sceats, J; \& Mackay, R (2004). Patterns of Family Formation and Change in New Zealand. Centre for Social Research and Evaluation, Ministry of Social Development. http://www.msd.govt.nz/documents/work-areas/csre/patterns-family-formation$\underline{\text { nz.pdf }}$

Dowling, E; \& Gorell Barnes, G. (2000). Working with children and parents through separation and divorce. The changing lives of children. London: MacMillan, 2000 . 
Duberman, L. (1973). Step-kin relationships. Journal of Marriage and the Family, 35, 283-292.

Duncan, G. J \& Gunn-Brooks, 2000. Family poverty, welfare reform and child development. Child development, 71(1) 188-196

Dunn, J. (2002). The adjustment of children in stepfamilies: Lessons from community studies. Child and Adolescent Mental Health, 7(4), 154-161.

Dunn, J. (2004). Understanding children's family worlds: Family transitions and children's outcome. Merrill-Palmer Quarterly, 50, 1-16.

Dunn, J. (2005). 'Daddy doesn't live here anymore'. The Psychologist, 18(1), 28-31.

Dunn, J; Davies, L; O'Connor, T. G; \& Sturgess, W. (2000). Children's perspectives on their family lives and friendships in step-, single-parent and non-step families. Manuscript submitted for publication.

Dunn, J; Deater-Deckard, K; Pickering, K; \& O’Connor, T. G. (1998). Children's adjustment and prosocial behaviour in step-, single- parent, and nonstrepfamily settings: findings from a community study. Journal of Child Psychology and Psychiatry, 39(8), 1083- 1095.

Dunn, J; Deater-Deckard, K; Pickering, K; \& O’Connor, T. G. (1998). Children's adjustment and prosocial behaviour in step-, single-parent, and non-stepfamily settings: findings from a community study. Journal of Child Psychiatry, 39 (8) 1083- 1095.

Dunn, J; Deater-Deckard, K; Pickering, K; \& ALSPAC Study Team. (1999). Siblings, parents, and partners: Family relationships within a longitudinal community study. Journal of Child Psychology and Psychiatry, 40, 1025-1037.

Dunn, J; \& Deater-Deckard, K. (2001). Children's views of their changing families. In J. R. Foundation (Ed.): York Publishing Services Limited: 64 Hallfield Road, Layerthorpe, York YO31 7ZQ.

Dunn, J; O'Connor, T; \& Levy, I. (2002). Out of the picture: A study of family drawings by children from step-, single-parent, and non-step families. Journal of Clinical Child and Adolescent Psychology, 31, 505-512.

Dupuis, S. B. (2007). A look at issues affecting remarried couples and the implications towards therapeutic techniques. Journal of Divorce and Remarriage, 48(1\&2), 91-104.

Edgar, D; \& Glezer, H. (1992). A man's place? Reconstructing family realities. Family Matters, 31, April, 36-39. 
England, P; \& Farkas, G. (1986). Households, Employment and Gender: A Social. Economic and Demographic View. New York: Aldine.

Erera-Weatherley, P. I. (1996). On becoming a stepparent: Factors associated with the adoption of alternative step parenting styles. Journal of Divorce and Remarriage, 25(3/4), 155-174.

Everett, L. W. (1998). Factors that contribute to satisfaction or dissatisfaction in stepfather-stepchild relationships. Perspectives in Psychiatric Care, 34(2), 2535 .

Falci, (2006). Family structure, closeness to residential and non-residential parents, and psychological distress in early and middle adolescence. Sociological Quarterly, 47(1), 123-146.

Feldman, S. S; \& Weinberger, D. A. (1994). Self-restraint as a mediator of family influences on delinquent behaviour: a longitudinal study. Child Development, $65,195-211$.

Felker, J. A; Fromme, D. K; Arnaut, G. L; \& Stoll, B. M. (2002) A qualitative analysis of stepfamilies: The stepparent. Journal of Divorce \& Remarriag, 38, 125-142.

Fellmann, I. E; Carrasco Galan, M. J; Roque, I. M; \& Galan, I. C. (2008). Spanish adaptation of the stepparent role strain index. The Spanish Journal of Psychology, 11(1), 314-322.

Fergusson, D; \& Horwood, L. (1987). The trait and method components of ratings of conduct disorder - part 1. Maternal and teacher evaluations of conduct disorder in young children. Journal of Child Psychology and Psychiatry, 28, 249-260.

Fergusson, D. M; Horwood, L. J; \& Dimond, M. E. (1985). A survival analysis of childhood family history. Journal of Marriage and thr Family, 47, 287-295.

Fergusson, D. M; Horwood, L.J; \& Lawton, J. M. (1988). The influence of family order and selection factors on the stability of first and second families.

Christchurch Child Development Study, Christchurch School of Medicine, Christchurch, New Zealand (1988).

Fergusson, D. M; Horwood, L. J; \& Lynskey, M. T. (1992). Family change, parental discord and early offending. Journal of Child Psychology and Psychiatry, 33, 1059-1075.

Fergusson, D. M; Horwood, L. J; Shannon, F. T. (1984). A proportional hazards model of family breakdown. Journal of Marriage and the Family, 46(3), 539-549. 
Ferri, E; \& Smith, K. (1998). Step-parenting in the 1990s. London and York: Family Policy Studies Centre/Joseph Rowntree Foundation.

Field, A. (2000). Discovering statistics using spss for windows. London, Thousand Oaks, New Delhi: SAGE Publications.

Fine, M. A. (1997). Helping children cope with marital conflict, divorce, and remarriage. In Session- Psychotherapy in Practice, 3(1), 55-67.

Fine, M. (1997). Stepfamilies from a policy perspective: Guidance from the empirical literature. Marriage and Family Review, 26(3/4), 249-264.

Fine, M. A; Ganong, L. H; \& Coleman, M. (1997). The relation between role constructions and adjustment among stepfathers. Journal of Family Issues, 18, $503-525$.

Fine, M. A; Coleman, M; \& Ganong, L. H. (1998). Consistency in perceptions of the step-parent role among step- parents, parents and step-children. Journal of Social and Personal Relationships, 15(6), 810-828.

Fine, M. A; Coleman, M; \& Ganong, L. H. (1999). A social constructionist multimethod approach to understanding the stepparent role. In E. M. Hetherington (Ed.). Coping with divorce, single parenting and remarriage (pp. 273-294). New Jersey, London: Lawrence Erlbaum Associates.

Fine, M. A; \& Everett, C. A. (1996). The clarity and content of the stepparent role: A review of the literature. In M. A. Fine; \& C. A. Everett (Eds.) Understanding stepfamilies: Their structure and dynamics (pp. 19-34). New York: The Haworth Press, Inc.

Fine, M. A; \& Fine, D. R. (1992). Recent changes in laws affecting stepfamilies: Suggestions for legal reform. Family Relations, 41, 334-340.

Fine, M. A; \& Kurdek, L. A. (1992). The adjustment of adolescents in stepfather and stepmother families. Journal of Marriage and the Family, 54(4), 725-736.

Fine, M. A; \& Kurdek, L. A. (1994a). A multidimensional cognitive-developmental model of stepfamily adjustment. In K. Pasley \& M. Ihinger-Tallman (Eds.). Step-parenting: Issues in theory, research, and practice (pp. 15-32). Westport, CT: Greenwood Press.

Fine, M. A; \& Kurdek, L. A. (1994b). Parenting cognitions in stepfamilies- differences between parents and stepparents and relations to parenting satisfaction. Journal of Social and Personal Relationships, 11(1), 95-112. 
Fine, M. A; Kurdek, L. A; \& Hennigen, L. (1992). Perceived self-competence, stepfamily myths, and (step)parent role ambiguity in adolescents from stepfather and stepmother families. Journal of Family Psychology, 6(1), 69-76.

Fine, M. A; Voydanoff, P; \& Donnelly, B. W. (1993). Relations between parental control and warmth and child well-being in stepfamilies. Journal of Family Psychology, 7, 222-232.

Fisher, P. A; Leve, L. D; O’Leary, C. C; \& Leve, C. (2003). Parental monitoring of children's behaviour: Variation across stepmother, stepfather, and two-parent biological families. Family Relations, 52, 45-52.

Fleming, R. (1999). Families of a different kind. Wellington, New Zealand: Families of Remarriage Project.

Flinn, M. V. (1988). Step- and genetic parent/offspring relationships in a Caribbean village. Ethology and Sociobiology, 9, 335-369.

Fomby, P; \& Cherlin, A. (2007). Family instability and child well-being. American Sociological Review, 72, 181 - 204.

Funder, K. (1996). Wellbeing in stepfamilies. In Remaking families (pp. 89-113). Melbourne: Australian Institute of Family Studies.

Furstenberg, F. F; Morgan, P. S; \& Allison, P. D. (1987). Paternal participation and children's well-being after marital dissolution. American Sociological Review, $52,695-701$.

Furstenberg, F. F; Nord, C. W; Peterson, J. L \& Zill, N. (1983) The life course of children of divorce: marital disruption and parental contact. American Sociological review, 48 (5) 656 - 668.

Furstenberg, F. F; \& Spanier, G B. (1984). Recycling the Family: Remarriage After Divorce. Beverly Hills, CA: Sage Publications.

Ganong, L; \& Coleman, M. (1986). A comparison of clinical and empirical literature on children in stepfamilies. Journal of Marriage and the Family, 48, 309-318.

Ganong, L; \& Coleman, M. (1989). Preparing for remarriage: Anticipating the issues, seeking solutions. Family Relations, 38, 28-33.

Ganong, L. H; \& Coleman, M. (1992). Adolescent stepchild-stepparent relationships: Changes over time. A paper presented at the National Council on Family Relations Annual Conference, Orlando, FL.

Ganong, L; \& Coleman, M. (1993). A meta-analytic comparison of the self-esteem and behavioural problems of stepchildren to children in other family structures. Journal of Divorce \& Remarriage, 19, (3 \&4), 143-164. 
Ganong, L; \& Coleman, M. (1993). An exploratory study of stepsibling subsystems. Journal of Divorce and Remarriage, 19(3-4), 125-141.

Ganong, L; \& Coleman, M. (1994a). Remarried family relationships. Newbury Park, CA: Sage.

Ganong, L. H; \& Coleman, M. (1994b). Adolescent stepchild-stepparent relationships: Changes over time. In K. Pasley \& Ihinger-Tallman (Eds.). Step parenting: Issues in theory, research and practice (pp. 87-106). New York: Greenwood.

Ganong, L; \& Coleman, M. (2004). Stepfamily relationships. New York: Kluwer/Plenum.

Ganong, L; Coleman, M; Fine, M; \& Martin, P. (1999). Stepparents' affinity-seeking and affinity-maintaining strategies with stepchildren. Journal of Family Issues, 20(3), 299-327.

Ganong, L; Coleman, M; \& Mapes, D. (1990). A meta-analytic review of family structure stereotypes. Journal of Marriage and the Family, 52, 287-297.

Ganong, L; Coleman, M; \& Mistina, D. (1995). Normative beliefs about parents' and stepparents' financial obligations to children following divorce and remarriage. Family Relations, 44(3), 306 -315.

Giles-Sims, J. (1997). Current knowledge about child abuse in stepfamilies. Marriage and Family Review, 26(3/4), 215-230.

Giles-Sims, J; \& Crosbie-Burnett, M. (1989). Adolescent power in stepfather families: a test of normative-resource theory. Journal of Marriage and Family, 51(4), $1065-1078$

Giles-Sims, J; \& Crosbie-Burnett, M. (1989). Stepfamily research: Implications for policy, clinical interventions, and further research. Family Relations, 38, 1924.

Glasgow, K. L; Dornbusch, S. M; Troyer, L; Steinberg, L; \& Ritter, P. L. (1997). Parenting styles, adolescents' attributions, and educational outcomes in nine heterogeneous high schools. Child Development, 68, 507-529.

Golish, T. D. (2000). Is openness always better? Exploring the role of topic avoidance, satisfaction, and parenting styles of stepparents. Communication Quarterly, 48(2), 137- 159 .

Golish, T. D. (2003). Stepfamily communication strengths: Understanding the ties that bind. Human Communication Research, 29(1), 41-80.

Golish, T; \& Caughlin, J. (2002). "I'd rather not talk about it": adolescents' and young adults' use of topic avoidance in stepfamilies. Journal of Applied Communication Research, 30 (1), 78-106. 
Gonzales, J. (2009). Prefamily Counselling: Working with blended families. Journal of Divorce and Remarriage, 50 (2), 148-157.

Goodman, R. (1997). The strengths and difficulties questionnaire: A research note. Journal of Child Psychology and Psychiatry, 38(5), 581-586.

Goodman, R. (1999). The extended version of the Strengths and Difficulties Questionnaire as a guide to child psychiatric caseness and consequent burden. Journal of Child Psychology and Psychiatry, 40, 791-799.

Goodman, R. (2001). Psychometric properties of the strengths and difficulties questionnaire (SDQ). Journal of the American Academy of Child and Adolescent Psychiatry, 40, 1337-1345.

Goodman, R; Meltzer, H; \& Bailey, V. (1998). The strengths and difficulties questionnaire: a pilot study on the validity of the self-report version. European Child and Adolescent Psychiatry, 7(3), 125-130.

Gorell Barnes, G; Thompson, P; Daniel, G; \& Bruchardt, N. (1998). Growing up in step-families. Oxford: Claredon Press.

Gosselin, J; \& David, H. (2005). Défis et contraintes des recherches sur les familles recomposées : L'exemple de la relation belle-mère/belle-fille, Psychologie française, 50 (2), 241-354.

Greif, G. (1995). Single custodial fathers and their past relationships: Blueprint for the future? Journal of Couples Therapy, 5(1/2), 55-68.

Grych, J. H \& Fincham, F. D. (1990). Marital conflict and children's adjustment: a cognitive-contextual framework. Psychological Bulletin, 108, 267- 290.

Guisinger, S; Cowan, P. A; \& Schuldberg, D. (1989). Changing parent and spouse relations in the first years of remarriage of divorced fathers. Journal of Marriage and the Family, 51, 445-456.

Halford, K; Nicholson, J; \& Sanders, M. (2007). Couple communication in stepfamilies. Family Process, 46(4), 471-484.

Hall, K. J; \& Kitson, G. C. (2000). Lesbian stepfamilies. Journal of Lesbian Studies, 4 (3), 31-47.

Hampson, R. B; Hulgus, Y. F; \& Beavers, W. R. (1991). Comparisons of self-report measures of the Beavers systems model and Olson's circumplex model. Journal of Family Psychology, 4, 326-340.

Haskey, J. (1994). Stepfamilies and stepchildren in Great Britain. Population Trends, 76, 17 -28. 
Hattie, J. (1992). Self-concept. Hillsdale, NJ: Lawrence Erlbaum.

Hawes, D; \& Dadds, M. (2004). Australian data and psychometric properties of the strengths and difficulties questionnaire. Australian and New Zealand Journal of Psychiatry, 38, 644-651.

Henry, C. S; Sager, D. W; \& Plunkett, S. W. (1996). Adolescents' perceptions of family system characteristics, parent-adolescent dyadic behaviours, adolescent qualities, and adolescent empathy. Family Relations, 45, 283-292.

Hetherington, E. M. (1993). An overview of the Virginia longitudinal study of divorce and remarriage: A focus on early adolescence. Journal of Family Psychology, 7, 39-56.

Hetherington, E. M; Bridges, M; \& Insabella, G. M. (1998). What matters? What does not? Five perspectives on the association between marital transitions and children's adjustment. American Psychologist, 53(2), 167-184.

Hetherington, E. M; \& Clingempeel, W. G. (1992). Coping with marital transitions: A family systems perspective. Monographs of the Society for Research in Child Development, 57, 1-229.

Hetherington, E. M; Cox, M; \& Cox, R. (1982). Effects of divorce on parents and children. In M. E. Lamb (Ed.). Non-traditional families: Parenting and child development (pp. 233-288). Lawrence Erlbaum Associates.

Hetherington, E. M; \& Henderson, S. H. (1997). Fathers in stepfamilies. In M. E. Lamb (Ed.). The role of the father in child development (pp. 212-226). New York: John Wiley \& Sons.

Hetherington, E., Henderson, S.H., \& Reiss, D. (1999). Adolescent siblings in stepfamilies: Family functionality and adolescent adjustment. Monographs of the Society for Research in Child Development, 64, v-222.

Hetherington, E; \& Jodl, K. M. (1994). Stepfamilies as settings for child development. In A. Booth \& J. Dunn (Eds.). Stepfamilies. Who benefits? Who does not? (Vol. 233): Lawrence Erlbaum.

Hetherington, M; \& Kelly, J. (2002). For better or for worse: Divorce reconsidered. New York: W.W. Norton.

Hetherington, E. M; \& Stanley-Hagan, M. (2000). Diversity among stepfamilies. In D. H. Demo; K. R. Allen; \& M. A. Fine (Eds.), Handbook of family diversity. (pp. 173 - 196). New York: Oxford University Press.

Hetherington, E. M; Stanley-Hagan, M; \& Anderson, E. (1989). Marital transitions: a child's perspective. American Psychologist, 44, 303-312. 
Hiller, D. V. (1984). Power Dependency and Division of Family Work. Sex Roles, 10, 1003-1019.

Hobart, C. (1991). Conflict in remarriages. Journal of Divorce and Remarriage, 15(3/4), 69-86.

Hobcraft, J. N. 1998. Intergenerational and Life-Course Transmission of Social Exclusion: Influences of Child Poverty, Family Disruption, and Contact with the Police. CASE Paper 15, ESRC Centre for the Analysis of Social Exclusion, London School of Economics.

Hofferth, S. L; \& Anderson, K. G. (2001). Biological and stepfather investment in children: National Institute of Child Health and Human development Family and Child Well-being Research Network.

Hofferth, S. L; Cabrera, N; Carlson, M; Coley, R. L; Day, R; \& Schindler, H. (2007). Resident father involvement and social fathering. In S. Hofferth \& L. M Casper (Eds.). Handbook of measurement issues in family research (pp. 335 - 374). Mahwah, NJ: Erlbaum.

Hollander, E. P (1985). Leadership and power. In Lindzay, C; \& Aronson, E. (Eds.). Handbook of Social Psychology ( ${ }^{\text {rd }}$ edition.) (pp. 485-537). New York: Random.

Howden, M. (2004). Making molehills out of mountains: A practical guide for stepfamilies. Melbourne: Stepfamily Association of Victoria.

Howden, M. (2007) Stepfamilies: Understanding and responding effectively (AFRC Briefing No. 6) Australian Family Relationships Clearinghouse, Melbourne, Australia.

Ishi-Kuntz, M; \& Coltrane, S. (1992a). Predicting the sharing of household labour - are parenting and housework distinct? Sociological Perspectives, 35(4), 629-647.

Ishi-Kuntz, M; \& Coltrane, S. (1992b). Remarriage, step parenting and household labour. Journal of Family Issues, 13, 215-233.

Jackson, J. (1998). Contemporary criticisms of role theory. Journal of Occupational Science, 5(2), 49-55.

James, S; \& Hunsley, J. (1995). The Marital Adaptability and Cohesion Evaluation Scale III: Is the relation with marital adjustment linear or curvilinear? Journal of Family Psychology, 9, 458-462.

Jenkins, J. M; Simpson, A; Dunn, J., Rasbash, J; \& O’Connor T. G. (2005) The mutual influence of marital conflict and children's behaviour problems: shared and non-shared family risks. Child Development, 76, 24-39. 
Johnson, M. K; \& Hutchinson, R. L. (1989). Effects of family structure on children's self-concepts. Journal of Divorce, 12, (2\&3), 129-138.

Kaiser, H. F. (1970). A second generation Little Jiffy. Psychometrika, 35, 401-415.

Kaiser, H. F; \& Rice, J. (1974). Little Jiffy Mark IV. Educational and Psychological Measurement, 34, 111-117.

Kamo, Y. (1988). Determinants of household division of labor: resources, power, and ideology. Journal of. Family Issues, 9, 177-200.

Kaplan, L; \& Hennon, C. B. (1992). Remarriage education: The personal reflections program. Family Relations, 41(2), 127-134.

Kaufman, T. S. (1993). The combined family: A guide to creating successful steprelationships. New York: Plenum Press.

Kasen, S; Cohen, P; Brook, J; \& Hartmark, C. (1996). A multiple-risk interaction model: Effects of temperament and divorce on psychiatric disorders in children. Journal of Abnormal Child Psychology, 24(2), 121-150.

Kashani, J. H; Allan, W. D; Dahlmeier, J. M; Rezvani, M; \& Reid, J. C. (1995). An examination of family functioning utilizing the circumplex model in psychiatrically hospitalized children with depression. Journal of Affective Disorders, 35, 65-73.

Kelloway, E. K; \& Barling, J. (1991). Job characteristics, role stress, and mental health. Journal of Occupational Psychology, 64, 291-304.

Keshet, J. K. (1990). Cognitive remodelling of the family: How remarried people view stepfamilies. American Journal of Corthopsychiatry, 60 (2), 196-203.

Keshet, J. M.; Cath, S. H; \& Shopper, M. (Eds). (2001). Uncounted stepfamilies: Remarried fathers and their wives. Stepparenting: creating and recreating families in America today (pp. 245-261). NJ: The Analytic Press.

Kiernan, K. E. (1992). The impact of family disruption in childhood on transitions made in young adult life. Population Studies, 46, 213-234.

Kim, J. E; Hetherington, E. M; \& Reiss, D. (1999). Associations among family relationships, antisocial peers, and adolescents' externalizing behaviours: Gender and family type differences. Child Development, 70(5), 1209-1230.

King, S. (1989). Sex differences in a causal mode of career maturity. Journal of Counselling and Development, 68, 208-215.

King, V. (2006). The antecedents and consequences of adolescents' relationships with stepfathers and non-resident fathers. Journal of Marriage and Family, 68, 910-928. 
Kirby, J. B. (2006). From single-parent families to stepfamilies: Is the transition associated with adolescent alcohol initiation? Journal of Family Issues, 27, $685-711$.

Klasen, H; Woerner, W; Wolke, D; Meyer, R; Overmeyer, S; Kaschnitz, W; Rothenberger, A; \& Goodman, R. (2000). Comparing the german version of the Strengths and Difficulties Questionnaire (SDQ-Deu) and the Child Behaviour Checklist. European Child and Adolescent Psychiatry, 9, 271-276.

Kurdek, L. A. (1999). The nature and predictors of the trajectory of change in marital quality for husbands and wives over the first 10 years of marriage. Developmental Psychology, 35, 1283-1296.

Kurdek, L. A; \& Fine, M. A. (1991). Cognitive correlates of satisfaction for mothers and stepfathers in stepfather families. Journal of Marriage and the Family, 53, 565-572.

Kurdek, L. A; \& Fine, M. A. (1993a). Parent and nonparent residential family members as providers of warmth and supervision to young adolescents. Journal of Family Psychology, 7(2), 245-249.

Kurdek, L. A; \& Fine, M. A. (1993b). The relation between family-structure and young adolescents' appraisals of family climate and parenting behaviour. Journal of Family Issues, 14(2), 279-290.

Kurdek, L. A; \& Fine, M. A. (1995). Mothers, fathers, stepfathers, and siblings as providers of supervision, acceptance, and autonomy to young adolescents. Journal of Family Psychology, 9(1), 95-99.

Kurdek, L. A; Fine, M. A; \& Sinclair, R. J. (1995). School adjustment in 6th-gradersparenting transitions, family climate, and peer norm effects. Child Development, 66(2), 430-445.

Lamb, M. E; \& Tamis-Lemonda, C. S. (2004). The role of the father: An introduction. In M. E. Lamb (Ed). The role of the father in child development (4th edition) (pp. 1-31). New York: Wiley.

Lansford, J. E; Ceballo, R; Abbey, A; \& Stewart, A. J. (2001). Does family structure matter? A comparison of adoptive, two-parent biological, single-mother, stepfather, and stepmother households. Journal of Marriage and the Family, $63,840-851$.

Larson, J. (1992). Understanding stepfamilies. American Demographics, 14(7), 36-40. 
LaRossa, R \& Reitzes, D. C. (1993). Symbolic interactionism and family studies. In P. G. Boss; W. J. Doherty; R. LaRossa; W. R. Schumm; \& S. K. Steinmetz, (Eds.) Sourcebook of family theories and methods: a conceptual approach (pp. 135 163). New York: Plenum.

Leduc, F. (2004). Tendances actuelles dans l'univers familial, Psychologie Québec, 21 (2), 34-38.

Leman, K. (1994) Living in a step-family without getting stepped on. Thomas Nelson ,Nashville, TN.

Leslie, L. A; \& Epstein, N. (1988). Cognitive-behavioural treatment of remarried families. In Epstein, N; Schlesinger, S. E; \& Dryden, W. (Eds.) CogntiiveBehavioural Therapy with Families (pp. 151-182). New York: Brunner /Mazel.

Levin, I. (1996). Stepfamily as Project. Marriage and Family Review, 26(1), 123-133.

Levin, I. (1997). The stepparent role from a gender perspective. Marriage and Family Review, 26(1/2), 177-190.

Lightcap, J. L; Kurland, J. A; \& Burgess, R. L. (1982). Child abuse: A test of some predictions from evolutionary theory. Ethology and Sociobiology, 3, 61-67.

Linton, R. (1936). The Study of Man. New York: Appleton-Century

Lutz, E. P. (1983). The stepfamily: An adolescent perspective. Family Relations, 32, 367-376.

Maccoby, E. E; Depner, C; \& Mnookin, R. H. (1988). Co-parenting after divorce: Communication, cooperation and conflict. Unpublished manuscript. Stanford University, Center for the Study of Youth Development.

Maccoby, E. \& Martin, J. (1983). Socialization in the context of the family: parentchild interaction. In E. M. Hetherington (Ed). Handbook of child psychology: socialization, personality and social development (pp. 1-101). New York: Plenum Press.

MacDonald, W; \& DeMaris, A. (1996) Parenting stepchildren and biological children: The effects of stepparent's gender and new biological children. Journal of Family Issues, 17, 5-25.

MacDonald, W. L; \& DeMaris, A. (2002). Stepfather-stepchild relationship quality. Journal of Family Issues, 23(1), 121-137.

Mackay, R. (2005). The impact of family structure and family change on child outcomes: a personal reading of the research literature. Social Policy Journal of New Zealand. Accessed February 18, 2008. 
Malia, S. E. C (2005). Balancing family members' interests regarding stepparent rights and obligations: a social policy challenge. Family Relations, 54, 298-319.

Marotz -Baden, R; Adams, G. R; Bueche, N; Munro, B; \& Munro, G. (1979). Family form or family process? Reconsidering the deficit family model approach. The Family Coordinator, 28(1), 5-14.

Marsiglio, W. (1991). Paternal engagement activities with minor children. Journal of Marriage and the Family, 53, 973-986.

Marsiglio, W. (1992). Stepfathers with minor children living at home: Parenting perceptions and relationship quality. Journal of Family Issues, 13(2), 195-214.

Marsiglio, W. (2004). When stepfathers claim stepchildren: A conceptual analysis. Journal of Marriage and the Family, 66, 22-39.

Marsiglio, P; \& Hinojosa, R. (2007). Managing the multifather family: Stepfathers as father allies. Journal of Marriage and Family, 69, 845-862.

Maslach, C; \& Goldberg, J. (1998). Prevention of burnout: New perspectives. Applied and Preventive Psychology, 7, 63-74.

Mason, M. A; Harrison-Jay, S; Svare, G. M; \& Wolfinger, N. H. (2002). Stepparents: defacto parents or legal strangers? Journal of Family Issues, 23(4), 507-522.

Mead, G. H. (1934). Mind, self \& society: From the standpoint of a social behaviorist. Chicago: The University of Chicago Press.

Mead, G. H. (2001). Mind, self and society. In Margolis, J; \& Catudal, J. (Eds.). The quarrel between invariance and flux: a guide for philosophers and other players. (pp. 23 -234). Penn State Press.

Mekos, D; Hetherington, E. M; \& Reiss, D. (1996). Sibling differences in problem behavior and parental treatment in non-divorced and remarried families. Child Development, 67, 2148-2165.

Melby, J. N; Conger, R. D. (2001). The Iowa Family Interaction Rating Scales: Instrument summary. In P. Kerig \& K. Lindahl (Eds.). Family observational coding systems: Resources for systematic research (pp. 33-58). Mahwah, NJ: Erlbaum.

Melby, J. N; Conger, R; Conger, K. J; \& Lorenz, F. O. (1993). Effects of parental behaviour on tobacco use by young male adolescents. Journal of Marriage and the Family, 55, 439-454. 
Melby J. N; Ge, X; Conger R. D; \& Warner, T. D (1995). The importance of task in evaluating positive marital interactions. Journal of Marriage and the Family. 57, 981-994.

Mellor, D. (2005) Normative data for the Strengths and Difficulties Questionnaire in Australia. Australian Psychologist, 40, 215-222.

Michaels, M. L. (2000). The stepfamily enrichment program: a preliminary evaluation using focus groups. American Journal of Family Therapy, 28(1), 61-73.

Michaels, M. L. (2006). Factors that contribute to stepfamily success. Journal of Divorce and Remarriage, 44, (3/4), 53-66.

Michaels, M. L. (2006). Stepfamily Enrichment Program: a preventative intervention for remarried couples. Journal for Specialists in Group Work, 31 (2), 135-152.

Michaels, M. L. (2007). Remarital issues in couple therapy. Journal of Couple and Relationship Therapy, 6(1/2), 125 -139.

Miller, J; \& Garrison, H. H. (1982). Sex roles: The division of labour at home and in the workplace. Annual Review of Sociology, 8, 237-262.

Milligan, S; Fabian, A; Coope, P; \& Errington, C. (2006). Family Wellbeing Indicators from the 1981-2001 New Zealand Censuses. Statistics New Zealand, Wellington.

Mills, D. M. (1984). A model for stepfamily development. Family Relations, 33, 365372 .

Montgomery, M. J; Anderson, E. R; Hetherington, E. M; \& Clingempeel, W. G. (1992). Patterns of court-ship for remarriage: Implications for child adjustment and parent-child relationships. Journal of Marriage and the Family, 54, 686698.

Moorw, S; \& Cartwright, C. (2005). Adolescents' and Young Adults' Expectations of Parental Responsibilities in Stepfamilies. Journal of Divorce and Remarriage, 43(1\&2), 109-128.

Mullick, M; \& Goodman, R. (2001). Questionnaire screening for mental health problems in 447 Bangladeshi children: A preliminary study. Social Psychiatry and Psychiatric Epidemiology, 36, 94-99.

Muris, P; Meesters C, \& Eijkelenboom A. (2004). The self-report version of the strengths and difficulties questionnaire: Its psychometric properties in 8 to 13 year old non-clinical children. British Journal of Clinical Psychology, 43, 437 448 .

Murphy, M; Glaser, K; \& Grundy, E. (1997). Marital status and long-term illness in Great Britain. Journal of Marriage and the Family, 59, 156-164. 
Nicholson, J. M; Fergusson, D. M; \& Horwood, L. J. (1999). Effects on later adjustment of living in a stepfamily during childhood and adolescence. Journal of Child Psychology and Psychiatry, 40(3), 405-416.

Nicholson, J. M; Halford, K; \& Sanders, M. (1996). Prevention of Distress in Stepfamilies: The Step Prep Project. In Family research: pathways to policy, 5th Australian Institute of Family Studies. Retrieved on 14 November, 2008, http://www.aifs.org.au.

Nicholson, J. M; Halford, W. K; Sanders, M. R; \& Phillips, M. (2007). A controlled trial of the Stepfamilies Positive Relationship Education Program (Step PREP). Paper under review.

Nicholson, J. M; Phillips, M; Whitton, S. W; Halford, K. W; Sanders, M. R. (2007). Promoting healthy stepfamilies: Couples' reasons for seeking help and perceived benefits from intervention. Family Matters, 77, 48-56

Nielsen, L. (1999). Stepmothers: Why so much stress? A review of the research. Journal of Divorce and Remarriage, 30, 115-148.

NSW Health Department (2001). Clinician's Reference Guide to NSW Mental Health Outcomes and Assessment Training, [MH-OAT], [Sydney], NSW Health Department.

Ochiltree, G. (1990). Children in stepfamilies. Sydney: Prentice Hall.

O’Connor, T. G; Dunn, J; Jenkins, J. M; Pickering, K; \& Rasbash, J. (2001). Family settings and children's adjustment: differential adjustment within and across families. The British Journal of Psychiatry, 179, 110-115.

Olson, D. H; \& Gorall, D. M. (2003). Circumplex model of marital and family systems. In F. Walsh (Ed.). Normal family processes (3rd edition)(pp. 514-48). New York: Guilford.

O'Connor, T. G; Hetherington, E. M; \& Clingempeel, W. G. (1997). Systems and bidirectional influences in families. Journal of Social and Personal Relationships, 14(4), 491-504.

O’Connor, T. G; Pickering, K; Dunn, J; Golding, J; \& the ALSPAC Study Team. (1999). Frequency and predictors of relationship dissolution in a community sample in England. Journal of Family Psychology, 13, 436-439.

Olson, D. H; Portner, J; Lavee, Y. (1985) Family adaptability and cohesion scales (FACES III). St Paul: University of Minnisota, Family Social Science.

Orchard, A; \& Solberg, K. (1999). Expectations of the stepmother's role. Journal of Divorce and Remarriage, 31, 107-123. 
Osborne, C; \& McLanahan, S. (2004). The effects of partnership instability on parenting and young children's health and behaviour. Centre for Research on Child Wellbeing Working Papers, No. 04-16-FF.

Palisi, B. J; Orleans, M; Caddell, D; \& Korn, B. (1991). Adjustment to step fatherhood: the effects of marital history and relations with children. Journal of Divorce and Remarriage, 14 (3/4), 89-106.

Papernow, P. (1988). Stepparent role development: from outsider to intimate. In W. R. Beer (1988). Relative Strangers: Studies of Step family Processes. (pp. 54-82). Totowa, NJ: Rowan \& Littlefield.

Papernow, P. L. (1993). Becoming a stepfamily: Patterns of development in remarried families. San Francisco: Jossey-Bass.

Papernow, P. (2006). Stepfamilies clinical update. Family Therapy Magazine, 5(3), 34-42.

Parsons, T; Shils, E. A. (1951). Toward a General Theory of Action. Cambridge, Mass: Harvard Univ. Press

Pasley, K; Dollahite, D. C; \& Ihinger-Tallman, M. (1993). Clinical applications of research findings on the spouse and stepparent roles in remarriage. Family Relations, 42(3), 315-322.

Pasley, K; \& Healow, C. L. (1987). .Adolescent self-esteem: a focus on children in stepfamilies. In E. M. Hetherington \& J. D. Arasten (Eds.). Impact of Divorce, Single Parenting, and Step Parenting on Children. (pp. 263-277). Hillsdale, NJ: Lawrence Erlbaum.

Pasley, K; \& Ihinger-Tallman, M. (1994). Step-parenting: Issues in theory, research, and practice. Westport, CT: Greenwood Press.

Pasley, K; Ihinger-Tallman, M; \& Lofquist, A. (1994). Remarriage and stepfamilies. In K. Pasley \& M. Ihinger-Tallman (Eds.). Step parenting (pp. 1-15). Westport, CT: Greenwood.

Patterson, G. R. (1982). Coercive family process. Eugene, OR: Castilia.

Peek, C. W; Bell, N. J; Waldren, T; \& Sorell, T. (1988). Patterns of functioning in families of remarried and first-married couples. Journal of Marriage and the Family, 50, 699-708.

Peiro, J. M; Gonzales-Roma, V; Tordera, N; \& Manas, M. A. (2001) Does role stress predict burnout over time among health care professionals? Psychology and Health, 16, 511-525. 
Pink, J. E. T; \& Wampler, K. S. (1985). Problem areas in stepfamilies: Cohesion, adaptability, and the stepfather-adolescent relationship. Family Relations, 34, 327-335.

Pittman, J. F; Solheim, C. A; \& Blanchard, D. (1996). Stress as a driver of the allocation of housework. Journal of Marriage and the Family, 58, 456-468.

Pleck, J. H. (1997). Paternal involvement: Levels, sources, and consequences. In M. E. Lamb (Ed.). The role of the fathers in child development (pp. 66-103). New York: Wiley.

Popenoe, D. (1994). The evolution of marriage and the problem of stepfamilies. In A. Booth \& J. Dunn (Eds.). Stepfamilies: Who benefits? Who does not? (pp. 3-27). Hillsdale, NJ: Erlbaum.

Pruett, C. L; Calsyn, R. J; \& Jensen, F. M. (1993). Social support received by child in stepmother, stepfather, and intact families. Journal of Divorce \& Remarriage, 19(3/4), 165-180.

Pryor, J. (2004). Resilience in stepfamilies. Ministry of Social development: Wellington, New Zealand.

Pryor, J. (2005). Children in Changing Family Structures. Keynote presentation at the conference of the Australasian Human Development Association (AHDA), July, Perth, Australia.

Pryor, J. (2008). Children in stepfamilies: relationships with non-resident parents. In J. Pryor (Ed). The International Handbook of Stepfamilies. (pp. 345 -369). John Wiley \& Sons, Inc.

Pryor, J; \& Rodgers, B. (2001). Children in changing families: Life after parental separation. Oxford, UK: Blackwell Publishers Ltd.

Pryor, J; \& Trinder, L. (2004). Children, families, and divorce. In J. Scott; J. Treas; \& M. Richards (Eds.). The Blackwell companion to the sociology of families. (pp 322 -339). Blackwell Publishing.

Qu, L; \& Weston, R. (2005). Snapshot of couple families with stepparent-child relationships. Family Matters, 70, 36-37.

Quick, D. S; Newman, B. M; \& Mckenry, P. C. (1995). Influences on the quality of the stepmother adolescent relationship. Journal of Divorce and Remarriage, 4(1-2), 99- 114 .

Redman, R. M. (1991). The support of children in blended families: A call for change. Family Law Quarterly, 25, 83- 94. 
Rigg, A; \& Pryor, J. (2006). Children's perceptions of families: what do they really think? Children and Society, 21 (1), 17-30.

Ritchey, P; Fishbein, N; \& Harold, D. (2001). Lack of association between adolescent friends' prejudices and stereotypes. The Merrill-Palmer Quarterly, 188-206.

Robertson, J. (2008). Stepfathers in families. In J. Pryor (Ed.) The International Handbook of Stepfamilies. (pp. 125 -150). John Wiley \& Sons.

Rodgers, B; \& Pryor, J. (1998). Divorce and separation: The outcomes for children. York, UK: Joseph Rowntree Foundation.

Rodgers, R. H; \& White, J. M. (1993). Family Development Theory. In P. Boss; W. Doherty; R. LaRossa; W. Shumm; \& S. Steinmetz. (Eds.) Sourcebook of Family Theories and Methods. New York: Plenum Press.

Rosin, M. B. (1988). Step fathering. New York: Ballentine.

Roy Mackenzie Centre for the Study of Families. Youth Connectedness Project. Families/Whanau: Year 1 Data. June, 2007. http://www.victoria.ac.nz/mckenzie-centre/research/youth-connectedness/

Russell, A; \& Search, E. (1997). The contribution of affective reactions and relationship qualities to adolescents' reported responses to parents. Journal of Social and Personal Relationships, 14(4), 539-548

Rustia, J; \& Abbott, D. (1993). Father involvement in infant care: Two longitudinal studies. International Journal of Nursing Studies, 30(6): 467-476.

Schenck, C. E; Braver, S. L; Wolchik, S. A; Saenz, D; Cookston, J. T; \& Fabricius, W. V. (2006). Relations between mattering to step- and non-residential fathers and adolescent mental health. Fathering: A Journal of Theory, Research, and Practice about Men as Fathers, 7(1), 70-90.

Schmeeckle, M; Giarrusso, R; Feng, D; \& Bengtson, V. L. (2006). What makes someone family? Adult children's perceptions of current and former stepparents. Journal of Marriage and Family, 68, 595 - 610.

Schultz, N. C; Schultz, C. L; \& Olson, D. H. (1991). Couple strengths and stressors in complex and simple stepfamilies in Australia. Journal of Marriage and the Family, 53, 555-564.

Schwebel, A. I; Fine, M. A; \& Renner, M. A. (1991). A study of perceptions of the stepparent role. Journal of Family Issues, 12(1), 43-57.

Shavelson, R. J; Bolus, R; \& Keesling, J. W. (1980). Self-concept: recent developments in theory and methods. New Directions for Testing and Measurement, 7, 25-43. 
Shelton, B. A. (1992). Women, men and time: gender differences in paid work, housework, and leisure. New York: Greenwood Press.

Shucksmith, J; Hendry, L. B; \& Glendenning, A. (1995). Models of parenting: Implications for adolescent well-being within different types of family contexts. Journal of Adolescence, 18, 253-270.

Smith, T. A. (1992). Family cohesion in remarried families. Journal of Divorce and Remarriage, 17(1\&2), 49-66.

Smith, M. A; Robertson, J; Dixon, J; Quigley, M; \& Whitehead, E. (2001). A study of stepchildren and step-parenting: Final report to the Department of Health. London: Thomas Coram Research Unit.

Smith, M. (2008). Resident mothers in stepfamilies. In J. Pryor (ed). The International Handbook of Stepfamilies: policy and practice in legal, research and clinical environments. Hoboken, NJ: Wiley.

Smyth, B. (2004). Parent-child contact and post-separation parenting. Australian Institute of Family Studies Research Report No. 9. Melbourne: Australian Institute of Family Studies.

Solomon, C. R. (1995). The importance of mother-child relations in studying stepfamilies. Journal of Divorce \& Remarriage, 24, 89-98.

Song, I. S. (1982). The dimensionality and relationships between home environments, self-concept and academic achievement. Unpublished doctoral dissertation, University of New England, New South Wales, Australia.

Song, I. S; \& Hattie, J. A. (1983). The dimensionality of self-concept. Manuscript submitted for publication.

Speer, R. B; \& Trees, A. R. (2007). The push and pull of stepfamily life: The contribution of stepchildren's autonomy and connection-seeking behaviours to role development in stepfamilies. Communication Studies, 58(4), 377-394.

Stafford, L; \& Bayer, C.L. (1993). Interaction between parents and children. Newbury Park, CA: Sage.

Stark, R. (2007). Sociology, Tenth Edition. Baylor University. Thomson Wadsworth, California.

Statistics Canada. (2002). Changing conjugal life in Canada (No. 89-576-XIE). Ottawa, Ontario: Statistical Reference Centre.

Statistics New Zealand. (1997). New Zealand official year book 1997. Wellington: Statistics New Zealand

Statistics New Zealand (2006). Marriages, civil unions and divorces: Year ended December 2005. Wellington, New Zealand: Author. 
Statistics New Zealand. (2007r, 3 May). Hot off the Press: Marriages, Civil Unions and Divorces: Year Ended December 2006. Wellington.

Statistics New Zealand. (2008a, 8 February). Hot off the Press: Household Labour Force Survey December 2007 Quarter. Wellington,

Stern, P. N. (1978). Stepfather families: Integration around child discipline. Issues in Mental Health Nursing, 1(2), 49-56.

Stern, P. N. (1982). Affiliating in stepfather families: Teachable strategies leading to stepfather-stepchild friendship. Western Journal of Nursing Research, 4(1), 7589.

Stewart, S. D. (1999). Nonresident mothers' and fathers' social contact with children. Journal of Marriage and the Family, 67, 894 - 907.

Stewart, S. D. (2005). How the birth of a child affects involvement with stepchildren. Journal of Marriage and the Family, 67, 461-473.

Stewart, S. (2008). Brave New Stepfamilies: Diverse Paths Toward Stepfamily Living Sage Publications.

Stokes, S. B; \& Wampler, R. S. (2002). Remarried clients seeking marital therapy as compared to those seeking family therapy: Differences in levels of psychological and marital distress. Journal of Divorce and Remarriage, 38, 91107.

Tabachnick, B.G; \& Fidell, L.S. (2007). Using multivariate statistics $\left(5^{\text {th }}\right.$ ed). Boston: Perason Education.

Taylor, J; \& Macdonald, F. (1998). Life at six: life chances and beginning school, Brotherhood of St Laurence, Melbourne.

The Oxford English Dictionary. (1989). OED Online (2 ${ }^{\text {nd }}$ ed.). Oxford University Press. 4 April 2000. Retrieved 7 August, 2010.

The Kiwi Nest, 60 years of change in New Zealand families. A Families Commission Report, No 3/08, June, 2008.

Thomson, E. (2003) Stepfamilies and childbearing: Desires in Europe. Center for Demography and Ecology, University of Wisconsin-Madison — CDE Working Paper \# 2003-09

Thomson, E; McLanahan, S. S; \& Curtin, R. B. (1992). Family structure, gender, and parental socialisation. Journal of Marriage and the Family, 54(2), 368-378. 
Thurstone, L. L. (1947). Multiple factor analysis. Chicago: University of Chicago Press.

Touliatos, J; Perlmutter, B. F; Staus, M. A. (2001). Handbook of family measurement techniques (vol, 2). Age Publications.

U.S. Bureau of the Census (2000). Statistical abstract of the United States. Washington, DC: U.S. Government Printing Office.

Vemer, E; Coleman, M; Ganong, L. H; \& Cooper, H. (1989). Marital satisfaction in remarriage: a meta-analysis. Journal of Marriage and the Family, 51, 713-725.

Visher, E. B \& Visher, J. S (1978). Common problems of stepparents and their spouses. American Journal of Orthopsychiatry, 48 (2), 252-262.

Visher, E; \& Visher, J. (1988). Old loyalties, new ties: Therapeutic interventions with stepfamilies. New York: Brunner/Mazel.

Visher, E. B; \& Visher, J. S. (1990). Dynamics of successful stepfamilies. Journal of Divorce and Remarriage, 14(1), 3-12.

Visher, E. B; \& Visher, S. (1996). Therapy with stepfamilies. Psychology Press.

Visher, E; \& Visher, J. (2003). The remarried Family: characteristics and interventions. In E. Visher \& J. Visher (Eds.). Textbook of Family and Couples Therapy: Clinical Applications (pp. 523-538). Washington, DC: American Psychiatric Publishing.

Visher, E. B; Visher, J. S. \& Pasley, K. (2003). Remarriage families and step parenting. In Walsh, F. (Ed.). Normal family processes. (pp. 153 -175). New York: Guilford Press.

Voydanoff, P; Fine, M. A; \& Donnelly, B. W. (1994). Family structure, family organization, and quality of family life. Journal of Family and Economic Issues, 15, 175-200.

Vuchinich, S; Hetherington, E. M; Vuchinich, R. A; and Clingempeel, W. G. (1991). Parent-child interaction and gender differences in early adolescents' adaptation to stepfamilies. Developmental Psychology, 27, 618-626.

Wald, E. (1981). The remarried family: Challenge and promise. New York: Family Service Association of America.

Walker, K; \& Messinger, L. (1979). Remarriage after divorce: Dissolution and reconstruction of family boundaries. Family Process, 18, 185-192.

Wallenstein, J. S; Lewis, J. N; \& Blakeslee, S. (2000). The unexpected legacy of divorce: A 25 year landmark study. New York: Hyperion. 
Walzer, S; Coleman, M; \& Ganong, L. (Eds). (2004) Encountering oppositions: A review of the scholarship about motherhood. Handbook of contemporary families. (pp. 209-223). Sage, Thousand Oaks, CA.

Watt, E. J. (2004). The D.I.Y approach to family law - appointing stepparents as additional guardians under the Care of Children Act 2004. Masters Thesis: Victoria University of Wellington.

Weaver, S. E; \& Coleman, M. (2005) A mothering but not a mother role: A grounded theory of the nonresidential stepmother role. Journal of Social and Personal Relationships, 22(4), 477-497.

White, L; \& Booth, A. (1985). The quality and stability of remarriages: The role of stepchildren. American Sociological Review, 50(5).689 -698.

White, L. K; Brinkerhoff, D; \& Booth, A. (1985). The effects of marital disruption on child's attachment to parents. Journal of Family Issues, 6, 5-22.

White, L; \& Gilbreth, J. G. (2001). When children have two fathers: Effects of relationships with stepfathers and noncustodial fathers on adolescent outcomes. Journal of Marriage and the Family, 63(1), 155-167.

Whitsett, D; \& Land, H. (1992). The development of a role strain index for stepparents. Families in Society: The Journal of Contemporary Human Services, 14- 22.

Wilson, B. F; \& Clarke, S. C. (1992). Remarriages: A demographic profile. Journal of Family Issues, 13, 123-141.

Wise, S. (2003). Family structure, child outcomes and environmental mediators: An overview of the development in diverse families study. Research paper no. 30, Melbourne: Australian Institute of Family Studies.

Woodward, L; Fergusson, D; \& Horwood, L. J. (2001). Risk factors and life processes associated with teenage pregnancy: Results from a prospective study from birth to 20 years. Journal of Marriage and Family, 63, 1170 - 1184.

Wright, E. O. (1997). Class counts: Comparative studies in class analysis. New York: Cambridge University Press.

Wu, Z; \& Penning, M. (1997). Marital instability after midlife. Journal of Family Issues, 18, 459-478.

Wu, L; \& Thomson, E. (2001). Race differences in family experience and early sexual initiation: Dynamic models of family structure and family change. Journal of Marriage and Family, 63, 682 - 696.

Ziegahn, S. (2002). The stepparent's survival guide: A workbook for creating a happy blended family. Oakland, CA: New Harbinger Publications. 


\section{APPENDIX A \\ Information Flier}




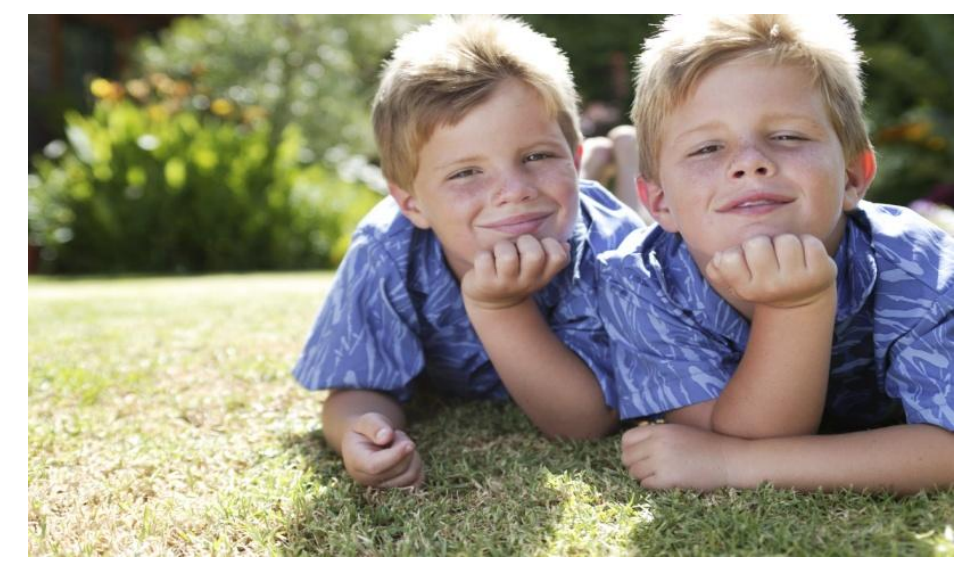

\section{Do you live in a stepfamily or are you living with a new partner?}

My name is Rebecca and I am doing my PhD at the Roy McKenzie Centre for the Study of Families at Victoria University. I am researching how re-partnered families, or stepfamilies, develop the important relationships within their families. Research like this is important since we still don't know that much about re-partnered families, although more and more children are growing up in them. To learn more we need to talk to families to learn from their experiences.

I'd like to talk to you, your partner and your child (who is between the ages of 7 and 11) about the relationships in your family.

For this research I am interested in talking to families where the partners have been living together or married for less than 4 years.

I can come to a place where it is convenient for you and you will be given a $\$ 25$

Warehouse Voucher to thank you for your help.

If this sounds like you, please call Rebecca on (04) 4636836 or email her at rebecca.graham@vuw.ac.nz

If you know someone who might be interested please let them know. 


\section{APPENDIX B \\ Principal Letter}


Dear Principal,

My name in Rebecca Graham and I am currently doing my $\mathrm{PhD}$ at the Roy McKenzie Centre for the Study of Families, which is located at Victoria University. I am writing to ask for your assistance in finding participants for my research.

My research will involve stepfamilies with children between the ages of 7 to 11 , and I am asking for your help to find families willing to be involved. I realise how busy schools are, and that you are frequently approached to be involved in research studies, and am asking only to make contact through the school with suitable families. I can discuss with you how this might most easily be done. One possible method would be a brief notice in your schools newsletter, inviting interested parents to contact me.

This research will explore how stepfamilies develop the important relationships within their families. Of particular focus is how the parent's new partner is integrated into the family since previous research suggests this is an important issue facing these families.

I will follow this letter with a call to you in the next week to arrange a time to discuss it with you or whoever would be appropriate in your school.

In the meantime, you could contact me (04 463 6836), or either of my supervisors, Associate Professor Jan Pryor (04 463 7428) or Dr Jeremy Robertson (04 463 6831) if you have any questions. You may wish to look at the Centre's website at www.vuw.ac.nz/mckenziecentre

Thank you for taking the time to read this letter, and I look forward to speaking to you soon.

With kind regards,

Rebecca Graham 
APPENDIX C

Recruitment Notice 


\section{Do you live in a stepfamily or are you living with a new partner?}

Some exciting research on re-partnered families or stepfamilies is underway at the Roy McKenzie Centre for the Study of Families at Victoria University. PhD student, Rebecca Graham is looking to talk to families with a child between the ages of 7 and 11, who have been together for less than 4 years. Research like this is important since we still don't know that much about re-partnered families, although more and more children are growing up in them.

To learn more we need to talk to families to learn from their experiences.

If this sounds like you, please call Rebecca on (04) 4636836 or email her at rebecca.graham@vuw.ac.nz If you know someone who might be interested please let them know. Participating families will receive a \$25 Warehouse voucher to thank them for their participation. 
APPENDIX D

\author{
Information Forms
}




\section{$\underline{\text { Parent Information Form }}$}

Hello!

Firstly, thank you very much for your call/email. This letter is designed to give you and your family a little more information about this project. Enclosed is an information form for the participating child to read so they know a bit about what is involved for them.

My name is Rebecca Graham and I am a PhD student at Victoria University of Wellington, at the Roy McKenzie Centre for the study of Families. Associate Professor Jan Pryor and Dr Jeremy Robertson are supervising this research, and it has been approved by the University ethics committee.

What is the purpose of this research?

Families come in many different forms today. Rather than growing up in a nuclear family, with two adults who are both the child's biological (or adoptive) parents, more and more children are growing up in re-partnered families, or stepfamilies. However we still need to know more about how these families work, so that we can provide helpful information to families in similar situations.

This project involves looking at the relationships developed amongst people in a stepfamily, so that we can better understand how stepfamilies develop the important relationships within them. In particular, I will be looking at how roles and responsibilities are sorted out in the family, since previous research suggests this is an important issue. As there is not much research available on this, this research is important in helping us to understand these issues better.

Who am I interested in talking to?

- I am interested in talking to families where there is an adult present who is not the child's biological parent but is in a partnership with the child's biological parent.

- This adult must be currently living with the child's biological parent, but may be either married or not married to this parent. The child must spend most of their time with these two adults.

- I am interested in talking to families who have been living together (whether married or not) for a period of more than 3 months but less than 4 years.

- My study is interested in the views of all the people in the family, so I want to talk to three family members in the household: the biological parent, the biological parent's partner, and the child (who is between the ages of 7 and 11 years).

What is involved if you agree to participate?

- Your participation is voluntary. Taking part in this study involves answering a questionnaire that asks you about several aspects of family life, at two different times, one year apart. You will be asked about the relationships in your family, 
and other aspects of family life, such as the daily activities that take place in your home.

- These questionnaires will be done at a time and place that is convenient for you

- It takes each family about 30- 40 minutes to complete these tasks.

- You do not have to answer any questions you do not want to and you can decide to withdraw from the project at any time with no penalty.

- When the research is completed, which is likely to be sometime in 2008 , an information sheet outlining the major findings of this study will be sent to your home address if you wish.

- You and your family will also be given a \$25 Warehouse voucher (at both phases of the study) to thank you for your participation.

\section{Privacy and Confidentiality}

- The results of the project will be used to write a thesis that may be published. The findings will also be shared with other interested organizations (e.g. Relationship Services etc) and may be discussed in conferences.

- However, the responses you give in the questionnaires are confidential. That is, no personal details will be used at any stage of the write-up (or conferences) that might identify you personally.

- Your data will be kept for at least five years after publication with Associate Professor Jan Pryor, Dr Jeremy Robertson and myself. It will be safely kept in a locked filing cabinet to which only myself, and my two supervisors, can open. After this time, questionnaires will be destroyed.

- In the event of this study being continued at a later stage, you will be asked whether you would like to be contacted again at some later stage.

Thanks for your interest in this project, and I look forward to meeting you and your family. If you have any more questions you can contact me at the Roy McKenzie Centre for the Study of Families (ph: 463 6836; email:rebecca.graham@vuw.ac), or my supervisors, Dr Jan Pryor (ph: 4638130; email: jan.pryor@ vuw.ac.nz), Dr Jeremy Robertson (ph: 463 6831; email: jeremy.robertson@vuw.ac.nz).

Best Wishes,

Rebecca Graham

Signed: 


\section{Child Information Form}

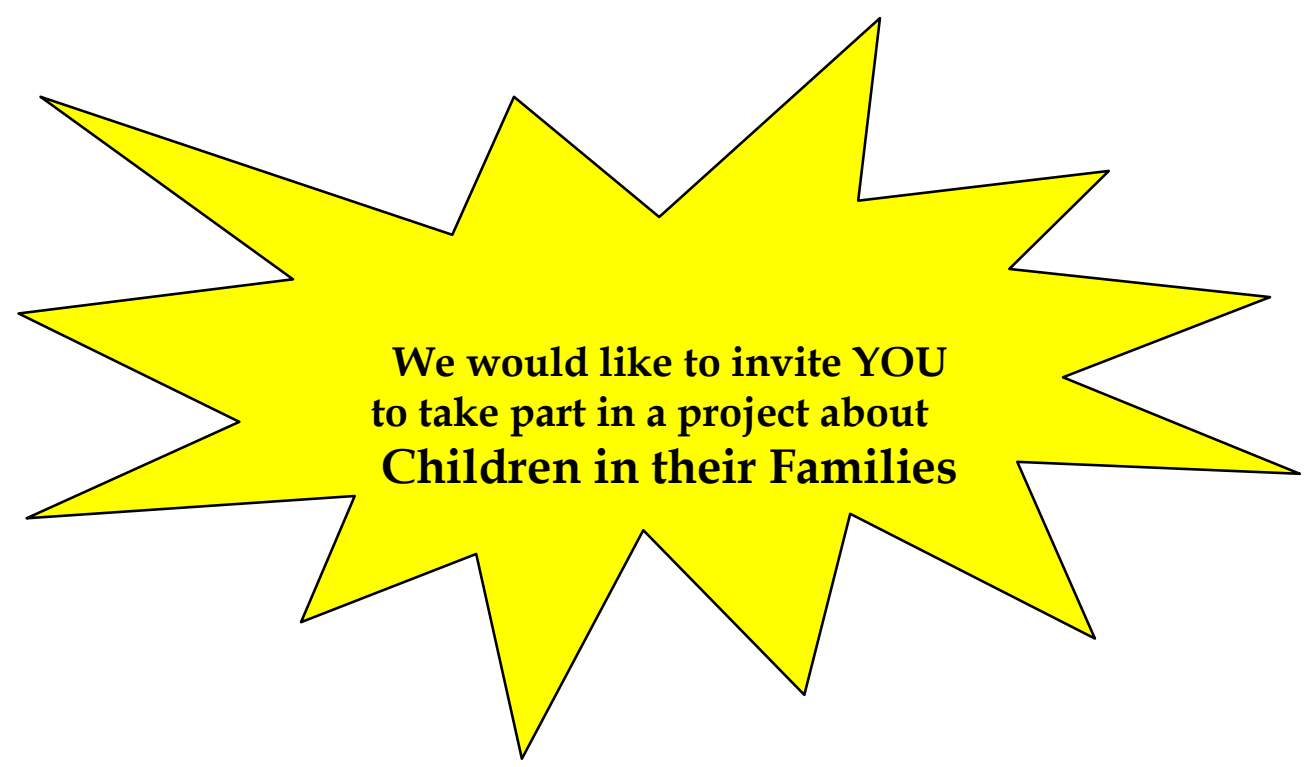

My name is Rebecca and I am doing a research project that involves talking to lots of children and finding out about how they feel about their families. Research involves finding out things that we don't know. With the answers that these children and their families give me, I hope to find out more about how children feel about parts of their family lives.
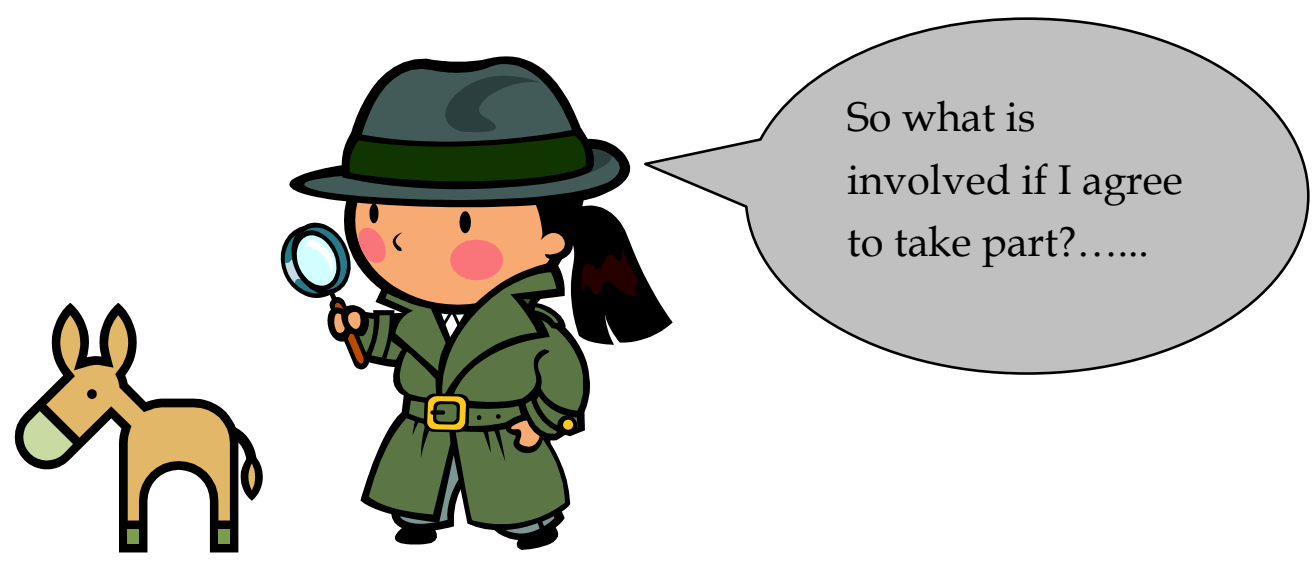
We would like you to take part in this research project that will ask questions about the people that you live with, and how you feel about yourself.

From the things that you tell me, we will be able to find out more about how children and their families are dealing with important family issues. This will also help other families who are dealing with similar issues.

I won't tell anyone else in your family what you have told me but it's not a secret.....you can tell them if you want to
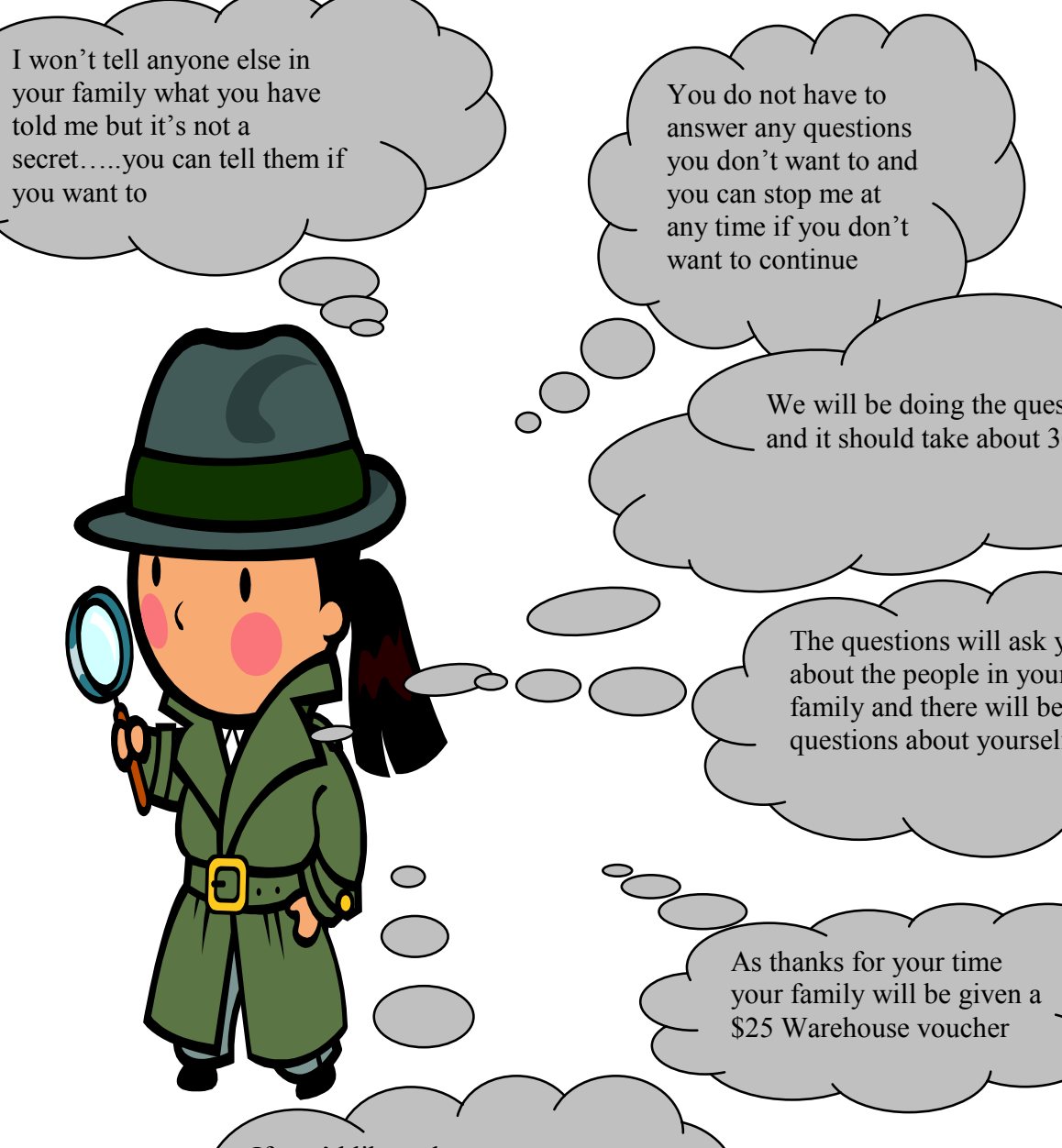

If you'd like to know more before you decide, get in touch with me by email or phone. I would be happy to speak with you!
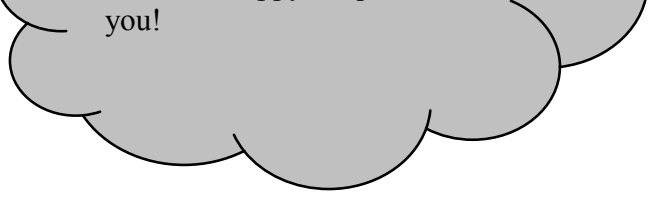

We will be doing the questions together, and it should take about 30 minutes to do

\section{Contacts:}

Rebecca Graham, Researcher, Roy McKenzie Centre for the Study of Families Phone: 4636836 / 02102712847 E-mail: rebecca.graham@vuw.ac.nz Jeremy Robertson, Supervisor, Roy McKenzie Centre for the Study of Families Phone: 4636831

Jan Pryor, Supervisor, Roy McKenzie Centre for the Study of Families Phone: 4637428 


\section{APPENDIX E}

Adult Consent Forms 


\section{$\underline{\text { Parent Consent Form }}$}

\section{Relationships in Stepfamilies}

I have been given and have understood an explanation of this research project. I have had an opportunity to ask questions and have them answered to my satisfaction. I understand that I may withdraw myself, or my child, from this project without having to give reasons and without any penalty.

I understand that my child will also be asked whether he/she wishes to participate in the research and the questionnaire will not go ahead if the child says no.

I understand that anything I say will be kept confidential to the researcher and her two supervisors. If the project ends up being published, I understand that my name or any other personal information that I have given will not be included. Also, no opinions that I have given will be included in any way that might identify me in the writing up of the thesis. I have been told that any interviews will be taped only if I feel comfortable with this. I understand that any tape recording of the interviews will be wiped and questionnaires destroyed 5 years after the project has been finished. I also understand that during that time, any interview tapes and questionnaires will be kept in a safe and secure place, to which only the researcher has access.

Would you like to be sent a summary of the results of this research when it is completed? (Please tick)

- Yes, I would.

Please provide me with the address to send this feedback to:

No, I would not

In the event of this study being continued further down the line, would you be interested in being contacted again?

- Yes, I would

․ No, I would not

Signed:

Date:

Participants Name:

(Please print clearly) 
In addition, I agree that child's name, who is under my guardianship, may take part in this research, unless they decide that they do not want to answer these questions.

Signed:

Date:

In order to keep in contact with you over the year period, could you please give me some other contact details e.g. close friend, relative

\section{CONTACT DETAILS}

\section{Contact 1}

Relationship to parent or child:

Phone number:

\section{Contact 2}

Relationship to parent or child:

Phone number: 


\section{Relationships in Stepfamilies}

I have been given and have understood an explanation of this research project. I have had an opportunity to ask questions and have them answered to my satisfaction. I understand that I may withdraw myself from this project without having to give reasons and without any penalty.

I understand that anything I say will be kept confidential to the researcher and her two supervisors. If the project ends up being published, I understand that my name or any other personal information that I have given will not be included. Also, no opinions that I have given will be included in any way that might identify me in the writing up of the thesis. I have been told that any interviews will be taped only if I feel comfortable with this. I understand that any tape recording of the interviews will be wiped and questionnaires destroyed 5 years after the project has been finished. I also understand that during that time, any interview tapes and questionnaires will be kept in a safe and secure place, to which only the researcher has access.

Would you like to be sent a summary of the results of this research when it is completed? (Please tick)

○ Yes, I would

Please provide me with the address to send this feedback to:

○ No, I would not

In the event of this study being continued further down the line, would you be interested in being contacted again?

- Yes, I would

№, I would not

Signed:

Date:

Participants Name:

(Please print clearly) 
APPENDIX F

Child Assent Form 


\section{Child Assent Form}

$\mathrm{Hi}$, my name is Rebecca and I am doing a research project that involves talking to lots of people like you, and finding out about how they feel about their families. Research involves finding out things that we don't know.

The questions I will ask you are mostly about how you feel about the other people you live with, and the way they act towards you. This should take about half an hour, and then we will have a break, before answering a few more questions. Your parent and stepparent are also answering similar questions. However, just because they are answering these questions, does not mean you have to answer them, and you will not be in any trouble if you decide you do not want to.

You do not have to answer any questions you don't want to and you can stop me at any time if you feel that you don't want to continue.

It's not a test, and there are no right or wrong answers. I'm just interested in what you think about certain things in your family.

I won't tell anyone else in your family what you told me, but it's not a secret either you can tell them or anyone else you want to what we talk about - if you want to.

I will also be calling your family again in one year's time to see if you can help me out again in the same way you are helping me this time.

Is there anything you do not understand?

Do you think it would be all right for us to talk?

Yes, I would like to

No, I would not like to

Would you like to be sent the results of this project when it is finished?

Yes, I would like to

No, I would not like to

Signature: 


\title{
APPENDIX G
}

\author{
Background Information Forms
}




\section{$\underline{\text { Parent Form }}$}

These questions are designed to give us basic information about you and your family.

Please indicate the appropriate answer in the following:

Gender (please circle): Female Male

Age: yrs

1) Education: What is the highest grade of education you have completed? Please circle

Primary

High School

University

Postgraduate

(Or Tafe equivalent)

2) Employment Status:

How many hours (approximately) per week do you work outside the home?

hrs

3) Which of the following best describes your racial or ethnic identification: please tick

ㄱZ European

a Maori

a Samoan

a Cook Island Maori

- Tongan

- Niuean

a Chinese

口 Indian

口 Other:

4) Family Income: What was your total family income before taxes during the last year?

口 Under $\$ 15,000$

- $\$ 15,000-\$ 20,000$

a $\$ 20,001-\$ 25,000$

口 $\$ 25,001-\$ 30,000$

- $\$ 30,001-\$ 40,000$

a $\$ 40,001-\$ 50,000$

a $\$ 50,001-\$ 60,000$

a $\$ 60,001-\$ 70,000$

a $\$ 70,001-\$ 100,000$

- $\$ 100,001$ or more 
5) What is the status of your relationship with this child's biological parent? (please tick)

口 Separated

口 Divorced

๑ Widowed

8. Since your relationship with this child's biological parent, how many cohabiting relationships have you been in? (not including your present partner).

9. How many months has there been between the end of your last cohabiting/marriage relationship (this may or may not be your child's other biological parent) and when your present partner moved into the home. Please try to be as accurate as possible. years _ months

10. How often does your child see their other biological (or adoptive) parent? 


\section{$\underline{\text { Stepparent Form }}$}

These questions are designed to give us basic information about you and your family.

Please indicate the appropriate answer in the following:

Gender (please circle): Female Male

Age: ___ yrs

1) Education: What is the highest grade of education you have completed? Please circle

Primary

High School

University

Postgraduate

(Or Tafe equivalent)

3) Employment Status:

How many hours (approximately) per week do you work outside the home?

hrs

4) Which of the following best describes your racial or ethnic identification:

Please tick

- NZ European

口 Maori

- Samoan

- Cook Island Maori

- Tongan

a Niuean

a Chinese

a Indian

- Other:

4) How many cohabiting or marriage partnerships have you been in (not including your present partner)?

5) Do you have any biological child(ren) with your present partner

YES NO

If YES, how many children?

6) Do you have any biological child(ren) with any previous partner(s)

YES NO 
If YES, how many children do you have from previous partner(s)?

Do your biological children from previous partner(s) spend time in this household?

$$
\text { YES NO }
$$

If YES, how much time do they spend in this household? 


\section{APPENDIX H}

Biological Parent Questionnaire 


\title{
Relationships in Stepfamilies
}

\author{
Questionnaire B
}

\section{Family ID}

\section{ID Number}

In parts of this questionnaire, you are asked questions about "your child". Please answer these questions in reference to the target child selected for this research.

Please check that you have answered all the questions at the end.

Remember that your answers are private.

Thank you 


\section{PARENT QUESTIONNAIRE}

\section{The first set of questions asks you about this target child.}

1. This child tries to be nice to other people.

$\mathrm{He} / \mathrm{she}$ cares about their feelings....

\section{Not}

Somewhat Certainly

True

True

True

2. This child is restless, and cannot stay still for long...

2

3

3. This child gets a lot of headaches, stomach aches or sickness. 1

4. This child usually shares with others

(food, games etc) 1

5. This child gets very angry and often loses his/her temper.

6. This child is usually on their own, and plays alone...

7. This child usually does what they are told...........

8. This child worries a lot............................

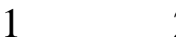

9. This child is helpful if someone is hurt, upset or feeling ill...........

10. This child is constantly fidgeting or squirming......

11. This child has one good friend or more 1

2

12. This child fights a lot and sometimes bullies people......

13. This child is often unhappy, downhearted or tearful...

14. Other people of this child's age generally like this child... 
15. This child is easily distracted, and finds it difficult to concentrate..

16. This child is nervous in new situations, and will easily lose confidence. 1

2

3

17. This child is kind to younger children........

18. This child is often accused of lying or cheating...

19. Other children or young people pick on this

Child or bully him/her...

r........................

20. This child often volunteers to help others (teachers, other children, parents)........

21. This child thinks before they do things

22. This child will take things that are not theirs from home, school or elsewhere

1

2

3

23. This child gets on better with adults than with people their own age

1

2

3

24. This child has many fears, and is easily scared

1

2

3

25. This child will finish the work they are doing.

Their attention is good

12

3

The following statements are about families. Please decide which is true of your family. By family I mean the grouping that is you, your partner, and the children that live in your household most of the time.

Please circle the answer that best describes your family.

26. People in my family ask each other for help when they need it

Usually True

27. We like each other's friends

Usually True
Usually False

Usually False 
28. We like to do things with just our family
Usually True
Usually False

29. People in my family feel closer to other family members than to people outside the family

Usually True Usually False

30. People in my family like to spend free time with each other
Usually True
Usually False

31. People in my family feel very close to each other
Usually True
Usually False

32. When our family gets together for gatherings, everyone comes along

Usually True Usually False

33. We can easily think of things to do as a family

Usually True Usually False

34. We talk to other people in our family about the decisions we make
Usually True
Usually False

35. Being together as a family is very important to us

Usually True Usually False 
Below are some statements about the way some families are.

Please tell me how true that statement is for your family.

Not at all True

Certainly True

36. People in my family really get on each other's nerves......

37. People in my family

criticise each other

38. People in my family solve

problems by arguing...........

39. People in my family can go

on arguing for a long time......

40. People in my family get

really mad about things that

are really stupid......

41. There's a lot of yelling and arguing in my family.......

$\begin{array}{lllllll}1 & 2 & 3 & 4 & 5 & 6 & 7\end{array}$

$\begin{array}{lllllll}1 & 2 & 3 & 4 & 5 & 6 & 7\end{array}$

The following questions ask you about your relationship with your partner

During the past month, when you and your partner have spent time talking or doing things together, how often did your partner....

Hardly Ever Sometimes Often Most of the Time

42. Get angry with you........... 1

2

3

4

43. Let you know he/she

really cares about you.........

44. Criticise you or your ideas... 1

2

3

4

45. Shout at you because

he/she was upset with you

1

2

3

4 
46. Act loving and affectionate to you...........

47. Let you know that he/she appreciates your ideas or the things you do.........

2

48. Help you do something that was important to you......... 1

49. Get into an argument with you... 1

2

3

50. Argue with you when you disagreed about something...1

51. Act supportive and understanding towards you...... 1

52. Insult or swear at you......... 1

55. Overall, how satisfied are you with your relationship with your partner?

$\begin{array}{lllllll}1 & 2 & 3 & 4 & 5 & 6 & 7\end{array}$

Not at all

Very

Satisfied

Satisfied 
The following section asks you how involved your partner is currently in various parenting tasks, and how involved you feel they should be at this point in time. (Desired involvement).

$$
1=\text { not at all involved, } 5=\text { very involved }
$$

56. Making sure that this child is ready for school in the morning

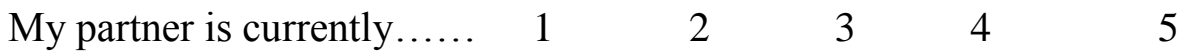

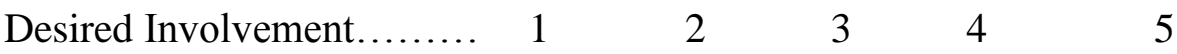

57. Making sure this child does not watch TV shows or movies that aren't good for them

$\begin{array}{llllll}\text { My partner is currently...... } & 1 & 2 & 3 & 4 & 5\end{array}$

$\begin{array}{llllll}\text { Desired Involvement........ } & 1 & 2 & 3 & 4 & 5\end{array}$

58. Hugging this child when they're upset

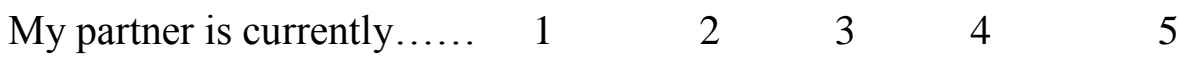

$\begin{array}{llllll}\text { Desired Involvement......... } & 1 & 2 & 3 & 4 & 5\end{array}$

59. Telling this child off when they have been naughty

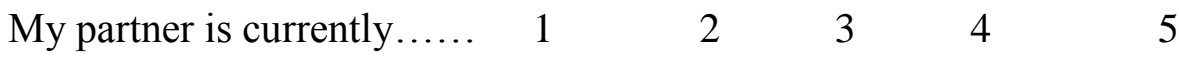

$\begin{array}{llllll}\text { Desired Involvement........ } & 1 & 2 & 3 & 4 & 5\end{array}$

60. Teaching this child to be polite

$\begin{array}{llllll}\text { My partner is currently...... } & 1 & 2 & 3 & 4 & 5\end{array}$

$\begin{array}{lllllll}\text { Desired Involvement........ } & 1 & 2 & 3 & 4 & 5\end{array}$

61. Helping this child with their reading or homework assignments

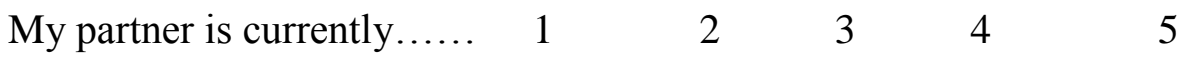

Desired Involvement........ $1 \quad 3 \quad 2 \quad 3 \quad 4 \quad 4$ 
62. Telling this child that there are certain places they can't go on their own My partner is currently..... $11 \quad 2 \quad 3 \quad 4 \quad 5$

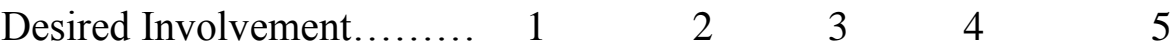

63. Helping this child fix any personal problems they may be having My partner is currently..... $11 \quad 2 \quad 3 \quad 4 \quad 4 \quad 5$

Desired Involvement........ $11 \quad 2 \quad 3 \quad 4 \quad 4 \quad 5$

64. Setting new rules for this child to follow

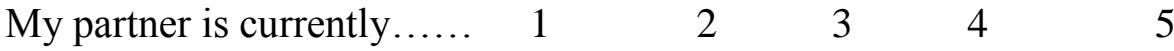

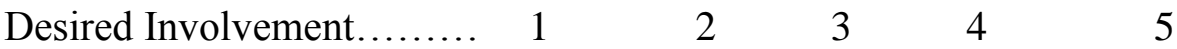

65. Telling this child when to say "please" and "thank you"

My partner is currently..... $11 \quad 2 \quad 3 \quad 4 \quad 4$

$\begin{array}{llllll}\text { Desired Involvement........ } & 1 & 2 & 3 & 4 & 5\end{array}$

66. Paying for major expenses for this child e.g. school fees, doctors bills $\begin{array}{llllll}\text { My partner is currently...... } & 1 & 2 & 3 & 4 & 5\end{array}$

$\begin{array}{llllll}\text { Desired Involvement......... } & 1 & 2 & 3 & 4 & 5\end{array}$

67. Going to activities at this child's school e.g. sports games, music recitals

My partner is currently..... $11 \quad 2 \quad 3 \quad 4 \quad 4$

$\begin{array}{lllllll}\text { Desired Involvement........ } & 1 & 2 & 3 & 4 & 5\end{array}$

68. Talking to this child about their friends

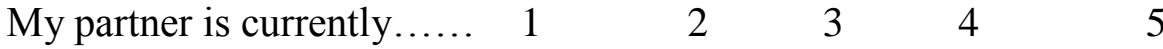

$\begin{array}{llllll}\text { Desired Involvement......... } & 1 & 2 & 3 & 4 & 5\end{array}$ 
69. If this child goes somewhere after school having to tell them where they're going

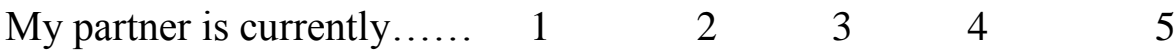

Desired Involvement........ $1 \quad 1 \quad 2 \quad 3 \quad 4 \quad 5$

70. Standing up for this child, such as when they are in trouble My partner is currently..... $11 \quad 2 \quad 3 \quad 4 \quad 5$

Desired Involvement........ $11 \quad 2 \quad 3 \quad 4 \quad 4 \quad 5$

71. Punishing this child when they have been

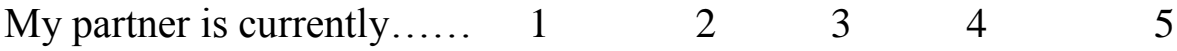

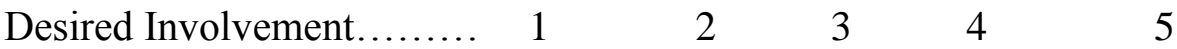

72. Teaching this child to take turns and share with others

My partner is currently..... $11 \quad 2 \quad 3 \quad 4 \quad 4$

$\begin{array}{llllll}\text { Desired Involvement........ } & 1 & 2 & 3 & 4 & 5\end{array}$

73. Driving this child to places they need to be (e.g. school in the mornings)

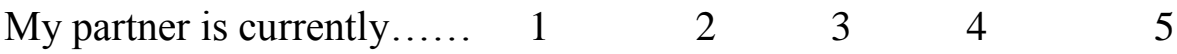

$\begin{array}{lllllll}\text { Desired Involvement......... } & 1 & 2 & 3 & 4 & 5\end{array}$

74. Making sure this child does not stay up too late

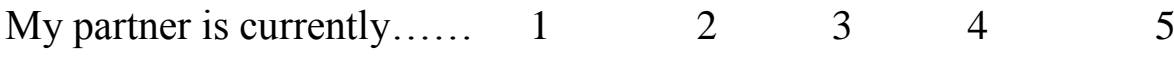

$\begin{array}{llllll}\text { Desired Involvement........ } & 1 & 2 & 3 & 4 & 5\end{array}$

75. Asking this child what happened during their day at school

My partner is currently..... $\quad 1 \quad 2 \quad 3 \quad 4 \quad 4 \quad 5$

$\begin{array}{lllllll}\text { Desired Involvement........ } & 1 & 2 & 3 & 4 & 5\end{array}$ 
76. Telling this child off when they are rude to you

$\begin{array}{llllll}\text { My partner is currently...... } & 1 & 2 & 3 & 4 & 5 \\ \text { Desired Involvement......... } & 1 & 2 & 3 & 4 & 5\end{array}$

77. Paying for minor expenses for this child e.g. clothes, activities etc

$\begin{array}{llllll}\text { My partner is currently...... } & 1 & 2 & 3 & 4 & 5 \\ \text { Desired Involvement......... } & 1 & 2 & 3 & 4 & 5\end{array}$

78. Teaching this child to consider other people's feelings

$\begin{array}{llllll}\text { My partner is currently...... } & 1 & 2 & 3 & 4 & 5 \\ \text { Desired Involvement......... } & 1 & 2 & 3 & 4 & 5\end{array}$

79. Rewarding this child when they behave well

$\begin{array}{llllll}\text { My partner is currently...... } & 1 & 2 & 3 & 4 & 5 \\ \text { Desired Involvement......... } & 1 & 2 & 3 & 4 & 5\end{array}$

80. Going to parent/teacher interviews for this child

$\begin{array}{cccccc}\text { My partner is currently...... } & 1 & 2 & 3 & 4 & 5 \\ \text { Desired Involvement......... } & 1 & 2 & 3 & 4 & 5\end{array}$

81. Which of the following names or labels best describes the role you would wish your partner to play in your child's life, at this point in time?

You can tick as many words as you like.

$\square$ Friend

$\checkmark$ Parent

$\checkmark$ Stepparent

$\checkmark$ Close relative e.g. aunt/uncle

a Flatmate

Mum/Dads partner

$\checkmark$ Other 
82. What role would you say they have at this point in time?

$\begin{array}{ll}\square & \text { Friend } \\ \square & \text { Parent } \\ \square & \text { Stepparent } \\ \square & \text { Close relative e.g. aunt/uncle } \\ \square & \text { Flatmate } \\ \square & \text { Mum/Dads partner } \\ \square & \text { Other }\end{array}$

How well do the following describe what you do?

Please answer these questions in reference to the target child

83. I want my partner to be involved in the daily care of this child (e.g. feeding, transporting, helping with homework etc)
1
2
3
4
$5 \quad 6$

Not at All

Very much so

84. I encourage my partner to spend time together with this child, just the two of them
1
2
3
4
5
6

Not at All

Very much so

85. My child and I do things together, just the two of us, which might make my partner feel excluded
1
2
3
4
5
6

Not at All

Very much so

86. Although I listen to my partners suggestions, I think I know what's best for this child

$\begin{array}{llllll}1 & 2 & 3 & 4 & 5 & 6\end{array}$

Not at All

Very much so 
87. I would like my partner to be more involved in my child's life than he/she is

$\begin{array}{llllll}1 & 2 & 3 & 4 & 5 & 6\end{array}$

$\begin{array}{ll}\text { Not at All } & \text { Very much so }\end{array}$

88. I ask my partner to care for this child on his/her own

$\begin{array}{llllll}1 & 2 & 3 & 4 & 5 & 6\end{array}$

Not at All

Very much so

89. I encourage my partner to be involved in the discipline of this child

$\begin{array}{llllll}1 & 2 & 3 & 4 & 5 & 6\end{array}$

$\begin{array}{ll}\text { Not at All } & \text { Very much so }\end{array}$

90. I have confidence in my partner's abilities as a parent

$\begin{array}{llllll}1 & 2 & 3 & 4 & 5 & 6\end{array}$

Not at All Very much so 


\section{Thank you for completing this questionnaire for me.}

\section{Further Assistance}

Sometimes when you talk about issues in your family, it may make you think about certain issues, and you may want to talk about these issues further with someone outside your family. Here are some numbers you can ring if you want to talk about these issues, or anything else, further. Your child has also been given some numbers to ring in case they want to talk about things further.

$\underline{\text { Plunketline }}$

For any concerns relating to your family or child $\quad 0800933922$

$\underline{\text { Relationship services }}$

0800735283

www.relate.org.nz

\section{$\underline{\text { Barnados }}$}

To ask about child and family services

available locally

0800222345

www.barnados.org.nz

Please tear off this sheet 


\section{APPENDIX I}

\section{Child Questionnaire}




\section{Child Questionnaire}

\section{Family ID:}

ID Number:

Start with asking child age:

Since I don't know much about the people who live in this house with you, to start with I would like you to tell me the people who live in this house with you.

Who lives in the household with child:

\section{$\underline{\text { Practice Questions }}$}

Just so that you understand what we are doing, we are just going to run through some practice questions that show you the kinds of questions I will be asking during our talk together.

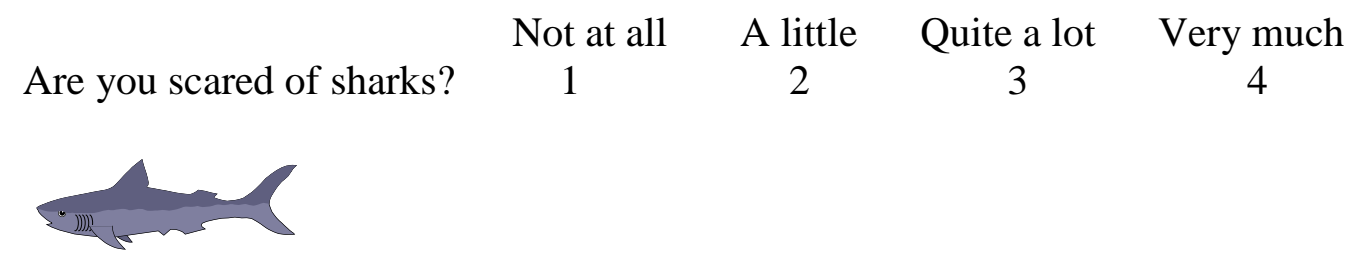

This question is a little bit different.

How much do you like Rugby?

$\begin{array}{ccccccc}1 & 2 & 3 & 4 & 5 & 6 & 7 \\ \text { Not at all } & & & & & & \text { Very Much }\end{array}$

(Make sure child understands that they can circle any number on the scale before continuing)

c. How much do you like maths?

$\begin{array}{ccccccc}1 & 2 & 3 & 4 & 5 & 6 & 7 \\ \text { Not at all } & & & & & & \text { Very Much }\end{array}$


During the past month, when you and your Mum/Dad have spent time talking or doing things together, how often did your Mum/Dad....

\section{Hardly Ever Sometimes Often Most of the Time}

1. Get angry with you......

1

2

3

4

2. Let you know he/she really cares about you......

3. Criticise you or your ideas (i.e. say bad things about your ideas).........

4. Shout at you because he/she was upset with you...... 1

5. Act loving towards you........ 1

6. Let you know that he/she likes your ideas or the things you do...........

7. Help you do something that was important to you......

8. Get into an argument with you......................

9. Argue with you when you did not agree about something...

10. Act supportive and understanding towards you

11. Insult or swear at you........ 1

12. Call you bad names........... 
14. How often do you feel angry with your Mum/Dad, because of something they have said or done?

$\begin{array}{ccccccc}1 & 2 & 3 & 4 & 5 & 6 & 7 \\ \text { Hardly ever } & & & \text { Sometimes } & & & \text { A lot of the time }\end{array}$

15. How close do you feel to your Mum/Dad?

$\begin{array}{lllllll}1 & 2 & 3 & 4 & 5 & 6 & 7\end{array}$

Not close at all Very close

\section{I now want to ask you some questions about your Mum/Dad (non-resident parent)}

16. How often do you see your Mum/Dad?

- More than once a week

- Once a week

- Once every two weeks

a Once a month

- Once every three months

- Once every six months

- Other (please describe)

17a. Is that enough time? In your opinion, is it.....

not enough enough or too much

a. How happy are you with the amount of time you get to spend with your Mum/Dad?

$\begin{array}{lllllll}1 & 2 & 3 & 4 & 5 & 6 & 7\end{array}$

Not happy at all

Very happy 
b. What time periods do you typically spend with your Mum/dad?

(e.g. overnight, weekend, weeks, school holidays etc)

During the past month, when you and your Mum/Dad have spent time talking or doing things together, how often did your Mum/Dad....

Hardly Ever Sometimes Often Most of the Time

18. Get angry with you.........

1

2

3

4

19. Let you know he/she

really cares about you......

1

2

3

4

20. Criticise you or your ideas

(ie say bad things

about your ideas)

21. Shout at you because

he/she was upset with you

1

2

3

4

22. Act loving towards you...

1

2

3

4

23. Let you know that he/she

likes your ideas

or the things you do

1

2

3

4

24. Help you do something that was important to you

25. Get into an argument with you

26. Argue with you when you did not agree about something

27. Act supportive and understanding towards you

28. Insult or swear at you

29. Call you bad names 
31. How close do you feel to your Mum/Dad?

$\begin{array}{lllllll}1 & 2 & 3 & 4 & 5 & 6 & 7\end{array}$

Not close at all

Very close

I just want to ask you some questions now about how you behave, and how you feel. Remember that no one else will see these answers, and you do not have to answer anything you do not want to.

Not true Sort of true Certainly true

32. I try to be nice to other people.

I care about their feelings.

1

2

33. I am restless, I cannot stay still for long..... 1

34. I get a lot of headaches, stomach aches or sickness...

35. I usually share with others (food, games etc)... 1

36. I get very angry and often lose my temper..... 1

37. I am usually on my own, and play alone.

38. I usually do what I am told................. 1

2

39. I worry a lot

40. I am helpful if someone is hurt, upset, feeling ill.

41. I fidget and squirm a lot................ 1

42. I have one good friend or more

43. I fight a lot and sometimes bully people.....

44. I am often unhappy or tearful 
46. I am easily distracted, I find it difficult to concentrate...

47. I am nervous in new situations,

I easily lose confidence.................. 1

48. I am kind to younger children

49. I am often accused of lying or cheating...

50. Other children or young people pick on me or bully me.............................. 1

51. I often volunteer to help others (teachers, other children, parents).

52. I think before I do things

53. I take things that are not mine from home, school or elsewhere.

54. I get on better with adults than with people my own age.

55. I have many fears, I am easily scared........ 1

56. I finish the work I am doing.

My attention is good.....

I now want to ask you some questions about how you feel about your stepparent.

During the past month, when you and your stepparent have spent time talking or doing things together, how often did they....

\section{Hardly Ever Sometimes Often Most of the Time}

57. Get angry with you......

58. Let you know he/she really cares about you......

59. Criticise you or your ideas (i.e. say bad things about your ideas)......... 
60. Shout at you because

he/she was upset with you......

61. Act loving towards you........ 1

62. Let you know that he/she

likes your ideas

or the things you do...........

2

3

4

63. Help you do something that was important to you......

2

64. Get into an argument with you...................... 1

2

65. Argue with you when you did not agree about something................

66. Act supportive and understanding towards you

67. Insult or swear at you........ 1

2

3

68. Call you bad names...........

2

69. Tell you he/she loves you..... 1

2

3

4

70. How often do you feel angry with your stepparent, because of something they have said or done?

$\begin{array}{lllllll}1 & 2 & 3 & 4 & 5 & 6 & 7\end{array}$

Hardly ever Sometimes A lot of the time

71. How close do you feel to your stepparent?

$\begin{array}{lllllll}1 & 2 & 3 & 4 & 5 & 6 & 7\end{array}$

Not close at all

Very close 
I am now going to list some ways that adults sometimes act towards children and I would like you to tell me how involved your stepparent is in doing these things for you. Then I will ask you whether this is ok for you, or if you'd rather they did these things more or less.

$1=$ not at all involved, $5=$ very involved

How involved is your stepparent in doing the following things for you?

72. Helping you get ready for school in the morning

73. Making sure you don't watch TV shows or movies that aren't good for you

74. Hugging you when you're upset

75. Telling you off when you've been naughty

76. Teaching you to be polite

77. Helping you with your reading or homework assignments

78. Telling you there are certain places you can't go on your own

79. Helping you fix any personal problems

80. Setting new rules for you to follow

81. Telling you when to say "please" and "thank you"

82. Paying for big things for you, like school fees, doctors bills

83. Going to activities at your school e.g. sports games etc

84. Talking to you about your friends

85. Having to tell them where you're going, if you go somewhere after school e.g. a friend's house

86. Standing up for you, such as when you are in trouble

87. Punishing you when you have been naughty

(e.g. sending you to your room, time-outs, grounding etc) 
88. Teaching you to take turns and share with others

89. Driving you to places you need to be

(e.g. school in the mornings)

90. Making sure you don't stay up too late

91. Asking you what happened during your day at school

92. Telling you off when you are rude to Mum/Dad

93. Paying for small things for you e.g. clothes, activities etc

94. Teaching you to consider other people's feelings

95. Rewarding you when you behave well

96. Going to parent/teacher interviews at your school

97. a. Have you ever talked to someone in your family about how you feel about your stepparent doing these things?

[if not]

b. Why not?

c. Who did you talk to?

98. Has your Mum/Dad ever checked in with you to see how you felt about living with $\mathrm{x}$ ? What did he/say? How did this make you feel?

99. There is a list here of words. I would like you to tell me which word best describes the relationship you would have with your stepparent if you could have it your way. If none of these seem to be the right word, you can tell me another word. You can tick more than one word.

a Friend

口 Parent

口 Stepparent

- Close relative e.g. Aunt/Uncle

- Mum/Dads girlfriend

- Someone we share a house with e.g. flatmate

口 Other 
100. a. Is this how they act towards you at the moment?

YES NO

b. If no, how does $\mathrm{x}$ act towards you now?

$\begin{array}{ll}\square & \text { Friend } \\ \square & \text { Parent } \\ \square & \text { Stepparent } \\ \square & \text { Close relative e.g. Aunt/Uncle } \\ \square & \text { Mum/Dads girlfriend } \\ \square & \text { Someone we share the house with e.g. Flatmate } \\ \square & \text { Other }\end{array}$

Comments:

101. a. How often would you say you and $\mathrm{x}$ do something fun together, just the 2 of you? (e.g. Go to the park, play sport together etc)

$\begin{array}{cccccc}1 & 2 & 3 & 4 & 5 & 6 \\ \text { Never } & \text { Once every } & \text { Once a } & \text { Once every } & \text { Once a week } & \text { Almost } \\ \text { Or rarely } & \text { couple of months } & \text { month } & \text { couples of weeks } & \text { Or more } & \text { every day }\end{array}$

b. What kinds of things do you do together?

102. How much do you enjoy spending time with $\mathrm{x}$ ?

$\begin{array}{ccccccc}1 & 2 & 3 & 4 & 5 & 6 & 7 \\ \text { Do not enjoy } & & & & & & \text { Enjoy very much }\end{array}$


I now just want to ask you a few questions about the way you feel about yourself. Remember that there are no right or wrong answers; I only want to know how you feel about these things.

Not at all

Certainly

True

True

103. Kids my age enjoy spending time with me...

$\begin{array}{llllll}1 & 2 & 3 & 4 & 5 & 6\end{array}$

104. I am a good looking person......1

$\begin{array}{lllll}2 & 3 & 4 & 5 & 6\end{array}$

105. I believe I can do things I want to do...

$\begin{array}{llllll}1 & 2 & 3 & 4 & 5 & 6\end{array}$

106. I am a happy person..............

107. I know what to do in school situations......

$\begin{array}{lllll}2 & 3 & 4 & 5 & 6\end{array}$

108. I am proud of how well I can do in school work

$\begin{array}{llllll}.1 & 2 & 3 & 4 & 5 & 6\end{array}$

109. I am just as good looking as

I would like to be

2

110. I am happy with the school work I do..........

$\begin{array}{llllll}1 & 2 & 3 & 4 & 5 & 6\end{array}$

111. I sometimes wish I had another family...

$\begin{array}{llllll}1 & 2 & 3 & 4 & 5 & 6\end{array}$

112. I feel good about how I do at school......

113. I would change things about myself if I could

$\ldots . .1$

114. I think I am able to get good grades in school work............

115. The way I look sometimes worries me.

$\begin{array}{lllll}2 & 3 & 4 & 5 & 6\end{array}$


116. I feel my family trusts me.....

2

2

117. My friends think I can do

things well..........

$\begin{array}{llllll}1 & 2 & 3 & 4 & 5 & 6\end{array}$

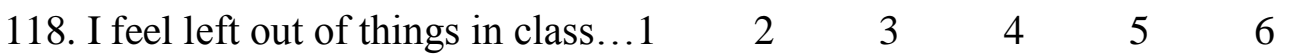

119. My family loves me............ $24 \quad 3 \quad 4 \quad 5 \quad 6$

120. I am popular with other kids

$\begin{array}{lllllll}\text { my own age..... } & 1 & 2 & 3 & 4 & 5 & 6\end{array}$

121. I am proud of my

$\begin{array}{llllllll}\text { school reports... } & 1 & 2 & 3 & 4 & 5 & 6\end{array}$

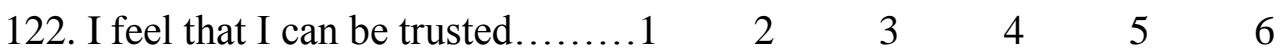

123. I get along well with

other kids...

$\begin{array}{llllll}1 & 2 & 3 & 4 & 5 & 6\end{array}$

124. I am clever enough to do my

school work...

$\begin{array}{llllll}1 & 2 & 3 & 4 & 5 & 6\end{array}$

125. I am satisfied with what I

do in school......

$\begin{array}{llllll}1 & 2 & 3 & 4 & 5 & 6\end{array}$

126. My family is sometimes

Disappointed in me

$\begin{array}{llllll}1 & 2 & 3 & 4 & 5 & 6\end{array}$

127. I am an important person to

my friends......

$\begin{array}{llllll}1 & 2 & 3 & 4 & 5 & 6\end{array}$

128. I am proud of my school

129. I am able to get the results I

would like to get in school..... $1 \quad 1 \quad 2 \quad 30 \begin{array}{llllll} & 3 & 4 & 5 & 6\end{array}$

130. I have respect for myself........ $\quad 2 \quad 3 \quad 4 \quad 4 \quad 5 \quad 6$

131. I sometimes feel unwanted at home...........

$\begin{array}{llllll}1 & 2 & 3 & 4 & 5 & 6\end{array}$

132. At school I feel I am as good as the other kids in my class.........

133. I sometimes feel like my teacher(s) does not understand me...

$\begin{array}{lllll}2 & 3 & 4 & 5 & 6\end{array}$


134. I would like to change how I look

$\begin{array}{lllll}2 & 3 & 4 & 5 & 6\end{array}$

135. I sometimes feel like I don't matter in class...

$\begin{array}{llllll}1 & 2 & 3 & 4 & 5 & 6\end{array}$

136. I feel good about my

school work............

137. Most of the time I think

$\begin{array}{lllllll}\text { I am pretty good... } & 1 & 2 & 3 & 4 & 5 & 6\end{array}$

The following statements are about families. Please decide which is true of your family.

138. People in my family ask each other for help when they need it

$$
\text { True False }
$$

139. We like each other's friends

$$
\text { True False }
$$

140. We like to do things with just our family

$$
\text { True False }
$$

141. People in my family feel closer to other family members, than to people outside the family

True False

142. People in my family like to spend free time with each other

$$
\text { True False }
$$

143. People in my family feel very close to each other

$$
\text { True False }
$$

144. When our family gets together for gatherings, everyone comes along 


\section{Thank you for completing this questionnaire for me.}

\section{Further Assistance}

Sometimes when we talk about things we can get upset, or we may just need someone else to talk to. Here are some phone numbers you can ring if you need to talk to anyone outside your family about things you might be concerned or want to talk more about. These calls are free.

Kidsline

To talk to an adult

To talk to an older kid

What's up

Youth line

(for 10 years and older)
0800543754

all day, 7 days a week

$4 \mathrm{pm}-6 \mathrm{pm}$ weekdays

08009428787

Mid-day to midnight,

7 days a week

0800376633

8 am - midnight

Email talk@youthline.co.nz

www.skylight.org.nz

Click on "info for you"

\section{Please tear of this sheet}




\section{APPENDIX J}

Adults' Role Negotiation Interview

Time One 


\section{$\underline{\text { Parent Interview }}$}

\section{Start with a description of who lives in this household.}

I just want to start by asking you a few questions about that period of time when you first moved in together.

1. Around the time when you and your partner moved in together, can you remember what role you hoped your partner/you would play in this child's life?

2. How do you see your partner's/your responsibilities as a stepparent now? How are these different to your/your partner's responsibilities to this child?

3. Do you feel that your views regarding these responsibilities to have changed over time? In what ways? Why do you think this has occurred?

\section{ROLE NEGOTIATION}

I just want to ask you a few questions about how your partner's/your role in this child's life has developed over time. For some families a lot of preparation and thought goes into sorting out the role the stepparent might play in the children's lives, whereas for other families things just sort of evolve naturally over time.

\section{Question 1.}

I want to first focus on that time before you all moved in together.

Can you remember having any talks before moving in together about your partner's role in the target child's life, or how involved he/she would be in this child's life? 


\section{IF NO}

Is there a reason why you didn't do this?

\section{IF YES}

Who was involved?

Ask for all:

What kinds of things were talked about?

How often did you do this?

4- Very frequently

3- Frequently

2- Not frequently-but from time to time

1- Occasionally_once or twice

$0-$ Not at all

Were these talks planned or spontaneous (as issues came up)?

Who was it that wanted these discussions?

Were any decisions made? IF NO, GO TO QUESTION 2

IF YES

What were these decisions? Can you give me an example.

\section{Question 2.}

NOW I want you to think about that time after you moved in together, up till now.

Have you had any talks at all since moving in together about your partners/your role in this child's life, or how involved he/she is/you are as a stepparent to this child?

$$
\text { YES NO }
$$


Is there a reason why you haven't done this?

Who was involved?

Ask for all:

What kinds of things were talked about?

How often do you do this?

Very frequently

Frequently

Not frequently-but from time to time

Occasionally—once or twice

Who was it that wanted these discussions?

Planned talks versus fleeting, spontaneous talks (as issues came up)?

Were any decisions made?

IF NO, GO TO QUESTION 3

What were these decisions? Can you give me an example?

\section{Question 3}

Do you ever check in with this child to see how child feels about what stepparent is doing i.e. how he/she is acting towards the child?

YES NO

If NO:

Is there a reason why you don't do this? 
IF YES:

How often does this happen?

Very frequently

Frequently

Not frequently-but from time to time

Occasionally — once or twice

Could you give me an example of a conversation had. Any reporting back to stepparent?

\section{Question 4}

Does your partner ever check in with you for feedback on how they are going with $\mathrm{x}$ ?

How often does this happen?

Very frequently

Frequently

Not frequently-but from time to time

Occasionally —once or twice

Anything that they typically ask you?

Asking you about things they have already done (e.g. checking that what they are doing is okay) or checking out your views on something they want to do

\section{Question 5}

Do you and your partner talk together about how you will handle issues concerning the kids? (these can be any issues e.g. whether child can go to a sleepover, how to handle any behaviour problems etc etc)?

$Y E S$

NO

\section{IF NO}

Is there a reason why you don't do this? 


\section{IF YES}

How often do you do this? (interviewer tick)

Very frequently

Frequently

Not frequently-but from time to time

Occasionally—once or twice

What sorts of things do you talk about most often?

When you and your partner talk about these issues, do you consider them to be an advisor (someone you go to for advice), a cooparent (someone who you make decisions with together) or something else?

\section{Question 6}

Do you believe that there are certain aspects of parenting that are your responsibility but not your partners?

YES NO (Finished!)

IF YES

Which aspects of parenting are these?

Do you think your partner knows how you feel about this? How?

How do you think they felt about this?

Have there been instances where your partner has not followed your wishes? How did you deal with that?

Do you think your partner feels that there are certain aspects of parenting that are your responsibility but not theirs?

Which aspects are these? 


\section{APPENDIX K}

Adults' Role Negotiation Questionnaire

Time Two 


\section{Adult Role Negotiation Questionnaire Time 2}

I am now going to ask you a few questions about how parenting roles and responsibilities have been sorted out in your family.

\section{Question 1}

a. Since we last spoke, have you had any talks with your partner about your partner's role or responsibilities as a stepparent?

$\begin{array}{lllll}1 & 2 & 3 & 5\end{array}$

Not at all Once or twice From Frequently Very Frequently Time to Time

If you circled $2,3,4$ or 5 , please answer the next questions. Otherwise go to Question 2.

b. What were these talks about?

c. Were these talks mostly planned or spontaneous (i.e. "just happened")

Mostly Planned Mostly Spontaneous

d. Who initiated these talks? (e.g. you, your partner etc)

e. Were any decisions made in these talks?

YES

NO 


\section{Question 2}

a. Since we last spoke, have you had any talks with your ex-partner (i.e. the child's other biological parent) about your partner's role or responsibilities as a stepparent? (If NA please circle 1)

2

3

4

5

Not at all

Once or twice

From

Frequently

Very Frequently

Time to Time

\section{If you circled $2,3,4$ or 5 , please answer the next questions.}

\section{Otherwise go to Question 3.}

b. What were these talks about?

c. Were they mostly planned or spontaneous (please circle)

\section{Mostly Planned Mostly Spontaneous}

d. Who initiated these talks? (e.g. you, your partner, your ex-partner etc)

Were any decisions made in these talks? $\quad Y E S \quad N O$

\section{Question 3}

a. Since we last spoke, have you had any talks with your child (i.e. the target child) about your partner's role or responsibilities as a stepparent?

1 2 3

4 5

Not at all Once or twice From Frequently Very Frequently

Time to Time 


\section{If you circled 2, 3, 4 or 5, please answer the next questions.}

\section{Otherwise go to Question 4.}

b. What were these talks about?

c. Were they mostly planned or spontaneous (please circle)

$$
\text { Mostly Planned Mostly Spontaneous }
$$

d. Who initiated these talks? (e.g. you, your partner, child etc)

e. Were any decisions made in these talks? YES NO

\section{Question 4}

a. Since we last spoke, have you had any talks about your partner's role or responsibilities as a stepparent with the family as a whole?

$\begin{array}{lllll}1 & 3 & 4 & 5\end{array}$

Not at all Once or twice From Frequently Very Frequently

Time to Time

If you circled 2, 3, 4 or 5, please answer the next questions.

Otherwise go to Question 5.

b. What were these talks about?

c. Were they mostly planned or spontaneous (please circle)

\section{Mostly Planned Mostly Spontaneous}

d. Who initiated these talks?

e. Were any decisions made in these talks? YES NO 


\section{Question 5}

a. Since we last spoke, have you ever checked in with this child to see how they feel about ways your partner is acting towards them, or how they feel about their relationship with their stepparent?

$$
2
$$

3

4

5

Not at all Once or twice From Frequently Very Frequently time to time

\section{If you circled 2, 3, 4 or 5, please answer the next questions. Otherwise go to Question 6.}

b. What were these talks about?

c. Do you ever report back to your partner about what is said in these talks?

YES NO

Other

\section{Question 6}

a. Since we last spoke, has your partner ever checked in with you for feedback on how they are going with the parenting of this child (e.g. if the way they are parenting is ok, if they should handle discipline etc differently?)?

1

2

3

4

5

Not at all Once or twice From Frequently Very Frequently time to time

\section{If you circled 2, 3, 4 or 5, please answer the next questions. Otherwise go to Question 7.}

a. When they do check in with you, do they ask about things they have already done 
(e.g. checking that what they did is okay) or do you check out your views on future ways to handle situations?

․ Mostly something they've already done

- Mostly future ways to handle situations

․ Equally Both

\section{Question 7}

When you and your partner have to make important decisions about this child (e.g. what school they go to etc), how do you think of your partner's role in the decisionmaking process most of the time?

- Like an advisor - someone I go to for advice

口 A sounding board - someone to bounce ideas off

口 A cooparent - someone to talk things over and make decisions together

\section{OR}

는 $\quad$ something else?

\section{Question 8}

Are there any aspects of parenting in your view that should be ultimately your responsibility as the biological parent to this child?

$$
\text { YES NO }
$$

Which aspects of parenting are these?

EVERYONE please answer question 10

\section{Question 9}

In relation to your answer for Question $9 . .$.

How do you think your partner feels about this? (ie do you think they agree, disagree with you etc) 


\section{APPENDIX L}

\section{Internal Consistency Scores at Time Two}


$\underline{\text { Table 1: Internal Consistency Scores for Time Two Measures - Total Scores }}$

\begin{tabular}{|c|c|c|}
\hline Measure & Stepfamily Member & Chronbach alpha \\
\hline \multirow[t]{3}{*}{ SDQ - Tot Diffs } & Parent & .82 \\
\hline & Stepparent & .85 \\
\hline & Children & .81 \\
\hline Self-Concept-Total & Children & .92 \\
\hline \multirow[t]{2}{*}{ Partner RQ } & Parent & .83 \\
\hline & Stepparent & .92 \\
\hline \multirow[t]{2}{*}{ SP_SC RQ } & Stepparent & .88 \\
\hline & Children & .88 \\
\hline BP_SC RQ & Children & .82 \\
\hline NRP_SC RQ & Children & .85 \\
\hline \multirow[t]{3}{*}{ Family Cohesion } & Parent & .82 \\
\hline & Stepparent & .88 \\
\hline & Children & .83 \\
\hline \multirow[t]{3}{*}{ Family Conflict } & Parent & .89 \\
\hline & Stepparent & .88 \\
\hline & Children & .87 \\
\hline \multirow[t]{2}{*}{ Gate keeping } & Parent & .75 \\
\hline & Stepparent & .77 \\
\hline
\end{tabular}

Table 2: Internal Consistency Scores for Stepparent Role Questionnaire for Time 2

\begin{tabular}{|l|l|l|c|}
\hline $\begin{array}{l}\text { SP Role } \\
\text { Dimension }\end{array}$ & $\begin{array}{l}\text { Actual } \mathrm{v} \\
\text { Ideal }\end{array}$ & SF Member & Chronbach alpha \\
\hline Warmth & Current & Parents & .88 \\
\hline & & Stepparents & .91 \\
\hline & & Children & .83 \\
\hline Warmth & Ideal & Parents & .91 \\
\hline & & Stepparents & .92 \\
\hline & & Children & .83 \\
\hline Control & Current & Parents & .95 \\
\hline & & Stepparents & .94 \\
\hline & & Children & .74 \\
\hline Control & Ideal & Parents & .94 \\
\hline & & Stepparents & .95 \\
\hline & & Children & .79 \\
\hline
\end{tabular}




\section{APPENDIX M}

Wording Changes for About Myself 


\begin{tabular}{|c|c|c|}
\hline Subscale & Old Version & New Version \\
\hline Peer & $\begin{array}{l}\text { Persons of my age group enjoy my } \\
\text { company }\end{array}$ & $\begin{array}{l}\text { Kids my age enjoy spending } \\
\text { time with me }\end{array}$ \\
\hline Physical & I am an attractive person & I am a good looking person \\
\hline Confidence & I have confidence in myself & $\begin{array}{l}\text { I believe I can do things I } \\
\text { want to do }\end{array}$ \\
\hline Confidence & I am a cheerful person & I am a happy person \\
\hline Classroom & $\begin{array}{l}\text { I am sure of myself in school } \\
\text { situations }\end{array}$ & $\begin{array}{l}\text { I know what to do in school } \\
\text { situations }\end{array}$ \\
\hline Ability & $\begin{array}{c}\text { I am proud of my ability in } \\
\text { academic work }\end{array}$ & $\begin{array}{c}\text { I am proud of how well I can } \\
\text { do in school work }\end{array}$ \\
\hline Physical & I am just as nice as I should be & $\begin{array}{l}\text { I am as good looking as I } \\
\text { want to be }\end{array}$ \\
\hline Achievement & $\begin{array}{l}\text { I am happy with the school work I } \\
\text { do }\end{array}$ & $\begin{array}{l}\text { I am happy with the school } \\
\text { work I do }\end{array}$ \\
\hline Family & $\begin{array}{l}\text { I wish I had been born into another } \\
\text { family }\end{array}$ & $\begin{array}{c}\text { I sometimes wish I had } \\
\text { another family }\end{array}$ \\
\hline Ability & $\begin{array}{c}\text { I feel good about my academic } \\
\text { ability }\end{array}$ & $\begin{array}{l}\begin{array}{l}\text { I feel good about how I do at } \\
\text { school }\end{array} \\
\end{array}$ \\
\hline Physical & $\begin{array}{l}\text { I would change many things about } \\
\text { myself if I could }\end{array}$ & $\begin{array}{c}\text { I would change things about } \\
\text { myself if I could }\end{array}$ \\
\hline Ability & $\begin{array}{l}\text { I think that I have the ability to get } \\
\text { good grades in school work }\end{array}$ & $\begin{array}{l}\text { I think I am able to get good } \\
\text { grades in school work }\end{array}$ \\
\hline Physical & My looks bother me & $\begin{array}{l}\text { The way I look sometimes } \\
\text { worries me }\end{array}$ \\
\hline Family & I feel my family trusts me & I feel my family trusts me \\
\hline Peer & My friends have confidence in me & $\begin{array}{l}\text { My friends think I can do } \\
\text { things well }\end{array}$ \\
\hline Classroom & I feel left out of things in class & $\begin{array}{l}\text { I feel left out of things in } \\
\text { class }\end{array}$ \\
\hline Family & I am loved by my family & My family loves me \\
\hline Peer & $\begin{array}{c}\text { I am popular with others of my own } \\
\text { age }\end{array}$ & $\begin{array}{c}\text { I am popular with other kids } \\
\text { my own age }\end{array}$ \\
\hline Achievement & I am proud of my school reports & $\begin{array}{l}\text { I am proud of my school } \\
\text { reports }\end{array}$ \\
\hline Confidence & I feel that I am trustworthy & I feel that I can be trusted \\
\hline Peer & I get along well with other people & $\begin{array}{c}\text { I get along well with other } \\
\text { kids }\end{array}$ \\
\hline Ability & $\begin{array}{l}\text { I think my ability is sufficient to } \\
\text { cope with school work }\end{array}$ & $\begin{array}{l}\text { I am clever enough to do my } \\
\text { school work }\end{array}$ \\
\hline
\end{tabular}




\begin{tabular}{|c|c|c|}
\hline Achievement & I am satisfied with my school work & $\begin{array}{l}\text { I am satisfied with what I do } \\
\text { at school }\end{array}$ \\
\hline Family & My family is disappointed in me & $\begin{array}{l}\text { My family is sometimes } \\
\text { disappointed in me }\end{array}$ \\
\hline Peer & $\begin{array}{l}\text { I am an important person to my } \\
\text { friends }\end{array}$ & $\begin{array}{l}\text { I am an important person to } \\
\text { my friends }\end{array}$ \\
\hline Achievement & I am proud of my school work & $\begin{array}{l}\text { I am proud of my school } \\
\text { work }\end{array}$ \\
\hline Ability & $\begin{array}{l}\text { I think that I am capable of getting } \\
\text { the results I would like to obtain in } \\
\text { school work }\end{array}$ & $\begin{array}{l}\text { I am able to get the results I } \\
\text { would like to get in school }\end{array}$ \\
\hline Confidence & I have respect for myself & I have respect for myself \\
\hline Family & I feel unwanted at home & $\begin{array}{l}\text { I sometimes feel unwanted at } \\
\text { home }\end{array}$ \\
\hline Classroom & $\begin{array}{l}\text { In the kinds of things we do in } \\
\text { school, I feel I am as good as the } \\
\text { other people in my class }\end{array}$ & $\begin{array}{l}\text { At school I feel I am as good } \\
\text { as the other kids in my class }\end{array}$ \\
\hline Classroom & $\begin{array}{c}\text { Most of my teachers do not } \\
\text { understand me }\end{array}$ & $\begin{array}{c}\text { I sometimes feel like my } \\
\text { teacher(s) does not } \\
\text { understand me }\end{array}$ \\
\hline Physical & $\begin{array}{l}\text { I would like to change my physical } \\
\text { appearance }\end{array}$ & $\begin{array}{l}\text { I would like to change how I } \\
\text { look }\end{array}$ \\
\hline Classroom & I feel worthless in class & $\begin{array}{l}\text { I sometimes feel like I don't } \\
\text { matter in class }\end{array}$ \\
\hline Achievement & I feel good about my school work & $\begin{array}{l}\text { I feel good about my school } \\
\text { work }\end{array}$ \\
\hline Confidence & I think I am good at all times & $\begin{array}{l}\text { Most of the time I think I am } \\
\text { pretty good }\end{array}$ \\
\hline
\end{tabular}




\title{
APPENDIX N
}

\author{
Wording Changes for FACES III
}




\begin{tabular}{|l|l|}
\hline Old FACES Items & New FACES Items \\
\hline Family members ask each other for help & $\begin{array}{l}\text { People in my family ask each other for } \\
\text { help when they need it }\end{array}$ \\
\hline We approve of each other's friends & We like each other's friends \\
\hline $\begin{array}{l}\text { We like to do things with just our } \\
\text { immediate family }\end{array}$ & $\begin{array}{l}\text { We like to do things with just our } \\
\text { family }\end{array}$ \\
\hline $\begin{array}{l}\text { Family members feel closer to other } \\
\text { family members than to people outside } \\
\text { the family }\end{array}$ & $\begin{array}{l}\text { People in my family feel closer to } \\
\text { other family members than to people } \\
\text { outside the family }\end{array}$ \\
\hline $\begin{array}{l}\text { Family members like to spend free time } \\
\text { with each other }\end{array}$ & $\begin{array}{l}\text { People in my family like to spend free } \\
\text { time together }\end{array}$ \\
\hline $\begin{array}{l}\text { Family members feel very close to each } \\
\text { other }\end{array}$ & $\begin{array}{l}\text { People in my family feel very close to } \\
\text { one another }\end{array}$ \\
\hline $\begin{array}{l}\text { When our family gets together for } \\
\text { activities, everyone is present }\end{array}$ & $\begin{array}{l}\text { When our family gets together for } \\
\text { gatherings, everyone comes along }\end{array}$ \\
\hline $\begin{array}{l}\text { We can easily think of things to do } \\
\text { together as a family }\end{array}$ & $\begin{array}{l}\text { We can easily think of things to do } \\
\text { together as a family }\end{array}$ \\
\hline $\begin{array}{l}\text { Family members consult other family } \\
\text { members on their decisions }\end{array}$ & $\begin{array}{l}\text { We talk to other people in our family } \\
\text { about the decisions we make }\end{array}$ \\
\hline $\begin{array}{l}\text { Family togetherness is very important } \\
\text { imping together as a family is very } \\
\text { important to us }\end{array}$ \\
\hline
\end{tabular}




\section{APPENDIX 0}

Dimensions of the Stepparent Role

Questionnaire 
Individual Role Perceptions: Actual versus Ideal Roles

\begin{tabular}{|c|c|c|}
\hline Actual v Ideal & $\begin{array}{l}\text { Role } \\
\text { Dimension }\end{array}$ & Conceptualisation \\
\hline \multirow{2}{*}{ Actual Stepparent Role } & Warmth & $\begin{array}{l}\text { Actual stepparent involvement in } \\
\text { warmth behaviours with target } \\
\text { stepchild }\end{array}$ \\
\hline & Control & $\begin{array}{l}\text { Actual stepparent involvement in } \\
\text { control behaviours with target } \\
\text { stepchild }\end{array}$ \\
\hline \multirow{2}{*}{ Ideal Stepparent Role } & Warmth & $\begin{array}{l}\text { Ideal stepparent involvement in } \\
\text { warmth behaviours with target } \\
\text { stepchild }\end{array}$ \\
\hline & Control & $\begin{array}{l}\text { Ideal stepparent involvement in } \\
\text { control behaviours with target } \\
\text { stepchild }\end{array}$ \\
\hline
\end{tabular}


APPENDIX P

Conceptualisation of

\section{Intra-Role and Inter-Role Discrepancies}


$\underline{\text { Table 1: Intra-role discrepancies }}$

\begin{tabular}{|c|c|c|}
\hline Discrepancy Score & $\begin{array}{l}\text { Dimension of } \\
\text { stepparent role }\end{array}$ & Conceptualisation \\
\hline \multirow{2}{*}{$\begin{array}{r}\text { Parent Intra-role } \\
\text { Discrepancy }\end{array}$} & Warmth & $\begin{array}{l}\text { The difference between parents views } \\
\text { of the stepparent's involvement in } \\
\text { current warmth behaviours and ideal } \\
\text { warmth behaviours. }\end{array}$ \\
\hline & Control & $\begin{array}{l}\text { The difference between parents views } \\
\text { of the stepparent's involvement in } \\
\text { current control behaviours and ideal } \\
\text { control behaviours. }\end{array}$ \\
\hline \multirow{2}{*}{$\begin{array}{r}\text { Stepparent Intra-role } \\
\text { Discrepancy }\end{array}$} & Warmth & $\begin{array}{l}\text { The difference between stepparents } \\
\text { views of their involvement in current } \\
\text { warmth behaviours and ideal warmth } \\
\text { behaviours. }\end{array}$ \\
\hline & Control & $\begin{array}{l}\text { The difference between stepparents } \\
\text { views of their involvement in current } \\
\text { control behaviours and ideal control } \\
\text { behaviours. }\end{array}$ \\
\hline \multirow{2}{*}{$\begin{array}{r}\text { Child Intra-role } \\
\text { Discrepancy }\end{array}$} & Warmth & $\begin{array}{l}\text { The difference between children's } \\
\text { views of the stepparent's involvement } \\
\text { in current warmth behaviours and ideal } \\
\text { warmth behaviours. }\end{array}$ \\
\hline & Control & $\begin{array}{l}\text { The difference between children's } \\
\text { views of the stepparent's involvement } \\
\text { in current control behaviours and ideal } \\
\text { control behaviours. }\end{array}$ \\
\hline
\end{tabular}


Table 2: Inter-role Discrepancies

\begin{tabular}{|c|c|c|}
\hline Discrepancy Score & $\begin{array}{l}\text { Dimension of } \\
\text { stepparent role }\end{array}$ & Conceptualisation \\
\hline \multirow{2}{*}{$\begin{array}{r}\text { Parent-Stepparent } \\
\text { Inter-role Discrepancy }\end{array}$} & Warmth & $\begin{array}{l}\text { The difference between parents and } \\
\text { stepparents views of the stepparent's } \\
\text { ideal involvement in warmth behaviours } \\
\text { and ideal warmth behaviours. }\end{array}$ \\
\hline & Control & $\begin{array}{l}\text { The difference between parents and } \\
\text { stepparents views of the stepparents } \\
\text { ideal involvement in control behaviours }\end{array}$ \\
\hline \multirow{2}{*}{$\begin{array}{l}\text { Stepparent - Stepchild } \\
\text { Inter-role Discrepancy }\end{array}$} & Warmth & $\begin{array}{l}\text { The difference between stepparents and } \\
\text { stepchildren's views of the stepparents } \\
\text { ideal involvement in warmth behaviours }\end{array}$ \\
\hline & Control & $\begin{array}{l}\text { The difference between stepparents and } \\
\text { stepchildren's views of the ideal } \\
\text { involvement of the stepparent in control } \\
\text { behaviours }\end{array}$ \\
\hline \multirow{2}{*}{$\begin{array}{r}\text { Parent - Stepchild } \\
\text { Inter-role Discrepancy }\end{array}$} & Warmth & $\begin{array}{l}\text { The difference between children's and } \\
\text { parents views of the ideal involvement } \\
\text { of the stepparent in warmth behaviours }\end{array}$ \\
\hline & Control & $\begin{array}{l}\text { The difference between children's and } \\
\text { parents views of the ideal involvement } \\
\text { of the stepparent in control behaviours }\end{array}$ \\
\hline
\end{tabular}




\section{APPENDIX Q}

\section{Changes to Outliers and Extreme Scores}


$\underline{\text { Table 1: Changes to Outliers for Family Conflict }}$

\begin{tabular}{|l|l|l|l|l|}
\hline Measure & SF Member & Family ID & Original Score & New Score \\
\hline Family Conflict & Parent & 804 & 37 & 35 \\
\hline & Stepparent & 859 & 38 & 37 \\
\hline & Stepparent & 832 & 38 & 37 \\
\hline
\end{tabular}

Table 2: Changes to Outliers for Stepparent Role Questionnaire at Time 1

\begin{tabular}{|l|l|l|l|l|}
\hline Measure & SF Member & Family ID & Original Score & New Score \\
\hline Ideal_Warmth & Parent & 882 & 1.3 & 1.8 \\
\hline Ideal_control & Parent & 854 & 1.3 & 1.8 \\
\hline
\end{tabular}

Table 2: Changes to Outliers for Stepparent Role Questionnaire at Time 2

\begin{tabular}{|l|l|l|l|l|}
\hline Measure & SF Member & Family ID & Original Score & New Score \\
\hline Ideal Warmth & Parent & 827 & 1.0 & 1.9 \\
\hline Ideal Warmth & Parent & 882 & 1.6 & 2.0 \\
\hline Ideal Control & Parent & 882 & 1.6 & 2.1 \\
\hline Ideal Control & Parent & 827 & 1.8 & 2.2 \\
\hline Actual Control & Parent & 827 & 1.8 & 2.1 \\
\hline Actual Control & Parent & 882 & 1.5 & 2.1 \\
\hline Actual Control & Parent & 876 & 1.4 & 2.1 \\
\hline Ideal Control & Child & 876 & 1.0 & 1.3 \\
\hline Actual Control & Child & 876 & 1.0 & 1.3 \\
\hline Ideal Control & Stepparent & 876 & 1.0 & 1.7 \\
\hline
\end{tabular}

Table 2: Changes to Outliers for Intra-role discrepancies

\begin{tabular}{|l|l|l|l|l|l|}
\hline Measure & SF Member & Time & Family ID & $\begin{array}{l}\text { Original } \\
\text { Score }\end{array}$ & New Score \\
\hline Intra Control & Child & Time 2 & 831 & .90 & .70 \\
\hline Intra Control & Child & Time 2 & 896 & .80 & .65 \\
\hline
\end{tabular}




\begin{tabular}{|l|l|l|l|l|l|}
\hline Intra Control & Child & Time 2 & 809 & .80 & .65 \\
\hline Intra Warmth & Child & Time 2 & 831 & .90 & .75 \\
\hline Intra Warmth & Child & Time 1 & 834 & 1 & .85 \\
\hline Intra Warmth & Child & Time 1 & 819 & 1 & .85 \\
\hline Intra Warmth & Child & Time 1 & 872 & .90 & .80 \\
\hline Intra Warmth & Child & Time 1 & 884 & .89 & .75 \\
\hline
\end{tabular}

Table 2: Changes to Outliers for Inter-role discrepancies

\begin{tabular}{|l|l|l|l|l|}
\hline Measure & Time & Family ID & Original Score & New Score \\
\hline BP_SC Warmth & Time 1 & 818 & 3.20 & 3.0 \\
\hline BP_SP Warmth & Time 1 & 852 & 3 & 2 \\
\hline & & 819 & 2.30 & 1.80 \\
\hline & & 820 & 1.80 & 1.70 \\
\hline & & 830 & 1.70 & 1.65 \\
\hline BP_SP Control & Time 1 & 852 & 3.30 & 2.20 \\
\hline & & 876 & 2.40 & 2 \\
\hline & & 856 & 2.40 & 2 \\
\hline SP_SC Warmth & Time 1 & 818 & 3.00 & 2.80 \\
\hline BP_SP Warmth & Time 2 & 827 & 2.10 & 1.90 \\
\hline BP_SP Control & Time 2 & 876 & 2.80 & 2.40 \\
\hline & & 821 & 2.60 & 2.35 \\
\hline & & 827 & 2.40 & 2.30 \\
\hline SP_SC Control & Time 2 & 838 & 3.40 & 3 \\
\hline SP_SC Warmth & Time 2 & 863 & 3.60 & 2.60 \\
\hline & & 849 & 3.20 & 2.50 \\
\hline & & 832 & 2.70 & 2.40 \\
\hline
\end{tabular}


$\underline{\text { Table 2: Changes to Outliers for Stepfamily Functioning Measures }}$

\begin{tabular}{|l|l|l|l|l|}
\hline Measure & Time & Family ID & Original Score & New Score \\
\hline BP Cohesion & Time 2 & 852 & 5.20 & 5.70 \\
\hline BP Partner RQ & Time 2 & 827 & 5.20 & 5.7 \\
\hline Child RP RQ & Time 2 & 852 & 2.08 & 2.60 \\
\hline & Time 2 & 873 & 1.77 & 2.30 \\
\hline & Time 2 & 876 & 2.46 & 2.4 \\
\hline Total SC & Time 2 & 819 & 2.54 & 2.50 \\
\hline Time 2 & 884 & 2.66 & 2.6 \\
\hline Child Cohesion & Time 2 & 895 & 4 & 2.8 \\
\hline SP Cohesion & Time 2 & 819 & 3.20 & 2.90 \\
\hline SP Partner RQ & Time 2 & 852 & 1.77 & 4.30 \\
\hline & Time 2 & 819 & 1.38 & 4.50 \\
\hline Child Total Diff & Time 2 & 873 & 31 & 2.20 \\
\hline SP Total Diff & Time 2 & 819 & 32 & 2.0 \\
\hline & Time 2 & 854 & 28 & 26 \\
\hline
\end{tabular}




\section{APPENDIX R}

\section{Comparison of Outcome Variables}

\section{With Norm Scores (SDQ, About Myself)}




\section{Strengths and Difficulties Questionnaire}

Current findings compared with representative sample of Australian children $\underline{\text { (Mellor, 2005) }}$

\section{Children}

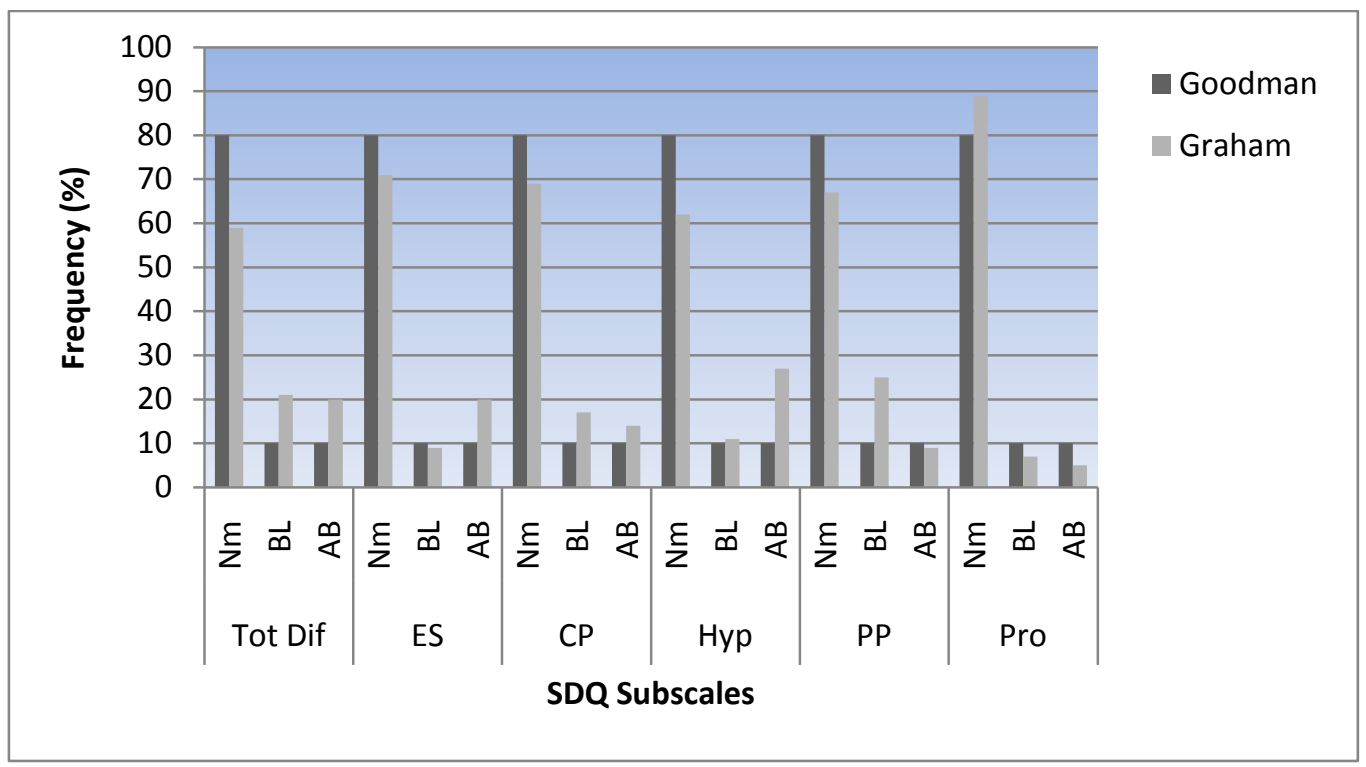

Biological Parents

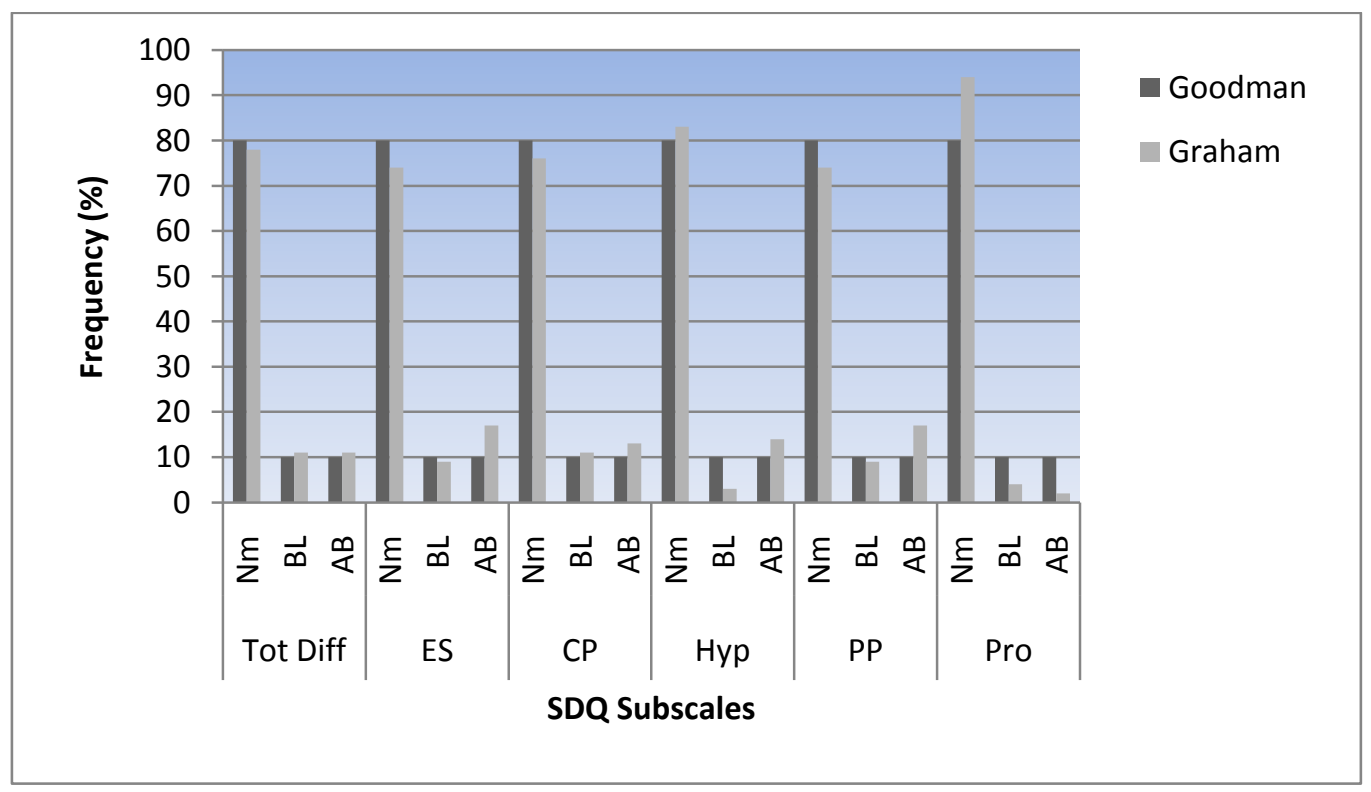




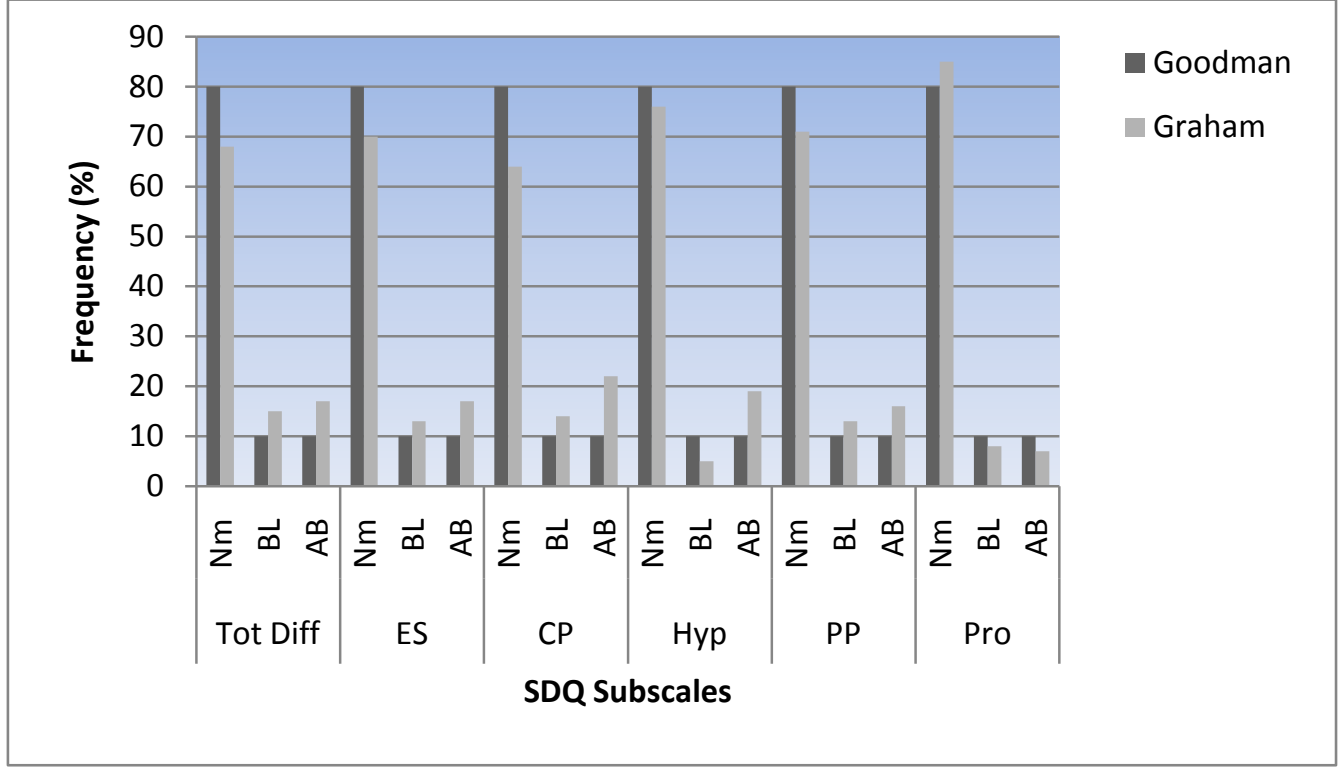

\section{About Myself Self-concept Scale}

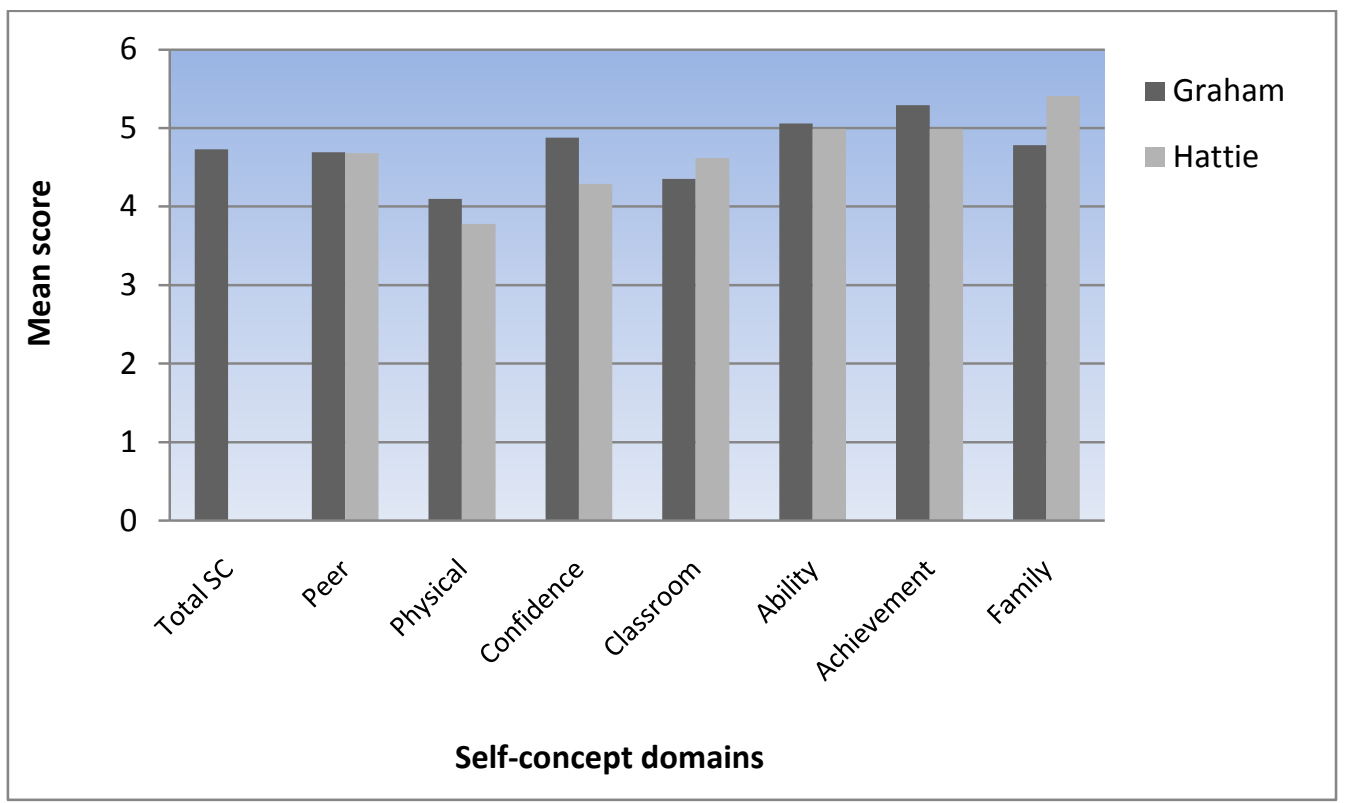




\section{APPENDIX S}

Cross-tabulations for Stepparent Role Labels at Time One 
Table 1: Actual Stepparent Role - Children

\begin{tabular}{|c|c|c|c|}
\hline Current Role & Combined with & Count & $\begin{array}{c}\text { Percent } \\
\%\end{array}$ \\
\hline \multirow[t]{6}{*}{ Parent } & & 26 & 24.8 \\
\hline & Friend & 6 & 5.7 \\
\hline & Stepparent & 4 & 3.8 \\
\hline & Friend + Stepparent & 1 & 1 \\
\hline & Close relative & 3 & 2.9 \\
\hline & Mum/Dads partner & 1 & 1 \\
\hline \multirow[t]{5}{*}{ Friend } & & 6 & 5.7 \\
\hline & Stepparent & 11 & 10.5 \\
\hline & Close relative & 2 & 1.9 \\
\hline & Mum/Dads partner & 2 & 1.9 \\
\hline & Partner + stepparent & 4 & 3.8 \\
\hline \multirow[t]{2}{*}{ Stepparent } & & 18 & 17.1 \\
\hline & Mum/Dads partner & 4 & 3.8 \\
\hline \multirow[t]{2}{*}{$\begin{array}{l}\text { Mum/Dad's } \\
\text { partner }\end{array}$} & & 4 & 3.8 \\
\hline & Close relative & 1 & 1 \\
\hline Close relative & & 2 & 1.9 \\
\hline All labels & & 3 & 2.9 \\
\hline Other & & 6 & 5.7 \\
\hline
\end{tabular}


Table 2: Ideal Stepparent Role - Children

\begin{tabular}{|c|c|c|c|}
\hline Ideal Role & Combined with & Count & $\begin{array}{c}\text { Percent } \\
\%\end{array}$ \\
\hline \multirow[t]{8}{*}{ Parent } & & 19 & $18.4 \%$ \\
\hline & Friend & 5 & $4.9 \%$ \\
\hline & Stepparent & 2 & $1.9 \%$ \\
\hline & Partner & 1 & $1 \%$ \\
\hline & Friend + stepparent & 1 & $1 \%$ \\
\hline & Close relative & 3 & $2.9 \%$ \\
\hline & Close relative + friend & 1 & $1 \%$ \\
\hline & $\begin{array}{lll}\begin{array}{l}\text { Close } \\
\text { stepparent }\end{array} & \text { relative } & + \\
\end{array}$ & 1 & $1 \%$ \\
\hline \multirow[t]{6}{*}{ Friend } & & 12 & $11.7 \%$ \\
\hline & Stepparent & 12 & $11.7 \%$ \\
\hline & Close relative & 2 & $1.9 \%$ \\
\hline & Mum/Dads partner & 2 & $1.9 \%$ \\
\hline & Close relative & 1 & $1 \%$ \\
\hline & Stepparent + partner & 1 & $1 \%$ \\
\hline \multirow[t]{3}{*}{ Stepparent } & & 17 & $16.5 \%$ \\
\hline & Mum/Dads partner & 4 & $3.9 \%$ \\
\hline & Close relative & 2 & $1.9 \%$ \\
\hline \multirow[t]{2}{*}{$\begin{array}{l}\text { Mum/Dad's } \\
\text { partner }\end{array}$} & & 6 & $5.8 \%$ \\
\hline & Close relative & 1 & $1 \%$ \\
\hline Close relative & & 4 & $3.9 \%$ \\
\hline Other & & 8 & $7.8 \%$ \\
\hline
\end{tabular}


$\underline{\text { Table 3: Actual Stepparent Role - Parents }}$

\begin{tabular}{|c|c|c|c|}
\hline Current Role & Combined with & Count & $\begin{array}{c}\text { Percent } \\
\%\end{array}$ \\
\hline \multirow[t]{7}{*}{ Parent } & & 9 & $8.6 \%$ \\
\hline & Friend & 9 & $8.6 \%$ \\
\hline & Stepparent & 3 & $2.9 \%$ \\
\hline & Partner & 2 & $1.9 \%$ \\
\hline & Friend + stepparent & 4 & $3.8 \%$ \\
\hline & $\begin{array}{l}\text { Mum/dads partner } \quad+ \\
\text { friend }\end{array}$ & 4 & $3.8 \%$ \\
\hline & $\begin{array}{lll}\begin{array}{l}\text { Mum/dads } \\
\text { stepparent }\end{array} & \text { partner } \quad+ \\
\end{array}$ & 3 & $2.9 \%$ \\
\hline \multirow[t]{4}{*}{ Friend } & & 3 & $2.9 \%$ \\
\hline & Stepparent & 9 & $8.6 \%$ \\
\hline & Mum/Dads partner & 4 & $3.8 \%$ \\
\hline & $\begin{array}{lll}\text { Mum/dads } & \text { partner } \quad+ \\
\text { stepparent }\end{array}$ & 7 & $6.7 \%$ \\
\hline \multirow[t]{3}{*}{ Stepparent } & & 19 & $18.1 \%$ \\
\hline & Mum/dads partner & 13 & $12.4 \%$ \\
\hline & $\begin{array}{l}\text { Mum/dads partner }+ \\
\text { close relative }\end{array}$ & 1 & $1 \%$ \\
\hline \multirow{2}{*}{$\begin{array}{l}\text { Mum/Dad's } \\
\text { partner }\end{array}$} & & 13 & $12.4 \%$ \\
\hline & Close relative & 1 & $1 \%$ \\
\hline Close Relative & & 1 & $1 \%$ \\
\hline
\end{tabular}


$\underline{\text { Table 4: Ideal Stepparent Role - Parents }}$

\begin{tabular}{|c|c|c|c|}
\hline Ideal Role & Combined with & Count & $\begin{array}{c}\text { Percent } \\
\%\end{array}$ \\
\hline \multirow[t]{9}{*}{ Parent } & & 12 & $11.4 \%$ \\
\hline & Friend & 15 & $14.3 \%$ \\
\hline & Stepparent & 4 & $3.8 \%$ \\
\hline & Partner & 2 & $1.9 \%$ \\
\hline & partner + stepparent & 5 & $4.8 \%$ \\
\hline & Mum/Dads partner + friend & 8 & $7.6 \%$ \\
\hline & Friend + stepparent & 5 & 4.8 \\
\hline & $\begin{array}{lll}\begin{array}{l}\text { Mum/Dads } \\
\text { stepparent }\end{array} & \text { partner } \quad+ \\
\end{array}$ & 5 & $4.8 \%$ \\
\hline & Friend + stepparent + partner & 2 & 1.9 \\
\hline \multirow[t]{4}{*}{ Friend } & & 3 & $2.9 \%$ \\
\hline & Stepparent & 12 & $11.4 \%$ \\
\hline & Mum/Dads partner & 4 & $3.8 \%$ \\
\hline & $\begin{array}{lll}\begin{array}{l}\text { Mum/Dads } \\
\text { stepparent }\end{array} & \text { partner } \quad+ \\
\end{array}$ & 7 & $6.7 \%$ \\
\hline \multirow[t]{2}{*}{ Stepparent } & & 16 & $15.2 \%$ \\
\hline & Mum/Dads partner & 7 & $6.7 \%$ \\
\hline \multirow[t]{2}{*}{$\begin{array}{l}\text { Mum/Dad's } \\
\text { partner }\end{array}$} & & 1 & $1 \%$ \\
\hline & Close relative & 1 & $1 \%$ \\
\hline All labels & & 1 & $1 \%$ \\
\hline Close Relative & & 0 & $0 \%$ \\
\hline
\end{tabular}


Table 5: Actual Stepparent Role - Stepparents

\begin{tabular}{|c|c|c|c|}
\hline Current Role & Combined with & Count & $\begin{array}{c}\text { Percent } \\
\%\end{array}$ \\
\hline \multirow[t]{9}{*}{ Parent } & & 8 & $7.8 \%$ \\
\hline & Friend & 3 & $2.9 \%$ \\
\hline & Stepparent & 4 & $3.9 \%$ \\
\hline & Friend + Stepparent & 2 & $1.9 \%$ \\
\hline & Mum/Dads partner & 1 & $1 \%$ \\
\hline & $\begin{array}{l}\text { Mum/Dads partner } \quad+ \\
\text { friend }\end{array}$ & 2 & $1.9 \%$ \\
\hline & $\begin{array}{lll}\begin{array}{l}\text { Mum/Dads } \\
\text { stepparent }\end{array} & \text { partner } \quad+ \\
\end{array}$ & 1 & $1 \%$ \\
\hline & $\begin{array}{l}\text { Mum/Dads partner }+ \\
\text { stepparent }+ \text { friend }\end{array}$ & 2 & $1.9 \%$ \\
\hline & Friend + close relative & 1 & $1 \%$ \\
\hline \multirow[t]{5}{*}{ Friend } & & 4 & $3.9 \%$ \\
\hline & Stepparent & 12 & $11.7 \%$ \\
\hline & Mum/Dads partner & 5 & $4.9 \%$ \\
\hline & $\begin{array}{lll}\begin{array}{l}\text { Mum/Dads } \\
\text { stepparent }\end{array} & \text { partner } \quad+\end{array}$ & 9 & $8.7 \%$ \\
\hline & $\begin{array}{l}\text { Mum/Dads partner }+ \\
\text { close relative }\end{array}$ & 1 & $1 \%$ \\
\hline \multirow[t]{4}{*}{ Stepparent } & & 23 & $22.3 \%$ \\
\hline & Mum/Dads partner & 7 & $6.8 \%$ \\
\hline & Close relative & 1 & $1 \%$ \\
\hline & $\begin{array}{l}\text { Mum/dads partner }+ \\
\text { close relative }\end{array}$ & 1 & $1 \%$ \\
\hline $\begin{array}{l}\text { Mum/Dad's } \\
\text { partner }\end{array}$ & & 13 & $12.6 \%$ \\
\hline Other & & 2 & $1.9 \%$ \\
\hline Close Relative & & 1 & $1 \%$ \\
\hline
\end{tabular}


Table 6: Ideal Stepparent Role -Stepparents

\begin{tabular}{|c|c|c|c|}
\hline Ideal Role & Combined with & Count & $\begin{array}{c}\text { Percent } \\
\%\end{array}$ \\
\hline \multirow[t]{13}{*}{ Parent } & & 14 & $13.6 \%$ \\
\hline & Friend & 12 & $11.7 \%$ \\
\hline & Stepparent & 6 & $5.8 \%$ \\
\hline & partner & 2 & $1.9 \%$ \\
\hline & Mum/dads partner & 2 & $1.9 \%$ \\
\hline & Partner + stepparent & 2 & $1.9 \%$ \\
\hline & $\begin{array}{l}\text { Mum/dads partner }+ \\
\text { friend }\end{array}$ & 1 & $1 \%$ \\
\hline & $\begin{array}{l}\text { Mum/Dads partner }+ \\
\text { friend }\end{array}$ & 2 & $1.9 \%$ \\
\hline & Friend + stepparent & 5 & $4.9 \%$ \\
\hline & $\begin{array}{l}\text { Close relative } \quad+ \\
\text { stepparent }\end{array}$ & 1 & $1 \%$ \\
\hline & friend + close relative & 1 & $1 \%$ \\
\hline & $\begin{array}{l}\text { Friend }+ \text { close relative }+ \\
\text { partner }\end{array}$ & 1 & $1 \%$ \\
\hline & $\begin{array}{l}\text { Friend }+ \text { stepparent }+ \\
\text { partner }\end{array}$ & 8 & $7.8 \%$ \\
\hline \multirow[t]{5}{*}{ Friend } & & 2 & $1.9 \%$ \\
\hline & Stepparent & 11 & $10.7 \%$ \\
\hline & Partner & 5 & 4.9 \\
\hline & $\begin{array}{l}\text { Close relative }+ \\
\text { stepparent }\end{array}$ & 1 & $1 \%$ \\
\hline & partner + stepparent & 7 & $6.8 \%$ \\
\hline \multirow[t]{4}{*}{ Stepparent } & & 11 & $10.7 \%$ \\
\hline & Close relative & 1 & $1 \%$ \\
\hline & Mum/dads partner & 5 & $4.9 \%$ \\
\hline & $\begin{array}{l}\text { Mum/dads partner }+ \\
\text { close relative }\end{array}$ & 1 & $1 \%$ \\
\hline $\begin{array}{l}\text { Mum/Dad's } \\
\text { partner }\end{array}$ & & 4 & $3.9 \%$ \\
\hline Close Relative & & 1 & $1 \%$ \\
\hline
\end{tabular}


$\underline{\text { Table 7: Frequencies for singular stepparent role labels }}$

\begin{tabular}{|l|l|l|l|l|}
\hline Member & \multicolumn{3}{|c|}{ Stepparent Role Label } & Total \\
\hline & Parents & Stepparents & Children & \\
\hline Parent & 10 & 8 & 25 & 43 \\
\hline Stepparent & 19 & 23 & 18 & 60 \\
\hline $\begin{array}{l}\text { Mum/Dads } \\
\text { Partner }\end{array}$ & 12 & 13 & 5 & 30 \\
\hline Friend & 3 & 4 & 6 & 13 \\
\hline
\end{tabular}




\section{APPENDIX T}

\section{Results from Factor Analysis: \\ Stepparent Role Questionnaire}


Factor analyses for warmth and control scales of SRQ

\begin{tabular}{|c|c|c|c|c|}
\hline Item & \multicolumn{5}{|c|}{ Components } \\
\hline & Component 1 & Component 2 & Component 3 & Component 4 \\
\hline School & .45 & .33 & .67 & .19 \\
\hline Hug & .56 & .53 & -.20 & -.21 \\
\hline Homework & .61 & .38 & .30 & -.22 \\
\hline Personal & .68 & .33 & -.16 & -.28 \\
\hline Activities & .50 & .40 & -.07 & .60 \\
\hline Friends & .69 & .40 & .00 & -.04 \\
\hline Stand Up & .69 & .23 & -.22 & .12 \\
\hline Drive & .64 & .38 & .11 & .20 \\
\hline Day & .66 & .37 & -.23 & -.28 \\
\hline PT interviews & .51 & .10 & -.37 & .29 \\
\hline Monitor TV & .65 & -.03 & .35 & -.12 \\
\hline Naughty & .70 & -.38 & .22 & -.02 \\
\hline Polite & .73 & -.37 & .08 & .06 \\
\hline New rules & .82 & -.26 & .02 & -.04 \\
\hline Please & .64 & -.43 & .13 & .22 \\
\hline Punish & .75 & -.43 & -.05 & -.15 \\
\hline Take turns & .80 & -.21 & -.12 & .20 \\
\hline Late & .71 & -.19 & .02 & -.33 \\
\hline Rude & .67 & -.44 & -.10 & .04 \\
\hline Consider & .80 & -.15 & -.27 & .02 \\
\hline
\end{tabular}

Scree Plot

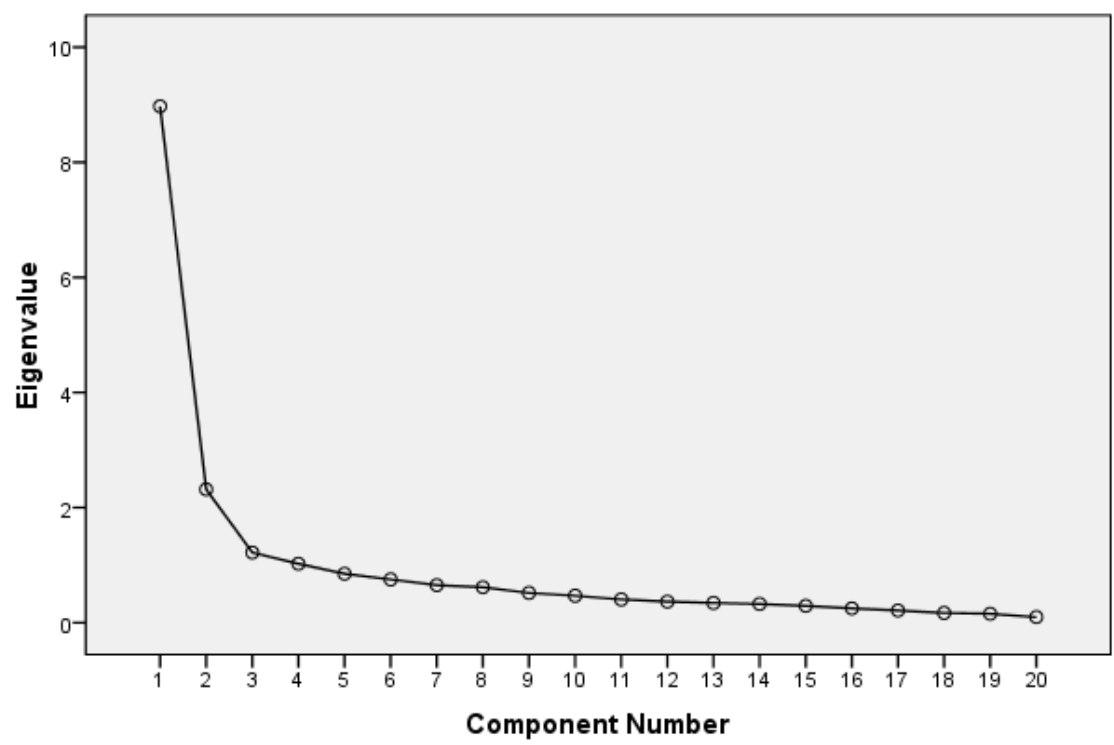




\section{APPENDIX U}

Distribution of Role Negotiation Variables:

Time One 
$\underline{\text { Role Negotiation Strategies Time One }}$

Pre-cohabitation

\begin{tabular}{|l|l|l|l|l|l|l|l|}
\hline & N & M & SD & Skew & $\begin{array}{l}\text { SE } \\
\text { Skew }\end{array}$ & Kurt. & $\begin{array}{l}\text { SE } \\
\text { Kurt. }\end{array}$ \\
\hline Parents & & & & & & & \\
\hline Partner Talks & 102 & 1.88 & 1.28 & 1.20 & .24 & .09 & .47 \\
\hline Child Talks & 102 & 1.53 & .96 & 1.96 & .24 & 3.24 & .47 \\
\hline Ex Talks & 102 & 1.10 & .48 & 6.42 & .24 & 46.98 & .47 \\
\hline Family Talks & 102 & 1.09 & .35 & 4.26 & .24 & 18.62 & .47 \\
\hline Stepparents & & & & & & & \\
\hline Partner Talks & 97 & 1.62 & .99 & 1.68. & .25 & 2.18 & .49 \\
\hline Child Talks & 97 & 1.06 & .28 & 5.01 & .25 & 27.12 & .49 \\
\hline Family Talks & 97 & 1.09 & .33 & 3.73 & .25 & 14.69 & .49 \\
\hline
\end{tabular}

Post-Cohabitation

\begin{tabular}{|l|l|l|l|l|l|l|l|}
\hline & $\mathrm{N}$ & $\mathrm{M}$ & $\mathrm{SD}$ & Skew & $\begin{array}{l}\text { SE } \\
\text { Skew }\end{array}$ & Kurt. & $\begin{array}{l}\text { SE } \\
\text { Kurt. }\end{array}$ \\
\hline Parents & & & & & & & \\
\hline Partner Talks & 101 & 2.33 & 1.37 & .45 & .24 & -1.24 & .48 \\
\hline Child Talks & 101 & 1.47 & .86 & 1.77 & .24 & 2.56 & .48 \\
\hline Ex Talks & 102 & 1.13 & .54 & 5.13 & .24 & 29.72 & .47 \\
\hline Family Talks & 102 & 1.36 & .76 & 1.99 & .24 & 2.78 & .48 \\
\hline Child Check-In & 96 & 2.13 & 1.31 & .63 & .25 & -1.03 & .49 \\
\hline $\begin{array}{l}\text { Partner Check- } \\
\text { In }\end{array}$ & 100 & 1.95 & 1.31 & 1.08 & .24 & -.23 & .48 \\
\hline Stepparents & & & & & & & \\
\hline Partner Talks & 97 & 1.90 & 1.28 & 1.05 & .25 & -.34 & .49 \\
\hline Child Talks & 97 & 1.16 & .57 & 3.42 & .25 & 10.74 & .49 \\
\hline Ex Talks & 97 & 1.03 & .17 & 5.50 & .25 & 28.90 & .49 \\
\hline Family Talks & 97 & 1.13 & .42 & 3.33 & .25 & 10.74 & .49 \\
\hline Child Check-In & 92 & 1.37 & .84 & 2.10 & .25 & 3.11 & .50 \\
\hline $\begin{array}{l}\text { Partner Check- } \\
\text { In }\end{array}$ & 95 & 2.21 & 1.34 & .65 & .25 & -.87 & .49 \\
\hline
\end{tabular}




\title{
APPENDIX V
}

\author{
Correlations between Demographic \\ Variables and Stepfamily Functioning and \\ Role Discrepancies
}


Correlations between Demographic and Individual Variables at Time 1 and Children's

Perceptions of Stepfamily Functioning at Time 2

\begin{tabular}{|r|r|r|r|r|}
\hline & Cohesion & Conflict & SP_SC RQ & BP_Ch RQ \\
\hline Income & -.003 & .13 & -.04 & -.08 \\
\hline $\begin{array}{r}\text { Number of cohabiting } \\
\text { relations - biological parent }\end{array}$ & -.13 & .05 & -.09 & -.18 \\
\hline Relationship Status & -.09 & .05 & -.11 & -.10 \\
\hline Parent Employment & -.04 & .06 & .04 & .09 \\
\hline Length of cohabitation & -.04 & .09 & -.08 & -.04 \\
\hline Stepparent Gender & .13 & -.08 & .14 & .04 \\
\hline SC Gender & -.08 & -.06 & .05 & .06 \\
\hline SC_NRP Contact & .05 & .11 & .04 & -.01 \\
\hline SC_NRP Closeness & .16 & -.20 & $.35^{* *}$ & .22 \\
\hline SC Age & -.15 & -.02 & -.06 & -.04 \\
\hline SP Employment & -.07 & .04 & -.20 & -.11 \\
\hline Oumber of bio children(SP) & $-.26^{*}$ & .01 & -.19 & -.07 \\
\hline Ours child & .07 & -.02 & .01 & .06 \\
\hline
\end{tabular}

Correlations between Demographic and Individual Variables at Time 1 and Children's $\underline{\text { Role Discrepancies at Time1 }}$

\begin{tabular}{|r|r|r|r|}
\hline & BP_Ch Warmth & Intra Control & Intra Warmth \\
\hline Income & .09 & -.01 & -.14 \\
\hline $\begin{array}{r}\text { Number of cohabiting } \\
\text { relations - biological parent }\end{array}$ & -.08 & .10 & .13 \\
\hline Relationship Status & & & .08 \\
\hline Parent Employment & .05 & .10 & -.08 \\
\hline Length of cohabitation & -.10 & .09 & -.06 \\
\hline Stepparent Gender & -.02 & .03 & .01 \\
\hline SC Gender & -.04 & -.03 & -.05 \\
\hline SC_NRP Contact & -.07 & -.05 & $.25^{*}$ \\
\hline SC_NRP Closeness & -.10 & .09 & -.22 \\
\hline SC Age & -.19 & -.12 & $-.27^{* *}$ \\
\hline SP Employment & .07 & -.15 & .02 \\
\hline .13 & -.02 & -.18 \\
\hline Number of bio children(SP) & .15 & -.03 & .07 \\
\hline Ours child & .08 & .05 & \\
\hline
\end{tabular}


